\title{
UM DIE ERNEUERUNG DER INTERNATIONALE: \\ ROSA LUXEMBURG CONTRA PIETER JELLES TROELSTRA
}

\author{
ZUR HALTUNG DER RADIKALEN LINKEN IN DEUTSCHLAND \\ NACH DEM 4. AUGUST 1914
}

\section{Einleitung}

Die Gemütsverfassung derer, die am Abend des 4. August 1914 - nach jener denkwürdigen Sitzung des Deutschen Reichstags, in der die sozialdemokratische Fraktion geschlossen für die Kriegskredite stimmte - in der Wohnung Rosa Luxemburgs zusammenkamen, könne man sich denken. Aber während etwa Karl Liebknechts folgende Kämpfe gegen die Parteiinstanzen in einem , nach dem Krieg erschienenen Briefwechsel” dokumentarisch festgelegt seien, unterrichte uns über Rosa Luxemburgs Leben in der ersten bitteren Zeit nach jenem 4. August ,,kein Brief, kein einziges Dokument" - schrieb etwa zwei Jahrzehnte später Henriette Roland Holst in ihrer Biographie der toten Freundin. ${ }^{1} \mathrm{Da} B$ solch ein Brief von Rosa Luxemburg sich ausgerechnet in dem Nachla $\beta$ ihres Landsmanns Troelstra finden könnte, jenes langjährigen Führers der holländischen Sozialdemokratie, den sie, selbst auf dem radikalen Flügel der holländischen Arbeiter-

1 Vgl. H. Roland Holst-van der Schalk, [Rosa Luxemburg. Haar leven en werken, Rotterdam 1935; deutsch:] Rosa Luxemburg. Ihr Leben und Wirken, Zürich [1937], S. 131f. Die Angaben über die Teilnehmer an der Zusammenkunft - laut Henriette Roland Holst: Franz Mehring, Clara Zetkin, Karl Liebknecht, Rosa Luxemburg - sind unzutreffend. Vgl. unten. Die Bemerkung über Liebknechts Briefwechsel bezieht sich vermutlich auf den Briefwechsel mit dem Parteivorstand vom Oktober 1914 (Liebknecht an den Parteivorstand, 2.10.1914; Scheidemann an Liebknecht, 7.10.1914; Liebknecht an den Parteivorstand, 10.10., 16.10.1914; Scheidemann an Liebknecht, 17.10., 23.10.1914; Liebknecht an den Parteivorstand, 26.10., 31.10.1914). Derselbe wurde zunächst in Form maschinenschriftlicher Abschriften verbreitet (s. unten, Anm. 411; Anhang, Nr 3 a, 5), dann auch in gedruckter Form. Vgl. das Exemplar im Nachlaß Grimm/Zimmerwald-Bewegung, I 22, Internationaal Instituut voor Sociale Geschiedenis. Danach wurde er nochmals abgedruckt in Liebknechts Broschüre Klassenkampf gegen den Krieg! Material zum ,Fall Liebknecht”. Als Manuskript gedruckt!, o.O. [1915] (Exemplar im IISG, a.a.O.), im folgenden zitiert nach Karl Liebknecht, Gesammelte Reden und Schriften, 9 Bde, Berlin 1958-68 (fortan KLGRS), Bd 8, S. 1-144. Henriette Roland Holst bezog sich wohl auf die um einen Anhang erweiterte Neuauflage: Karl Liebknecht, Klassenkampf gegen den Krieg, Berlin [1919], S. 21-33. 
bewegung stehend, fortgesetzt befehdet hatte, ${ }^{2}$ dürfte ihr kaum in den Sinn gekommen sein.

Das Inventar des Troelstra-Nachlasses im Internationaal Instituut voor Sociale Geschiedenis führte bis vor kurzem unter der Nummer III.F.551 einen undatierten Brief von ,,Leibeck?” auf. Der bei einer systematischen Durchsicht aufkommende Verdacht, daß statt ,Leibeck" vielmehr , ,Lübeck” zu lesen sein, d.h. es sich um einen Brief von Rosa Luxemburg handeln könnte, ließ sich leicht verifizieren: die Handschrift, in der die beiden Hälften eines quer gefalteten Bogens $(230 \times 179 \mathrm{~mm})$ jeweils beidseitig beschrieben sind, die am Kopf angegebene Adressse ,BerlinSüdende, Lindenstr. 2", die Unterschrift, die in der Tat „R. Lübeck” lautet, ließen keinen Zweifel. ${ }^{3}$ Der Adressat war wohl, obwohl sein Name nicht genannt ist, Troelstra selbst. Daß der Brief 1914, zu Beginn des Kriegs, geschrieben wurde, läßt schon die Bemerkung über den ,,Verlust Jaurès" annehmen. ${ }^{4}$

Der Brief ist nicht der einzige erhaltene Brief von Rosa Luxemburg aus jener Zeit. Als Henriette Roland Holst die einleitend zitierten Sätze schrieb, war schon, abgesehen von dem Schreiben an den Labour Leader vom Dezember $1914,{ }^{5}$ der bedeutsame Brief an Carl Moor vom 12. Oktober 1914 , wenngleich schwer zugänglich, veröffentlicht. ${ }^{6}$ Seit dem zweiten Weltkrieg wurden peu à peu - zumeist erst in den letzten Jahren - weitere Briefe aus den letzten Monaten des Jahres 1914 an verschiedene Adressaten - Hans Diefenbach, Camille Huysmans, Paul Levi, Franz Mehring, Ernst Meyer, Clara Zetkin, Kostja Zetkin u.a. - publiziert. ${ }^{7}$

${ }^{2}$ Zu Troelstra vgl. P. J. Troelstra, Gedenkschriften, 4 Bde, Amsterdam 1927-31 (kritisch hierzu A. Mellink, ,De Gedenkschriften van Troelstra”, in: Bulletin Nederlandse Arbeidersbeweging, August 1984, S. 5-37); E. Hueting, F. de Jong Edz., R. Ney, Ik moet, het is mijn roeping. Een politieke biografie van Pieter Jelles Troelstra, o.O. 1981 . - Zu Henriette Roland Holst vgl. K. F. Proost, Henriëtte Roland Holst in haar strijd voor gemeenschap, Arnhem 1937; H. Roland Holst-van der Schalk, Het vuur brandde voort. Levensherinneringen, Amsterdam, Antwerpen [1949].

${ }^{3}$ In der Lindenstr. 2 wohnte Rosa Luxemburg seit dem Herbst 1911. Vgl. J. P. Nettl, Rosa Luxemburg, 2 Bde, London, New York, Toronto 1966, Bd 2, S. 475. Seit ihrer 1897 zur Erlangung der deutschen Staatsangehörigkeit eingegangenen Scheinehe mit Gustav Lübeck war - trotz 1903 erfolgter Scheidung - ihr offizieller Name, dessen sie sich auch gelegentlich in ihrer Korrespondenz bediente, Lübeck. Ebd., Bd 1, S. 109f., 200.

4 Vgl. Anhang, Nr 1.

5 Vgl. Liebknecht, Klassenkampf, S. 69-71; näheres unten.

' E. Meyer, ,,Gegen den Strom! Ein unveröffentlichter Brief Rosa Luxemburgs", in: Niedersächsische Arbeiterzeitung, 1926, Nr 182 (7.8.), Beilage.

7 Vgl. Rosa Luxemburg, Briefe an Freunde, nach dem von L. Kautsky fertiggestellten Manuskript hrsg. von B. Kautsky, Hamburg [1950]; F. Tych, , Listy Róży Luksemburg do Franciszka Mehringa (w 50 rocznice śmierci)", in: Z Pola Walki, Jg. 12 (1969), Nr 1, S. 145-80; S. Quack, Geistig frei und niemandes Knecht. Paul Levi - Rosa Luxemburg. 
Nichtsdestoweniger verdient der jetzt gefundene, im Anhang ( $\mathrm{Nr}$ 1) veröffentlichte Brief von Rosa Luxemburg besondere Beachtung: ihre früheste bisher bekannte Einschätzung der Reaktion der sozialistischen Parteien auf den ausgebrochenen Krieg enthaltend, wirft er neues Licht auf ihre Haltung nach dem 4. August 1914.

Obwohl namentlich die Historiographie der DDR, die sich der radikalen Linken in der alten $\mathrm{SPD}^{8}$ besonders angenommen hat, hierzu eine Fülle Material erschlossen hat, ist die Beginnphase des Prozesses, in dem sich jene Strömung nach dem 4. August zu einer besonderen Kraft formierte, noch immer unzureichend untersucht. ${ }^{9}$ Schon früh trat die - in der

Politische Arbeit und persönliche Beziehung. Mit 50 unveröffentlichten Briefen, [Köln 1983]; Rosa Luxemburg, Gesammelte Briefe, hrsg. vom Institut für Marxismus-Leninismus beim ZK der SED, 5 Bde, Berlin 1982-84 (fortan RLGB). Im folgenden wird nach dieser Ausgabe zitiert, die - auBer dem an Huysmans - alle bislang publizierten Briefe an die o.a. Personen enthält. - $\mathrm{Zu}$ den bisher veröffentlichten Briefen Rosa Luxemburgs im IISG vgl. G. Langkau, , Briefe Rosa Luxemburgs im IISG - Ein Nachtrag”, in: International Review of Social History, Jg. 21 (1976), S. 412-44, wo die vorangegangenen Publikationen nachgewiesen sind.

${ }^{8}$ Für verschiedene Parteien werden im folgenden die üblichen Abkürzungen benutzt. BSP: British Socialist Party; Bund: Allgemeiner Jüdischer Arbeiterbund in Litauen, Polen und Rußland; ILP: Independent Labour Party; KPD: Kommunistische Partei Deutschlands; POB: Parti Ouvrier Belge (Belgische Werkliedenpartij); PPS: Polska Partja Socjalistyczna; PSI: Partito Socialista Italiano; SDAP: Sociaal-Demokratische Arbeiderspartij; SDKPiL: Socjaldemokracja Królestwa Polskiego i Litwy; SDP: Sociaal-Demokratische Partij; SFIO: Section française de l'Internationale ouvrière; SLP: Socialist Labor Party; SPA: Socialist Party of America; SPD: Sozialdemokratische Partei Deutschlands; SPS: Sozialdemokratische Partei der Schweiz.

9 Vgl. besonders J. Kuczynski, Der Ausbruch des Ersten Weltkrieges und die deutsche Sozialdemokratie. Chronik und Analyse, Berlin 1957; L. Dornemann, Clara Zetkin. Ein Lebensbild, Berlin 1957; W. Bartel, Die Linken in der deutschen Sozialdemokratie im Kampf gegen Militarismus und Krieg, Berlin 1958; J. Schleifstein, Franz Mehring. Sein marxistisches Schaffen 1891-1919, Berlin 1959; H. Wohlgemuth, Burgkrieg, nicht Burgfriede! Der Kampf Karl Liebknechts, Rosa Luxemburgs und ihrer Anhänger um die Rettung der deutschen Nation in den Jahren 1914-1916, Berlin 1963; Geschichte der deutschen Arbeiterbewegung, hrsg. vom Institut für Marxismus-Leninismus beim ZK der SED, 8 Bde, Berlin 1966; H. Wohlgemuth, Die Entstehung der Kommunistischen Partei Deutschlands 1914 bis 1918, Berlin 1968; A. Laschitza, G. Radczun, Rosa Luxemburg. Ihr Wirken in der deutschen Arbeiterbewegung, Berlin 1971; H. Wohlgemuth, Karl Liebknecht. Eine Biographie, Berlin 1973. - Sonst wären außer Nettls LuxemburgBiographie (s. Anm. 3) besonders zu nennen: C. E. Schorske, German Social Democracy 1905-1917. The Development of the Great Schism, Cambridge, Mass., 1955; G. Badia, ,L'attitude de la gauche social-démocrate allemande dans les premiers mois de la guerre (août 1914 - avril 1915)”, in: Le Mouvement Social, Nr 49 (1964), S. 81-105; S. Miller, Burgfrieden und Klassenkampf. Die deutsche Sozialdemokratie im Ersten Weltkrieg, Düsseldorf [1974]; G. Badia, Rosa Luxemburg. Journaliste, polémiste, révolutionnaire, Paris [1975]; H. Trotnow, Karl Liebknecht. Eine politische Biographie, [Köln 1980]; M. Scharrer, Die Spaltung der deutschen Arbeiterbewegung [2. Aufl., Stuttgart 1985]. 
marxistisch-leninistisch orientierten Literatur bis heute herrschende - Tendenz hervor, statt der bei Kriegsausbruch eingetretenen ,,Zersprengung, ja Atomisierung" des bisherigen radikalen Flügels der Partei, von der Liebknecht 1915 schrieb, ${ }^{10}$ vielmehr die in der Gründung der KPD resultierenden Neuansätze zu betonen - derart, daß der Eindruck einer von Anfang an planvollen, energischen Aktion entstand. So hieß es bereits 1924 in einem wohl von Hugo Eberlein stammenden Bericht über die ,,ersten Schritte” im Hinblick auf die Zusammenkunft bei Rosa Luxemburg am 4. August 1914, daß dieser Tag so, ,nicht nur der Tag des schmählichsten Verrats der sozialdemokratischen Partei [war], sondern gleichzeitig der Gründungstag des Spartakusbundes, der seine Arbeit [. . .] unermüdlich fortsetzte, bis aus ihm die Kommunistische Partei [. . . ], die Kommun[istische] Internationale erwuchs". ${ }^{11}$ Von diesem Standpunkt aus betrachtet, verkürzte sich der ProzeB, in dem sich die erwähnten Neuansätze ihrerseits herauskristallisierten, zu der scheinbaren Quantité négligeable ,,weniger Tage", ${ }^{12}$ wobei manches unklar - bzw. in dem Zwielicht, wo Legenden blühen - blieb.

Die Veröffentlichung des bewußten Briefs, bei deren Vorbereitung sich noch weiteres Material fand, bot einen willkommenen Anlaß, auf jenen Proze $B$ noch einmal einzugehen, was lohnend schien, da sich auf Grund der nun vorhandenen Quellen einige Momente im Verlauf desselben weit präziser fassen lassen.

Gleichzeitig schien sinnvoll, bei dieser Gelegenheit noch zwei weitere - nicht unbekannte, aber in den Gesammelten Briefen nicht enthaltene, bisher nur in Übersetzung bzw. in Faksimile veröffentlichte - Briefe Rosa Luxemburgs $(\mathrm{Nr} 4,6)^{13}$ sowie, ergänzend, einige Briefe Liebknechts ( $\mathrm{Nr} 2$, 3 a-c, 5,7$)$ aus den ersten Monaten des Kriegs zu publizieren. ${ }^{14}$

${ }^{10}$ Liebknecht, Klassenkampf, S. 26.

1 [Hugo Eberlein?], ,,Die ersten Schritte”, in: Die Revolution, Nr 2 (August 1924), Gedächtnisnummer zum 10. Jahrestag der Gründung des Spartakus-Bundes, hrsg. von der Kommunistischen Partei Deutschlands, S. 3. Besonders ausgeprägt Wohlgemuth, Die Entstehung, a.a.O., S. 45ff. Laut Laschitza und Radczun, Rosa Luxemburg, a.a.O., S. 331, stand vor Rosa Luxemburg und ihren Freunden die, geschichtlich notwendige Aufgabe”, eine ,,selbständige marxistisch-leninistische Kampfpartei” zu schaffen.

12 Vgl. [Eberlein?], ,,Diè ersten Schritte", S. 3, wo sich die Formulierung ,,wenige Tage später" auf ein Ereignis - die Veröffentlichung der Erklärung vom 10. September 1914 - bezieht, das erst am 30. Oktober, d.h. drei Monate nach dem 4. August, stattfand (s. unten). Auch in neueren Arbeiten wird von dem ,,schweren Beginn des widerspruchsvollen organisatorischen Formierungsprozesses der deutschen Linken um Rosa Luxemburg und Karl Liebknecht", auf den Laschitza und Radczun, Rosa Luxemburg, S. 333, hinweisen, nur wenig sichtbar.

${ }_{13}$ Vgl. Rosa Luxemburg, J'étais, je suis, je serai! Correspondance 1914-1919, textes réunis, trad. et annotés sous la dir. de G. Haupt par G. Badia, I. Petit, C. Weill, Paris 1977, Nr 238, S. 58f.; Ch. Voigt, Robert Grimm. Kämpfer, Arbeiterführer, Parlamentarier. Eine politische Biographie, [Bern 1980] S. 115. 
Ausgehend von den erwähnten Briefen, konzentriere ich mich auf die Position der deutschen Linken in der durch den Zusammenbruch der II. Internationale ausgelösten Auseinandersetzung über Grenzen, Möglichkeiten, Sinn des von den sozialistischen Parteien bislang fortgesetzt beschworenen ,Internationalismus", wobei ich diese Position der Troelstras gegenüberstelle. Dabei interessiert hier nicht so sehr das vielerörterte Problem des Zusammenbruchs, ${ }^{15}$ sondern mehr die Frage der Erneuerung der Internationale. Allerdings vollendete sich gerade in der Kontroverse über diese letztere Frage der Zerfall der alten Internationale, kündete sich darin doch schon die Entstehung nicht nur einer, sondern zweier neuer Internationalen an.

Noch nicht per se ihren Zusammenbruch bedeutend, hatte der Ausbruch des Weltkriegs die überraschende Ohnmacht der II. Internationale offenbart; denn das gemeinsame Bemühen der ihr angeschlossenen Parteien hatte sich, ursprünglich bzw. letztlich auf die Aufhebung des herrschenden Systems gerichtet, seit Beginn des zwanzigsten Jahrhunderts zunehmend auf die Verhütung eben dieses ständig drohenden allgemeinen Kriegs konzentriert. Während die II. Internationale nationale Verteidigungs-, geschweige denn Befreiungskriege im Prinzip nie abgelehnt hatte, hatte bei allen sonstigen Differenzen - ein genereller Konsens darüber bestanden, daß der allgemeine Krieg, auf den die imperialistische Politik der großen Mächte zutrieb, eine grausame Konsequenz des herrschenden Systems wäre, die es den Völkern möglichst zu ersparen galt. ${ }^{16}$

14 Zwei der genannten Briefe (Nr 3 b, 5) stammen aus dem Wibaut-NachlaB im IISG. Drei weitere Briefe (Nr 3 c, 6, 7) stammen aus dem Grimm-Nachlaß; von dem einen (Nr $3 \mathrm{c}$ ) fand sich das Original, von den beiden anderen ( $\mathrm{Nr} 6,7)$ je eine Kopie bei den von Willy Keller in den siebziger Jahren dankenswerterweise übermittelten Ergänzungen zu dem die Zimmerwald-Bewegung betreffenden Nachlaßteil im IISG. Die drei übrigen Briefe (Nr 2, 3 a, 4) stammen aus dem Branting-Nachlaß im Besitz des Stockholmer Arbetarrörelsens Arkiv (AA), dem für die Genehmigung zum Abdruck hier gedankt sei. - Gleichzeitig möchte ich hier für Unterstützung durch Auskünfte, Kopien etc. den Kolleginnen und Kollegen vom AA, vom Arbejderbevaegelsens Bibliotek og Arkiv, Kopenhagen (ABA), vom Archiv der sozialen Demokratie, Bonn (AsD), vom Institut für Marxismus-Leninismus beim ZK der SED, Berlin, und vom Sozialarchiv, Zürich (SA), danken, namentlich Stellan Andersson, Martin Graß, Klaus Miesgeld (AA), Gerd Callesen (ABA), Werner Krause, Rüdiger Zimmermann (AsD) und Karl Lang (SA), ferner - last, but not least - meinen Kolleginnen und Kollegen vom IISG selbst.

15 Zuletzt hierzu ausführlich K.-H. Klär, Der Zusammenbruch der Zweiten Internationale, Frankfurt, New York [1981]. Von der dort aufgeführten älteren Literatur sei besonders erwähnt $G$. Haupt, Le congrès manqué. L'Internationale à la veille de la première guerre mondiale, Paris 1965, deutsch: Der Kongreß fand nicht statt. Die Sozialistische Internationale 1914, Wien, Frankfurt, Zürich [1967].

$16 \mathrm{Vgl}$. hierzu H.-J. Steinberg, Die Stellung der II. Internationale zu Krieg und Frieden, Trier [1972], ferner - für die deutsche Sozialdemokratie - F. Boll, Frieden ohne 
Der Kriegsausbruch verkehrte - erst dadurch kam es zum Zusammenbruch der Internationale - den Konsens ins Gegenteil, zunächst, insofern die Parteien beider Seiten zu dem Schluß gelangten, daß die Abwehr der Bedrohung, die von der jeweils anderen Seite ausging, oberstes Gebot sei, also ihrer eigenen Regierung folgten, sodann, insofern die Opposition gegen diese Haltung zum Bruch quer durch die einzelnen Parteien führte. Ging die Rechte - dies galt insbesondere für Deutschland - davon aus, daß der loyale Kriegseinsatz der massenhaft mobilisierten Arbeiter zwangsläufig zu demokratischen Reformen führen müsse, baute die revolutionäre Linke, die antimilitaristische Agitation fortsetzend, auf den radikalisierenden Effekt des durch den Krieg erzeugten Elends. Der Widerpart der deutschen Linken in der Auseinandersetzung über die Erneuerung der Internationale war zunächst indessen nicht die Rechte innerhalb der eigenen Partei, die sich für diese Frage damals wenig interessierte, sondern waren die Sozialisten im neutralen Ausland, die zu retten suchten, was zu retten war.

Die Parteien der neutralen Länder spielten eine Sonderrolle, da sie gleichfalls, was die Sicherung des Landes gegen jede äußere Bedrohung anging, ihrer eigenen Regierung folgten, aber dennoch - nur darauf bedacht, das eigene Land, wenn möglich, aus dem Krieg herauszuhalten - in dem Stand der Unschuld zu verharren, nämlich nur die Friedenspolitik der Internationale fortzusetzen schienen. Nicht genötigt, sich auf die gegenseitigen Vorwürfe der Parteien der kriegführenden Länder einzulassen, schienen sie prädestiniert, diese erneut zusammen-, auf den Weg der Friedenspolitik zurückzuführen, wozu sie in der Tat - zumal im Hinblick auf die bürgerliche Friedensbewegung, die in den neutralen, jedoch vom Krieg nicht unbetroffenen Ländern schnell erstarkte - bald bereit waren. ${ }^{17}$

Die Führung übernahm hierbei zunächst die holländische SDAP, besonders Troelstra, der nicht nur, was die Wiederherstellung der Internationale anging, bemerkenswert früh bemerkenswert klare Ideen hatte, sondern sich zudem - nicht frei von Ehrgeiz ${ }^{18}$ - zu Beginn des Kriegs besonders stark

Revolution? Friedensstrategien der deutschen Sozialdemokratie vom Erfurter Programm 1891 bis zur Revolution 1918, Bonn [1980].

$17 \mathrm{Vgl}$. hierzu besonders M. Graß, Friedensaktivität und Neutralität. Die skandinavische Sozialdemokratie und die neutrale Zusammenarbeit im Krieg, August 1914 bis Februar 1917, Bonn-Bad Godesberg [1975]; A. Blänsdorf, Die Zweite Internationale und der Krieg. Die Diskussion über die internationale Zusammenarbeit der sozialistischen Parteien 1914-1917, [Stuttgart 1979].

18 Vgl. u.a. das Urteil von F. Domela Nieuwenhuis, Van christen tot anarchist. Gedenkschriften, Amsterdam [1910], S. 394, über Troelstra: ,Naast een grenzenlooze eerzucht, die hem niet tevreden deed zijn met een bescheiden plaats in de partij, maar die hem dreef naar het opperste leiderschap, zonder daarbij kieskeurig te zijn in de door hem 
in dieser Richtung engagierte. ${ }^{19} \mathrm{Karl}$ Kautsky meinte dementsprechend - in einer Postkarte an Troelstra - im Oktober 1914:

Das kleine Holland scheint noch bestimmt, eine große Rolle in der Internationale zu spielen. ${ }^{20}$

Es ist daher nicht bloße Willkür, wenn die Herausbildung der Position der radikalen Linken, insbesondere ihrer führenden Theoretikerin, d.h. Rosa Luxemburgs, hier in Beziehung zu der Troelstras dargestellt wird, einer Position, die nicht zufällig beim deutschen Zentrum starken Anklang fand. Die Beziehung, die schon deshalb interessant scheint, weil die Eigenart der beiden Positionen in der Gegenüberstellung deutlicher hervortritt, ist hegelsch ausgedrückt - durchaus nicht nur für uns, sie war für die zwei Hauptakteure selbst: verband dieselben - ungeachtet aller Differenzen anfangs das Bewußtsein, daß sie ihrerseits der Internationale treu geblieben waren, so wurden sie in kurzer Zeit gewahr, daß sie in ihrer Sorge um die Zukunft dieser Internationale, von verschiedenen Positionen ausgehend, zu konträren Schlüssen kamen.

$\mathrm{DaB}$ der Gegensatz in diesem Fall so schnell so scharf hervortrat, dürfte u.a. darauf zurückzuführen sein, daß in beider Heimatländern - in Rosa Luxemburgs Fall Russisch-Polen - die sozialistische Bewegung bereits vor dem Krieg gespalten war, d.h. gewisse Konflikte, die die Internationale sonst nach Möglichkeit verschleiert hatte, offen ausgefochten worden waren. So hatte Rosa Luxemburgs polnische Partei, die 1893 entstandene SDKP (ab 1900: SDKPiL), dem ,,sozial-patriotischen" Programm der kurz zuvor entstandenen PPS, gemäß dem es zunächst die Unabhängigkeit Polens zu erkämpfen galt, das eigene, ,internationalistische" Programm entgegengesetzt, das das traditionelle Programm der polnischen Arbeiterbewegung war; dabei hatte ,,internationalistisch" einen klaren Sinn gehabt, nämlich den absoluten Vorrang des internationalen Klassenkampfs vor den engeren nationalen Interessen, der internationalen Solidarität des revolutionären Proletariats vor der nationalen Solidarität der Klassen eines

aangewende middelen, bezat hij een taai volhardingsvermogen en beschikte hij over een welsprekendheid, die het volk wist te pakken. Geen moeite was hem te groot, geen werk te min, als het maar kon bijdragen om te komen waar hij wezen wilde. Niemand karakteriseerde hem beter dan v. Emmenes [...]: Macedonië is te klein voor Alexander.",

19 Die Aktivitäten Troelstras in den ersten Monaten des Kriegs sind ausführlich, jedoch nicht immer treffend insbesondere von Graß und Blänsdorf in den o.a. Arbeiten (s. Anm. 17) dargestellt.

20 Kautsky an Troelstra, 5.10.1914, NachlaB Troelstra, IISG (fortan NT), 550/11. 
Volks bedeutet. ${ }^{21}$ Umgekehrt hatte Troelstra schon seit Jahren einen unerbittlichen Kampf gegen die radikalen Marxisten um das Wochenblatt $D e$ Tribune - David Wijnkoop,Herman Gorter u.a. - geführt, die, 1909 aus der SDAP ausgeschlossen, eine eigene Partei, die SDP, gegründet hatten; im Vordergrund der Kontroversen stand hier nicht die nationale Frage, sondern - die Einführung des allgemeinen Wahlrechts war in nächster Zukunft zu erwarten - die Bedeutung pragmatischer Tages-, besonders parlamentarischer Politik, die allerdings - im Gegensatz zum internationalen Klassenkampf, für den die SDP eintrat - einstweilen auf den nationalen Rahmen fixiert war. ${ }^{22}$

Wenn die beiden Fragen, bei denen es im Grunde ja nur um verschiedene Aspekte einer Sache ging, nicht neu waren, offenbarte - scheint es - erst das Debakel vom August 1914 ihre Relevanz für die Konzeption der Internationale selbst.

Obwohl die Konzeptionen der zwei Hauptakteure, denen hier paradigmatische Bedeutung beigemessen wird, im Prinzip bereits auf die von Komintern und SAI hindeuteten, interessieren sie hier nicht in erster Linie qua Momente linearer „,Vorgeschichte”, sei es dieser, sei es jener. Was vielmehr in erster Linie interessiert, ist der Prozeß der Trennung jener Wege selbst, nämlich wie der ausgebrochene Krieg die unterschiedlichen Positionen, die in der alten Internationale koexistiert hatten, derart auseinandertrieb, daß sie einander, jede für sich konsequent entwickelt, gegenübertraten.

Es bedarf kaum der Erwähnung, daß sich die Entwicklung beider Positionen, ihres Gegensatzes nicht in einem Vakuum vollzog, sondern einerseits im jeweiligen nationalen, andererseits im internationalen Kontext. Ich beziehe diese Kontexte nur ein, soweit sie für die interessierende Entwicklung relevant erscheinen. Obgleich die letztere in beiden Fällen eine Reaktion auf dasselbe Ereignis, d.h. den Krieg, war, obgleich darin in beiden Fällen eine innere Logik zu erkennen ist, läßt sich ihr Ablauf doch nicht darauf reduzieren. Vielmehr kann die Rekonstruktion desselben nicht von der bestimmten Erfahrung, dem bestimmten Handeln, dem tatsächlichen Informationsstand abstrahieren. Gerade für die ersten Monate des Kriegs, durch den die normalen Kommunikationslinien erst einmal unterbrochen wurden, kommt der exakten Feststellung des Informa-

${ }^{21}$ Vgl. u.a. G. W. Strobel, Die Partei Rosa Luxemburgs, Lenin und die SPD. Der polnische , europäische" Internationalismus in der russischen Sozialdemokratie, Wiesbaden 1974, sowie meine Rezension im Archiv für Sozialgeschichte, Bd 17 (1977), S. 66166.

$22 \mathrm{Vgl}$. Troelstra, Gedenkschriften, a.a.O., Bd 3, S. 89-128; Hueting u.a., Ik moet, het is mijn roeping, a.a.O., S. $97 \mathrm{ff}$. 
tionsflusses besondere Bedeutung zu. Auch von der Seite des Bewußtseins her betrachtet, sind historische Prozesse ja konkret-empirische Prozesse. Die hier interessierende Entwicklung läßt sich - vorzugsweise mittels des im IISG vorhandenen Materials ${ }^{23}$ - auf eine sehr konkrete, sehr präzise Weise rekonstruieren.

\section{In der alten Internationale: gemeinsam in der gleichen Kutsche}

Pieter Jelles Troelstra (1860-1930), friesischer Dichter, promovierter Jurist, 1914 in der Internationale allgemein geachtet, hatte $1894 \mathrm{zu}$ den Gründern der SDAP gehört, in deren Leitung er seitdem weitgehend den Ton angab. Seit 1897 vertrat er die Partei in der Zweiten Kammer des niederländischen Parlaments, wobei er das Amt des Fraktionsvorsitzenden bekleidete. Obwohl er während des Revisionismusstreits in der deutschen Partei in gewissen Punkten Bernstein Recht gab, stand er laut eigener Aussage, was die Theorie betraf, im allgemeinen auf der Seite Kautskys; was jedoch die Praxis anging, trat er offen für einen pragmatischen Reformismus ein. ${ }^{24}$ Der normale Klassenkampf war für ihn ,,die alltägliche Arbeit von Propaganda, Organisation, Wahlen, allgemein: Machtbildung". ${ }^{25}$ Seinen radikalen Kritikern warf er vor, sie suchten die Partei auf einen Kurs zu drängen, der dieselbe ,,aus einem Stück Arbeiterbewegung umformen würde in ein unbedeutendes Klübchen etwas dogmatischer Propagandisten, ohne Einfluß auf die Arbeiter, das Leben, die Entwicklung unseres Volkes". ${ }^{26}$ Als er 1909 den Bruch forcierte, kam es ihm indessen darauf an, nicht etwa die ,Marxisten" insgesamt, sondern nur eine kleine Gruppe intransigenter Extremisten aus der Partei auszuschlieBen, ${ }^{27}$ was ihm in der Tat gelang. Die gemäßigte Mehrheit seiner marxistischen Kritiker um Florentinus Marinus Wibaut blieb in der Partei, Wibaut selbst übernahm - zunächst mit Henriette Roland Holst, dann mit Frank van der Goes - die Redaktion von Het Weekblad, einer neu geschaffenen wöchentlichen Beilage zu dem Parteiorgan Het Volk. Wibauts Kritik galt ohnehin nur Troelstras rigorosem Vorgehen, nicht aber seiner reformisti-

23 Für die niederländischen Archivbestände sei hier besonders hingewiesen auf die verdienstvolle Publikation von M. Campfens, De Nederlandse archieven van het Internationaal Instituut voor Sociale Geschiedenis te Amsterdam, Amsterdam 1984.

24 Troelstra, Gedenkschriften, Bd 2, S. 304f.

25 Ebd., Bd 3, S. 104. - Die niederländischen Zitate werden im Text in deutscher Übersetzung wiedergegeben; nur im Fall von ungedruckten Quellen wird in der betreffenden Fußnote die niederländische Originalfassung gegeben; nur in dieser werden die ergänzenden Zitate in den Fußnoten gebracht.

26 Troelstra an den Parteivorstand der SDAP, 3.12.1908, ebd., S. 109.

27 Ebd., S. 119. 


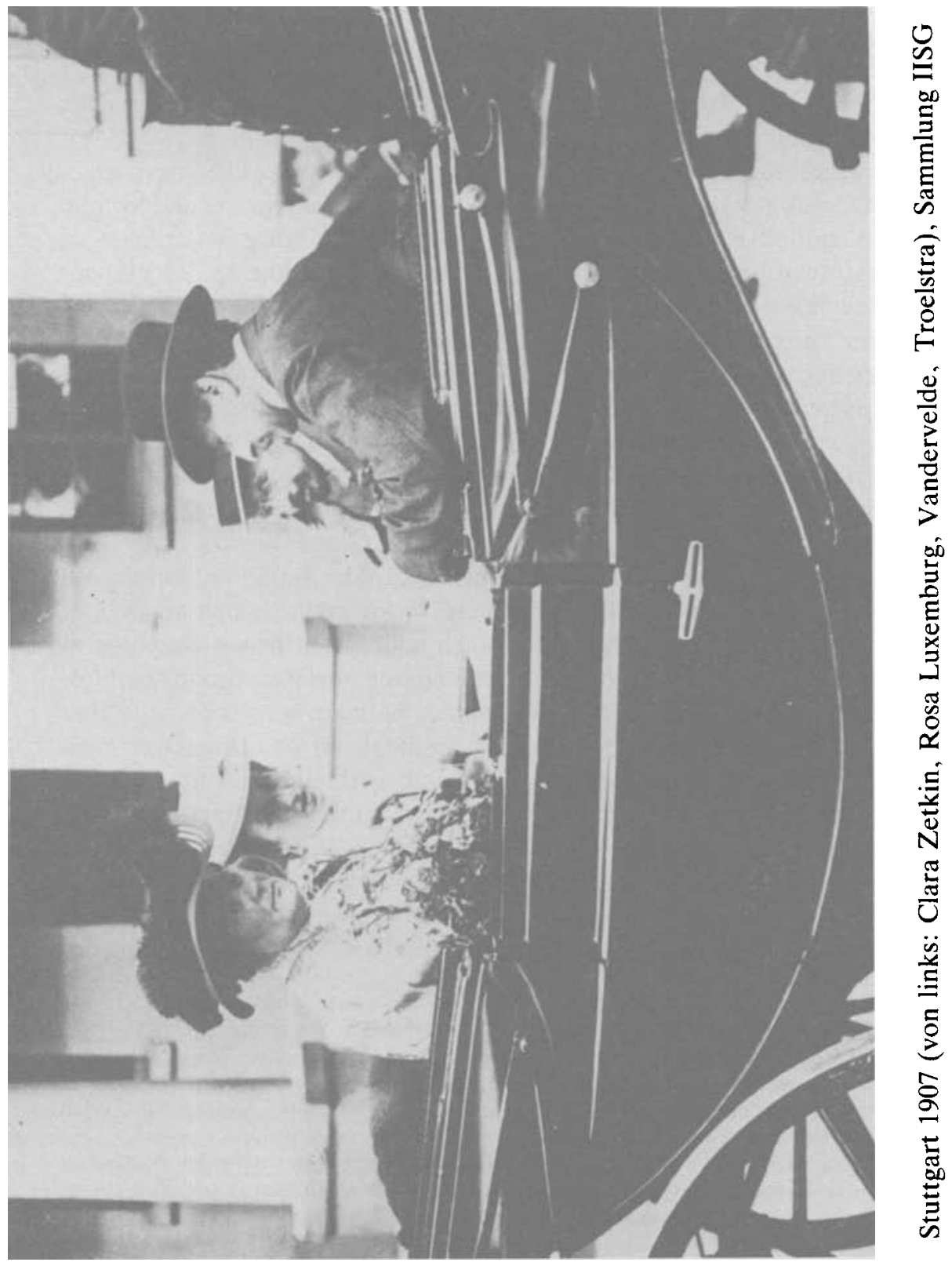


schen Politik, die er, kurz vor Kriegsausbruch zum Stadtrat von Amsterdam gewählt, durchaus bejahte. ${ }^{28}$ Übrigens schloß Troelstra selbst die Möglichkeit revolutionärer Aktion nie gänzlich aus, was sich besonders im November 1918 zeigte. ${ }^{29}$

Troelstra war Rosa Luxemburg erstmals 1893 auf dem internationalen sozialistischen Kongreß in Zürich begegnet; die Weise, in der sie dort wenngleich erfolglos - um die Anerkennung ihres von der PPS angefochtenen Mandats gekämpft hatte, hatte ihm , große Bewunderung und Sympathie" eingeflößt ${ }^{30}$ Auf dem Londoner Kongreß drei Jahre später hatte sie seine Unterstützung für ihren Gegenantrag zu dem Antrag der PPS zur polnischen Frage gewonnen, wobei sie ihn an ,eine Spinne, die dabei ist, ihr Netz zu spinnen", erinnert hatte. ${ }^{31}$ Später waren sie einander - außer auf den internationalen Kongressen ${ }^{32}$ - insbesondere anläßlich der Zusammenkünfte des 1900 errichteten Internationalen Sozialistischen Büros begegnet, in dem Troelstra die SDAP, Rosa Luxemburg - seit 1904 - die SDKPiL vertrat. Troelstra erinnerte sich später besonders an die anläßlich der Marokko-Krise im September 1911 in Zürich abgehaltene Sitzung des ISB, in der erneut die Frage eines eventuellen Generalstreiks zur Verhütung eines Kriegs zur Sprache gekommen war. Die Frage war bereits auf mehreren internationalen Kongressen erörtert worden, zuletzt ausgiebigst 1907 auf dem Stuttgarter Kongreß. Nach leidenschaftlichen Debatten in der betreffenden Kommission hatte der Kongreß eine Resolution beschlossen, die bei Kriegsgefahr die arbeitenden Klassen verpflichtete, , alles aufzubieten, um durch die Anwendung der ihnen am wirksamsten erscheinenden Mittel den Ausbruch des Krieges zu verhindern"; ${ }^{33}$ aber auf die besonders von französischer Seite geforderte Nennung bestimmter Mittel bis hin zum Generalstreik - war infolge deutschen Widerspruchs verzichtet worden; nur ein Amendement Lenin-Luxemburg-Martov, nach dem es, wenn es doch zum Krieg kam, nicht nur auf dessen schnelle Beendigung hinzuwirken, sondern ebenso die eintretende Krise ,zur Aufrüttelung des

${ }^{28} \mathrm{Zu}$ Wibaut vgl. F. M. Wibaut, Levensbouw. Memoires, Amsterdam 1936.

$29 \mathrm{Vgl}$. Troelstra, Gedenkschriften, Bd 4, S. 162ff.; H. J. Scheffer, November 1918. Journaal van een revolutie die niet doorging, Amsterdam 1971.

30 Troelstra, Gedenkschriften, Bd 2, S. 139; zu Rosa Luxemburgs Auftreten in Zürich vgl. Nettl, Rosa Luxemburg, a.a.O., Bd 1, S. $69 \mathrm{ff}$.

31 Troelstra, Gedenkschriften, Bd 2, S. 139f.; zu den Anträgen der beiden polnischen Parteien vgl. Tagesordnung für den Internationalen Sozialistischen Arbeiter- und GewerkschaftskongreB. London, 1896. St. Martins Town Hall, London 1896, S. 12f.

$32 \mathrm{Zu}$ den Begegnungen in Amsterdam (1904) und Stuttgart (1907) - nur beiläufig Troelstra, Gedenkschriften, Bd 3, S. 74, 26.

33 Internationaler Sozialisten-KongreB zu Stuttgart. 18. bis 24. August 1907, Berlin 1907, S. 64-66 (Resolution), 81-105 (Beratung in der Kommission). 
Volkes auszunutzen" galt, war angenommen worden. ${ }^{34}$ Der Kopenhagener Kongre $B$ hatte drei Jahre später die betreffenden Sätze der Stuttgarter Resolution ausdrücklich bestätigt; ein Amendement Vaillant-Keir Hardie, das zur Verhütung eines Kriegs erneut besonders einen ,,allgemeinen Streik der Arbeiter" empfahl, war dem ISB zum Studium überwiesen worden. ${ }^{35}$

Durch den sog. , ,Panthersprung nach Agadir”, der Europa im Juli 1911 an den Rand des Krieges brachte, hatte die Frage neue Aktualität erhalten. Da der deutsche Parteivorstand - deshalb von den Radikalen, in erster Linie Rosa Luxemburg, erst in der Presse, dann auf dem Parteitag heftig angegriffen ${ }^{36}$ - die Einberufung des ISB zunächst für unnötig gehalten hatte, fand die Sitzung erst am 23.-24. September statt. ${ }^{37}$ Laut der Darstellung von Troelstra wurde von französischer Seite erneut auf eine klare Stellungnahme zugunsten eines Massenstreiks gedrängt, die Bebel erneut ablehnte.

Danach kam es zu einer sehr scharfen Debatte zwischen Rosa Luxemburg, die ebenfalls eine klare Aussage zugunsten der äußersten Mittel wollte, auf der einen und Bebel und Molkenbuhr auf der anderen Seite, wobei der letztere die, wie sich später erwies, zutreffende Prophezeiung tat, daß die Massen, wenn der Kriegszustand erst einmal da wäre, vollkommen mitgerissen werden und wir machtlos dastehen würden. Im gleichen Geist sprach Victor Adler [. . . ${ }^{38}$

Troelstra, der vermittelnd eingriff, schlug in der Überzeugung, daß das ISB sich nicht auf eine neue Resolution beschränken könne, die - dann beschlossene - Abhaltung von internationalen Friedensdemonstrationen vor; was den Generalstreik betreffe, seien erst die Resultate der beschlossenen Untersuchung seiner Chancen abzuwarten. ${ }^{39}$

${ }^{34}$ Ebd., S. 66, 102.

${ }^{35}$ Internationaler Sozialisten-KongreB zu Kopenhagen. 28. August bis 3. September 1910, Berlin 1910, S. 32-43.

${ }^{36} \mathrm{Zu}$ den von Rosa Luxemburg im Juli-August 1911 in der Leipziger Volkszeitung und der Gleichheit veröffentlichten Artikeln vgl. Rosa Luxemburg, Gesammelte Werke, hrsg. vom Institut für Marxismus-Leninismus beim ZK der SED, 5 Bde, Berlin 1972-75 (fortan RLGW), Bd 3, S. 5-44; zu ihrer Kritik auf dem Parteitag vgl. Protokoll über die Verhandlungen des Parteitages der Sozialdemokratischen Partei Deutschlands. Abgehalten in Jena vom 10. bis 16. September 1911, Berlin 1911, S. 204-07.

${ }^{37}$ Vgl. Haupt, Der KongreB fand nicht statt, a.a.O., S. 39ff.

${ }^{38}$ Troelstra, Gedenkschriften, Bd 3, S. 272f.

${ }^{39}$ Ebd., S. 273. Ein Protokoll der Sitzung wurde nicht veröffentlicht; vielmehr wurde nur die beschlossene Resolution publiziert. Vgl. Nachlaß Victor Adler, IISG; Bulletin Périodique du Bureau Socialiste International, Nr 8, S. 127f. Im Troelstra-NachlaB befindet sich ein Blatt, auf dem untereinander ein ,,Antrag Troelstra” und ein ,Antrag Luxemburg" stehen; der erstere, laut dem das ISB beschließen sollte, ,,die Initiative zu 
Die letzte Zusammenkunft des ISB, die Troelstra ebenfalls ausführlich memoriert, war die am Vorabend des Kriegs nach Brüssel einberufene Sitzung. ${ }^{40}$ Trotz der Verschärfung der Krise - dem österreichischen Ultimatum an Serbien vom 23. Juli 1914 war am 28. Juli die Kriegserklärung gefolgt - konnten die Teilnehmer der Sitzung, die am 29.-30. Juli stattfand, noch hoffen, daß die Begrenzung des Konflikts gelingen würde. Rosa Luxemburg hatte noch am 28 . Juli bezweifelt, daß die deutsche Regierung kriegsbereit sei, ${ }^{41}$ während Troelstra beim Abschied von seiner Frau, auf die Stuttgarter Resolution anspielend, spöttisch gefragt hatte: ,Werden wir nun wirklich Revolution machen?"42 Die Stimmung in der Sitzung sei in keiner Weise revolutionär gewesen. ${ }^{43}$ Zunächst berichtete Victor Adler - sichtbar deprimiert - über die aussichtslose Lage der österreichischen Partei:

Le parti est incapable d'agir. (Wehrlos.) [ . . . On manifeste en faveur de la guerre à la rue. [ . . .] Nous ne pouvons pas écarter le danger. Des démonstrations sont rendues impossibles. [. . .] On risque d'anéantir le travail de trente ans, sans aucun résultat politique. N'est-ce pas un danger d'encourager la Serbie à l'intérieur de notre pays? [ . . ] Nous devons sauvegarder nos institutions. Les idées de grève, etc., ne sont que des fantaisies. ${ }^{44}$

Nach den Aufzeichnungen des spanischen Delegierten Fabra Ribas machte der Bericht einen fatalen Eindruck; Hugo Haase sei verärgert, Rosa Lu-

weiteren internationalen Kundgebungen gegen den Krieg [. . .] zu ergreifen und die Bewegung gegen den Krieg mit allen ihm zu Gebote stehenden Mitteln zu fordern", entspricht etwa dem Absatz IV der beschlossenen Resolution, der zweite etwa dem Absatz III; der ,Antrag Luxemburg” lautete in seiner ursprünglichen Form: „Das I.S.B. fordert desgleichen die sozialistischen Parteien auf, eine Protestbewegung hervorzurufen gegen jede Erweiterung der Kolonialbesitzungen der europäischen Staaten auf dem Wege des diplomatischen Schachers, der gegenwärtig hinter dem Rücken der Nationen und ihrer Volksvertretungen am Werke ist, um neue Zuspitzungen der internationalen Gegensätze und neue Kriegsursachen für die Zukunft zu schaffen.” NT 399/1. 40 Vgl. Haupt, Der KongreB fand nicht statt, S. $147 \mathrm{ff}$.

41 Rosa Luxemburg, ,Der Friede, der Dreibund und wir”, in: [Sozialdemokratische Korrespondenz, Nr 85 (28.7.1914)] RLGW, Bd 3, S. 477. Die einzige echte Garantie des Friedens - hatte sie gemeint - bestehe jedoch darin, ,,die latente Macht des Proletariats in Bewegung zu setzen, eine so nachdrückliche Massenaktion gegen den Krieg zu organisieren, daß die lauen ,Friedenswünsche' der Regierungen in einen heißen Schreck vor den unabsehbaren Konsequenzen des Krieges gewandelt werden"; dabei hatte sie auf den Congrès national der SFIO hingewiesen, der ,,seine Bereitschaft zur Entfaltung nachdrücklichster Massenaktionen" ausgedrückt, d.h. sich zugunsten des Amendements Vaillant-Keir Hardie ausgesprochen hatte. Ebd., S. 478f.

${ }_{42}$ Troelstra, Gedenkschriften, Bd 3, S. 290.

43 Ebd., S. 291.

44 So gemäß dem von Georges Haupt im ISB-Archiv gefundenen, von Huysmans angefertigten Protokoll der Sitzung: , Compte rendu de la réunion du B.S.I. tenue à Bruxelles les 29-30 juillet", in: Haupt, Le congrès manqué, a.a.O., S. 252f. 
xemburg direkt empört gewesen. ${ }^{45}$ Haase verlas ein Telegramm, durch das ihn Otto Braun davon informiert hatte, daß die Berliner Arbeiter am Abend vorher massenhaft gegen den Krieg demonstriert hatten; Rosa Luxemburg forderte entschlossenes Handeln, hatte aber gleichfalls, was das ISB anging, nur eine indirekte Aktion im Sinn: „Nous ne devons pas faire de manifeste, seulement il nous faut encore décider du Congrès." ${ }^{46}$ Auf Vorschlag Haases wurde beschlossen, den Kongreß, der Ende August in Wien hatte zusammentreten sollen, bereits zum 9. August nach Paris einzuberufen. Dagegen fand der von Angelica Balabanoff gemachte Vorschlag, zu prüfen, ob das ISB nicht unmittelbar etwas beschließen könne, keinen Anklang. ${ }^{47}$ Was den Generalstreik anging, meinte Troelstra später, hätten die Franzosen, deren Parteitag sich kurz vorher dafür ausgesprochen hatte, in Brüssel geschwiegen. ,Und ich sah zu Rosa Luxemburg hinüber [. . . ]; auch sie schwieg." 48

Das unmittelbare Ergebnis der Sitzung war eine einstimmig angenommene Resolution, die die Parteien aufrief, nicht nur ihre Demonstrationen gegen den Krieg zu intensivieren, sondern ebenso die eigene Regierung zu bestimmen, daß sie ihrerseits auf Österreich bzw. Rußland mäßigend einwirkte bzw. sich für eine schiedsgerichtliche Lösung des Konflikts einsetzte. ${ }^{49}$ Troelstra erinnerte sich später:

Zu Rosa Luxemburg sagte ich nach Ende dieser Zusammenkunft: ,,Wissen Sie, was wir jetzt getan haben? Wir haben die Sache in die Hände der vielgeschmähten Diplomaten gelegt."

${ }^{45}$ A. Fabra Ribas, ,Jean Jaurès à Bruxelles, les 29 et 30 juillet 1914", in: La Vie Socialiste, Jg. 9 (1931), Nr 247, S. 12.

46 ,Compte rendu de la réunion du B.S.I.", a.a.O., S. $254 f$.

47 Vgl. ebd., S. $256 \mathrm{f}$.

48 Troelstra, Gedenkschriften, Bd 3, S. 292. Angelica Balabanoff schreibt, daB sie das Thema durchaus angeschnitten habe; nur von den Engländern sei eine positive Reaktion gekommen. A. Balabanoff, Erinnerungen und Erlebnisse, Berlin 1927, S. 55f. Laut dem Protokoll erklärte Troelstra selbst gegen Haase, der empfohlen hatte, diese kontroverse Frage in Paris doch besser im Interesse des geschlossenen Eindrucks auszuklammern: „En discutant l'impérialisme, il nous faudra discuter la grève générale, la conduite de la bourgeoisie en temps de paix, etc.” „Compte rendu de la réunion du B.S.I.”, S. 257ff. ${ }^{49}$ Ebd., S. 266. Gegen den Vorschlag von Vaillant, der meinte, die Sozialisten der neutralen Länder ,,pourraient intervenir d'une façon extrêmement utile en faveur du réglement arbitral du conflit", hatte Troelstra zunächst eingewandt, das ISB dürfe dem KongreB nicht vorgreifen, nicht alle Parteien teilten in der Schiedsgerichtsfrage die Ideen von Jaurès, worauf Victor Adler gemeint hatte: ,Nous faisons maintenant le travail du moment. Les camarades de tous les pays seront contents, malgré leurs principes, si de cette façon le conflit pouvait prendre fin." Ebd., S. 266.

${ }^{50}$ Statt des offiziellen , u" hat Troelstra im Holländischen das vertraulichere ,,je" (Weet je) benutzt, das jedoch nicht notwendig dem deutschen ,Du” entspricht. Troelstra, Gedenkschriften, Bd 3, S. 292; vgl. hierzu P. J. Troelstra, De wereldoorlog en de sociaaldemokratie, Amsterdam 1915, S. 50: Ein Aufruf zur Fortsetzung der Demonstra- 
Noch in dem Massenmeeting im Cirque Royal am Abend des 29. Juli, in dem mehrere Teilnehmer der Sitzung - last but not least Jean Jaurès - das Wort erhielten, hatte er betont, ,,que le prolétariat ne doit pas abandonner la politique internationale à la bourgeoisie, mais qu'il doit la conduire luimême". 51

Unmittelbar nach Sitzungsschluß fuhr Troelstra am 30. Juli zurück nach Holland, wo er am 31. Juli in Amsterdam auf einer Kundgebung gegen den Krieg sprach..$^{52}$ Am nächsten Morgen las er in der Zeitung: , ,Jaurès ermordet."53 15 Jahre später schrieb er:

Es ist mir bis zu diesem Augenblick unmöglich, ohne Bewegung an den Schmerz zurückzudenken, der mich damals übermannte. ,Jaurès ermordet!" Unser Anführer gefallen! Und das in einem Moment, in dem auf niemand weniger als ihn verzichtet werden konnte. Gleich einem Pistolenschu $ß$ traf mich die Nachricht. Vor meinen Augen geriet die Internationale ins Wanken. Nicht nur der fähige und allgemein geliebte politische Führer, sondern auch der Freund, der tief verehrte große Mensch, der Held, zu dem wir alle aufsahen, auf den unser aller Vertrauen gegründet war - ermordet. Ich brach in Tränen aus [ . . ]. ${ }^{54}$

Jaurès war am Nachmittag des 30 . Juli nach Paris zurückgekehrt, wo er sogleich Ministerpräsident Viviani aufgesucht hatte, der durchblicken ließ, $\mathrm{da} \beta$ die Mobilmachung bevorstand, aber zugleich versicherte, daß die Regierung alles vermied, was provozierend wirken konnte. In seinem Leitartikel vom 31 . Juli hatte Jaurès nochmals aufgerufen, nicht die Nerven zu verlieren; ${ }^{55}$ aber nach einem Besuch bei dem Unterstaatssekretär Abel Ferry am gleichen Abend war er zu dem Schluß gekommen, daß es kaum noch Hoffnung gab. An der Tatkraft der französischen Regierung gegenüber Rußland zweifelnd, hatte er noch einen klärenden Artikel geplant ,l'article décisif par lequel aurait été dégagée la responsabilité de notre Parti". ${ }^{56}$ Aber noch bevor er diesen hatte schreiben können, war er in dem

tionen, Versuche, die Diplomatie zugunsten des Friedens zu beeinflussen, und ein Kongreß - ,ziedaar wat de Internationale kon besluiten in dit historisch moment. Verder ging haar macht niet."

${ }^{51}$ „Un Meeting socialiste international à Bruxelles. Une Démonstration formidable contre la Guerre", in: Le Peuple, 1914, Nr 211 (30.7.). Zum Spotten war Troelstra nicht mehr zumute: ,,ik was niet in staat een behoorlijke rede te houden." Troelstra, Gedenkschriften, Bd 3, S. 293. Auch Rosa Luxemburg war so erschöpft, daß Vandervelde davon absah, ihr das Wort zu erteilen.

52 Vgl. ,Ons protest tegen den oorlog!”, in: Het Volk, Nr 4392 (1.8.1914).

53 ,Jaurès vermoord", ebd.

${ }^{54}$ Troelstra, Gedenkschriften, Bd 3, S. $293 f$.

${ }_{55}$ Jean Jaurès, ,Sang-Froid Nécessaire”, in: l'Humanité, Nr 3757 (31.7.1914).

\$6 Marcel Cachin, ,La dernière démarche de Jaurès était pour la paix”, ebd., Nr 3758 (1.8.1914). 
Café, in dem er kurz etwas gegessen hatte, von einem nationalistischen Einzelgänger, Raoul Villain, erschossen worden. ${ }^{57}$

Die Gefühle, die Troelstra bei der Nachricht davon überkamen, wurden in der Internationale allgemein - von rechts bis links - geteilt. ,,Der Verlust Jaurès' hat mir", schrieb Rosa Luxemburg, die dann ,,mir" in ,uns" verbesserte, in ihrem Brief an Troelstra, ,,einen Schlag beigebracht, den man nie verwindet." ${ }^{58}$ Nicht zuletzt verkörperte Jaurès für viele den tiefen Friedenswillen der Internationale, dem er in seiner letzten öffentlichen Rede - in dem Brüsseler Meeting am Abend des 29. Juli - noch einmal kraftvoll Ausdruck verliehen hatte, wobei er für den Kriegsfall gewarnt hatte, daß

à mesure que le typhus achèverait l'oeuvre des obus, à mesure que la mort et la misère frapperaient, les hommes dégrisés se tourneront vers les dirigeants allemands, français, russes, italiens, demanderont quelles raisons ils peuvent donner de tous les cadavres. ${ }^{59}$

Allerdings wurde das Kriegselend durch diese revolutionäre Perspektive für Jaurès nicht weniger furchtbar. ,,Cette guerre”, bemerkte er in einer Unterhaltung, ,va réveiller toutes les passions bestiales qui dorment au coeur de l'humanité", ${ }^{00}$ während sein radikaler Widerpart in der französichen Partei, Jules Guesde, damals erklärte: , Je n'ai pas la même crainte de l'avenir, la guerre est mère de révolution." 61

Die Einstellung von Rosa Luxemburg glich eher der von Guesde. Als Heinrich Schulz ihr gegenüber damals äußerte: ,Hoffentlich kann der Krieg vermieden werden", habe sie - berichtete er, Scheidemann zufolge, später - ihrerseits gerufen: ,Hoffentlich nicht!" ${ }^{2}$ Die Episode dürfte sich jedoch schon vor der Brüsseler Sitzung zugetragen haben; denn als Rosa Luxemburg am 31. Juli nach Berlin zurückkehrte, war bereits der Zustand der drohenden Kriegsgefahr verkündet. Am 1. August folgte erst der Mobilmachungsbefehl, dann die Kriegserklärung an Rußland, am 3. August die an Frankreich. Am Nachmittag des 3. August faßte die sozialdemokratische Fraktion gegen 14 Stimmen den Beschluß, den Kriegskrediten

57 Vgl. hierzu ausführlich M. Le Clère, L'assassinat de Jean Jaurès, [Tours 1969]; zur damaligen Haltung von Jaurès vgl. A. Kriegel, ,Jaurès en juillet 1914”, in: Le Mouvement Social, Nr 49, S. 63-77.

58 Anhang, Nr 1.

59 ,Un Meeting socialiste international", a.a.O.

${ }^{60}$ Am. D[unois], ,,Souvenirs de la nuit du 30"', in: l'Humanité, Nr 5454 (24.3.1919).

${ }^{61}$ Zitiert nach A. Zévaès, Jules Guesde (1845-1922), Paris 1928, S. 174.

${ }^{62} \mathrm{Vgl}$. Ph. Scheidemann, Memoiren eines Sozialdemokraten, 2 Bde, Dresden 1928, Bd 1, S. 298f. 
zuzustimmen, was sie am Nachmittag des 4 . August geschlossen tat. ${ }^{63}$ „,Versuche, eine abweichende Abstimmung der Vierzehn im Plenum zu erzielen, waren", so Liebknecht, ,,in der Überstürzung der wenigen Stunden mißlungen." Abgesehen davon, daß die Minderheit sich scheute, sich in der Gefahr, in der sie die Partei wähnte, öffentlich von der Mehrheit zu trennen, ging sie davon aus, daß die Partei ,,im übrigen dennoch eine oppositionelle Politik, eine Politik des Klassenkampfes [...] treiben werde". 64

\section{Rosa Luxemburgs unmittelbare Reaktion auf den ,Zusammenbruch} dessen, was uns das Theuerste war"

Schon am 31. Juli - nach ihrer Rückkehr nach Berlin - war Rosa Luxemburg zu dem Schluß gekommen: ,Aus dem Kongre B in Paris wird wohl nichts, da der Krieg vor der Türe steht." ${ }^{65}$ Gleichwohl war sie, als der Krieg dann ausbrach, , ,tief erschüttert" ${ }^{66}$ Allerdings monierte sie Paul Levis tief pessimistische Stimmung: ,So [. . . ] darf man eine weltgeschichtliche Wendung nicht betrachten." 67 Aber obwohl sie wohl schon ahnte, was bevorstand, ${ }^{68}$ brachte sie der Beschluß der Fraktion vom 3. August vollkommen aus der Fassung. ,,Als ich die Botschaft meinen Redaktionskollegen überbrachte", berichtet Heinrich Ströbel, der an der Sitzung für die Redaktion des Vorwärts teilgenommen hatte, ,waren sie zerschmettert. Rosa Luxemburg, die gleichfalls den Bescheid erharrte, wurde von konvulsivischen Wein- und Wutkrämpfen geschüttelt." ${ }^{69}$ Die Zustimmung der Fraktion zu den Kriegskrediten sei für sie, so Paul Lensch, ein ,,furchtbarer Schlag" gewesen; den Krieg habe sie nicht gefürchtet, er sei für sie ein revolutionäres Element gewesen, das dem Aufstieg der Partei zugute kommen mußte, wenn sie ihrerseits in klarer Opposition blieb; aber diese Voraussetzung sei nun fortgefallen - ,,eine direkt verzweifelte Stimmung brach über sie herein." ${ }^{\prime 70}$ Laut Eberlein, der sie nach der Reichstagssitzung

${ }^{63}$ Vgl. hierzu ausführlich D. Groh, Negative Integration und revolutionärer Attentismus. Die deutsche Sozialdemokratie am Vorabend des Ersten Weltkrieges, [Frankfurt, Berlin, Wien 1973] S. 653ff.; Miller, Burgfriede und Klassenkampf, a.a.O., S. $31 \mathrm{ff}$.

64 Liebknecht, Klassenkampf, S. 22.

${ }^{65}$ Rosa Luxemburg an Levi, [31.7.1914,] RLGB, Bd 5, S. 451.

66 An Kostja Zetkin, [1.8.1914,] ebd., S. 7.

${ }^{67}$ An Levi, [2.8.1914,] ebd., S. 451.

${ }_{68}$ An Kostja Zetkin, [2.8.1914,] ebd., S. 7. Schon am 1. August hatte Wilhelm Düwell berichtete Rosa Luxemburg fünf Wochen später - in Berlin Heinrich Peus getroffen, ,,der freudig mitteilte, 85 Mann der Fraktion seien schon für Bewilligung der Kriegskredite." Artur Crispien, Tagebuch (mschr. Ms.), AsD, Eintragung vom 11.9.1914.

${ }^{6}$ H. Ströbel, Die Kriegsschuld der Rechtssozialisten, Berlin 1919, S. 12.

$x$ P. Lensch, ,Ein Ende und ein Anfang”, in: Die Glocke, Jg. 4 (1919), S. 1335. 
aufsuchte, erwog sie, „fassungslos vor Empörung”, demonstrativen Selbstmord; ihre Freunde brachten sie von dem Gedanken ab. ${ }^{71}$

Die erste Besprechung, zu der sich am gleichen Abend einige Freunde Franz Mehring, Julian Marchlewski, Hermann Duncker, Wilhelm Pieck, Ernst Meyer, Hugo Eberlein - bei ihr zusammenfanden, führte zu dem Schluß, daß ein Austritt aus der Partei nicht in Frage kam. ${ }^{72}$ Wenn tatsächlich der Plan aufkam, die bekannten linksradikalen Genossen aus dem ganzen Reich zu einer Beratung zusammenzurufen (laut Eberlein wurden über 300 Telegramme aufgegeben), ${ }^{73}$ dann hatte er inmitten der Mobilmachung von vornherein nur wenig Aussicht auf Erfolg. Unmittelbar wurde eine Protesterklärung beschlossen, die Rosa Luxemburg und Mehring formulierten. Am folgenden Tag wurde sie Lensch vorgelegt, der ebenfalls zur Unterschrift bereit war; auf Rosa Luxemburgs Bitte unternahm er dann noch den Versuch, zwei weitere Fraktionskollegen zu gewinnen; aber der eine - Georg Ledebour, der die Bewilligung der Kredite in der Fraktion besonders scharf bekämpft hatte - war nicht zu Hause; der andere Liebknecht - lehnte ab, wonach Lensch sich ebenfalls zurückzog. Laut Liebknecht war die Erklärung, die den Tenor hatte: ,, Wir treten nur darum nicht aus der Partei, weil ...", eine Halbheit; außerdem billigte er der Fraktion damals noch guten Glauben zu. ${ }^{74}$ Clara Zetkin mahnte, telegra-

${ }^{71}$ [Eberlein?], ,Die ersten Schritte”, S. 2. Rosa Luxemburg selbst erzählte dies Luise Kautsky. Vgl. M. Berger, La nouvelle Allemagne (Enquêtes et Témoignages), Paris 1919, S. 262f.

72 [Eberlein?], ,Die ersten Schritte”, S. 2. Ein einfacher Parteiaustritt schien Rosa Luxemburg nie sinnvoll. Vgl. ihren Brief an Henriette Roland Holst, o.D. (1911), in Roland Holst, Rosa Luxemburg, a.a.O., S. 220f.: „Nun höre ich: Dir persönlich, gesundheitlich gehe es gut, Du willst aber aus der SDAP. austreten. Das Erstere freut mich aufrichtig, das Letztere - nein! [ . . ] Du willst, wie ich höre, nicht in die SDP. eintreten. [. . . ] Aber dann bedeutet Dein Austritt aus der SDAP. einfach den Austritt aus der sozialdemokratischen Bewegung! [ . . .] Die schlechteste Arbeiterpartei ist besser wie keine. Und die Zeiten können sich ja ändern. [. . . ] Aber auf diese Zeiten darf man nicht draußen warten, man muB den Kampf, mag er noch so steril scheinen, weiter führen - bis zum Äußersten. Du bist fertig, tot für die polit[ische] Bewegung, wenn Du abseits stehst. Thu das nicht! Du hast auch gegen die Internationale Verpflichtungen. Bleib in Reih' und Glied, das ist unsere Pflicht, wir sind alle Soldaten." Ebenso an Kostja Zetkin, [2.8.1914,] a.a.O., S. 7: ,Über Dein ,Austreten aus der Partei' habe ich gelacht. Du großes Kind, willst Du vielleicht aus der Menschheit auch ,austreten'?"

3 [Eberlein?], ,,Die ersten Schritte”, S. 2.

${ }^{7}$ Vgl. die Darstellung von Lensch in seinem - für den Parteiausschuß bestimmten Brief an Ebert, 1.7.1915, NachlaB Levi, $\mathrm{Nr}$ 141, AsD, auszugsweise abgedruckt in $\mathrm{R}$. Sigel, Die Lensch-Cunow-Haenisch-Gruppe. Eine Studie zum rechten Flügel der SPD im Ersten Weltkrieg, Berlin [1976], S. 22f., sowie die Richtigstellung Mehrings in seinem Rundschreiben vom 12.7.1915, Nachla B Victor Adler, IISG. Laut Mehring hatte Lensch auf Rosa Luxemburgs Frage, ob er sich an dem Protest beteiligen wolle, ,,mit dem jubelnden Zurufe [geantwortet]: ,Ich habe diesen Idioten gestern schon gesagt, daß sie 
phisch befragt, ebenfalls zur Überlegung: der Protest, der nichts mehr ändern würde, ,, bliebe eine rein persönliche Kundgebung, die jetzt von Niemand verstanden würde, nur zeigte, daß wir völlig isoliert in der Luft stehen"; er würde den eigenen Flügel völlig sprengen, während es im Hinblick auf die spätere Auseinandersetzung darauf ankomme, , zusammenzuhalten, was sich zusammenhalten läßt".

Es ist berechtigt und schön zu sagen: alles verloren, außer der Ehre. Wenn ich meinem Empfinden folgen wollte, so hätte ich mit tausend Freuden ein Ja telegraphiert. Aber wir müssen jetzt mehr als je kühl denken und handeln. ${ }^{75}$

Ob Clara Zetkin hier auf eine Formulierung bezug nahm, derer Rosa Luxemburg und Mehring sich in ihrem Telegramm bedient hatten, ist nicht erkennbar. Jedenfalls benutzte Rosa Luxemburg danach die gleiche - auf eine Äußerung des französischen Königs Franz I. nach der verlorenen Schlacht bei Padua (1525) zurückgehende - Wendung von der nicht verlorenen Ehre in dem Brief an Troelstra. ${ }^{76}$

Der Brief, der erkennen läßt, daß die Erinnerung an die Ereignisse vom 31. Juli bis 4. August noch frisch war, daß der Schock noch nachwirkte, aber die erste Aufwallung verzweifelter Empörung abgeebbt war (der

die Eingeweide der Internationalen auf den Tisch legen.' Ob er gegen den milderen, seiner zornigen Aufwallung allerdings nicht entfernt entsprechenden Wortlaut des kurzen, von der Genossin Luxemburg vorgeschlagenen Protestsatzes eben deshalb Bedenken äußerte, vermag ich nicht mehr zu sagen; jedenfalls beeiferte er sich, die Propaganda des Protestes zu übernehmen [ . . . ]. Es stimmt, daß er Ledebour nicht zu Hause traf und von Liebknecht eine Absage erhielt, was vielleicht seinen flammenden Unwillen über diesen ,Quertreiber' erklärt." Karl Liebknecht, Betrachtungen und Erinnerungen aus der ,,großen Zeit”, KLGRS, Bd 9, S. 276f.; Lensch, „Ein Ende und ein Anfang”, a.a.O., S. 1335.

${ }^{75}$ Der vom 5.8.1914 datierende Brief Clara Zetkins ist abgedruckt in Kuczynski, Der Ausbruch des Ersten Weltkrieges, a.a.O., S. 97f. Laut Kuczynski fand sich der Brief ,,in einer ganzen Sammlung Briefe von ihr an den Genossen Westmeyer. Er ist der einzige unter ihnen, in dem die Unterschrift mit Schreibmaschine geschrieben ist." Vermutlich handeite es sich um eine Abschrift für Westmeyer bzw. einen Entwurf für die in dem Brief selbst erwähnte Besprechung ,,mit Westm[eyer] und Crispien", die der letztere jedoch in seinem Tagebuch, a.a.O., erst am 7.8.1914 erwähnt: ,Luxemburg und Mehring haben die Genossin Zetkin befragt, ob sie einen Protest gegen die Reichstagsfraktion unterzeichnen wolle. Zetkin fragt Westmeyer und mich um Rat. Wir sind der Meinung, daß wir nichts mehr ändern können. Die Radikalen seien an Händen und Füßen gebunden, und wie sollte ein solcher Protest an die Öffentlichkeit gebracht werden? Die Tagwacht habe ja, unter Gefahr des Verbots, eine Abrechnung mit der Fraktion angekündigt. Zetkin stimmt zu." Crispien bezieht sich auf den Leitartikel „Harmonie”, in: Schwäbische Tagwacht, 1914, Nr 180 (6.8.).

${ }^{76}$ Anhang, Nr 1. 
Selbstmord-Gedanke klingt nur noch ganz leise nach), dürfte etwa vier Wochen später - um den 31. August - geschrieben sein. Der terminus ante quem ergibt sich aus Rosa Luxemburgs Brief an Mehring vom 8. September, aus dem hervorgeht, daß sie kurz zuvor in Stuttgart angekommen war. ${ }^{77}$ Umgekehrt besagt der Hinweis in dem Brief an Troelstra, daß sie ,,nächstens" dorthin fahren wolle, wenig: den Plan, nach Süddeutschland zu fahren, hegte Rosa Luxemburg bereits seit Ende Juli. ${ }^{78}$ Nach dem 4. August, besonders nach dem Scheitern des Versuchs, durch einen Protest zu retten, was zu retten war, fühlte sie das Bedürfnis, die dortigen Freunde - Clara Zetkin in Stuttgart, Paul Levi in Frankfurt - zu besuchen, desto stärker, zumal sie in Berlin nichts hielt. Eine briefliche Verständigung kam nur bedingt in Frage - abgesehen davon, da 3 der Postverkehr zunächst gestört war. Erst nach dem Empfang eines Briefs von Levi vom 13. August begann sie, schrieb sie dann, zu hoffen,

daß es einen Zweck hat, Briefe zu schreiben. Freilich fällt einem meist die Feder aus der Hand, wenn man jetzt schreiben soll. [ . . .] Sich aussprechen wäre nötig [. . .]. So viel ist zu erzählen! Erfreuliches wenig, gar nichts. Aber da ist nicht Zeit, melancholisch zu werden, man muß sich vor allem über den ganzen Umfang des Geschehenen klarwerden, über die nächsten und weiteren Perspektiven, über das, was zu tun übrigbleibt. Vor allem ist es nötig, die tatsächliche Strömung objektiv festzustellen, soweit das jetzt möglich ist. Dazu wäre es sehr nötig, daß man sich sieht [. . . ]. ${ }^{79}$

Schon am 7. August hatte Rosa Luxemburg gedacht, , in den nächsten Tagen zu reisen"; aber die durch die Mobilmachung bedingte Störung des Bahnverkehrs führte zu einer immer neuen Verschiebung der Fahrt; noch am 27. August konnte sie ,,momentan nicht sagen", wann sie führe; am 31. August hoffte sie jedoch erneut, ,,baldigst" reisen zu können. ${ }^{80}$

Weitere Aufschlüsse in bezug auf die Datierung gibt die Nachschrift. Die geschlossene Abstimmung am 4. August hatte ihre Wirkung nicht verfehlt. ${ }^{81}$ Von den Auseinandersetzungen in der Fraktion, die der Abstimmung vorausgegangen waren, wußte in den ersten Wochen, da es der Mehrheit darauf ankam, den geschlossenen Eindruck zu erhalten, selbst in

7 Rosa Luxemburg an Mehring, 8.9.1914, RLGB, Bd 5, S. 9.

78 An Levi, [vor dem 25.7.1914,] ebd., S. 450.

79 An Levi, [Mitte August 1914,] ebd., S. 452.

so An Levi, [7.8.1914,] [Mitte August 1914,] 31.[8.1914], ebd. S. 452-54; an Clara Zetkin, [27.8.1914,] ebd., S. 8.

81 Vgl. u.a. Das Kriegstagebuch des Reichstagsabgeordneten Eduard David, 1914 bis 1918, hrsg. von E. Matthias und S. Miller, Düsseldorf [1966] (fortan David, KTB), 5.8.1914, S. 13: ,Die Wirkung unserer Zustimmung nach außen ist sehr stark. Das Gefühl der nationalen Geschlossenheit beherrscht alles". 
der Partei kaum jemand;2 sogar gewissen Radikalen - konstatierte Rosa Luxemburg am 31. August - sei anzumerken, daß sie bisher nur die Version der Mehrheit kennten, weshalb es höchste Zeit sei, daß sie von den Vorgängen in der Fraktion einmal ,, aus anderem Munde" hörten.$^{83}$ Ebenso nötig schien dies hinsichtlich der ausländischen Parteien, zumal, nachdem die Vossische Zeitung am 28. August berichtet hatte, Albert Südekum habe in dem Organ der schwedischen Partei einen Artikel publiziert, in dem er u.a. erklärt habe, daß in der Fraktion über die Notwendigkeit der Bewilligung der Kriegskredite ,,keine ernstliche Meinungsverschiedenheit geherrscht hat". ${ }^{84}$ Die Nachschrift zu dem Brief an Troelstra sollte eben diesen Eindruck korrigieren. Anscheinend wußte Rosa Luxemburg noch nicht, daß Anton Pannekoek, der, vom Kriegsausbruch in Holland überrascht, danach noch einmal kurz in Bremen gewesen war, wo ihn wohl Alfred Henke unterrichtet hatte, bereits am 26. August in De Tribune ausführlich über die fraktionsinterne Diskussion berichtet hatte, ${ }^{85}$ was sich Anfang September in Berlin in der Partei herumsprach. ${ }^{86}$

Es ist durchaus bemerkenswert, daß Rosa Luxemburg in ihrer Nachschrift nach Haase und Ledebour, den beiden prominentesten der 14 Gegner der Kreditbewilligung in der Fraktion, an dritter Stelle - sie hatte zunächst ,Haase, Ledebour u.a.” geschrieben - Liebknecht nennt; denn

82 Vgl. u.a. Crispien, Tagebuch, 7.9.1914: ,Genosse Walcher erhält vom Genossen W. Zimmer, Düsseldorf, eine Karte, nach der 14 oder 17 Mitglieder der deutschen soz[ialdemokratischen] Reichstagsfraktion gegen die Kriegskredite gewesen sind; sie hätten sich nur dem Fraktionszwang gefügt. - Sie hätten sich nicht fügen sollen!!"

83 Rosa Luxemburg an Levi, 31.[8.1914], a.a.O., S. 453.

84 ,Die Haltung der deutschen Sozialdemokratie”, in: Vossische Zeitung, 1914, Nr 436 (28.8., Abendausgabe); der Bericht bezieht sich auf den Artikel von Albert Südekum, ,Tyskland och kriget. Ett ord till Sverges socialdemokrater”, in: Social-Demokraten, 1914, Nr 194 (24.8.). Südekum hatte eine Mitte August in privater Angelegenheit unternommene Reise nach Malmö zu einem Abstecher nach Stockholm benutzt. Vgl. ders., „,Reise nach Schweden” (mschr. Ms., 27 S.), NachlaB Südekum, Nr 11, Bundesarchiv, Koblenz. In den dort geführten Gesprächen sowie dem Artikel, den er danach schrieb, hatte er die Politik der deutschen Regierung, den Einfall in Belgien und die Haltung der SPD-Reichstagsfraktion verteidigt.

85 Vgl. A. P[annekoek], ,,De Duitsche sociaaldemocratie en de oorlog”, in: De Tribune, 1914, Nr 95 (26.8.). „,Wel streden”, hatte Pannekoek dort u.a. geschrieben, ,Haase, Liebknecht, Lensch en Ledebour met alle kracht voor een weigering, wezen op Bebels houding in 1870, op 't imperialistische karakter van den oorlog enz.; maar slechts 17 man stonden aan hun kant." Ferner ders., Herinneringen. Herinneringen uit de arbeidersbeweging. Sterrenkundige herinneringen, bearb. von B. A. Sijes, J. M. Welcker und J. R. van der Leeuw, Amsterdam 1982, S. 178f.

86 David hörte davon am 2. September von Curt Baake, während Scheidemann, der kurz vorher in Amsterdam gewesen war, den Artikel nicht erwähnt hatte. Vgl. David, KTB, 2.9.1914, S. 31; ebd., 5.9.1914, S. 34: ,Pannekoeks Artikel [. . .] wird von der Generalkommission übersetzt. Die Sache wird kaum noch geheim bleiben." 
abgesehen davon, daß diesen damals noch nicht der Nimbus umgab, den er erst durch seinen späteren, offenen Kampf gegen den Krieg erwarb, stand ihr von jenen 14 zunächst Lensch am nächsten. Zu Liebknecht kam sie gemäß dessen eigenen Bericht erst am 29.-30. August in engeren Kontakt.

Ende August forderte ich den Berliner Zentralvorstand zur Abhaltung von Protestversammlungen [gegen die Annektionshetze] auf [...]. Falls sie abgelehnt würden, plante ich, Ledebour, Lensch und Rosa Luxemburg dafür zu gewinnen, da $B$ wir 4 auf eigene Faust Protestversammlungen einberufen. Noch ehe mein Antrag [. . .] entschieden war, traf ich [am 29. August] zufällig Lensch im ,Vorwärts” und schlug ihm eine Zusammenkunft vor. Er teilte mir mit, daB Rosa Luxemburg ihn und Ledebour gerade für diesen Abend zu sich gebeten habe; ich möchte dorthin kommen. [. . .] Ich befolgte Lenschs Vorschlag und - blieb mit Rosa allein [ . . .]! Wir beide beschlossen, zum nächsten Tag (Sonntag) Lensch und Ledebour in meine Wohnung zu bestellen. Bei dieser Zusammenkunft zeigte sich Ledebour bereits sehr zurückhaltend und empfindlich. Meinen Vorschlag [ . . . wies er energisch zurück; über meinen Antrag beim Berliner Zentralvorstand war er ärgerlich. Da auch Lensch für diese Aktion nicht zu haben war, gingen wir ohne Ergebnis auseinander. [. . . ] Die Folge dieser Besprechung war, daß wir zwei, Rosa und ich, nun allein vorgingen [ . . ..$^{87}$

Die Nennung Liebknechts könnte also darauf deuten, daß Rosa Luxemburg den Brief an Troelstra nach dem 30. August schrieb. Vermutlich war am 29.-30. August nicht nur ihre jetzt ,,baldigst" geplante Reise nach Stuttgart, Frankfurt etc. zur Sprache gekommen, ${ }^{88}$ sondern ebenso wohl auf Anregung von ihrer Seite - eine Kampagne zur Aufklärung der Partei sowie der ganzen Internationale über die Vorgänge in der Fraktion beschlossen worden. Jedenfalls sandte Liebknecht seinerseits am 3. September an die Bremer Bürger-Zeitung ein Schreiben, in dem er, sich auf die erwähnte Notiz in der Vossischen Zeitung beziehend, konstatierte, , ,daß in der Fraktion über die bezeichneten Punkte diametral gegensätzliche Auffassungen geherrscht haben". ${ }^{89}$

Aus Rosa Luxemburgs Brief geht hervor, daß derselbe eine Antwort war

87 Liebknecht, Betrachtungen und Erinnerungen, a.a.O., S. 277. Unzutreffend G. Radczun, ,,Vorwort”, in: RLGW, Bd 4, S. 3* : ,Gemeinsam traten Karl Liebknecht und Rosa Luxemburg in den August- und Septembertagen 1914 in zahlreichen Versammlungen gegen die Sozialchauvinisten auf." Da sie erst am 29./30. August in nähere Fühlung kamen und Liebknecht danach vom 4. bis 14. September nicht in Deutschland war, dürfte die erste Versammlung, in der sie, gemeinsam [...] gegen die Sozialchauvinisten" auftraten, die Berliner Referentenversammlung am 27. September (s. unten) gewesen sein.

$\$$ Vgl. Rosa Luxemburg an Levi, 31.[8.1914], S. 454: ,,Vielleicht kommt Karl Liebkn[echt] mit mir. Er hat Lust."

89 Liebknecht, Klassenkampf, S. 25. 
auf ,Zeilen" Troelstras, der wohl - so eng war ja die Beziehung nicht ${ }^{90}-$ nicht ohne triftigen Grund geschrieben hatte.

\section{Troelstra - ,Die Stimme der Internationale”}

Während Troelstra nach der ISB-Sitzung in Brüssel noch die Hoffnung ausgesprochen hatte, da $B$, wenn es doch zum Krieg käme, die von den sozialistischen Parteien bewiesene einwandfreie Haltung ihre Wirkung auf die Massen nicht verfehlen würde, ${ }^{91}$ mußte er bald feststellen, daß die tatsächliche Haltung vielmehr zu Verwirrung in den eigenen Reihen führte, wobei die SDAP, deren Kammerfraktion am 3. August den Mobilmachungskrediten zugestimmt hatte, ${ }^{92}$ keine Ausnahme darstellte. Besonders Troelstras Erklärung in der Kammer, daß die Kritik an der Regierung einstweilen verstummen müsse, ,, weil unter diesen ernsten Umständen der nationale Gedanke die [inner]nationalen Differenzen zurücktreten läßt", ${ }^{93}$ wurde nicht nur von der SDP, sondern ebenso der Linken in der SDAP scharf kritisiert. ${ }^{94}$ Troelstra war indessen, von der Mehrheit darin unterstützt, der Meinung, daß es jetzt in erster Linie darauf ankam, die Niederlande aus dem Krieg herauszuhalten. Als der Vorsitzende der Partei, Willem Hubert Vliegen, am 5. August - unter dem Eindruck des deutschen Einfalls in Belgien - in Het Volk einen eventuellen Kriegseintritt auf der Seite der Entente suggerierte, ${ }^{95}$ übernahm Troelstra selbst zeitweise die

90 In den bekannten Briefen Rosa Luxemburgs wird nur ein ,,prächtiger Brief" von Troelstra und seiner Frau vom Herbst 1904 erwähnt, der anscheinend eine Einladung zu einem Besuch enthielt. Vgl. die Briefe an Karl und Luise Kautsky, [9.9.1904,] RLGB, Bd 2, S. 67; [nach dem 20.9.1904,] ebd., S. 70. Troelstra erwähnt Rosa Luxemburg in seinen Memoiren nur sechsmal kurz; dabei meinte er, daß das Pseudonym Kruszyńska, dessen sie sich u.a. in Zürich 1893 bedient hatte, ihr Mädchenname gewesen sei, später habe sie ,voor den vorm [ . . . ] een dr. Luxemburg” geheiratet. Troelstra, Gedenkschriften, Bd 2, S. 139.

91 Vgl. [P. J. Troelstra,] ,Het Internationaal Bureau en de Oorlog”, in: Het Volk, Nr 4391 (31.7.1914); fortgesetzt unter dem Titel ,De Internationale en de Oorlog”, ebd., $\mathrm{Nr} 4392$ (1.8.1914), $\mathrm{Nr} 4393$ (3.8.1914).

"2 Vgl. ,Fraktievergadering van 3 Aug[ustus 19]14" (Abschrift des Protokolls), NT 713/ 1.

${ }_{93}$ Handelingen der Staten-Generaal. Tweede Kamer. 1913-1914, Bd 2, S. 2587.

94 Vgl. ,Fraktievergadering van 15 September 1914" (Abschrift des Protokolls), NT 713/2-4. Ausdrücklich erklärte Troelstra hier: ,,voor haar steun voor de mob[ilisatie-] cred[ieten] staat fraktie in haar geheel - voor de woorden der motivering sta ik (Tr.) alleen verantwoordelijk." Vgl. auch ders., Gedenkschriften, Bd 3, S. 299ff.

${ }^{95}$ [W. H. Vliegen,] ,Holland's positie", in: Het Volk, Nr 4395 (5.8.1914): ,En de vraag kan opkomen of een ingrijpen onzerzijds om de Fransch-Belgische kansen te versterken, uit een oogpunt van zelfbehoud geen wijze politiek is." Vgl. hierzu W. H. Vliegen, Die onze kracht ontwaken deed. Geschiedenis der Sociaaldemocratische Arbeiderspartij in Nederland gedurende de eerste 25 jaren van haar bestaan, 3 Bde, Amsterdam 19[24] 38, Bd 3, S. 26ff. 
politische Leitung des Blatts, ${ }^{96}$ wobei er darauf hinwies, daß es für die Niederlande, die ohnehin zu schwach waren, um den Ausgang dieses Kriegs entscheidend zu beeinflussen, nicht den geringsten Grund gab, in ihn einzutreten.

Dieser Krieg ist kein Kampf für ein herrliches Ziel, sondern ein Wahnsinn, Folge eines wahnwitzigen Wettlaufs der großen Mächte um mehr Macht, mehr Ausbeutungsgebiet für kleine Gruppen Kapitalisten [. . . ]: die einzig mögliche Politik der Niederlande in diesem Krieg ist die der striktesten Neutralität. ${ }^{97}$

Gleichzeitig hielt er den Kritikern von links entgegen, der Krieg versetze alle Völker, selbst die Völker, deren Regierung ihn herbeigeführt hatte, in einen Notwehrzustand, d.h. einen Zustand, in dem die nationale Selbstbehauptung faktisch oberstes Gebot sei; gegen eine Partei, die das verkenne, wende sich das ganze Volk. ${ }^{98}$ Das organisierte Proletariat, erklärte Troelstra, sei unfähig, den Krieg zu verhindern, solange es nicht stark genug sei, das kapitalistische System, aus dem der Krieg hervorgehe, zu überwinden. Noch vor Kautsky wies er darauf hin, daß sich die Internationale nie bestimmt darüber ausgesprochen habe, was zu tun sei, wenn der Krieg einmal tatsächlich ausgebrochen sei; insbesondere habe sie nie den Beschluß gefaßt, das Proletariat in diesem Fall zum Generalstreik, zum Aufstand gegen die Regierung aufzurufen; ,,man" habe erkannt, da $B$ im Moment des Kriegsausbruchs die Bedingungen für eine revolutionäre Bewegung ungünstiger denn je seien. Das aber bedeute nicht, daß der Krieg den Kampf gegen das kapitalistische System unmöglich mache; vielmehr könne dieser Kampf aus dem Elend, das der Krieg bringe, neue Kräfte schöpfen.

Mit dem, was die Internationale bisher getan hat, ist also nicht ihr letztes Wort in dieser Weltkrise gesprochen. Sie hat sich bereitzuhalten, um [ . . ] aus dem Elend des Heute den Drang, den Willen, die Macht zur Neuordnung der Gesellschaft in Richtung auf den Sozialismus hervorgehen zu lassen. [. . .]

Darum ist es so richtig, was das Manifest des Parteivorstands sagt, daß es

96 Vgl. ,,Vergadering van het Partijbestuur 6 Augustus 1914", SDAP-Archiv, Mappe 26, IISG; Kommuniqué in Het Volk, Nr 4397 (7.8.1914). Troelstra legte dieses Amt jedoch, da er sich ungenügend unterstützt fühlte, schon im September wieder nieder. Troelstra an den Parteivorstand der SDAP, 5.9.1914, SDAP-Archiv, Mappe 134 c; ,,Vergadering van het Partijbestuur, 10. September 1914", ebd., Mappe 26.

${ }^{97}$ [P. J. Troelstra,] ,Nederland en de Oorlog”, in: Het Volk, Nr 4397 (7.8.1914). Außerdem gab Troelstra am 6. August in der Kammer eine Erklärung zugunsten der Neutralität ab. Vgl. Handelingen der Staten-Generaal. Tweede Kamer. 1913-1914, Bd 2, S. 2594.

98 [P. J. Troelstra,] ,Het Proletariaat en de Oorlog”, in: Het Volk, Nr 4399 (10.8.1914). 
nämlich die erste Aufgabe der Parteigenossen ist, die Macht- und Kampfmittel der Bewegung intakt zu halten. Für uns gilt jetzt mehr denn je das berühmte Wort: Bereit sein ist alles. ${ }^{99}$

Der Gedanke, da $B$ die Internationale tot sei, lag Troelstra dementsprechend fern. Die Internationale - führte er, seine Gedanken in einer einige Monate später publizierten Broschüre im Zusammenhang darstellend, ${ }^{100}$ aus - wäre erst tot, wenn sie beim Friedensschluß, der die Ausgangslage für die künftige Entwicklung schüfe, abermals versagte. Die Diplomaten würden nämlich, wenn die Völker sie gewähren ließen, einen Frieden schlieBen, der, imperialistischen Interessen dienend, den Keim zu neuen Kriegen in sich trüge. Diese Gefahr bestehe besonders dann, wenn eine Seite einen klaren Sieg erringe; besonders das Proletariat der siegreichen Nationen müsse sich dann den imperialistischen Kräften im eigenen Land entgegenstemmen. ${ }^{101}$

Die Überzeugung teilend, daß der Krieg in absehbarer Zeit ein Ende finden würde, erwartete Troelstra nicht, da $\beta$ derselbe die Klassenverhältnisse entscheidend zugunsten der Sozialdemokratie ändern würde, derart, $\mathrm{da} ß$ eine sozialistische Revolution möglich würde. ${ }^{102}$ Abgesehen davon, $\mathrm{da} ß$ die sozialistischen Parteien nichts in dieser Richtung täten, würde jene Losung das Proleratiat isolieren, ja zu seiner eigenen Spaltung führen, wodurch die Möglichkeiten, Einfluß auszuüben, noch geringer würden. Wenn der Krieg - etwa dort, wo er zum offenen Eroberungskrieg würde eine revolutionäre Bewegung auslösen würde, wäre diese auf den Frieden, nicht aber auf die Aufhebung des kapitalistischen Systems gerichtet, die durchaus nicht eine Conditio sine qua non für jenen sei: 1) müsse sich die

99 [P. J. Troelstra,] ,Nog niet sterk genoeg!”, ebd., Nr 4403 (14.8.1914). Mit den letzten - deutsch zitierten - Worten knüpfte Troelstra unübersehbar an den Schluß der von Marchlewski verfaßten Broschüre Imperialismus oder Sozialismus [Sozialdemokratische Flugschriften, XII], Berlin 1912, S. 16 an: ,So wächst sich der Kampf gegen den Imperialismus immer mehr zum Entscheidungskampf zwischen Kapital und Arbeit aus. Kriegsgefahr, Teuerung und Kapitalismus - Friede, Wohlstand für alle, Sozialismus! so ist die Frage gestellt. Großen Entscheidungen geht die Geschichte entgegen. Unablässig muß das Proletariat an seiner welthistorischen Aufgabe arbeiten, die Macht seiner Organisation, die Klarheit seiner Erkenntnis stärken. Möge dann kommen, was da will, mag es seiner Kraft gelingen, die fürchterlichen Greuel eines Weltkrieges der Menschheit zu ersparen oder mag die kapitalistische Welt nicht anders in die Geschichte versinken, wie sie aus ihr geboren ward, in Blut und in Gewalt: die historische Stunde wird die Arbeiterklasse bereit finden, und bereit sein ist alles."

${ }^{100}$ Troelstra, De wereldoorlog en de sociaaldemokratie, a.a.O. Die Abfassung der Broschüre begann Troelstra im September. Vgl. Troelstra an Ankersmit, 5.9.1914, NachlaB Ankersmit, IISG. Sie erschien im Februar 1915.

${ }_{101}$ Troelstra, De wereldoorlog en de sociaaldemokratie, S. 116ff.

102 Ebd., S. 130f. 
Entwicklung des Kapitalismus nicht notwendig auf imperialistischem Weg, d.h. dem der bewaffneten Expansion, vollziehen; 2) werde dieser Weg nicht unisono vom gesamten Bürgertum befürwortet; im Gegenteil - breite bürgerliche Schichten lehnten ihn im Hinblick auf die immer drückenderen Lasten, die er ihnen auferlegte, die sinnlosen Opfer, die er jetzt forderte, entschieden $a b .{ }^{103}$

Das Proletariat, dessen Friedensprogramm - Demokratisierung der auswärtigen Politik, schiedsgerichtliche Lösung internationaler Konflikte, Abrüstung etc. - nicht nur seinen Klassen-, sondern allgemeineren Interessen diene, müsse sich an die Spitze einer starken Volksbewegung für den Frieden setzen, die anti-imperialistisch, aber nicht notwendig anti-kapitalistisch wäre; wenn es gelänge, die Entwicklung des Kapitalismus in friedliche Bahnen zu lenken, wäre bereits viel gewonnen. Was die Demokratisierung der auswärtigen Politik betreffe, müßten sich die Parlamente selbst um eine Ausdehnung ihres Einflusses bemühen, etwa dadurch, daß sie parallel zu dem Friedenskongre $B$ der Diplomaten einen interparlamentarischen Kongre $B$ abhielten, der für die erwähnten Forderungen einzutreten hätte. Der Kampf für diese müsse aber noch im Krieg, durch den das herrschende System erschüttert sei, beginnen. Da sich diese Forderungen naturgemäß nur in internationalem Rahmen realisieren ließen, werde der Kampf für sie zum vorrangigen Zweck der Internationale, die aber nur Druck ausüben könne, wenn sie selbst geschlossen auftrete. ${ }^{104}$

Dementsprechend galt es, möglichst bald die in der Internationale selbst entstandene Kluft zu überbrücken. Es war erwünscht, daß zu gegebener Zeit Vertreter der einzelnen Parteien, besonders der Parteien der kriegführenden Länder, auf neutralem Grund zusammenkämen - n.b. nicht, um über eine neue Resolution zu diskutieren, sondern um über eine gemeinsame Friedensaktion zu beraten. Allerdings mußte solch eine Konferenz, wenn sie ihren Zweck erfüllen sollte, durch eine vermittelnde Wiederherstellung der abgerissenen Kontakte, den diskreten Austausch von Informationen, die systematische Sammlung relevanter Dokumente etc. gut vorbereitet sein. Diese Vorbereitung war eigentlich Sache des belgischen Exekutivkomitees des ISB in Brüssel, das jedoch dazu, da Belgien in den Krieg verwickelt war, kaum in der Lage war, weshalb die Übernahme seiner Funktionen durch eine neutrale Partei nahelag. Troelstra hatte hier in erster Linie seine eigene Partei, die SDAP, im Sinn, wobei er sich selbst eine maßgebliche Rolle zudachte.

Es scheint, daß Troelstra seine vorstehend skizzierte Konzeption in ihren

${ }^{103}$ Ebd., S. $121 \mathrm{ff}$.

104 Ebd., S. 125ff. 
Grundzügen bereits im Laufe des August entwickelte, wobei das stets wiederkehrende Leitmotiv war, daß das Proletariat, das sich vom Krieg habe überrumpeln lassen, sich nicht ebenso vom Frieden überrumpeln lassen dürfe. Schon bei Kriegsausbruch stand für ihn fest,

daß die Arbeiterparteien nichts unversucht lassen werden, um dem Kriegführen ein Ende zu machen. Auch bei der Festsetzung der Friedensbedingungen werden sie sich ohne Zweifel melden, sie werden für Schonung der besiegten Seite eintreten; für die Verminderung der Chancen für die spätere Entstehung neuer Kriege. ${ }^{105}$

\section{Über die Internationale bemerkte er am 12. August:}

In kurzer Zeit, wenn der Kampf ausgefochten ist, werden sich die Vertreter des Proletariats der verschiedenen Nationen wieder treffen. Zuerst wahrscheinlich in Brüssel, dem Sitz unseres Internationalen Büros [. . .]. ${ }^{106}$

Allerdings drohte zunächst einmal die Einnahme von Brüssel durch die deutschen Truppen, im Hinblick worauf Troelstra am 14. August an Huysmans schrieb:

$\mathrm{Da} \beta$ auch meine Sympathien mit Eurem tapferen Volk sind, brauche ich Dir nicht zu sagen. Auch halte ich ein Debakel in Deutschland für die für das Proletariat beste Lösung dieser Krise. Einstweilen erlegt mir die sehr verantwortliche Stellung, die ich hier einnehme, die Pflicht auf, jeden Anschein, als gäbe es hier ein Bemühen für oder gegen eine der kriegführenden Seiten, zu vermeiden. [... .]

Was später kommt, müssen wir abwarten. Schwarze Reaktion kann kommen - auch: ein großer Schritt vorwärts. „Bereit sein ist alles.” Und ein Land wie das unsere, das durchaus ökonomisch erschüttert, aber doch außerhalb des Krieges ist, bietet die beste Gelegenheit, um klar und ruhig in die Zukunft zu blicken und sich in die neuen Möglichkeiten einzudenken.

Wie steht es mit dem Archiv des Internationalen Büros. Kann das in Brüssel sicher bleiben? Wenn nicht, so verfüge über uns. ${ }^{107}$

105 [Troelstra,] ,De Internationale en de Oorlog”, a.a.O., Nr 4393.

106 [P. J. Troelstra,] ,,De Internationale en de Natiën”, ebd., Nr 4401 (12.8.1914).

107 Troelstra an Huysmans, 14.8.1914, ISB-Archiv, Mf. III, IISG (die Verweise auf das ISB-Archiv beziehen sich fortan stets auf die Mikrofilme im IISG): ,Dat ook mijne sympathien zijn met jullie dapper volk, behoef ik je niet te zeggen. Ook acht ik een débacle in Duitschland voor het proletariaat de beste oplossing van deze krisis. Intusschen legt mij de zeer verantwoordelijke positie, die ik hier inneem, den plicht op, elk voorwendsel, alsof hier een streven zou zijn vóór of tegen een der oorlogvoerende partijen, te vermijden. [ . . .] / Wat later komt, moeten we afwachten. Zwarte reaktie kan komen - óok: een groote stap vooruit. ,Bereit sein ist alles.' En een land als het onze, dat wél ekonomisch geschokt, maar toch buiten den oorlog is, biedt de beste gelegenheid, om de toekomst helder en rustig in te zien en zich in de nieuwe mogelijkheden in te denken. / Hoe staat het met het archief v[an] h[et] I[nternationaal] B[ureau]. Kan dat te 
Als sein Parteifreund Bernard van Praag am 29. August - Brüssel war bereits am 21. August gefallen - anregte, da $B$ das ganze ISB gegen das deutsche Vorgehen in Belgien protestieren sollte, ${ }^{108}$ antwortete er:

es ist bisher unmöglich, vom ISB aus irgendetwas zu tun. Wir sind dabei, zu sehen, da $\beta$ wir es hierher bekommen, dann wird das besser. Inzwischen müssen wir vor allem aufpassen, daß wir nichts tun, wodurch die Möglichkeit der Erneuerung der internationalen Beziehungen in Gefahr gebracht wird. ${ }^{109}$

Wenn von nun an - mißverständlich - von dem Plan der Verlegung des ISB nach Holland die Rede war, so hatte Troelstra, von dem der Plan stammte, die Übernahme der Funktionen der Exekutive des ISB durch das Büro der Kammerfraktion der SDAP im Sinn. ${ }^{110}$ Unter diesem Aspekt scheint bedeutsam, daß Troelstra am 26. August von der Tribüne der Kammer aus die Proletarier aller Länder aufrief, , der Internationale trotz des Umstands, daß ihre Weltmacht noch unzureichend war, treu zu bleiben". ${ }^{111}$ Anscheinend suchte sich Troelstra durch diesen Aufruf, durch den er kurzfristig wohl nicht nur der bürgerlichen Friedensbewegung den Rang ablaufen, sondern ebenso die durch seine Erklärung vom 3. August provozierte Kritik von links parieren wollte, zugleich für seine internationale Mission zu profilieren; jedenfalls kommentierte er den Aufruf selbst am nächsten Tag unter dem bezeichnenden Titel ,,Die Stimme der Internationale". ${ }^{112}$ Die Fraktion habe nur ihre Pflicht getan, wenn sie nun, da die internationalen Organisationen durch den Krieg gelähmt seien, das eigene

Brussel veilig blijven? Zoo neen, beschik dan over ons." Der Brief war eine Antwort auf die Bitte Huysmans', die holländische Regierung zu bestimmen, zur Entlastung Belgiens Druck auf Deutschland auszuüben: Huysmans an Troelstra, 11.8.1914, NT 547/21-22. Anscheinend zunächst einen deutschen Sieg erwartend, schrieb Troelstra Ende August: ,Zeker zal zij [de Duitsche regeering] de Triple Entente willen breken; maar of dit ten voordeele der Westersche kultuurvolken, tot vrijmaking der demokratische landen van het Czarisme zal zijn, dan wel tot vrijmaking van het Czarisme van die landen en tot het verbinden van het Czarisme aan het, eveneens absolute, keizerschap? / Het antwoord op deze vraag, waarvan het kan afhangen, of de oorlog ons reaktie zal brengen of vooruitgang, wachten wij met angstige spanning van den verderen loop der gebeurtenissen." [P. J. Troelstra,] ,Duitsche gezichtspunten”, in: Het Volk, $\mathrm{Nr} 4415$ (28.8.1914).

108 Van Praag an Troelstra, 29.8.1914, SDAP-Archiv, Mappe 2084.

${ }_{109}$ Troelstra an Van Praag, [Anfang September 1914,] ebd.: ,"'t is tot heden onmogelijk, iets van wege het I.S.B. te doen. We zijn bezig te zien, het hier te krijgen, dan wordt dat beter. Intusschen dienen wij dan vóor alles op te passen, niets te doen, waardoor de mogelijkheid der hernieuwing v[an] d[e] intern[ationale] betrekkingen in gevaar wordt gebracht."

$110 \mathrm{Vgl}$. Anm. 191, 357.

${ }^{111}$ Handelingen der Staten-Generaal. Tweede Kamer. 1913-1914, Bd 2, S. $2602 f$.

112 [P. J. Troelstra,] ,De Stem der Internationale”, in: Het Volk, Nr 4414 (27.8.1914). 
Parlament zur Tribüne gemacht habe, ,,von wo aus die Internationale [!] ihr mahnendes Wort zum Proletariat spricht". ${ }^{113}$

\section{5. , Lieber Freund . . .": nicht für alle eine Zwangslage in gleichem Maße}

Nichts deutet darauf hin, daß Troelstra in dem Brief, auf den sich Rosa Luxemburg bezieht, bereits auf seine Pläne eingegangen wäre; aber es ist anzunehmen, daß der Brief selbst diesen Plänen diente, die ja nur bei Unterstützung durch das ISB realisierbar waren. ${ }^{114}$ Während kurz vorher Vliegen in einem Brief an Bernstein, auf Grund dessen der Parteivorstand dann Scheidemann nach Holland schickte, seiner Empörung über den deutschen Einfall in Belgien Ausdruck verliehen hatte, ${ }^{115}$ hatte Troelstra, nach der Antwort Rosa Luxemburgs zu urteilen, in dem Brief an sie wohl einen prononciert neutralen Standpunkt eingenommen; vermutlich hatte er sich etwa in dem Sinne seiner - ihr wohl kaum bekannten - Leitartikel in Het Volk geäußert. Anscheinend hatte er ihr die bewußten , Zeilen" in der zweiten Hälfte des August zukommen lassen; es ist nicht ausgeschlossen, $\mathrm{da} ß$ er die Gelegenheit der Heimfahrt Scheidemanns am 30. August benutzt hatte. ${ }^{116}$

Wenn Rosa Luxemburg in ihrer Antwort ihrer Freude über Troelstras ,Zeilen”- wohl die ersten aus dem Ausland - Ausdruck gab, so war das

113 Ebd. Troelstra bemerkte ferner: ,Heeft onze fraktie op hare wijze, en zich richtend tot onze uiteengeslagen vredesscharen, getracht, de beweging voor den vrede weer te verzamelen en dezen voor te bereiden - de andere vrienden van den vrede in het Parlement deden daarvoor nog niets."

$114 \mathrm{Vgl}$. Albarda an Vandervelde, 25.10.1914, NT 560/3 (Abschrift): ,Depuis quelques temps, et cela conformément au désir du parti hollandais, Troelstra s'occupe de rétablir les liens entre les différents partis, liens que la guerre a gâtés. A cet effet il s'est mis en rapport avec quelques camarades étrangers, membres du bureau international."

115 Vgl. Tagebücher Otto Brauns, Geheimes Staatsarchiv, Berlin, A 92, Eintragung vom 21.8.1914: ,Zur Sitz[ung] d[es] P[artei-]V[orstands] kam E. Bernstein mit einem Brief von Vliegen aus Holland, der in den heftigsten Worten seiner Empörung über die brutale Kriegführung der Deutschen in Belgien Ausdruck gibt. Die Stimmung in Holland werde immer kriegerischer gegen Deutschland." Zunächst sollte Südekum nach Holland fahren, wogegen Haase im Hinblick darauf, daß jener den Bruch der belgischen Neutralität öffentlich verteidigt hatte, Einspruch erhob. Ebd., 22.8.1914. Vgl. auch Scheidemann, Memoiren, a.a.O., Bd 1, S. 261f. Zur Haltung von Vliegen vgl. Vliegen an Huysmans, 11.8.1914, ISB-Archiv, Mf. III: ,Een toestand, [ . . . ] waarin men licht onbillijk wordt voor anderen. / Ik bedoel niet je oordeel over de Duitsche sociaaldemokraten, dat deel ik ten volle en ik denk nog wel en met bitterheid aan al de fraseologie van de Internationale Congressen, waartusschen ik trouwens altijd in zeer sceptische stemming zat." - Außer der Entsendung von Scheidemann nach Holland (s. unten) beschloß der Parteivorstand die Entsendung Janssons nach Dänemark und Schweden, Südekums nach Italien (s. Anm. 222) und Otto Brauns und Richard Fischers in die Schweiz (s. Anm. 221).

116 Zum Datum der Rückkehr Scheidemanns vgl. dessen Memoiren, Bd 1, S. 263. 
wohl in diesem Fall nicht nur die übliche façon de parler. Deutschland war seit dem 31. Juli faktisch von der Welt abgeschnitten. Die Entente-Staaten hatten, als der Krieg ausbrach, die deutschen Kabellinien unterbrochen; die deutsche Zensur, die bei Verhängung des Kriegs- bzw. ,,Belagerungszustands" in Aktion trat, tat ein übriges. ${ }^{117}$ Unzensierte Nachrichten über das, was außerhalb des Machtbereichs der Mittelmächte vorging, waren, wenn, dann nur über die neutralen Länder zu bekommen. Rosa Luxemburg war daher nicht die einzige, die Troelstra um Het Volk bzw. sonstiges Material bat. ${ }^{118}$

Bemerkenswerterweise interessierte Rosa Luxemburg primär, ,was man im Auslande über uns schreibt", d.h. das Urteil der ausländischen Parteien über die Haltung der deutschen Partei, besonders das Votum der Reichstagsfraktion am 4. August, über das ihr eigenes Urteil bereits feststand. Überraschend mag dabei der Nachdruck scheinen, den die marxistische Theoretikerin auf die „Ehre” legt, wobei ein Gegensatz zu Clara Zetkin, die in ihrem Brief vom 5. August, der ,,persönlichen Ehre” die ,,politische Aktion” gegenüberstellend, sich zugunsten letzterer ausgesprochen hatte, ${ }^{119}$ nur auf den ersten Blick besteht. Rosa Luxemburg sprach nicht von einzelnen Personen, deren Ehre durch die Haltung der Parteiinstanzen nicht berührt war, sondern der Partei: eine Partei, die ihre Grundsätze preisgab, verlor samt ihrer ,Ehre” ihre raison d'être-dankte politisch ab. ${ }^{20}$

Was hatte Rosa Luxemburg von der Partei erwartet? Abweichend von anderen Radikalen ${ }^{121}$ war sie nicht der Meinung, daß die Partei den Gene-

117 Vgl. den Brief an Carl Moor, 12.10.1914, RLGB, Bd 5, S. 14: „In der jetzigen Zeit ist einem jeder Gruß und jedes Lebenszeichen von Gesinnungsgenossen aus dem Auslande doppelt teuer. Wir fühlen uns ja hier von der Welt abgeschnitten, und zwar durch eine doppelte Mauer: den Belagerungszustand und das Parteioffiziösentum." Da das in Art. 68 der Reichsverfassung vorgesehene Reichsgesetz über den Kriegszustand noch immer nicht erlassen war, galt das preußische ,Gesetz über den Belagerungszustand” vom 4.6.1851, Gesetz-Sammlung für die Preußischen Staaten, 1851, S. 451ff.

$118 \mathrm{Vgl}$. Bernstein an Troelstra, 13.9.1914, NT 543/10-14: ,Zu dem vielen, was uns sonst bewegt, ist die Unterbrechung des geistigen Verkehrs mit der Außenwelt eine schmerzliche Zugabe." Kautsky an Troelstra, 5.10.1914, NT 550/11: „Humanité und Daily Citizen bekomme ich seit 1. Aug[ust] nicht mehr. Meine Hauptinformationsquelle über das Ausland ist jetzt Het Volk, das ich mit großer Aufmerksamkeit und Freude lese." 119 A.a.O. (Anm. 75), S. 98.

$120 \mathrm{Vgl}$. Rosa Luxemburg, ,,Der Wiederaufbau der Internationale”, in: [Die Internationale, Heft 1 (April 1915), S. 1ff.] RLGW, Bd 4, S. $20 f f$.

${ }^{121}$ So erklärte z.B. Friedrich Westmeyer in der Stuttgarter Vertrauensmännerversammlung am 21. September 1914: ,,Wäre es der Internationale möglich gewesen, den Krieg zu verhindern? Ich behaupte es! Wenn in Deutschland nur 500000 Arbeiter in den Generalstreik eingetreten wären, dann hätte sich die Regierung das Gefahrvolle des Krieges noch einmal überlegt." Die Vorgänge in der Schwäbischen Tagwacht und ihre 
ralstreik hätte proklamieren müssen. Was die Führer der Partei zu geben hatten, erklärte sie in der im April 1915 verfaßten Junius-Broschüre, waren ,,nicht lächerliche Vorschriften und Rezepte technischer Natur, sondern [war] die politische Losung". ${ }^{122}$ Ausdrücklich verwies sie hier auf ihre Massenstreik-Broschüre von 1906, in der sie die Aufgabe der Partei bei Massenaktionen, die ,,nicht künstlich ,gemacht', nicht ins Blaue hinein ,beschlossen', nicht ,propagiert"' würden, erläutert hatte: die Partei sei berufen, die politische Leitung zu übernehmen, die Parole, die Richtung zu geben, die Taktik so einzurichten, daß sie der Entwicklung der tatsächlichen Kräfteverhältnisse vorauseilte. ${ }^{123}$ Ausgehend von den Erfahrungen der russischen Revolution von 1905 hatte sie schon damals die Meinung kritisiert, daß das Proletariat den Kampf erst dann beginnen könnte, wenn seine Organisationen dazu ,stark genug" seien; vielmehr würden sie erst im Kampf stark. ${ }^{124}$ Die Parlamentstribüne, schrieb sie 1915, sei am 4. August 1914 der einzige Ort gewesen, von dem aus international vernehmbar, frei gesprochen werden konnte; sie wäre dementsprechend der ideale Ort für die in der Stuttgarter Resolution vorgesehene ,,Volksaufrüttelung”' gewesen, wobei es nicht auf die direkte Wirkung angekommen wäre; vermutlich hätte die Partei sich schwersten Repressalien ausgesetzt; aber eines hätte sie erreicht - , daß die Ehre des deutschen Proletariats gerettet war", daß den aber Tausenden von Proletariern, die in diesem Krieg umkamen, im Moment des Tods der ,,Lichtfunken im Hirn” blieb, ,,daß das, was ihnen im Leben das Teuerste war: die internationale, völkerbefreiende Sozialdemokratie, kein Trugbild sei". Ferner hätte die Partei durch ihre mutige Stimme von Anfang an den chauvinistischen Rausch gedämpft, im weiteren Verlauf des Kriegs aber, bei zunehmendem Katzenjammer, zunehmend ,,alles Lebendige, Ehrliche, Humane, Fortschrittli-

Ursachen, hrsg. vom Landesvorstand der Sozialdemokraten Württembergs, Stuttgart [1914], S. 14.

122 Junius [Rosa Luxemburg], Die Krise der Sozialdemokratie [Anhang: Leitsätze über die Aufgaben der internationalen Sozialdemokratie, Zürich 1916], RLGW, Bd 4, S. 49-164 (fortan Junius-Broschüre), S. 149.

${ }^{123}$ Ebd., S. 149f.; Rosa Luxemburg, Massenstreik, Partei und Gewerkschaften [Hamburg 1906], RLGW, Bd 2, S. 100, 133.

${ }^{124}$ Ebd., S. 141ff. Für Deutschland erinnerte sie dort an die Erfahrungen unter dem Sozialistengesetz: ,,Allerdings entspricht die Methode, nach der die Gewerkschaften im Kampfe mit dem Sozialistengesetz gesiegt haben, nicht dem Ideal eines friedlichen, bienenartigen ununterbrochenen Ausbaus; sie gingen erst im Kampfe sämtlich in Trümmer, um sich dann aus der nächsten Welle emporzuschwingen und neu geboren zu werden. Dies ist aber eben die den proletarischen Klassenorganisationen entsprechende spezifische Methode des Wachstums: im Kampfe sich zu erproben und aus dem Kampfe wieder reproduziert hervorzugehen." Ebd., S. 142. 
che" um ihre Fahnen geschart. ,Die deutsche Sozialdemokratie wäre in dem allgemeinen Strudel [. . .] der hohe Leuchtturm der Internationale geblieben". ${ }^{125}$

Das Votum der Reichstagsfraktion am 4. August war für Rosa Luxemburg nicht nur falsche Politik, sondern der ,,gewaltigste Zusammenbruch", der ,,tiefste Fall", ein ,,jämmerliches, beispielloses Versagen”, , schwere Schuld", ,Verrat", ${ }^{126}$ wobei sie die Beziehung dieses stark moralischen Verdikts zu ihrer eigenen marxistischen Geschichtsauffassung selbst erläuterte:

Ob es so kommen mußte? Ein Geschehnis von dieser Tragweite ist gewiß kein Spiel des Zufalls. Es müssen ihm tiefe und weitgreifende objektive Ursachen zugrunde liegen. Aber diese Ursachen können auch in Fehlern der Führerin des Proletariats, der Sozialdemokratie, im Versagen unseres Kampfwillens, unseres Muts, unserer Überzeugungstreue liegen. Der wissenschaftliche Sozialismus hat uns gelehrt, die objektiven Gesetze der geschichtlichen Entwicklung zu begreifen. Die Menschen machen ihre Geschichte nicht aus freien Stücken. Aber sie machen sie selbst. ${ }^{127}$

Während Rosa Luxemburgs Urteil über die Haltung der deutschen Sozialdemokratie von Anfang an feststand, derart, daß die später ausgearbeitete Kritik in ihrem Brief an Troelstra bereits angedeutet ist, lag ihr die später in den Junius-Thesen ausgesprochene Verurteilung von allen Sozialisten, die bei Kriegsausbruch den Burgfrieden verkündet hatten, ${ }^{128}$ damals fern. Sie stand damals durchaus nicht auf dem Standpunkt Lenins, der bereits zu jener Zeit in seinen Thesen zum europäischen Krieg nicht nur den Führern der deutschen Partei ,,Verrat" vorwarf, sondern bemerkte:

Die gleiche Verurteilung verdient das Verhalten der Führer der belgischen und der französischen sozialdemokratischen Partei, die den Sozialismus verrieten, indem sie in bürgerliche Kabinette eintraten. ${ }^{129}$

${ }_{125}$ Junius-Broschüre, S. 150ff.

126 Ebd., S. 55, 147.

127 Ebd., S. 61.

128 Ebd., S. 43-47.

129 W. I. Lenin, ,,Die Aufgaben der revolutionären Sozialdemokratie im Krieg”, in: Ders., Werke, 40 Bde, 2 Erg.bde, 2 Reg.bde, Berlin 1955-71, Bd 21, S. 2; vgl. auch ,,Der europäische Krieg und der internationale Sozialismus”, ebd., S. 6: „Üben die Sozialisten Frankreichs und Belgiens etwa nicht einen ebensolchen Verrat? Sie entlarven ausgezeichnet den deutschen Imperialismus, sind aber leider erstaunlich blind gegenüber dem englischen, französischen und dem besonders barbarischen russischen Imperialismus!" Da Lenin hier ausdrücklich auf ,,Zibordis Artikel(,Avanti!' vom 2. September)" verweist, , in dem nicht nur der deutsche und österreichische Chauvinismus entlarvt wird [. . .], sondern auch der französische, in dem festgestellt wird, daß der Krieg ein Krieg der Bourgeoisie aller Länder ist", dürfte zu bezweifeln sein, daß er die Abfassung dieser kurzen Skizze bereits ,Ende August” begonnen habe. Zur ersten Reaktion von Lenin, 
Daß Rosa Luxemburg über die Haltung informiert war, die die Fraktion der SDAP bzw. Troelstra, den sie - n.b. - nicht „,Werter Genosse”, sondern ,Lieber Freund" anspricht, ja dessen ,Freundeshand” sie gerne drückt, am 3. August in der Kammer eingenommen hatte, ist kaum anzunehmen. Der Vorwärts hatte Anfang August nur über das Faktum des Zusammentritts der Kammer ,,zur Beratung eines dringlichen Gesetzentwurfs wegen des Krieges" berichtet; ${ }^{130}$ danach referierte er erst am 2. September ausführlich die Erklärung Troelstras vom 26. August. ${ }^{131}$ Über die Haltung Camille Huysmans', des Sekretärs des ISB, den sie - die freundschaftliche Beziehung datierte erst von der letzten Sitzung des ISB Ende Juli132 - ,, bei der ersten Möglichkeit" zu grüßen bittet, konnte sie nicht im geringsten Zweifel sein.Daß sich die belgische Partei einhellig zur Verteidigung des Landes bekannt, den Kriegskrediten zugestimmt, ihren Führer Vandervelde gleich bei Kriegsbeginn ins Kabinett entsandt hatte all das war allgemein bekannt. Was die Haltung der französischen Partei anging, hatte der Vorwärts am 15. August nach dem Corriere della Sera berichtet, daß die französische Kammer am 4. August die Kriegskredite einstimmig bewilligt habe; ${ }^{133}$ am 20 . August hatte er den Basler Vorwärts zitiert, laut dem sich die französische Partei zugunsten der Verteidigung des Landes gegen einen deutschen Angriff ausgesprochen hatte. ${ }^{134}$ Am 27. August hatten die Abendblätter die Nachricht gebracht, daß in das von

den der Kriegsausbruch in der Tatra überraschte, auf die Nachricht von der Abstimmung der SPD-Reichstagsfraktion am 4. August 1914 vgl. G. Sinowjew, N. Lenin. Sein Leben und seine Tätigkeit, [Berlin] 1920, S. 25: ,Er wollte das zuerst nicht glauben: ,Das ist nicht möglich, sagte er, das ist wahrscheinlich eine falsche Nummer des Vorwärts, welche diese elenden deutschen Bourgeois herausgegeben haben, um uns zu täuschen und so uns zum Verrat an der Internationale zu zwingen.' / Doch dem war leider nicht so. [. . . ] Als Lenin ebenfalls zu dieser Überzeugung gekommen war, war sein erstes Wort: "Die Zweite Internationale hat aufgehört zu existieren.",

130 Vgl. „,Holland”, in: Vorwärts, 1914, Nr 211 (5.8.).

131 Vgl. ,,Eine Erklärung der holländischen sozialistischen Kammerfraktion”, ebd., $\mathrm{Nr}$ 239 (2.9.): danach hatte Troelstra alle Proletarier aufgerufen, ,, der Internationale treu zu bleiben, obwohl ihre Macht noch zu gering war, den jetzigen Krieg zu verhindern”, ferner ,,bei der Erfüllung ihrer nationalen Pflicht jeder chauvinistischen Verhetzung fernzubleiben", aber alles zu tun, daß ,,aus den Greueln dieses Krieges die Einsicht geboren werde, daß nur die Festigung eines Verbandes der freien Völker Europas [. . .] jeden kapitalistischen Wettkampf [...] und damit jeden Krieg unmöglich machen könne.’"

132 Vgl. Rosa Luxemburg an Diefenbach, 23.6.1917, RLGB, Bd 5, S. 263f.; Huysmans an Benedikt Kautsky, 11.3.1949, in Rosa Luxemburg, Briefe an Freunde, a.a. O., S. 116. 133 ,,Die frarzösische Kammer und die Kriegskredite”, in: Vorwärts, 1914, Nr 221 (15.8.).

134 ,,Unsere französischen Parteigenossen und der Krieg”, ebd., Nr 226 (20.8.). 
Viviani gebildete Gouvernement de défense nationale die Sozialisten Marcel Sembat und Jules Guesde eingetreten waren, ${ }^{135}$ was - besonders, was den letzteren betraf - kaum überraschen konnte. Noch auf dem Congrès national im Juli hatte Guesde sich gegen einen Generalstreik ausgesprochen; ,,car nous ne voulons pas organiser l'invasion d'un pays au bénéfice de l'autre". 136

Rosa Luxemburg kannte Guesde bereits seit vielen Jahren, hatte sich indessen in der Anrede nicht seines Vornamens bedient. ${ }^{137}$ Desto bemerkenswerter scheint, daß sie in ihrem Brief an Troelstra, nachdem sie darin ebenfalls erst ,Guesde" geschrieben hatte, den Nach- durch den Vornamen ersetzte, indem sie diesen über jenen schrieb. Noch bemerkenswerter scheint dies, wenn die Annahme zutrifft, daß sie den Brief erst nach dem 27. August, d.h. als Guesdes Eintritt in das Kabinett bereits bekannt war, schrieb. Das gilt ebenso hinsichtlich ihres Urteils über die von Jaurès vermutlich eingenommene Haltung, über die später so viel spekuliert wurde. So meinte etwa Jacques Sadoul 1919 bei der Einweihung eines Denkmals für Jaurès in Moskau, Jaurès, der es der Arbeiterklasse zur Pflicht gemacht habe ,,de faire sortir la révolution sociale de la guerre [ . . . ], eût été des premiers parmi les socialistes d'Occident [ . . .] à tendre la main à Lénine." 138 Schon 1915 schrieb Charles Rappoport, der sich in den ersten Monaten des Kriegs der Opposition in der französischen Partei anschloB:

Jaurès hatte, als er die Kammer [am 31. Juli 1914] zum letztenmal verließ, die Absicht, am folgenden Tage in der Humanité eine Art von J'accuse! zu schreiben [. . .]. Diese Absicht wurde in reaktionären Kreisen bekannt. Als Jaurès von dem Staatssekretär [. . .], von Abel Ferry, gefragt wurde, was

135 Vgl. David, KTB, 27.8.1914, S. 27: „Die Abendblätter bringen die Nachricht, daß das Ministerium Viviani sich auf eine breitere Basis gestellt hat. Marcel Sembat und Jules Guesde sind in das Ministerium eingetreten. Damit ist auch die Ministerfrage für die Internationale gelöst. / Unsere Radikalen werden fassungslos sein."

136 ,La Question de l'Impérialisme devant le Congrès Socialiste”, in: l'Humanité, Nr 3743 (17.7.1914). Als am Vortag Sembat, der sich seinerseits für den Generalstreik ausgesprochen hatte, erläutert hatte, daß dieser nur in Frage käme, , si nous sommes sûrs que ce que nous ferons, on le fera aussi de l'autre côté de la frontière", hatte Guesde ihm zugerufen: , Le danger, Sembat, ce serait de livrer la nation la plus socialiste à celle que le serait le moins." "Contre l'Impérialisme et contre la Guerre”, ebd., Nr 3742 (16.7.1914).

137 In dem letzten ihrer wenigen Briefe an Jules Guesde, vom 27.1.1913, hatte Rosa Luxemburg die Anrede ,Cher camarade" benutzt. Vgl. Rosa Luxemburg, Vive la lutte! Correspondance 1891-1914, textes réunis, trad. et annotés sous la dir. de G. Haupt par C. Weill, I. Petit, G. Badia, Paris 1975, Nr 198, S. 363.

138 ,"La Révolution russe et Jean Jaurès, in: l'Humanité, Nr 5446 (16.3.1919). 
die Sozialisten angesichts der Sachlage tun werden, antwortete ihm Jaurès: ,,Unsere Kampagne gegen den Krieg fortführen!'”39

Pierre Renaudel, der die Version von Rappoport, der nur aus zweiter Hand berichtete, bestritt, meinte dagegen unter Hinweis auf die letzten Äußerungen von Jaurès:

Aucun homme de bonne foi n'eût pensé pouvoir en tirer une indication qui soit contraire à l'attitude prise au début de la guerre par le Parti socialiste, tout ému, tout chaud encore de la pensée de son chef. ${ }^{140}$

Rosa Luxemburg teilte in diesem Punkt im August 1914 eindeutig das Urteil Renaudels - was sie nicht davon abhielt, ihrer Erschütterung über Jaurès' Tod unumwunden Ausdruck zu verleihen. ${ }^{141}$ Während sie der Behauptung der deutschen Regierung, daß ihr der Krieg durch die Entente aufgezwungen sei, von vornherein nicht den geringsten Glauben schenkte, dementsprechend also eine deutscherseits abzuwehrende russische Gefahr nicht sah, ${ }^{142}$ blieb sie überzeugt, daß die Erklärung von Jaurès in Brüssel, daß die französische Regierung einen Krieg nicht wollte, wahr war. ${ }^{143}$ Angesichts des deutschen Angriffs im Westen, des brutalen Überfalls auf das neutrale Belgien, des rasanten Vorstoßes der deutschen Truppen auf Paris, der in der letzten Woche des August in vollstem Gange war, ${ }^{144}$ war Rosa Luxemburg, deren Sympathien auf der Seite des bedrohten Frankreich waren, selbst noch nicht zu jener später dargelegten historisch-politischen Sicht des Weltkriegs fähig, laut der die allseits beschworene Idee der nationalen Verteidigung nur eine ,,Illusion" war. ${ }^{145}$ Sie erkannte vielmehr an, daß im Gegensatz zu den deutschen Sozialisten ,,jene", d.h. die Belgier und Franzosen, in einer ,,furchtbaren Zwangslage" waren, die selbst den Eintritt in das Kabinett rechtfertigte. Lensch, laut dem in ihrer damaligen

${ }^{139}$ Charles Rappoport, ,,Was hätte Jaurès getan?”, in: Berner Tagwacht, 1915, Nr 176 (31.7.).

${ }^{140}$ Pierre Renaudel, ,,Réponse nécessaire à un étrange article”, in: l'Humanițé, Nr 4151 (29.8.1915); vgl. auch ders. an Grimm, 24.6. [1915], Nachlaß Grimm/ZimmerwaldBewegung, Suppl.: , Je ne veux pas tarder pour vous dire que nous considérons tous ici l'article de Rappoport sur Jaurès comme une infamie."

${ }^{141}$ Vgl. auch den Brief an Kostja Zetkin, [Dezember 1914,] RLGB, Bd 5, S. 31: „,Wir haben viele Freunde in diesem Jahr verloren: Jaurès [ . . .]"; ferner den Brief an Sophie Liebknecht, 14.1.1918, ebd., S. 57. Dort über Rodin: ,,Das muß ein Prachtmensch gewesen sein: offen, natürlich, überströmend von innerer Wärme und Intelligenz; er erinnert mich entschieden an Jaurès."

142 Vgl. Junius-Broschüre, S. 63ff., 108f.

${ }^{143}$ Ebd., S. 137.

${ }_{144}$ Vgl. Crispien, Tagebuch, 24.8.1914: „Gestern hat der Einmarsch in Frankreich begonnen - armes Frankreich!"

145 Vgl. Junius-Broschüre, S. 136ff. 
Einstellung alte bürgerlich-demokratische Traditionen, besonders die frankophilen Traditionen der polnischen Intelligenz, nachwirkten, schrieb 1919:

Die Niederlage der französischen Waffen schmerzte sie tief, und sie frohlockte förmlich, als sie mir eines Tages von Fortschritten im französischen Artilleriewesen berichten konnte. Darüber kam es zu Differenzen zwischen uns, die sich noch verschärften, als sie den Eintritt der französischen Sozialisten in das Kabinett guthieß. ${ }^{146}$

Die Überzeugung, daß - im Gegensatz zu den deutschen Sozialisten - die französischen und belgischen Sozialisten im August 1914 in einer ,Zwangslage" waren, klang ebenfalls in dem Artikel ,Gegen den Franktireurkrieg", durch, in dem Rosa Luxemburg wenig später - es war anscheinend ihr erster Artikel seit dem Kriegsausbruch - die rüde, durch ein Manifest der beiden Parteien ,,An das deutsche Volk" veranlaßte Polemik des Hamburger Echo gegen die gesamte Internationale zurückwies. ${ }^{147}$ Das von den Vertretern der beiden Parteien im ISB unterzeichnete Manifest, in dem - in der Unterstellung, daß die deutschen Arbeiter nur unzureichend unterrichtet seien - das Recht auf die Verteidigung der beiden Länder gegen den brutalen deutschen Angriff proklamiert wurde, erschien zunächst - am 29. August - in einem bürgerlichen holländischen Blatt, dem Algemeen Handelsblad $;{ }^{148}$ aber nicht nur in dieser Version, die Scheidemann in Amsterdam bekannt wurde, sondern ebenso in der Version, die der Redakteur von Het Volk, Johan Ankersmit, am 3. September im Auftrag des ISB dem deutschen Parteivorstand übermittelte, war es von den vier Belgiern (Anseele, Bertrand, Huysmans, Vandervelde), die zugleich die Exekutive des ISB bildeten, nicht für die belgische Partei, sondern das ISB unterzeich-

146 Lensch, „,Ein Ende und ein Anfang”, S. 1336. Lensch fährt hier fort: , ,Ich erklärte das als einen schweren Fehler; denn der Kampf gegen die Kreditbewilliger in Deutschland werde unmöglich, wenn die französischen Sozialdemokraten Hand in Hand mit Herrn Poincaré und dem Blutzaren die ,Zivilisation' retten wollten. Ablehnung der Kredite sei nur möglich als ein internationaler Akt, einseitig betrieben sei er eine feindliche Stellungnahme gegen das eigene Land." Vgl. auch Crispien, Tagebuch, 29.8.1914: „Ins französische Ministerium sind die Genossen Sembat und Guesde eingetreten! - Sozialdemokraten eilen, einer kapitalistischen Regierung aus dem Dreck zu helfen."

147 [Rosa Luxemburg,] ,Gegen den Franktireurkrieg”, in: [Sozialdemokratische Pressekorrespondenz, Nr 100 (17.9.1914)] RLGW, Bd 4, S. 6-8. Rosa Luxemburg schrieb diesen Artikel am 13.9.1914. Vgl. ihren Brief an Mehring vom gleichen Tag, RLGB, Bd 5, S. 10. Sie bezog sich auf den Artikel ,Eine notwendige Erklärung”, in: Hamburger Echo, 1914, Nr 211 (10.9.).

148 ,Een socialistisch manifest", in: Algemeen Handelsblad, $\operatorname{Nr} 27800$ (29.8.1914, ochtendblad); Het Volk, Nr 4416 (29.8.1914). Zur Vorgeschichte vgl. Blänsdorf, Die Zweite Internationale, a.a.O., S. 59ff. 
net. ${ }^{149}$ Am 9. September ließ der Parteivorstand - n.b. nur zur ,,persönlichen Information" - eine Übersetzung des von Ankersmit übermittelten Texts den Redaktionen der Parteipresse zugehen; ${ }^{150}$ ferner lie $B$ er durch das Pressebüro eine Erklärung vom gleichen Tag verbreiten, in der er nicht nur dagegen protestierte, daß das ISB, ohne Kontakt zur deutschen Partei aufzunehmen, ein durchaus ,,einseitiges” Manifest ,An das deutsche Volk" erließ, sondern ebenso dagegen, daß es - laut l'Humanitét ${ }^{151}$ - die Parteien der neutralen Länder über die ,Greueltaten der Deutschen” informieren wollte, ,während es sich über hinterlistige Überfälle belgischer Franktireurs auf deutsche Soldaten ausschweigt", ja ,über die Greueltaten der Russen in Ostpreußen nichts zu melden weiß". ${ }^{152}$

Rosa Luxemburg fand die Manier, in der das Hamburger Echo, durch diese Erklärung animiert, ,, unsere Brüder jenseits der Grenzen" - nicht nur die ,,französischen und belgischen Genossen”, die die Auffassung zum Ausdruck gebracht hätten, daß ihre Länder angegriffen seien, sondern ebenso die ,italienischen, schweizerischen, holländischen, schwedischen Genossen", die ,,so ziemlich dieselbe Auffassung" hätten - abkanzeln zu können meinte, in der es sie belehrte, da $\beta$ sie von wahrem Internationalismus keine Ahnung hätten, ,,daß ihre Führer [. . . ] feile Streber seien, die sich auf Kosten des Proletariats mästen", einfach unerhört. Obwohl sie schrieb: „Der Ausbruch des imperialistischen Weltkriegs zerriß den Bund", ließ sie durchblicken, daß das Versagen der Internationale für sie zunächst einmal das Versagen der deutschen Partei war, wobei sie aber den ,Brüdern im Ausland" die Versicherung gab, daß viele in der deutschen Partei - ,vielleicht die Mehrheit" - sich von Herzen danach sehnten, ,,ihnen wieder die Bruderhand drücken, ihnen manches erklären und manches abbitten zu dürfen". Überzeugt, daß die deutschen Sozialdemokraten den ,Brüdern von der Internationale" einmal wieder ,Auge in Auge" gegenüberstehen würden, warnte sie vor einem ,,brudermörderischen Franktireurkrieg der sozialistischen Presse”, der das nicht erleichtern würde. ${ }^{153}$

149 Vgl. Scheidemann an Troelstra, 17.10.1914, NT 556/6-7; ,,Erklärung”, in: Vorwärts, 1914, Nr 255 (18.9.). Von französischer Seite wurde demgegenüber erklärt, daß das Manifest von den Delegierten der beiden Parteien im ISB für die Parteien, nicht aber für letzteres unterzeichnet worden und an die Internationale, nicht aber an das deutsche Volk gerichtet wäre. Vgl. ,Un manifeste des Partis socialistes belge et français à l'Internationale", in: l'Humanité, Nr 3794 (6.9.1914).

${ }_{150} \mathrm{Vgl}$. das Zirkular des Parteivorstands vom 9.9.1914, Nachlaß Kautsky, H 8, IISG.

151 Vgl. , Les Puissances neutres convoquées par le Gouvernement Belge", in: l'Humanité, Nr 3771 (14.8.1914); H., ,L'Appel aux Neutres”", ebd., Nr 3772 (15.8.1914).

152 „Erklärung", in: Vorwärts, 1914, Nr 247 (10.9.).

${ }_{153}$ [Luxemburg,] ,Gegen den Franktireurkrieg", a.a.O., S. 6-8. 
Von ähnlichen Ideen ließ sich Liebknecht auf der Reise leiten, die ihn zunächst - vom 4. bis 12. September - nach Belgien, dann - am 13. September - nach Amsterdam führte. ${ }^{154}$ Der unmittelbare Zweck der Reise war die Suche nach dem jüngsten, bei Kriegsausbruch in Lüttich studierenden Bruder seiner russischen Frau Sophie, Abraham (Beba) Ryss, ein weiterer - der wahre - die Aufnahme des Kontaks zu ,,Genossen der Bruderparteien". ${ }^{155}$ So traf Liebknecht in Belgien - von Lüttich über Namur, Andenne, Huy bis nach Brüssel weiterfahrend - u.a. Huysmans und Vandersmissen, ${ }^{156}$ in Amsterdam - n.b. - nicht die Führer der radikalen SDP, sondern die der SDAP: Wibaut, Vliegen, Van der Goes und Mendels. ${ }^{157}$ Troelstra konnte nicht zugegen sein, da er die Einladung zu spät erhalten hatte. ${ }^{158}$ Seinerseits bemühte Liebknecht sich in den Gesprächen, einen adäquaten Eindruck von der Stimmung in Deutschland, besonders in der deutschen Partei, zu vermitteln; ohne seinen eigenen Standpunkt zu verhehlen, berichtete er über die Vorgänge in der Fraktion ,,so objektiv, daß z.B. die holländischen Genossen nach ihrer Erklärung [. . .]

$154 \mathrm{Vgl}$. Liebknecht, Klassenkampf, S. 24.

$155 \mathrm{Vgl}$. Sophie Liebknecht und Haase an Vliegen, 13.9 .1914 (Telegr.), an Wibaut, 14.9.1914 (Telegr.), Sophie Liebknecht an Wibaut, 18.9., 24.9. (Telegr.), 28.9., 6.10.1914 (Telegr.), Nachlaß Wibaut, Mappe 27, IISG. Sophie Liebknecht fürchtete, daß ihr Bruder, der in Lüttich studierte, als der Krieg ausbrach, und seitdem vermißt war, sich zum Dienst in der belgischen Armee gemeldet haben könnte. , Wie dankbar ich Ihnen aber sein würde", schrieb sie in ihrem Brief vom 18.9., ,,wenn Sie meinen Bruder irgend wie auffinden könnten, kann ich gar nicht sagen. Meine Mutter grämt sich ganz krank um den Jungen und auch [ich] finde keinen Augenblick Ruhe. [. . .] Da es nun leider mehr oder weniger sicher ist, daß er in der Armee ist, müBte man vielleicht die belgischen Verlustlisten verfolgen?” Ferner in der Nachschrift: „Mein Bruder heißt Abraham Ryss, nennt sich aber meist nach alter Gewohnheit als unser Jüngster Beba Ryss." Die Nachforschungen blieben erfolglos. Vgl. Anhang, Nr 5. - Liebknecht, Klassenkampf, S. 32 (Brief an den Parteivorstand, 2.10.1914).

156 Vgl. ,,Socialistes belges et Socialistes allemands", in: l'Humanité, $\mathrm{Nr} 3895$ (16.12.1914); kritisch zu diesem Bericht von belgischer Seite, in dem ,,manche Irrtümer" unterlaufen seien, Liebknecht, Klassenkampf, S. 81; ferner C. Fabry, Karl Liebknecht en Belgique pendant la guerre. Relation inédite, [Brüssel 1920]; L. Bertrand, Souvenirs d'un Meneur Socialiste, 2 Bde, Brüssel 1927, Bd 2, S. $245 \mathrm{ff}$.

157 Vgl. Anhang, Nr 2; Wibaut, Levensbouw, a.a.O., S. 113: ,Ik kende Karl Liebknecht [. . . ] niet. Maar in de wereldoorlog heb ik hem leren kennen. Toen hij uit België kwam, vertoefde hij een dag bij ons in Amsterdam. Ik begreep toen de oorzaken van de bezorgdheid van zijn vader, en uit het optreden van Karl Liebknecht met Rosa Luxemburg heb ik dat nog beter begrepen. Ik heb voor zijn persoonlijkheid toen en later grote eerbied gehad." Vliegen, Die onze kracht ontwaken deed, a.a.O., Bd 3, S. 68: „In September [. . .] kwam Karl Liebknecht naar Amsterdam. [ . . .] Wibaut en ik aten met hem samen bij Wibaut thuis en natuurlijk werd over niet veel anders gesproken dan over den oorlog."

158 Vgl. Anm. 176. 
ein gewisses Verständnis für die Haltung der Mehrheit gewannen”; ${ }^{159} \mathrm{ja}$, zu dieser Zeit noch einen schnellen deutschen Sieg erwartend, wies er seine belgischen Gesprächspartner darauf hin, daß eine deutsche Annektion des Landes im Hinblick auf die weit fortschrittlichere deutsche Sozialgesetzgebung für die belgische Arbeiterklasse durchaus vorteilhaft sein könnte: ,,vous auriez", erklärte er laut Bertrand, ,,une série de réformes sociales que l'on vous refuse ici." 160 Selbst die deutschen Berichte über die Taten belgischer Franktireurs brachte er zur Sprache. ${ }^{161}$ Aber was er daraufhin von seinen belgischen Gesprächspartnern zu hören bekam, was er selbst in Belgien sah, verfehlte nicht seine Wirkung; zutiefst erschüttert, erklärte er Huysmans beim Abschied, er wisse nun, was sich abgespielt habe, und werde seine Pflicht tun. ${ }^{162}$

Was Liebknecht in Belgien erfuhr, bestärkte ihn in seiner Ansicht, daß der Krieg, , im allgemeinen eine Folge der von uns grundsätzlich bekämpften kapitalistisch-imperialistischen Entwicklung", im besonderen ein deutscher Präventivkrieg war, der von der deutschen Partei ,,die schärfste Form des Protestes" verlangt hätte. ${ }^{163}$ Der ,,Sündenfall” der deutschen Partei vom 4. August, schrieb er nach seiner Rückkehr nach Berlin an den Vorsitzenden der schwedischen Partei, Hjalmar Branting, habe auf sie selbst, die ganze Internationale eine verheerende Wirkung gehabt, ja sei

159 Liebknecht, Klassenkampf, S. 33 (Brief an den Parteivorstand, 2.10.1914); Bertrand, Souvenirs, a.a.O., Bd 2, S. 247.

160 Ebd., S. 245; vgl. auch Vliegen, Die onze kracht ontwaken deed, Bd 3, S. 68: „Het is bekend genoeg dat Liebknecht van den beginne af an tot de weinige Duitschers behoorde die de schuld van Duitschland erkende en b.v. over den inval in België even scherp oordeelde als wij, maar toen ik twijfel opperde of Duitschland den oorlog wel winnen zou, bleek dat ook hij daar geen oogenblik over dacht. De onoverwinnelijkheid van de Duitsche legers stond ook voor hem buiten elken twijfel. Ook van hem kregen we de gewone redeneering te hooren. Duitschland zou eerst het Fransche leger vernietigen, daarna met behulp van Oostenrijk Rusland verslaan. Dan bleef wel is waar Engeland over met zijn heerschappij ter zee, maar de Engelschen zouden zoo wel erkennen dat de partij verloren was en te vinden zijn voor een schappelijken vrede. Liebknecht stond dan natuurlijk op het standpunt dat er geen afstand van grondgebied mocht worden geëischt, dat België zijn onafhankelijkheid moest terugkrijgen enzoovoort. Maar dat de Duitschers verslagen zouden worden was ook voor hem . . . ausgeschlossen!"

161 Vgl. Fabry, Karl Liebknecht en Belgique, a.a.O., S. 12f.; Bertrand, Souvenirs, Bd 2, S. $247 \mathrm{f}$.

162 Vgl. Huysmans an Renaudel, 22.5.1916, in l'Humanité, Nr 4428 (1.6.1916): ,Liebknecht ne savait rien de ce qui s'était passé en Belgique quand il est venu voir notre pays. Il a emporté l'impression que les Belges n'étaient pas vendus à la Grande-Bretagne, q'ils n'ont pas organisé des bandes de franc-tireurs, - qu'ils n'ont pas assassiné les blessés allemands, et que les exécutions allemandes en Belgique sont injustifiables. [. . .]/Les Belges [. . . ] lui ont serré la main avec effusion quand ils ont appris qu'il était venu pour découvrir et dire la vérité." Huysmans an Benedikt Kautsky, 11.3.1949, a.a.O., S. 70. 163 Liebknecht, Klassenkampf, S. 26-28 (Schreiben vom 26.9.1914). 
selbst ,,vom ,patriotischen' Gesichtspunkt aus” verkehrt gewesen, nämlich durch ,die Beseitigung aller Hemmungen, die im Auslande (dem feindlichen) gegen den Krieg bestanden". Er begriff nach allem nicht nur die Erbitterung der anderen Parteien über die Haltung der deutschen Partei, sondern gelangte seinerseits, durch moralische Empörung radikalisiert, zu dem Schluß, daß das loyale Verhalten der Minderheit der Fraktion am 4. August wenig adäquat gewesen sei. Jedenfalls mußten die ausländischen Parteien wissen, daß es diese Minderheit gab; denn daraus resultiere der ,,vorläufig geringe, aber doch reale Trost einer Hoffnung auf Rehabilitation der deutschen Sozialdemokratie". ${ }^{164}$ Nicht ahnend, daß die Bremer Bürger-Zeitung sein Schreiben von 3. September nicht gebracht hatte, stimmte er in Amsterdam der Publikation desselben in Het Volk zu. ${ }^{165}$

Es zeugt von dem tiefen Eindruck, den die Fahrt durch Belgien hinterlassen hatte, wenn Liebknecht danach - unabhängig davon, was er von den sozialistischen Parteien selbst erwartete - Branting bat, er möge ,,den Gedanken einer gemeinsamen Demarche aller neutralen Mächte" prüfen; denn ,,das ,Phantastische' dieses Vorschlags" nicht übersehend, wollte er nichts unversucht lassen, was einer ,Beendigung des wahnwitzigen Massenmords" dienen konnte. ${ }^{166}$

\section{Die holländische Initiative zur Schaffung eines ,,zentralen Organi- sationspunkts"}

Wenn Rosa Luxemburg - zunächst, gleich Liebknecht, hinsichtlich der anderen Parteien ohne Vorbehalt - erfreut die ,Freundeshand" von Troelstra drücken konnte, so deuteten sich in ihrer Ablehnung von dessen unterschiedsloser Rechtfertigung der Haltung aller sozialistischen Parteien, die die der deutschen einschloß, schon die künftigen Gegensätze an; denn auf der Unterstellung, daß sich keine der Parteien im August 1914 anders hätte verhalten können, basierte Troelstras ganze Konzeption. Abgesehen davon, daß er im eigenen Land die Radikalen konsequent bekämpfte, konnte Troelstra in der Internationale die beabsichtigte vermittelnde, koordinierende Rolle jedenfalls nur spielen, wenn er, was die einzelnen Parteien anging, nicht nur strikte Neutralität wahrte, sondern zudem in erster Linie den Kontakt zu ihren offiziellen Führern pflegte. Das

164 Vgl. Anhang, Nr 2.

165 Vgl. ,De Duitsche Rijksdagsfraktie en de oorlogsberichten”, in: Het Volk, Nr 4429 (14.9.1914): ,,Naar wij vernemen heeft ons partijblad, de ,Bremer Bürgerzeitung', het volgende schrijven ontvangen van het rijksdaglid, onzen partijgenoot Karl Liebknecht: [...]."

166 Vgl. Anhang, Nr 2. 
galt nicht zuletzt für die deutsche Partei, ihre Führer, ja Troelstra maß der deutschen Sozialdemokratie, der er besonders nahestand, noch immer die entscheidende Bedeutung bei. ${ }^{167}$

Dementsprechend hatte er sich in Het Volk eines Urteils über das Votum der Reichstagsfraktion ausdrücklich enthalten. ${ }^{168} \mathrm{Obwohl}$ ihn das anscheinend von Scheidemann - jedoch kaum dazu - überbrachte Weißbuch der deutschen Regierung in der Auffassung bestärkte, daß das entscheidende Motiv derselben die Stärkung der Weltmachtstellung Deutschlands auf Kosten der Triple-Entente, nicht aber die Abwehr der ,,russischen Gefahr" war, die sie nur vorschob, um den Krieg ,,bei der gesamten, auch der sozialistischen Bevölkerung populär zu machen", billigte er der deutschen Partei guten Glauben zu. ${ }^{169}$ Was die Kreditbewilligung betraf, erklärte er Scheidemann in der Aussprache in Amsterdam am 27. September, es sei klar, daß in einer Notlage entsprechende Kredite beantragt würden; das sei in Holland ebenfalls passiert: ,,Jeder von uns versteht, daß man für die Kriegskredite gestimmt hat." ${ }^{170}$ Wenn Troelstra der deutschen Partei etwas vorwarf, dann, daß sie nicht in angemessener Weise gegen den Bruch der belgischen Neutralität protestiert hatte, was in seinen Augen symptomatisch war für ihre allgemeine Haltung. Die Kritik aufgreifend, die Jaurès an dieser zehn Jahre vorher, auf dem Amsterdamer Kongreß, geübt hatte, ${ }^{171}$ erklärte Troelstra:

wir stehen nun noch am Beginn einer neuen Periode, wo man sich Fragen stellt über die Entwicklung der Internationale und der deutschen Partei. Wir haben von Scheidemann zweimal gehört, daß sie in Deutschland keine politische Macht besitzen; daß sie nichts durchsetzen können. Grund ist der negative Standpunkt, den sie immer eingenommen haben [. . . ]. Über die demokratische Gesinnung der bürgerlichen Parteien haben wir jetzt viel

167 Vgl. hierzu Vliegen, Die onze kracht ontwaken deed, Bd 3, S. 69: ,dat Troelstra altijd eenigzins eenzijdig georiënteerd was naar den Duitschen kant, niet in dien zin dat hij een Duitsche overwinning wenschte, maar in dien zin dat hij feitelijk alleen met de Duitschers geregeld contact had en met de anderen niet. Blijkbaar was hij van meening dat de beslissing over de vraag: oorlog of vrede, ook nu nog alleen bij Duitschland lag." 168 Vgl. [Troelstra,] ,Het Proletariaat en de Oorlog", a.a.O.

169 Vgl. [Troelstra,],,Duitsche gezichtspunten", a.a.O. (Anm. 107); Liebknecht, Klassenkampf, S. 82: „Ein Mitglied des Parteivorstandes verbreitet im Auslande deutsche Weißbücher".

170 ,,Vergadering van het Partijbestuur met Scheidemann [. . . ] en de Kamerfractie, de redactie van Het Volk en het Dageliksch bestuur van het N.V.V. - op Donderdag 27 Augustus 1914 in De Dageraad te Amsterdam", SDAP-Archiv, Mappe 26: ,,Ieder onzer begrijpt dat men voor oorlogscredieten stemde."

$171 \mathrm{Vgl}$. Sixième Congrès Socialiste International tenu à Amsterdam du 14 au 20 août 1904. Compte-rendu analytique, publié par le Secrétariat Socialiste International, Brüssel 1904 , S. 67-82. 
günstigere Nachrichten erhalten als früher. Wird sich unter dem Einfluß der deutschen Kriegspolitik die Haltung gegenüber den bürgerlichen Parteien ändern [ . . .], so daß wir einer anderen Zukunft entgegengehen? ${ }^{172}$

Scheidemann erwiderte, dies sei eine Frage, die er nur für sich persönlich beantworten könne:

Bei Fortsetzung der gegenwärtigen Politik noch 100 Jahre, bis wir die Mehrheit haben. Marxismus ist glänzende Theorie, aber keine Richtschnur für die Praxis. [. . .] Wenn man sozialdemokratische Macht erhalten will, muß man weg von der negativen Politik. Militärpolitik wird die Partei niemals treiben. Aber negative Politik, auch in Kleinigkeiten immer gegen die Regierung sein, d.h. aus Prinzip, werden wir fahren lassen müssen. Er ist bereit, ohne das Prinzip preiszugeben, eine andere Politik zu treiben, das wollen auch andere tun, aber man traut sich nicht aus Angst vor ein paar Schreihälsen in großen Versammlungen. Die Arbeiter sind auf die Dauer nicht zufrieden. Lernen ist schwer, aber umlernen ist schwerer. ${ }^{173}$

Während Scheidemann, der den Eindruck erhielt, daß es ihm gelungen sei, die holländischen Vorbehalte auszuräumen, ${ }^{174}$ Troelstra nochmals ausdrücklich für seine Hilfe dankte, ,,durch die die Amsterdamer Aussprache so schnell ermöglicht worden ist", ${ }^{175}$ informierte Troelstra ihn seinerseits in einem Brief, der dem Parteivorstand am 17. September vorlag, darüber,

172 ,,Vergadering van het Partijbestuur met Scheidemann”, a.a.O.: ,, wij zijn nu nog in den aanvang van een nieuwe periode, waarin men zich vragen stelt over de ontwikkeling der Internationale en der Duitsche partij. We hebben van Scheidemann tweemaal gehoord, dat zij in Duitschland geen politieke macht hebben; dat zij niet iets tot stand kunnen brengen. Oorzaak is het negatieve standpunt, dat zij steeds innamen [. . .]. Over demokratische gezindheid burgerlijke partijen hebben we nu veel gunstiger berichten gehoord dan vroeger. Zal onder invloed van de Duitsche oorlogspolitiek de houding ten opzichte van de burgerlijke partijen zich wijzigen [. . . ], zoodat wij een andere toekomst tegemoet gaan?"

173 Ebd.: ,,Bij volhouden tegenwoordige politiek nog 100 jaar, voor wij meerderheid hebben. Marxisme is Glänzende theorie maar geen leiddraad voor politiek. [ . . .] Wanneer men soc[iaal-]dem[okratische] macht wil behouden [sic], dan moet men afzien van negatieve politiek. Militaire politiek zal de partij nooit drijven. Maar negatieve politiek, ook in kleinigheden altijd tegenover de regeering staan, dus in beginsel gevoerd, zullen we moeten laten varen. $\mathrm{Hij}$ is bereid zonder principe op te offeren andere politiek te drijven, dat willen ook anderen doen, maar men durft niet uit vrees voor wat schreeuwers in groote vergaderingen. De arbeiders zijn op den duur niet tevreden. Lernen ist schwer, aber umlernen ist schwerer."

174 Vgl. Ph. Scheidemann, Der Zusammenbruch, Berlin 1921, S. 19; ders., ,,,Scheidemann in Holland'. Eine Antwort" (mschr. Ms., 5 S.), NT 29/1-5; ders., Memoiren, Bd 1, S. 262f. - Vliegen an Bernstein, 30.8.1914, Nachlaß Bernstein, D 789, IISG: ,Ich hoffe, daß die Zerstörung Löwens ihnen endlich die Augen öffnet - ich meine die deutschen Sozialdemokraten - wozu die deutsche Armee kommt. [. . .] Genosse Scheidemann war hier und hat uns kein Wort neues erzählt. Wir sind hier nicht einseitig informiert. [. . . / Wenn's so weiter geht, ist's am besten, das Wort Kultur zu streichen."

175 Scheidemann an Troelstra, 3.9.1914, NT 556/4-5. 
daß Liebknecht in Amsterdam unter Kritik der deutschen Partei seine abweichende Meinung dargelegt habe und Pannekoek in Holland die deutsche Partei fortgesetzt herunterreiße, woran er die Befürchtung knüpfte, daß innere Kämpfe die deutsche wie die holländische Partei hindern könnten, nach dem Krieg eine führende Rolle zu spielen. ${ }^{176}$

Gleichzeitig berichtete Troelstra von einem Projekt des französischen Sozialisten Augustin Hamon, das auf der Linie des französisch-belgischen Manifests vom August lag. Hamon hatte, damals in England, Anfang September angeregt, da $B$ angesichts dessen, daß das ISB, das seinen Sitz in dem besetzten Brüssel habe, ,, quite disorganized" sei, die BSP ,, as soon as possible" - ohne Rücksicht darauf, daß die deutschen und österreichischen Sozialisten daran kaum teilnehmen könnten - eine internationale Konferenz nach London einberufen sollte. ${ }^{177}$

$176 \mathrm{Vgl}$. Tagebücher Otto Brauns, a.a.O., 17.9.1914: ,,In der P[artei-]V[orstands-]S[itzung] lag ein Schreiben von Troelstra aus Amsterdam vor. [ . . .]/Geradezu skandalös ist das Treiben einzelner deutscher Genossen. So soll Liebknecht in Amsterdam eine Sitzung mit den dortigen leitenden Genossen abgehalten und dort unter Kritik der Haltung der deutschen Partei seinen pers[önlichen] Standpunkt dargelegt haben. Troelstra ist auch eingeladen gewesen, hat aber die Einladung zu spät erhalten und deshalb zu der Sitzung nicht erscheinen können. [. . .] / Ein ganz treuloser Bursche ist ja dieser holländische Sternkucker, der Pannekoek". Scheidemann an Troelstra, 17.9.1914, NT 556/6-7; ders., Memoiren, Bd 1, S. 265.

17 Außer an Troelstra hatte sich Hamon auch an Branting gewandt. Vgl. Hamon an Branting, 3.9.1914, Anlage: Hamon an die BSP, 3.9.1914, Nachlaß Branting, AA. Der Brief an Troelstra, der etwa den gleichen Wortlaut gehabt haben dürfte, liegt nicht vor. Zu Troelstras Antwort vom 7.9. vgl. seinen Brief an Huysmans (s. unten), ferner Hamon an Troelstra, 12.9.1914, NT 547/3-4: , ,Je crois, en effet, que la conférence à Amsterdam ou La Haye serait mieux qu'à Londres à cause de la possibilité de venue des socialistes allemands et autrichiens. / Si nous ne voulons pas voir l'Internationale être brisée en deux, il faut se hater à avoir cette conférence. / Si vous attendez l'adhésion de Anseele et C. Huysmans, vous perdrez du temps. [. . .] D'ici un mois sans doute les allemands seront presque repoussés hors de France et de Belgique; les alliés entreront sur territoire allemand. Il faut avant, que l'Internationale ait dit des paroles de fraternité". Andere Ziele verfolgten die Belgier (Terwagne, Destrée), auf deren Zustimmung Hamon sich berief. Vgl. Terwagne an Troelstra, 8.9.1914, NT 557/1: ,Le bureau de l'Internationale étant séparé de nous à Bruxelles . . . quelques amis anglais et français ainsi que Destrée et moi voudrions voir convoquer pour la fin du mois une conférence des délégués socialistes ( 3 délégués par pays) des nations neutres et belligérantes non allemandes pour nous concerter. Hyndman propose réunion à Londres." Anscheinend informierte Troelstra Scheidemann in seinem o.a. Brief (s. Anm. 176) von dieser letzteren Version des Plans: nach der Wiedergabe Otto Brauns ,, beabsichtigten die verehrten Genossen in der Exekutive des intern[ationalen] Bureaus eine internationale Konferenz nach London einzuberufen, von der die deutschen Parteien ausgeschlossen werden soliten." Braun hierzu: ,Eine nette Internationale! Uns hat man offenbar bisher als zahlungsfähiges Anhängsel in der Internationale geduldet. Dieses Vorhaben reiht sich würdig dem Manifest an das deutsche Volk an. Diese Vorgänge werden uns zwingen, bei der Neukonstituierung der Internationale, wenn es dazu kommt, unsere Haltung zu ihr ganz gründlich zu revidieren." 
Troelstra hatte bereits unmittelbar nach dem Erscheinen des französisch-belgischen Manifests zur Zeit von Scheidemanns Besuch in Amsterdam demselben seine Hilfe bei einem eventuellen Versuch, Huysmans zu kontaktieren, angeboten; danach hatte er es übernommen, diesem einen ersten Protest des deutschen Parteivorstands zu übermitteln; ferner hatte er nicht versäumt, Scheidemann wissen zu lassen, daß der Vorstand der SDAP den Mißbrauch der Exekutivfunktion durch die Belgier ebenfalls ablehnte. ${ }^{178}$ Was nun den von einigen englischen, französischen und belgischen Sozialisten unterstützten Vorschlag von Hamon anging, so wandte er sich - deutlich bemüht, sich für seine internationale Rolle zu profilieren nicht nur an Scheidemann, sondern ebenso an Guesde und Renaudel, die sich beide davon distanzierten. ${ }^{179}$ Huysmans, den er gleichfalls informierte, ließ er wissen, daß er seinerseits Hamon von seinem Plan entschieden abgeraten habe, da es nicht anginge, eine internationale Konferenz einzuberufen, ohne das ISB, ja selbst ohne dessen Sekretär hinzuzuziehen.

Auch müßte der Aufruf von der Partei eines neutralen Landes ausgehen und die Konferenz in einem neutralen Land abgehalten werden, so daß alle Parteien, von beiden kriegführenden Seiten, präsent sein könnten. [ . . .] Indessen glaube ich nicht, daß die Zeit jetzt für eine Konferenz reif ist. ${ }^{180}$

Zugleich sah Troelstra sich veranlaßt, die Realisierung seiner eigenen Pläne zu forcieren. ${ }^{181}$ Am 12. September legte er die Sache dem Parteivorstand der SDAP vor, der zu dem Schluß kam, daß an eine Zusammenkunft des ISB einstweilen kaum zu denken sei; der 2. Sekretär im Vorstand, Jan Willem Matthijsen, sollte in Belgien versuchen, Kontakt zur Exekutive aufzunehmen, um die erwünschte Verlegung zu besprechen. ${ }^{182}$,,Unsere Sorge ist", schrieb Troelstra namens des Parteivorstands an Anseele, ,,daß die Internationale von dieser Katastrophe einen gewaltigen Schock bekommt." 183 Das Sekretariat sei unerreichbar, die Exekutive zerschlagen,

$178 \mathrm{Vgl}$. Scheidemann an Troelstra, 3.9., 17.9.1914, a.a.O.; ,,Vergadering Partijbestuur 12 September 1914", SDAP-Archiv, Mappe 26.

$179 \mathrm{Vgl}$. Renaudel an Troelstra, 25.9.1914 (Telegr,), NT 555/2; Guesde an Troelstra, [25.9.1914,] NT 546/4-5.

180 Troelstra an Huysmans, 9.9.1914, NT 531/9-10 (der Brief kam, weil nicht zustellbar, zurück): ,,Ook zou de oproep van de Partij van een neutraal land moeten uitgaan en de Konf[erentie] in een neutraal land moeten worden gehouden, opdat alle partijen, van beide oorlogvoerende combinaties, er op tegenwoordig konden zijn. [ . . ]/ Intusschen geloof ik niet, dat de tijd thans rijp is voor een Conferentie."

181 Unrichtig die Annahme von Blänsdorf, Die Zweite Internationale, S. 68, erst das belgisch-französische Manifest und der Vorschlag Hamons hätten in Holland „Überlegungen über die Wiederherstellung der Internationale ausgelöst".

182 Vgl. ,Vergadering Partijbestuur 12 September 1914", a.a.O.

${ }_{183}$ Troelstra an Anseele, 13.9.1914, NT 528/4: ,Onze zorg is, dat de Internationale van deze catastrophe een geweldige schok zal krijgen." 
Belgien in den Krieg verwickelt; eine Kontaktstelle sei indessen dringend nötig, was der Vorschlag von Hamon beweise; aber jede Initiative, die von einer der Parteien der kriegführenden Länder ausgehe, wirke von vornherein einseitig. Die Frage sei daher,

ob es von Ihrer Seite Einwände dagegen gäbe, daß sich die holländische Partei vorläufig als Adresse der Internationale konstituiert, d.h. als Büro, bis wir aus Brüssel Nachricht erhalten haben, $\mathrm{da} B$ das Büro dort wieder funktionieren kann. ${ }^{184}$

Am 18. September konnte Matthijsen nach einem Besuch in Gent berichten, da $\mathrm{B}$ Anseele einverstanden sei, aber empfohlen habe, daß sie noch nach Brüssel führen, um auch die Zustimmung von Huysmans einzuholen sowie ihn zu veranlassen, ,, das Archiv, soweit es für die Einberufung einer internationalen Konferenz zur Besprechung der Lage nötig ist, an Holland abzutreten". ${ }^{185}$ Kurz darauf - wohl am 20. September - konnte Matthijsen in Brüssel an einer gemeinsamen Sitzung des Büros des Conseil Général der belgischen Partei und der Exekutive des ISB, von deren Seite außer Bertrand, der zugleich jenem angehörte, Huysmans und Anseele zugegen waren, teilnehmen. ${ }^{186}$ Nachdem man zunächst Berichte über die Besuche deutscher Genossen - Liebknecht, Wendel, Noske, Köster - angehört hatte, erklärte Anseele, wohl auf den Vorschlag von Hamon bezug nehmend, , qu'il faudrait que le C[omité] E[xécutif] consulte les autres Partis sur l'opportunité d'une réunion plénière du B.S.I., à Londres, pour examiner la situation"; selbst die Idee einer Konferenz unterstützend, empfahl er, Matthijsen anzuhören, , qui doit avoir à nous faire des propositions en ce sens". Darauf berichtete Matthijsen, der Parteivorstand der SDAP habe kürzlich die Lage der Internationale erörtert; dabei sei die Idee zur Sprache gekommen, ,qu'il convenait de provoquer une réunion de délégués des Partis affiliés". So verständlich die Erbitterung der Belgier sei, es müsse klar sein,

184 Ebd.: ,of er van Uw kant bezwaar zou bestaan, dat de Hollandsche Partij zich voorloopig als het adres der Internationale constitueert, dus als Bureau, totdat wij van uit Brussel tijding ontvangen, dat het Bureau aldaar weer functionneeren kan."

185 Matthijsen an den Parteivorstand der SDAP, [18.9.1914,] SDAP-Archiv, Mappe 2113: , het archief, voor zoover het noodig is ter bijeenroeping eener Internationale conferentie om den toestand te bespreken, aan Holland af te staan".

$186 \mathrm{Vgl}$. ,Conseil Général: Bureau. Procès-Verbal de la séance du 30[!]-9-1914”, ISBArchiv, Mf. III. Vom Bureau waren - außer Bertrand - Wauters, Lekeu, Delporte, Baeck, Vandersmissen, Mertens und Serwy anwesend. Die Sitzung fand frühestens am 19. , spätestens am 22. September statt. Zum ersten Datum vgl. den Brief von Matthijsen (s. Anm. 185), laut dem Anseele ,, niet voor zaterdag" von Gent weg konnte; zum zweiten Datum s. Anm. 187. Bertrand, Souvenirs, Bd 2, S. $227 \mathrm{f}$. 
que le puissant mouvement ouvrier en Allemagne est d'un tel poids dans le mouvement international qu'il ne peut être question d'écarter celui-là de celui-ci. C'est là déjà une raison pour laquelle il y a lieu de réunir une conférence à bref délai; cette conférence n'aurait pas pour objet de prendre des résolutions; on y échangerait des vues; elle serait suivie, si l'accord s'établissait à ce sujet, d'une nouvelle conférence où des résolutions fermes seraient prises [...].

Voraussetzung des Erfolgs sei, daß die Konferenz durch ein neutrales Gremium einberufen werde. Der Parteivorstand der SDAP schlage daher vor:

$1^{\circ}$ Le transfert provisoire du siège et des pouvoirs du B.S.I. à Amsterdam, entre les mains du comité directeur du S.D.A.P.

$2^{\circ}$ La convocation d'une conférence pour le début d'octobre de deux ou trois délégués par parti affilié à l'internationale dans le but:

a) d'étudier les moyens de mettre, par une action concertée de tous les partis, fin à la guerre.

b) de faire en sorte qu'après la guerre l'internationale reste debout avec toutes ses sections et toute sa puissance.

Auf den ersten Vorschlag wurde in der Diskussion kaum eingegangen. Laut Huysmans war die Verlegung des ISB unnötig; für die Parteien sei nur schwierig, nach Brüssel zu schreiben. ,La Hollande pourrait, le cas échéant, être notre correspondant." Vandersmissen meinte, wenn manchen Belgien jetzt nicht neutral genug scheine, gelte gleiches in bezug auf Holland, ,mais dans un autre sens". - Die Diskussion konzentrierte sich auf den zweiten Vorschlag, der, zumal im Hinblick auf die Teilnahme der Deutschen, ,,qui - so Huysmans - ont par leur attitude tué l'internationale", von allen außer Anseele entschieden abgelehnt wurde. Jedoch wurde dann der Kompromiß, den letzterer vorschlug, akzeptiert: die Exekutive des ISB sollte in einem von Huysmans zu verfassenden Zirkular die angeschlossenen Parteien bitten, sich zu dem von der holländischen Partei gemachten Vorschlag einer im Oktober in Amsterdam abzuhaltenden Konferenz zu äußern, wobei der Parteivorstand der SDAP ersucht wurde, ,,de bien vouloir servir d'intermédiaire entre le C.E. et les partis". In dem entsprechenden Zirkular, dessen Text - von Anseele in einem Brief vom 22. September übermittelt - am 26. September in Het Volk erschien, war von einer Verlegung des ISB keine Rede. ${ }^{187}$

187 Vgl. ,Circulaire aux Partis affiliés”, ISB-Archiv, Mf. III; Anseele an [Matthijsen?], 22.9.1914, SDAP-Archiv, Mappe 2084; ,,Een internationale konferentie", in: Het Volk, Nr 4440 (26.9.1914). - Unmittelbar nach der Sitzung beschloß das Büro des Conseil Général, das sich als Parteileitung des POB konstituierte, negativ auf das Zirkular zu reagieren. „Conseil Général: Bureau. Procès-Verbal de la séance du 30[!]-9-1914”, a.a.O. 
Die Enttäuschung Troelstras über dieses Resultat, das seine Pläne erst einmal durchkreuzte, läßt sich ahnen. Dabei ging es nicht in erster Linie darum, daß die Belgier nicht neutral waren. Als ihn Branting damals - in einem Brief vom 16. September - fragte, was er von einer von den Parteien der neutralen Länder - ,Skandinavien und Holland, wenn möglich auch Schweiz" - herbeizuführenden ,,kleinen Konferenz von führenden Genossen" halte, die eine neutrale, für die Parteien beider kriegführenden Seiten akzeptable Plattform auszuarbeiten hätte, ${ }^{188}$ winkte Troelstra - in einem Brief vom 21. September - gleichfalls ab. Eine formlose ,,Privatunterredung einiger führender Genossen aus den neutralen Ländern”, für die der beste Ort vielleicht Den Haag sei, könne gewiß nützlich sein; denn in der Tat:

Uns Neutralen wartet in der neu aufzubauenden Internationale eine große Aufgabe - je mehr, wo uns Bebel und Jaurès fehlen, um die entzweiten Brüder zu einigen.

Aber eine Konferenz sei noch verfrüht. Der Augenblick für eine Konferenz sei erst gekommen, wenn ,, auf Grund konkreter Thatsachen" über den Frieden gesprochen werden könne.

Jetzt, meine ich, würde man sich nur in Rekriminationen verlieren; nur die positive Aktion für den Frieden wird einigend wirken. ${ }^{189}$

Aber angesichts dessen, daß Troelstra damals davon ausging, daß es nicht in allzu ferner Zeit zum Frieden käme, scheint es fraglich, ob es ihm tatsächlich primär um den Zeitpunkt ging. Maßgeblich war wohl vielmehr die Sorge, daß ihm andere das Konzept verpfuschen könnten; denn er hatte von den Aufgaben, die die bewußte Konferenz erfüllen sollte, eine ziemlich klare Vorstellung. Wenn sie sich nicht in gegenseitigen Vorwürfen verlieren, sich nicht auf die Formulierung einer wohllautenden, aber zu nichts verpflichtenden Resolution beschränken, sondern zu konkreten Schlüssen führen sollte, mußte sie gut vorbereitet sein - am besten durch ihn selbst. Dementsprechend hatte - was Matthijsen wohl nicht klar gewesen war - für Troelstra die Verlegung des ISB, durch die er die entsprechenden Befugnisse erhielte, absolute Priorität; erst danach kam eine internationale Konferenz in Frage.

Eine derartige Besprechung vorzubereiten habe ich mir als erste Aufgabe des Bureaus gedacht, sobald es hier bei uns in Sicherheit gebracht ist. ${ }^{190}$

188 Branting an Troelstra, 16.9.1914, NT 543/21.

189 Troelstra an Branting, 21.9.1914, Nachlaß Branting.

190 Ebd. Vgl. hierzu Blänsdorf, Die Zweite Internationale, S. 91f. Die dort suggerierte Auffassung, daß Matthijsen, der sich in Brüssel auf den Parteivorstand der SDAP berief, 
Über die Versuche, ,das Int[ernationale] Soz[ialistische] Bureau nach Holland überzubringen", hatte Troelstra Branting bereits einleitend ausführlich informiert.

Was die Mission Matthijsens anging, zunächst ausgesprochen optimistisch, hatte Troelstra schon am 22. September, d.h. bevor derselbe von der Fahrt nach Brüssel zurückgekehrt war, die Zustimmung der Fraktion eingeholt, deren Büro nach seinem Plan die Funktionen der Exekutive des ISB übernehmen sollte. ${ }^{191}$ Nach der Brüsseler Aussprache schien dieser Weg blockiert.

Am 26. September lag Anseeles Brief dem Parteivorstand der SDAP vor. ${ }^{192}$ Matthijsen, der Bericht erstattete, resümierte, nun seinerseits den ,,belgischen” Vorschlag befürwortend, derselbe laufe darauf hinaus, daß die verschiedenen Parteien gefragt würden, ob sie der Verlegung des ISB nach Holland zustimmten. Demgegenüber sahen seine Zuhörer - wohl zu Recht - in jenem Vorschlag nur eine geschickte Parade ihres eigenen Vorstoßes. Troelstra wies darauf hin, daß die Einberufung einer internationalen Konferenz bereits von verschiedenen Seiten betrieben würde; erneut betonend, da 3 es dazu noch zu früh sei, stellte er die Frage, ,ob es erwünscht sei, vor der Übertragung des Büros eine Konferenz abzuhalten". ${ }^{193}$ Auf Vorschlag Vliegens, der ebenfalls betonte, man habe Matthij-

in Wahrheit eigene Ideen vorgetragen habe, die im Gegensatz zu denen des Parteivorstands, besonders Troelstras, standen, dürfte unzutreffend sein. Vielmehr dürften die betreffenden Ideen in der Sitzung des Parteivorstands am 12. September zur Sprache gekommen sein; im Protokoll der Sitzung heiBt es hierzu nur: ,,Schrijven van Hamon aan Troelstra en diens antwoord er op. / Op dit oogenblik is aan een samenkomst van het Bureau niet te denken; als de tijd zoover gekomen is, dat er overleg met het bureau kan plaats hebben, is misschien de tijd gekomen om tot een bijeenkomst over te gaan. [ . . ]/ Hierna wordt in het algemeen gediscussieerd over het bureau en over de wenschelijkheid dat er voorzorgsmaategelen waren genomen om tijdens den oorlog het bureau te verplaatsen, in ons land te vestigen bijv. [. . . ]." Außerdem war Matthijsen nach der ersten Unterredung mit Anseele in Gent, in der ebenfalls die Frage einer internationalen Konferenz zur Sprache gekommen war, noch einmal in Den Haag gewesen, wo er Troelstra gesprochen hatte. Vgl. Matthijsen an den Parteivorstand der SDAP, [18.9.1914,] a.a.O. Nach jener Unterredung hatte es geschienen, da $B$ die Belgier keine Schwierigkeiten machen würden, weshalb Matthijsen sich in Brüssel dann so freimütig geäußert hatte. Wenn es einen Gegensatz zu Troelstra gab, dann kaum in der Sache selbst, sondern im Vorgehen.

$191 \mathrm{Vgl}$. Albarda an das Sekretariat der SDAP, 19.10.1914, SDAP-Archiv, Mappe 2084: ,Ik kan u nog meedelen dat het denkbeeld het bureau naar Holland te verplaatsen en het bureau der Kamerfraktie als executif comité ervan te beschouwen, in de vergadering der Kamerfraktie van 22 Sept[ember 19]14 door Troelstra is besproken en met algemeene instemming is begroet."

192 Vgl. ,,Vergadering Partijbestuur 26 September 1914”, SDAP-Archiv, Mappe 26.

${ }^{193}$ Ebd.: ,, of het wenschelijk is om voor de overdracht van het bureau een conferentie te houden". 
sen nur nach Belgien geschickt, , um das Büro zu bekommen", ${ }^{194}$ wurde beschlossen, die angeschlossenen Parteien über die Verlegung bzw. darüber, ob vorher eine Konferenz erwünscht sei, schriftlich zu befragen. Nach Troelstras Meinung war der beste Weg ein Telegramm, das seinem Konzept zufolge lauten sollte:

Weil Int[ernationales] Soz[ialistisches] Bureau Brüssel wegen Kriegszustand isoliert, erachtet Holländische Partei Verlegung nach neutralem Lande während Krieg nothwendig. Belgische Freunde wünschen keine Verlegung ohne Zustimmung Parteien und sind bereit zu Konferenz. Wir erachten Konferenz vorläufig inopportun. Bitte über Konferenz und Verlegung Bureau Meinung [. . .] zu schreiben. Wir sind bereit, vorläufig Bureau zu übernehmen. Troelstra-Scheveningen. ${ }^{195}$

Möglicherweise wurde dieses Telegramm, wenn überhaupt, dann nur an die deutsche und die österreichische Partei versandt; ${ }^{196}$ jedenfalls liegt nur von diesen zwei Parteien eine Antwort vor. Aber seine deutschen Freunde hatte Troelstra wohl schon vorher brieflich über seine Pläne informiert; denn schon am Morgen des 27. September konnte Ebert, die Verdienste Troelstras anerkennend, dem Parteiausschuß berichten:

Bezeichend für die Auffassungen im Internationalen Bureau ist, daß man dort den Vorschlag machte, im Oktober in England eine Sitzung des Internationalen Sozialistischen Bureaus ohne die deutsche und die österreichische Partei abzuhalten. Troelstra erhob dagegen Einspruch. Es ist ein groBer Schaden, daß der Sitz des Internationalen Sozialistischen Bureaus sich in einem der kriegführenden Länder befindet. [. . .] Die Holländer haben vorgeschlagen, den Sitz während des Krieges nach Holland zu verlegen; über den Erfolg ihres Vorschlags ist eine Nachricht noch nicht da. ${ }^{197}$

Während Victor Adler, anscheinend die Frage Troelstras mißverstehend, am 30. September zurücktelegraphierte, daß die österreichische Partei ,,prinzipiell bereit zu jedem aussichtsvollen Versuch eines Meinungs-

194 Ebd.: ,om het bureau te krijgen".

195 Der formlose Begleitbrief trägt das Eingangsdatum des 29.9.1914; in Troelstras Konzept: ,,Meinung deutsche Partei zu schreiben”. SDAP-Archiv, Mappe 2084.

196 Laut Troelstras Begleitbrief war ein Telegramm, ,wegens slecht postverkeer beter dan brief"; dasselbe war zu senden ,, aan de Secr. der 3 Britsche partijen, de Duitsche, Oostenrijksche, Tsechoslavische (Brucha), Hongaarsche (Buchinger), Fransche, Ital., Spaansche, 2 Russische, Finsche, Poolsche (Rosa Luxemburg, thans bei Kunstmaler Zundel, Wilhelmshöhe bei Stuttgart), de 3 Scand. landen, Zwitserl., Bulgarije (Hristoff), V.S. 2 partijen, en: M. Hillquith, Chicago". Von Troelstras Hand nachträglich hinzugefügt: ,,Belgische”. Notiz von anderer Hand: ,21 tel - $f$ 190.95”.

197 Vgl. Protokolle der Sitzungen des Parteiausschusses der SPD. 1912 bis 1921. Nachdrucke, hrsg. von D. Dowe, 3 Bde, Berlin, Bonn 1980 (fortan Prot. PA SPD), Bd 1, 27.9.1914, S. [91]f. 
austausches" sei, ${ }^{198}$ antwortete Scheidemann am 1. Oktober namens des deutschen Parteivorstands:

Vollkommen einverstanden mit Ihren Vorschlägen, besonders mit Bureauverlegung nach Holland. ${ }^{199}$

Die eigentliche Befragung der im ISB vertretenen Parteien erfolgte dann in einem Rundschreiben vom 2. Oktober, in dem betont wurde, daß das Büro, , ,insbesondere wenn die Zeit der Friedensvorbereitung sich nähert", eine große Aufgabe zu erfüllen habe, für die es nicht nur beizeiten das nötige Material sammeln, sondern möglichst regelmäßig Kontakte zu den angeschlossenen Parteien unterhalten müsse.

Auch ist es für das Fortbestehen und die gute Wirkung der Internationale im Allgemeinen erwünscht, daß mitten im Sturme der nationalen Leidenschaften wenigstens ein zentraler Organisationspunkt da ist, wo die angeschlossene[n] Parteien einander zu finden wissen.

Der Gedanke, über die Verlegung eine internationale Konferenz abzuhalten, scheine gegenwärtig ,,noch nicht ausführbar". ${ }^{200}$

Unter den Adressaten war - gemäß der Anweisung von Troelstra „,Rosa Luxemburg, p/a Kunstmaler Zundel, Wilhelmshöhe bei Stuttgart" für die polnische Partei, d.h. die SDKPiL. ${ }^{201}$

\section{Rosa Luxemburgs Warnung vor ,,voreiligen, unbedachten Schritten”}

Während Troelstra im Hinblick auf die erstrebte Reaktivierung der Internationale vorzugsweise die Führung der deutschen Partei umwarb, die sich ihrerseits erkenntlich zeigte, wurde Rosa Luxemburg auf Grund ihrer zunehmenden Erbitterung über die Führung der deutschen Partei, was die Erneuerung der alten Internationale anging, immer skeptischer. Wenn sie jedoch in ihrem Brief an Troelstra nicht nur dessen Versuch einer Rechtfertigung der Haltung der deutschen Partei a tempo zurückgewiesen, sondern, ihrerseits auf eine starke Opposition dagegen hoffend, ebenso die ,,großen Sympathien" erwähnt hatte, derer sich die Gegner der Kreditbewilligung ,,was man so hören kann" - erfreuen sollten, ${ }^{202}$ hatte sie wohl eher einen Wunsch geäußert. Laut Lensch war es am 5. August ,,unmöglich [gewe-

198 Victor Adler an Troelstra, 30.9.1914 (Telegr.), NT 542/2.

199 Scheidemann an Troelstra, 1.10.1914 (Telegr.), NT 556/9.

200 Zirkular an die dem ISB angeschlossenen Parteien, 2.10.1914, SDAP-Archiv, Mappe 2084; ebd. holländisches Konzept von Troelstras Hand, holländische Version vom 1.10.1914, Übersetzungen ins Englische und Französische.

201 Liste der Adressaten gemäß Troelstras Anweisung (s. Anm. 196), SDAP-Archiv, Mappe 2084.

202 Vgl. Anhang, Nr 1. 


\section{Sociaal-Democratische Arbeiders-Partij in Nederland}

ALS RECHTSPERSOON ERKEND BI] KONINKLIIK BESLUIT D.D. 22 SEPTEMBER $1997 \mathrm{~N}^{*} .25$.

SECRETAMAAT

OE GENESTETBTRAAT 16

AMSTERDAM

NTERCOMM. FELEPHOON 6600.

AXSTERDAM,

2. Oktober

1914.

0

Nr.

Verxowike bf beantwoording hierven Nr.en Datun an to goven.

An dx dea I. B. B. angeschlononon Parteien,

\section{Parteigenosen,}

Der Kriegasuntand hit sur Yolge, dass dat I.S.B. In

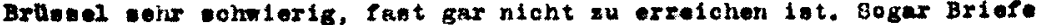

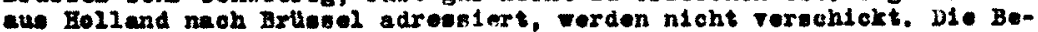
setzung croseer Telle Bolgtens von don deutechen Iruppen hemit oder verhindert den verkehr. Und nicht rorauszusegen ist, wie lange di eser Zuetand dauern wird.

Io int klar, dase hi orduroh die wirkung des Burean's unmblich gewoxden int. Frotsde wird das Bureau, ingbesondere tonn die zelt der Triedengrorbereitung leh nthert, ine grosse Aufgabe zu erruilen haben, fur welche ochon belselten das notige katerial aus vielen Ilindern zu canion haben wird und mit den Partelen in rogelmkenger verbinduns su etoher hat.

Aueh lot os flis das portbest then und die gute Wirkung der Internet1onalo in 1 lgemeinen erwhocht, dass mitten im Sturme der nationalen

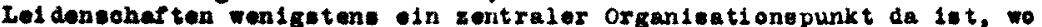
die angenchlosene Paxtelon olnander zu finden wionon.

Diene Irwikgngen boben un demu gefuhrt, mit den bolgitchon yreunde daraber wu beraton, ob ele nicht dasu mitrirken konnten deindt das

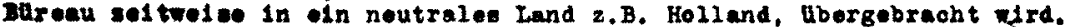

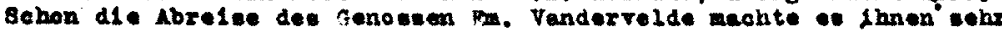
ochwioric dlese Frage su bejahen. Auch int es erwinscht eine dorartifge mtsobelaune nioht ohne Beraturs mit den angeschlosenen Partoien su tretson.

Dor Gedenke, diese Berstung ir elner International on Konferens absurasten dinkt uns bel nilherer Mrwikung in heutigen stadium der Internetlonal m verwieklungen noeh nlcht aus fuhrbar. Une erer Erachtene ist dor zol tpunkt fur eine derartige Xonferens oret da, wonn e10 ich mit der Dohandiung dor su cohli aseonden yriedons bofaseon kann. Dafllr aber aind die materielien vorbedingungen noch nicht da. Eo liegt jetst in uneerer Absloht uneeren Vorschieg den belgitechen prounden gegentiber su vieder-

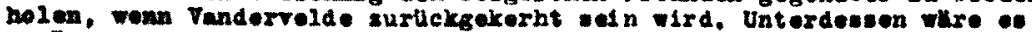
orwineoht, dass dit angeschiosene Partelen uns ror dienen Zeitpunkt thro Holnung su dience Vorachlag altellen wirden. Wir bitten 8ie al so dies su tun und orsuchen sie lhre Antwort wo bald wie möglioh de uitclied doe 1. 8. B., den genowen Troels tra in Bchereningen zu echleken su

Die Deiegierten

1. 1. B. B. roelitir. Tan Xol.
Mit internationale Gruas der Pertel vorotand der Sosialdemokrat1 soho Arbelterpartel in Holland. 7. H. Viegen. Vorsitsender. 
sen], in Berlin auch nur ein halbes Dutzend Stimmen zum Protest gegen die Kreditbewilligung aufzutreiben". ${ }^{203}$ Clara Zetkin hatte am 5. August ebenfalls den Eindruck gehabt, ,,daß wir völlig isoliert in der Luft stehen”. ${ }^{204}$ Laut Eberlein war das Echo auf die nach dem 4. August versandten 300 Telegramme nicht ermutigend gewesen. ${ }^{205}$ Aber Ende August schien eine Änderung der Lage absehbar. Rosa Luxemburg wußte damals bereits von der Opposition in Stuttgart, wo in der Sitzung der Vertrauensmänner am 21. August die Mehrheit die Kreditbewilligung verurteilt hatte ${ }^{206}$ über die Stimmung in Frankfurt a.M. war sie durch Paul Levi informiert; vermutlich wußte sie ferner von der Opposition in Braunschweig (Otto Antrick war Ende August kurz in Berlin gewesen ${ }^{207}$ ), Bremen, Hamburg, Gotha etc. ${ }^{208}$ Aber in erster Linie bezog sie sich wohl auf Berlin, wo die Urteile über die Stimmung stark divergierten. Während etwa Eduard David am 7./8. August von seiner geschiedenen Frau hörte, ,,daß in den Kreisen der Zehlendorfer Genossen große Erbitterung über unser Votum herrscht", wußten Schöpflin, Groger u.a. zu berichten, ,die Berliner Genossen seien in großer Mehrheit [. . .] durchaus einverstanden". ${ }^{209}$ Am 10. September berichtete der Polizeipräsident über die Anfang des Monats in den sechs sozialdemokratischen Wahlvereinen des Berliner Stadtbezirks abgehaltenen Zahlabende.

Trotz schriftlicher Einladung waren die Zahlabende fast durchweg sehr schwach besucht. Auf einigen soll eine geradezu patriotische Stimmung geherrscht haben, während auf den anderen einzelne, besonders radikale Genossen eifrig bemüht gewesen sind, durch heftige Reden eine kriegsfeindliche Erregung hervorzurufen. ${ }^{210}$

Was die allgemeine Kriegsbegeisterung betraf, hatte Rosa Luxemburg bereits Anfang August gemeint: ,In einigen Monaten, wenn Hunger

203 Lensch, ,Ein Ende und ein Anfang”, S. 1335.

204 Oben, S. 20.

${ }^{205}$ [Eberlein?], ,,Die ersten Schritte”, S. 2f.: ,,Die, die überhaupt antworteten, antworteten in faulen und dummen Ausreden."

206 Vgl. Crispien, Tagebuch, 21.8.1914: ,Die erste Sitzung der Vertrauensmänner der Partei (Stuttgart) seit dem Kriege. Verhältnismäßig gut besucht, etwa 100 Personen. Viel Erbitterung über Bewilligung der Kriegskredite durch Sozialdemokraten."

zor Vgl. Tagebücher Otto Brauns, 24.8.1914: , Zur P[artei-]V[orstands-]S[itzung] waren Antrick aus Braunschweig und Bader aus Magdeburg mit Beschwerden über ihre Zeitungszensur".

$208 \mathrm{Vgl}$. Wohlgemuth, Die Entstehung, S. 46f.

209 David, KTB, 7.-8.8.1914, S. 14.

210 Bericht des Polizeipräsidenten von Berlin an das Oberkommando in den Marken, 10.9.1914, abgedruckt in Kuczynski, Der Ausbruch des Ersten Weltkrieges, S. 112. 
kommt, wird sich das Blatt allmählich wenden."211 Über Arbeitslosigkeit bzw. sonstige kriegsbedingte Verdienstausfälle wurde in der Tat bald zunehmend geklagt - , gerade in dieser Hinsicht"', berichtete die Polizei Ende August über den Berliner Norden, ,,ist die Stimmung unter den breiteren Volksschichten sehr gedrückt."212 Gleichzeitig begannen die Berliner Radikalen systematischer zu agitieren. ${ }^{213}$ Mitte September wurde in Berlin laut David angenommen, daß die ,L-L-L”, d.h. Liebknecht-LuxemburgLedebour, ,, bereits die Mehrheit der Berliner Vertrauensleute hinter sich haben."214 Anfang Oktober gab Wolfgang Heine seiner Sorge Ausdruck, , daß in Berlin der terroristische Radikalismus die Oberhand behalten [. . . ] könnte".

Unter der Hand [. . . ] entfalten Haase, Ledebour, die Rosa Luxemb[ur]g, Dr. Duncker, Mehring und ein Teil der Redactöre des Vorwärts und eine Anzahl ähnlicher Geister eine intensive Wühltätigkeit, um Stimmung zu machen gegen den Beschluß vom 4. August und gegen jede Änderung in der Haltung der Partei. Wie man hört, haben sie dieselben großen Erfolge in den engeren Konventikeln, in denen sie auftreten.

211 Rosa Luxemburg an Kostja Zetkin, [2.8.1914,] S. 8.

212 Bericht des 3. Kommissariats, 26.8.1914, abgedruckt in Kuczynski, Der Ausbruch des Ersten Weltkrieges, S. 110.

213 Vgl. W. Pieck, ,,Der Kampf der Linken gegen die Burgfriedenspolitik. Erinnerungen. 1920", in: Ders., Gesammelte Reden und Schriften, 2 Bde, Berlin 1959, Bd 1, S. 330f.: ,Wir benutzten alle Zusammenkünfte der Genossen - so die Zahlabende, die Frauenleseabende, Jugendsektionsversammlungen - , um scharf Stellung zu nehmen gegen die Verwirrung, die durch die Haltung der Parteileitungen in die Organisationen hineingetragen worden war." So hörte David von seiner früheren Frau, ,,daß in Steglitz eine Versammlung der Funktionäre stattgefunden hat, wo Mehring und Duncker die Fraktion scharf angegriffen haben". David, KTB, 1.9.1914, S. 30. Vgl. ferner die im Berliner Lokalteil des Vorwärts unter dem Titel „,Parteiveranstaltungen” enthaltenen Hinweise für August-September 1914: in Nr 225 (19.8.) ist für den gleichen Tag ein Vortrag Dunckers vor der Neuköllner Jugendsektion angekündigt; in Nr 236 (30.8.) für den folgenden Tag ein Vortrag Dunckers über ,,Ferdinand Lassalle” in TempelhofMariendorf; in Nr 239 (2.9.) für den gleichen Tag, , der erste von den fünf Vorträgen des Genossen Dr. Duncker über ,Das Wesen des Kapitalismus"' vor der Neuköllner Jugendsektion; in $\mathrm{Nr} 252$ (15.9.) für den gleichen Tag ein Vortrag Ledebours ,,Wie ist der Mieternot abzuhelfen" in einer öffentlichen Versammlung seines VI. Berliner Wahlkreises; in Nr 254 (17.9.) für den gleichen Tag ein Vortrag Dunckers vor den 18-21jährigen Mitgliedern des IV. Wahlkreises; in Nr 256 (19.9.) für den 23. September Vorträge der ,Genossen E. Neumann, W. Pätzel, Frau Käte Duncker und W. Pieck" zum Thema „Proletarische Pflichten in schwerer Zeit" vor den Jugendabteilungen des VI. Wahlkreises; in Nr 263 (26.9.) für den 30. September ein Vortrag von Julian Borchardt vor der Jugendabteilung in Britz-Buckow; in Nr 264 (27.9.) für den 29. September ein Vortrag von Duncker ,,Zum fünfzigsten Geburtstag der Internationale" vor der Jugendsektion Tempelhof-Mariendorf; ferner ein Vortrag von Käte Duncker über ,,Patriotische Aufgaten in schwerer Zeit" im Lichterfelder Frauen-Leseabend am 28. September.

214 David, KTB, 25.9.1914, S. 43. 
Es ist sehr schwer, hiergegen anzukämpfen, weil die wenigen vernünftigen Leute unmöglich in den tausenden von Zahlabenden, die monatlich stattfinden, überall anwesend sein können. ${ }^{215}$

Allerdings konnte Ende August von ,,großen Sympathien" für die Bewilligungsgegner in der Fraktion schon deshalb nicht die Rede sein, weil es damals ja noch kaum bekannt war, daß es diese Gegner gab. Als die Bremer Bürger-Zeitung das Schreiben Liebknechts vom 3. September nicht brachte, ergriff Rosa Luxemburg daher die erste sich bietende Gelegenheit für einen Versuch, durch eine öffentliche Kundgebung das hemmende Tabu über den parteiinternen Gegensätzen zu durchbrechen: den Protest des Parteivorstands gegen das französisch-belgische Manifest vom August, der am 10. September in der Parteipresse erschien. ${ }^{216}$ Nachdem sie auch noch den betreffenden Artikel im Hamburger Echo zu Gesicht bekommen hatte, schrieb sie am 13. September an Mehring:

Sie haben wohl den ,Protest" des Parteivorstandes gegen die Internationale und das ,Hamburger Echo" gelesen. Ich glaube, da ist unmöglich, zu schweigen. Wir wollen (Klara [Zetkin] und ich) in der ausländischen Parteipresse (Schweiz, Italien, Holland, Schweden) einige Zeilen veröffentlichen, worin wir nur feststellen, daß wir wie viele andere Genossen nicht die Möglichkeit haben, jetzt unsere abweichende Auffassung zum Ausdruck zu bringen, und daß wir die ausländischen Genossen bitten, dies in Betracht zu ziehen. Wollen Sie uns ermächtigen, Ihre Unterschrift mit darunter zu setzen? Sie sind im Auslande so bekannt, daß dies von großer moralischer Wirkung wäre und eine verdiente Ohrfeige für den infamen ,,Protest” des Parteivorstandes. Nächstens kommt Karl L[iebknecht] her, und ich hoffe, er wird mitzeichnen. Bitte, antworten Sie telegraphisch gleich nach dem Empfang dieser Zeilen.

[. . .] Ich schreibe heute übrigens für unsere ,,[Sozialdemokratische]

215 Heine an von Vollmar, 8.10.1914, Nachlaß von Vollmar, Nr 873, IISG. Aufschlußreich Heines Schilderung seiner eigenen Erfahrung anläßlich seines öffentlichen Vortrags über ,,Kultur und Nation” am 5. Oktober im Verein für Frauen und Mädchen der Arbeiterklasse, in dem ,,im allgemeinen die vernünftigeren Leute" seien: ,Ich habe [ . . ] ausdrücklich gemeint, man möge bei diesem vaterländischen Empfinden, das ja doch in den weitesten Kreisen der Arbeiter eine Tatsache sei, ein gutes Gewissen haben. Ich habe auch bei vielen Besuchern [ . . ] Anklang gefunden [ . . ]. Ich habe aber wohl gemerkt, wie unendlich schwer es den Leuten fällt, sich in diese neue Stimmung und diese neuen Gedanken hineinzugewöhnen. Ich habe wirklich nur das Harmloseste gesagt, und doch betonten mehrere Besucher mir persönlich gegenüber lobend den großen Mut, den ich dabei gezeigt hätte, nicht ohne einen leichten Unterklang von Angst vor dem terroristischen Geschrei, das darauf folgen könnte. Unter den Besuchern der Versammlung aber hat sich viel Widerspruch, wenn auch leiser, geltend gemacht, Walther, der weiter hinten sa $\mathrm{B}$, hat einiges davon zu hören bekommen. Auch ich hörte beim Weggehen, wie ein erregter junger Mann von ,Skandal' und ,nationalliberal' redete."

216 Vgl. Anm. 152. 
Korrespondenz" eine leise Polemik gegen das ,,[Hamburger] Echo”. Ob man's bringt, wer weiß. ${ }^{217}$

Während sich die Erklärung ursprünglich gegen den ,,infamen ,Protest' des Parteivorstandes" richten sollte, was ihre spätere Datierung auf den 10. September erklärt ${ }^{218}$ nahm sie - im Gegensatz zu Rosa Luxemburgs , ,leiser Polemik gegen das ,[Hamburger] Echo""219 - in der Form, die sie sodann erhielt, auf jenen nicht mehr explizit bezug; statt dessen richtete sie sich gegen den Artikel Südekums im Social-Demokraten, ${ }^{220}$ einen von Richard Fischer damals im Züricher Volksrecht publizierten Artikel, ${ }^{221}$ neue, im Avanti! referierte Äußerungen Südekums in Italien. ${ }^{222}$ Anscheinend entstand nunmehr zunächst die undatierte Fassung, von der ein Exemplar, auf dem von Clara Zetkins Hand unter den maschinenschriftlichen Text die Namen der vier Unterzeichner - ,,Karl Liebknecht, Dr. Franz Mehring, Dr. Rosa Luxemburg, Clara Zetkin" - gesetzt sind, im Institut für Marxismus-Leninismus beim ZK der KPdSU in Moskau überliefert ist.

\section{Erklärung.}

Die Genossen Dr. Südekum und Richard Fischer haben in der Parteipresse des Auslands (in Schweden, Italien und in der Schweiz) den Versuch unter-

217 Rosa Luxemburg an Mehring, 13.9.1914, a.a.O., S. 10. Mehring telegraphierte am 17.9.1914 an Clara Zetkin: ,,Sehr einverstanden herzlichen Gruß." Zitiert nach Wohlgemuth, Burgkrieg, a.a.O., S. 68.

$218 \mathrm{Vgl}$. unten.

${ }^{219} \mathrm{Vgl}$. [Luxemburg,] „,Gegen den Franktireurkrieg”, S. 6: ,Das ,Hamburger Echo’ bringt - allerdings ermuntert durch den Protest des Parteivorstandes gegen ein Manifest der französischen und belgischen Genossen - einen langen pathetischen Artikel [. . . ]." $220 \mathrm{Vgl}$. Anm. 84.

221 Richard Fischer hatte während eines Aufenthalts in der Schweiz die Kritik zurückgewiesen, die das Volksrecht an dem deutschen Vorgehen in Belgien und der Haltung der ,führenden Genossen im Reiche” geübt hatte. Vgl. „,Der europäische Krieg. Vandalen”, in: Volksrecht, 1914, Nr 202 (1.9.); Richard Fischer, ,,,Vandalen'”, ebd., Nr 206 (5.9.). Kritisch hierzu ,Der Krieg und die deutsche Sozialdemokratie”, in: Berner Tagwacht, 1914, Nr 208 (7.9.). Zu der Reise Otto Brauns und Richard Fischers in die Schweiz vgl. Tagebücher Otto Brauns, 31.8. bis 6.9.1914; H. Schulze, Otto Braun oder Preußens demokratische Sendung. Eine Biographie, [Frankfurt, Berlin, Wien 1977] S. $179 f$.

222 Südekum hatte, vom Parteivorstand Ende August nach Italien entsandt, um die Haltung der deutschen Partei zu erklären, dies zunächst in einem von Angelica Balabanoff redigierten Interview getan: , La guerra europea e i socialisti tedeschi”, in: Avanti!, 1914, Nr 238 (29.8.). Ferner hatte der Avanti! ein kurzes Protokoll des Gesprächs veröffentlicht, in dem Südekum am 1. September in Rom der PSI-Führung den Standpunkt der deutschen Partei erläutert hatte: ,Il convegno di Roma fra la Direzione del Partito e un rappresentante dei socialisti tedeschi", ebd., Nr 242 (2.9.). Zu Südekums Reise nach Italien vgl. die Eintragungen vom 28.8. bis 4.9.1914 in seinen Tagebüchern, Nachlaß Südekum, Nr 106, Bundesarchiv; Balabanoff, Erinnerungen und Erlebnisse, a.a.O., S. $71 \mathrm{ff}$. 
nommen, die Haltung der deutschen Sozialdemokratie im gegenwärtigen Kriege im Lichte ihrer Auffassung darzustellen. Wir sehen uns deshalb gezwungen, den ausländischen Genossen zu versichern, daß wir und sicherlich viele andere deutsche Sozialdemokraten den Krieg, seine Ursachen, seinen Charakter sowie die Rolle der Sozialdemokratie in der gegenwärtigen Lage von einem Standpunkt betrachten, der demjenigen der Genossen Südekum und Fischers nicht entspricht. Der Belagerungszustand macht es uns vorläufig unmöglich, unsere Auffassung öffentlich zu vertreten. ${ }^{223}$

Da die Artikel Südekums und Fischers im Social-Demokraten bzw. im Volksrecht, obwohl Rosa Luxemburg bereits bekannt, ${ }^{224}$ in ihrem Brief an Mehring vom 13. September nicht erwähnt sind, die Äußerungen Südekums in Italien dagegen in Stuttgart erst am 13. September - nach dem Vorwärts vom Tag vorher - bekannt wurden, ${ }^{225}$ ist anzunehmen, daß diese Fassung erst danach entstand. Es ist ferner anzunehmen, daß die Änderung auf Liebknecht zurückging, der bereits in Belgien die Artikel Südekums und Fischers heftig kritisiert hatte. ${ }^{226}$ Ebenso wurde wohl erst, nachdem Liebknecht - spätestens am 17. September - in Stuttgart eingetroffen war, ${ }^{227}$ beschlossen, zu versuchen, weitere Unterzeichner zu gewinnen,

223 Vgl. Dokumente und Materialien zur Geschichte der deutschen Arbeiterbewegung, hrsg. vom Institut für Marxismus-Leninismus beim ZK der SED, Reihe II, Bd 1: Juli 1914 - Oktober 1917, Berlin 1958, Nr 15, S. 31. Die obige Wiedergabe erfolgt nach dem Faksimile in Clara Zetkin, Ausgewählte Reden und Schriften, 2 Bde, Berlin 1957-60, Bd 1, bei S. 656. Unzutreffend die Feststellung von Wohlgemuth, Burgkrieg, S. 67: ,Dieser öffentlichen Kundgebung gegen die Kriegspolitik einiger Opportunisten folgte bald eine zweite, die sich gegen die Unterstützung des Krieges durch den sozjaldemokratischen Parteivorstand richtete. Über ihre Entstehung gibt ein Brief Rosa Luxemburgs an Franz Mehring vom 13. September 1914 wertvolle Hinweise." Der Hinweis, daß diese ,zweite" Erklärung ,, am 31. Oktober 1914 in der ,Berner Tagwacht”" erschienen sei (ebd., S. 68), ist aus der Luft gegriffen. Der Wahrheit näher kommt ders., Die Entstehung, S. 52, 321.

${ }_{24}^{24} \mathrm{Zu}$ dem Artikel Südekums vgl. Anm. 84; zu dem Artikel Fischers vgl. Crispien, Tagebuch, 8.9.1914.

225 Vgl. ,Die Auffassung der italienischen Sozialisten”, in: Vorwärts, 1914, Nr 249 (12.9.), Beilage; Crispien, Tagebuch, 13.9.1914: „,Der deutsche Parteivorstand schickt Genossen ins neutrale Ausland (Vorwärts vom 12. Sept[ember 19]14. Nr 249: Die Auffassung der italienischen Sozialisten), um die Sozialdemokratie dieser Staaten ,über die Haltung der deutschen Partei zu informieren'. - Wie kommt man dazu? Die deutsche Partei hat noch gar nicht Stellung nehmen können. Es gibt auch in Deutschland Sozialdemokraten, die die Haltung der deutschen Fraktion für schmachvoll halten."

$226 \mathrm{Vgl}$. Bertrand, Souvenirs, Bd 2, S. 247.

${ }^{27}$ Laut dem Brief von Sophie Liebknecht an Wibaut vom 18.9.1914, a.a.O., hatten die Telegramme vom 13. und 14.9., a.a.O., die die Aufforderung enthielten, gleich nach Munsterlager zu fahren, Liebknecht ,, noch zeitig unterwegs erreicht. Er war in Munsterlager". Vgl. auch Anhang, Nr 2. Erst von Munsterlager fuhr er dann nach Stuttgart, wo er spätestens am 17. September eintraf. Vgl. Crispien, Tagebuch, 17.9.1914: „,Besprechung zwischen Luxemburg, Liebknecht (Karl), Westmeyer und mir. Beschluß: In 
wobei sich ein frontaler Angriff auf den Parteivorstand, der nicht nur Haase abgehalten hätte, nicht empfahl. Allerdings blieb den betreffenden Versuchen dennoch der Erfolg versagt. ${ }^{228}$ Liebknecht selbst erinnerte sich 1916:

Auf Ansto $B$ von dritter Seite suchte ich noch Ledebour in einer langen Unterredung in seiner Wohnung zur Unterschrift zu bewegen. Ohne Erfolg. Er erhob tausend Einwendungen - wollte erst versuchen, mindestens die 14 Männer [d.h. die Gegner der Kreditbewilligung in der Fraktion] zur Teilnahme zu bestimmen etc. ${ }^{229}$

Bei der rigiden Haltung der Parteiinstanzen, die, was die ,Politik des 4. August" betraf, keinerlei Kritik, ja selbst keinen Hinweis darauf, daß es Kritik gab, zu tolerieren bereit waren, wurde die Opposition gegen jene Politik zwangsläufig zum kompromißlosen Kampf gegen sie selbst, so daß es - parallel zu den Bemühungen um die Erklärung - zu Versuchen einer Sammlung der verstreuten oppositionellen Kräfte kam. Eine Besprechung bei Clara Zetkin am 11. September, an der außer dieser und ihrem Sohn Kostja noch Rosa Luxemburg, die über die Vorgänge in der Fraktion berichtete, Paul Levi, Edwin Hoernle, Fritz Westmeyer und Artur Crispien teilnahmen, kam zu dem Ergebnis: ,Fühlung nehmen und Verbindungen anknüpfen." ${ }^{230}$ Eine Besprechung in Frankfurt am 18. September,,Teilnehmer: Rosa Luxemburg, Karl Liebknecht (Berlin), Dr. Paul Levi, Dißmann (Frankfurt a.M.), Schnellbacher, Dr. Wagner (Hanau), Peter

Stuttgart eine Parteiversammlung mit dem Thema: Gegen die Annektionshetze zu veranstalten. Referent Liebknecht."

228 Vgl. hierzu Clara Zetkin, ,,Der zweiten Auflage zum Geleit”, in: Rosa Luxemburg, Die Krise der Sozialdemokratie (Juniusbroschüre), [2. Aufl.] Berlin 1919, S. v: ,,Kaum war die Bewilligung der Kriegskredite durch die sozialdemokratische Reichstagsfraktion bekannt geworden, so erhob Rosa mit einigen wenigen Freunden das Banner der Rebellion gegen den Verrat an der Internationale, am Sozialismus. Zwei Umstände bewirkten, daß diese Rebellion nicht sofort vor der breitesten Öffentlichkeit erschien. Der Kampf sollte mit einem Protest gegen die sozialdemokratische Kreditbewilligung einsetzen, der so gehalten sein mußte, daß er nicht von den Nücken und Tücken des Belagerungszustandes und der Zensur abgewürgt wurde. Außerdem und vor allem hätte es unzweifelhaft seine Bedeutung gehabt, wäre der Protest von vornherein von einer stattlichen Zahl bekannter sozialdemokratischer Kämpfer getragen worden. Wir waren deshalb bestrebt, ihn so zu fassen, daß sich mit ihm möglichst viele der führenden Genossen solidarisierten, die in der Reichstagsfraktion und im kleinen Kreise scharfe, ja vernichtende Kritik an der Politik des 4. August übten. Eine Rücksichtnahme, die viel Kopfzerbrechen, Papier, Briefe, Telegramme und kostbare Zeit kostete, und deren Ergebnis doch gleich Null war."

229 Liebknecht, Betrachtungen und Erinnerungen, S. 278.

230 Crispien, Tagebuch, 11.9.1914. 
Berten (Düsseldorf), C[arl] Minster (Duisburg), Crispien (Stuttgart)" führte zu dem gleichen Resultat: ,,Verbindungen anknüpfen”; aber in dieser Besprechung, an der Liebknecht teilnahm, wurde eine weitere Losung ausgegeben: ,die Rettung der Internationale vorzubereiten, die Schmach von der zertrümmerten Internationale zu tilgen". ${ }^{231}$ Das letztere Thema behandelte Liebknecht, der - im Gegensatz zu Rosa Luxemburg, die von Frankfurt direkt nach Berlin zurückkehrte - über Gotha und Nürnberg noch einmal nach Stuttgart fuhr, ${ }^{232}$ dort am 21. September in einer Vertrauensmännerversammlung, in der er laut eigener Darstellung vom 2. Oktober erklärte,

daß ein Wiederaufbau der Internationale [ . . . ] nur vom Boden einer Auffassung aus möglich ist, die den Standpunkt der Fraktionsmehrheit verwirft; [. . . ] daß die deutsche Partei [. . .] von der Haut bis zum Mark regeneriert werden muß, wenn sie das Recht nicht verwirken will, sich sozialdemokratisch zu nennen, wenn sie sich die jetzt gründlich verscherzte Achtung der Welt wieder erwerben will [ . . ], daß der Kampf, der dazu erforderlich ist, doppelt schwer sein wird, weil er [. . . ] auch gegen gewisse offizielle Parteiinstanzen [ . . .] zu führen ist - gegen Strömungen, die die Partei heute in gewissem Umfang zu einem offiziösen Regierungsinstrument haben werden lassen $[\ldots . .]^{233}$

Eine neue Gelegenheit, Kontakte anzuknüpfen, bot sich Ende des Monats in Berlin, wo am 27. September, einem Sonntag, eine Sitzung des Parteiausschusses und am 28. September eine Konferenz von Parteiredakteuren stattfand. Wilhelm Pieck erinnerte sich 1920:

Wir hatten die Genossen, von denen wir annahmen, daß sie in Opposition standen, zum Sonnabend- und Sonntagabend zu einer Besprechung in das Restaurant Patzenhofer an der Potsdamer Brücke (in Berlin) eingeladen. Am Sonnabendabend berichteten uns die Genossen über die Vorgänge in der entscheidenden Fraktionssitzung bei Ausbruch des Krieges, über die bisher strengstes Geheimnis bewahrt worden war, und am Sonntagabend wurde uns über den Verlauf der Parteiausschußsitzung berichtet. ${ }^{234}$

231 Ebd., 18.9.1914.

232 Vgl. Rosa Luxemburg an Levi, [zwischen 19. und 22.9.1914,] RLGB, Bd 5, S. 454; Liebknecht, Betrachtungen und Erinnerungen, S. 269, 277.

${ }^{233}$ Liebknecht, Klassenkampf, S. 34 (Brief an den Parteivorstand, 2.10.1914). Laut einem späteren Bericht Jacob Walchers übte Liebknecht in seinem Schlußwort Selbstkritik, was seine - in der Versammlung scharf kritisierte - Abstimmung am 4. August betraf: ,Ich habe mich eines schweren Fehlers schuldig gemacht”. Dokumente und Materialien zur Geschichte der deutschen Arbeiterbewegung, Reihe II, Bd 1, a.a.O., Nr 17, S. 35. Allerdings nahm Liebknecht zugleich die Fraktionsmehrheit, gegen gewisse schwere Vorwürfe" in Schutz. Liebknecht, Klassenkampf, S. 33 (Brief an den Parteivorstand, 2.10.1914).

234 Pieck, ,,Der Kampf der Linken”, a.a.O., S. 329. 
Das Datum seines - gleich anderen Schreiben Liebknechts aus jener Zeit in einer Mehrzahl maschinenschriftlicher Kopien überlieferten - Schreibens vom 26. September 1914 läßt vermuten, daß es ursprünglich an die Teilnehmer dieser Besprechung gerichtet war. ${ }^{235}$ Zunächst ausdrücklich konstatierend, daß er ,,das Recht und die Pflicht zur nationalen Selbstverteidigung und Selbstbehauptung" nie im geringsten angezweifelt habe, betonte Liebknecht darin nochmals, , daß es [. . .] die Pflicht der deutschen Reichstagsfraktion gewesen wäre, in der schärfsten Form jede Verantwortung für diesen Krieg abzulehnen", wobei er in seiner Begründung unverkennbar einiges von dem verarbeitete, was er in Belgien kurz zuvor erfahren hatte. Er schloß:

Meine Hoffnung ist die, daß es noch jetzt, während des Krieges, gelingen möge, die dem Krieg entgegenwirkenden und ihn abschwächenden Kräfte zum Heile der gesamten Menschheit und jedes einzelnen Volkes zu entfalten. ${ }^{236}$

Allerdings fand selbst in diesem Kreis der - jetzt von Liebknecht unterstützte - Standpunkt Rosa Luxemburgs, daß am 4. August nicht nur die Mehrheit der Fraktion versagt habe, sondern ebenso die Minderheit, weil sie nicht öffentlich opponiert habe, nicht allgemeine Zustimmung; besonders Lebebour wies das zurück: „,Die Stellung zur Politik des 4. August dürfe nicht in den Vordergrund gerückt werden; das ergebe eine falsche Bruchlinie usw." 237 In der Parteiausschußsitzung und in der Redakteurkonferenz, wo die Opposition nur schwach - durch Dißmann bzw. Crispien vertreten war, fand die Kritik der ,,Politik des 4. August" kaum Resonanz; im Gegenteil: in beiden Gremien wurde vielmehr das Verhalten Liebknechts kritisiert. ${ }^{238}$

Nicht nur wegen seiner Rede in der Stuttgarter Versammlung, über die Wilhelm Keil sogleich Scheidemann informiert hatte, ${ }^{239}$ sondern ebenso wegen seines Auftretens in Belgien und Holland wurde Liebknecht danach vom Parteivorstand, dem dazu - außer dem erwähnten Brief von Troelstra - eine Reihe von entstellenden Notizen in der Presse vorlag, scharf gerügt.

${ }^{235}$ Vgl. Liebknecht, Klassenkampf, S. 26-28. Nur wenig spricht für die Annahme von Wohlgemuth, Burgkrieg, S. 210, daß das Schreiben , an einen ausländischen Genossen" gerichtet gewesen sei; allerdings wurden auch von diesem Schreiben später maschinenschriftliche Abschriften im Ausland verbreitet. Vgl. unten.

236 Liebknecht, Klassenkampf, S. 26ff.

237 Ders., Betrachtungen und Erinnerungen, S. 278.

238 Vgl. Prot. PA SPD, Bd 1, 27.9.1914, S. [91]ff., bes. S. [97]f., [103]; Liebknecht, Klassenkampf, S. 34 (Brief an den Parteivorstand, 2.10.1914), 43f. (Scheidemann an Liebknecht, 17.10.1914).

239 Vgl. Tagebücher Otto Brauns, 22.9.1914. 
Die Vorwürfe, die der Parteivorstand ihm in der Sitzung am 2. Oktober machte, waren der Ausgangspunkt zu dem von Henriette Roland Holst erwähnten Briefwechsel, in dem er sein Verhalten nochmals rechtfertigte. ${ }^{240}$ Anscheinend war - sei es, daß Troelstra sich mißverständlich ausgedrückt, sei es, daß der Parteivorstand ihn mißverstanden hatte - der Eindruck entstanden, daß Liebknecht auf seiner Reise quasi , im Auftrag des P[artei-]V[orstandes]" aufgetreten wäre. ${ }^{241}$

Die Erbitterung der Radikalen wurde ferner noch verstärkt durch Vorgänge in der Berliner Organisation. In einer von der Groß-Berliner Parteileitung zum 25. September einberufenen Referentenversammlung entlud sich die zunehmende Spannung in Zusammenstößen von bis dahin ungekannter Vehemenz. Eine Vorstellung von der erregten Atmosphäre, die in der Versammlung herrschte, vermitteln - sei es nicht aus radikaler Sicht die Tagebuchnotizen Otto Brauns.

Von der Gr[oß-]Berliner Parteileitung sind für Anfang Oktober Mitgliederversammlungen geplant [. . . ]. Damit strittige Fragen über den Krieg in den Versammlungen nicht erörtert werden, waren [ . . . ] die Referenten zusammenberufen, denen [Eugen] Ernst darlegte, daß sie ihre Referate so einrichten sollten, daß Diskussionen nicht provoziert würden. Da kam er bei Liebknecht und Rosa [Luxemburg] schön an. L[iebknecht] hielt eine $3 / 4^{-}$ stündige Rede, in der er uns Schafsköpfe eingehend belehrte, was wir reden müßten und wie wir es reden müßten. Sein weibl[iches] Pendant aus Russisch-Polen ergänzte ihn noch in ihrer geradezu unausstehlichen schulmeisterlichen Manier. Sie belehrte uns, daß die Klassengegensätze nach dem Kriege nicht beseitigt sein würden und auch der Klassenkampf seinen Fortgang nehmen müsse. Auch über den Imperialismus als Ursache der Kriege müsse man reden, und was dergleichen Plattheiten mehr sind. Um das zu hören, mußte man sich den Nachmittag um die Ohren schlagen. David charakterisierte ganz zutreffend diese schematische Denkweise, nach der jede Erscheinung im politischen Leben in die Schablone des Imperialismus gezwängt wird [. . . ]. Nachdem noch Ledebour mit Rich[ard] Fischer einige Liebenswürdigkeiten gewechselt hatte, von deren Charakter sich Jeder ein Bild machen kann, der die Kampfhahnnatur Ledebours kennt [ . . ], da kam dem großen Kind Ede Bernstein offenbar eine Eingebung. Er jammerte, $\mathrm{da} \beta$ man in den Versammlungen nicht über alle Vorgänge offen sprechen könne, daß man nicht sprechen könne von den Greueln in Ostpreußen, wo [von Hindenburgs Truppen] 150000 Russen [in den Masurischen Seen] versäuft sein sollen. Wie ein engl[ischer] Baptistenprediger rief er aus: ,Hätte ich das gewußt, als ich für die Kriegskredite stimmte, dazu habe ich meine Hand geboten!" Darob bei dem Trio Rosa [Luxemburg], Liebknecht, Ströbel [. . . ] großes Entzücken und Händeklatschen, und als dann 
einige Genossen Ede durch Zuruf fragten, ob denn die deutschen Soldaten sich vernichten lassen sollten [. . .], [Gustav] Bauer ihm gar den Rat gab, diese Predigt doch vor alten Weibern zu halten, da gab es bei den 3 sensiblen Seelen, die kein Wort der Entrüstung über die wochenlangen Mordbrennereien der Russen in Ostpreußen hatten, einen hysterischen Tobsuchtsausbruch, der die getretene Menschlichkeit zur Geltung bringen sollte. Wie von der Tarantel gestochen sprangen sie auf, bearbeiteten mit ihren Fäusten die Tische und gebärdeten sich wie toll [. . .]. Mitten im höchsten Stadium des Ausbruchs politischer Hysterie nahm ich schleunigst meinen Hut und verließ das Lokal [ . . ]. ${ }^{242}$

Gleichzeitig spitzten sich die Auseinandersetzungen über die Haltung des Vorwärts zu, die Rosa Luxemburg, die der Preßkommission desselben angehörte, zur Rückkehr nach Berlin genötigt hatten. Die Redaktion des Vorwärts, deren Mehrheit bereits am 4. August in einer nicht publizierten Erklärung gegen die Bewilligung der Kriegskredite protestiert hatte ${ }^{243}$ war bemüht, das Blatt auf seinem herkömmlichen Kurs zu halten, was indessen binnen kurzem die Zensurbehörden auf den Plan rief. So mußte Stadthagen am 2. September schriftlich erklären, daß er ,,dem Wunsch des Oberkommandierenden [in den Marken], daß die Einheitlichkeit der patriotischen Begeisterung nicht gestört werde, nachkommen werde". 244 Die ,,unpatriotische" Berichterstattung des Vorwärts stieß selbst innerhalb der Partei zunehmend auf Kritik; vor allem die Generalkommission der Gewerkschaften beschwerte sich darüber. Am 11. September kam es darüber - laut Otto Braun - in der Sitzung des Parteivorstands ,,zu einer gründlichen Auseinandersetzung z.T. recht persönlicher Natur", da Haase, der im Vorstand für den Vorwärts verantwortlich war, die Vorwürfe gegen das Blatt, das - so Scheidemann - , jetzt geradezu skandalös redigiert werde", auf sich bezog. ${ }^{245}$ Nachdem der Vorwärts am 21. September auf drei Tage verboten worden war, fand am 23. September eine Sitzung von Parteivorstand, Generalkommission, Groß-Berliner Aktionsausschuß, Preßkommission und Redaktion statt, auf die am 24. September eine neue Sitzung von Parteivorstand, PreBkommission und Redaktion folgte, in der - so Otto Braun - der erstgenannte schriftlich formulierte Richtlinien vorlegte, an die die Redaktion sich halten sollte.

Obwohl die Redaktion erklärte, nach diesen Richtlinien bisher bereits sich gerichtet zu haben, trat die Preßkommission ihnen nicht bei, sondern be-

${ }^{242}$ Tagebücher Otto Brauns, 4.10.1914. Vgl. auch David, KTB, 25.9.1914, S. 42f.; Liebknecht, Betrachtungen und Erinnerungen, S. 277f.

243 Vgl. Kuczynski, Der Ausbruch des Ersten Weltkrieges, S. 105ff.

244 Anlage zum Zirkular des Parteivorstands vom 11.7.1916, Nachlaß Kautsky, H 8.

$245 \mathrm{Vgl}$. Tagebücher Otto Brauns, 11.9.1914. 
schloß in gesonderter Sitzung eine offenbar von der Rosa im Einverständnis mit der Redaktion verfaßte Resolution, die die wesentlichsten Beschwerdepunkte gar nicht erwähnt, dahingegen der Redaktion uneingeschränkte Billigung ausspricht und den Beschwerdeführern unterstellt, sie hätten vom „,Vorwärts" ein Abweichen von dem sozialistischen Klassenkampfstandpunkt und eine Förderung der chauvinistischen Hetze verlangt. Das schönste war, daß man uns noch zumutete, dieser Resolution beizutreten. ${ }^{246}$

Als der Vorwärts bereits am 27. September erneut - diesmal auf unbestimmte Zeit - verboten wurde, lehnte es der Parteivorstand zunächst ab, sich nochmals für ein Blatt einzusetzen, auf das er keinen Einfluß habe; nur Haase wollte abermals vermitteln. Als der Oberkommandierende in den Marken nunmehr die Bedingung stellte, der Vorwärts müsse sich verpflichten, daß er im Krieg das Thema ,Klassenhaß und Klassenkampf' nicht mehr berühren würde, überließ der Parteivorstand die Entscheidung der Redaktion. Es fand - am Nachmittag des 29. September - eine neue Sitzung von Parteivorstand, Groß-Berliner Zentralvorstand, Preßkommission und Redaktion statt, in der sich letztere - gegen den erbitterten Widerstand Rosa Luxemburgs, die , lieber auf den V[orwärts] als auf den Klassenkampf verzichten wollte" - dem Druck der Berliner fügen mußte, die ,unter allen Umständen ihr Blatt wieder haben [wollten]". Als die Erklärung Eberts, daß sich einer der Redakteure ja vorher schon zu weitaus mehr verpflichtet habe, von Stadthagen bestritten wurde, konnte Ebert aus dessen eigenem Protokoll vom 2. September vorlesen. „Das schlug ein wie eine Bombe. Rosa schnappte nach Luft wie ein Karpfen in der Julisonne. "247 Am 1. Oktober konnte der Vorwärts wieder erscheinen, mußte aber auf der ersten Seite oben ein Schreiben des Generaloberst von Kessel abdrucken, in dem ausdrücklich festgestellt wurde, daß die Redaktion die erwähnte Bedingung akzeptiert habe. ${ }^{248}$

,Ich war", schrieb Rosa Luxemburg am 6. Oktober an Levi, , durch den Ausgang der ,großen Schlachten' hier so deprimiert, daß es mir bis jetzt nicht möglich war, zu schreiben." ${ }^{249}$ War ihr schon vorher , die Unhaltbarkeit des Ganzen" immer schärfer zu Bewußtsein gekommen, so daß sie sich gefragt hatte, ,,wie die Partei das überstehen soll”, ${ }^{250}$ so schrieb sie am 12. Oktober an Carl Moor, daß kaum noch jemand hoffe, nach dem Krieg ,,die altgepriesene Einigkeit der Partei bei so tiefgehendem inneren Zwiespalt aufrechterhalten zu können", denn:

246 Ebd., 4.10.1914.

247 Ebd.

248 Vgl. Vorwärts, 1914, Nr 268 (1.10.); Scheidemann, Memoiren, Bd 1, S. 268-71.

${ }^{249}$ Rosa Luxemburg an Levi, 6.10.1914, RLGB, Bd 5, S. 455.

250 An Levi, [zwischen 19. und 22.9.,] a.a.O., S. 455. 
Schon jetzt hat der stille innere Kampf begonnen, obwohl wir ihn wahrhaftig unter so ungünstigen Bedingungen nicht aufnehmen wollen. Das gegenseitige Mißtrauen und der gegenseitige $\mathrm{Ha} B$ lassen sich aber kaum verdecken und züngeln schon in ganz feinen Flämmchen an die Oberfläche. ${ }^{251}$

Rosa Luxemburg sah bereits damals eine Spaltung der Partei voraus, hegte aber, zumal nach den jüngsten Ereignissen, was die damalige Stärke der Opposition anging, keine Illusionen: einstweilen waren , alle Zentralinstitutionen der Partei [. . .] von opportunistischen Elementen beherrscht", während ,,gerade den Gegnern der parteioffiziellen Taktik das Maul verbunden" war; zugleich war ,,das politische Leben der Massen völlig erdrückt". ${ }^{252}$ Unter diesen Umständen mußte die radikale Linke in der Partei alles unterlassen, was der Rechten den gesuchten Vorwand zu ihrem Ausschluß böte. ${ }^{253}$ So vermied sie in Berlin selbst die Beteiligung an einem Zirkel Julian Borchardts, die - laut Pieck - für die Leitung der Berliner Partei ,,ein willkommenes Argument gewesen wäre, um bei den Arbeitern Stimmung gegen die Radikalen wegen Organisationszersplitterung zu machen".

Es kam uns nicht darauf an, einen geschlossenen Verein der Opposition zu schaffen, sondern vielmehr eine informatorische Verbindung zwischen der Opposition im ganzen Lande herbeizuführen, um durch diese Verbindung den Kampf gegen die Kriegspolitik der Partei zu organisieren. ${ }^{254}$

Hinsichtlich der Zukunft waren die Radikalen optimistisch. ,Wir hoffen”, schrieb Liebknecht am 23. September an Branting, ,,daß die Minorität zur Majorität wird." 255 Rosa Luxemburg erwartete die eigentliche Auseinandersetzung erst, wenn der Krieg vorbei, die Zensur aufgehoben, die eingezogenen Männer heimgekehrt sein würden, meinte aber bereits, ,,eine wachsende Erbitterung allenthalben" feststellen zu können, die sie zuversichtlich stimmte. ${ }^{256}$

Am 23. Oktober berichtete Karl Radek seinem Freunde Henke aus Berlin:

251 An Moor, 12.10.1914, S. 15.

252 Ebd., S. 14.

${ }^{253}$ Vgl. David, KTB, 6.10.1914, S. 47: ,Wels bei mir im Archiv. Meint, daB Liebknecht und Genossen ihrerseits die Spaltung der Partei betreiben. - Das wäre das beste, was sie tun könnten.” Ebd. 29.10.1914, S. 57: ,Gespräch mit Schöpflin, der mit Ebert zusammen war. Er berichtet, daß die Mehrheit des Vorstandes entschlossen ist, zu gegebener Zeit mit der radikalen Gruppe gründlich abzurechnen. Man müsse nur alles vermeiden, um durch zu weitgehende Aktionen von rechts die Situation zu erschweren. Die Liebknechtgruppe müsse möglichst reduziert werden."

254 Pieck, ,,Der Kampf der Linken”, S. 329.

$255 \mathrm{Vgl}$. Anhang, Nr 2.

256 Rosa Luxemburg an Moor, 12.10.1914, S. 14. 
Hier findet zweifelsohne eine Sammlung der radikalen Elemente [statt]. In den Zahlabenden wie sonst taucht allmählich eine größere Anzahl von Genossen [auf], die die Politik vom 4. August nicht mitmachen will. Teils wollte sie es von anfangs nicht, teils ernüchtert sie vom Rausche. Leider sammeln sie sich nicht zu einer Front, sondern zu besonderen Kliquen. Es gibt aber Elemente, die als Bindeglied zwischen den drei schon existierenden Gruppen vermitteln. Auch sind direkte Bemühungen im Gange, sie zum gemeinsamen Handeln zu bringen. Es kann sich einstweilen nur um eine propagandistische Tätigkeit handeln, wie nur ein Bremsen gegen den Marsch nach Rechts. Das erste wird durch Vorträge, das zweite durch Wirken in den Instanzen gemacht. [. . .] In den radikalen Kreisen rechnet man damit, da $\beta$ nach dem Kriege es zu einer Spaltung kommt. Die Mehrheit der Partei wird für eine Reformpolitik sein. Ja man ist teilweise der Meinung, da $\beta$ eine reine Scheidung vom Nutzen sein wird, angesichts der Resultate, zu denen die Entwicklung der Partei seit Mannheim geführt hat.

Meine Meinung ist: mit allen Kräften die Sammlung der radikalen [Elemente] fördern, wobei die Sammlung einstweilen mehr eine geistige als eine organisatorische sein muß. [. . .] Man muß mit der Prov[inz] Fühlung suchen. Propagandistische Zirkeln unserer Richtung müssen überall, wo wir nur einen Menschen haben, zur Klärung beitragen. [ . . . ] Auf eine Spaltung darf man nicht hinarbeiten, da wir nicht wissen, ob die weiteren Ereignisse die Mehrheit der organisierten Arbeiterschaft nicht in unsere Arme treiben. Sollte die Partei eine Reformpolitik treiben, dann ja: Schwert, nicht Friede, selbst wenn wir anfangs eine Minderheit sein sollten. ${ }^{257}$

Dabei erhielt für Rosa Luxemburg die Auseinandersetzung, die sich in der deutschen Partei anbahnte, einen neuen internationalen Sinn; denn daß sich alle anderen Parteien einwandfrei verhalten hätten, begann sie damals zu bezweifeln, wozu wohl - abgesehen davon, daß die Marne-Schlacht der akuten Bedrohung der französischen Republik ein Ende gemacht hatte u.a. die Berner Tagwacht beitrug, die sie laut dem Brief an Moor, ,nunmehr [. . .] ins Haus" bekam. ${ }^{258}$ Chefredakteur des Blatts war seit fünf Jahren Robert Grimm, der - obwohl erst 33 Jahre alt - nicht nur in der SPS, die er seit 1909 im Berner Stadtrat, seit 1910 im Großen Rat des Kantons, seit 1911 im Nationalrat vertrat, bereits eine führende Rolle spielte, sondern auch in der Internationale nicht mehr unbekannt war. ${ }^{259}$ Seit Mitte September behandelte Grimm, mit dem Lenin seine Kriegsthesen, Aksel'rod seine

\footnotetext{
257 R[adek] an Henke, 23.10.[1914], Nachlaß Henke, Nr 106, AsD.

${ }^{258}$ Rosa Luxemburg an Moor, 12.10.1914, S. 14.

${ }^{259} \mathrm{Zu}$ Grimm vgl. Ch. Voigt, Robert Grimm. Kämpfer, Arbeiterführer, Parlamentarier. Eine politische Biographie, [Bern 1980]. - Zur Politik der SPS vgl. Y. Collart, Le Parti Socialiste Suisse et l'Internationale 1914-1915. De l'Union nationale à Zimmerwald, Genf 1969.
} 
Ideen zur Erneuerung der Internationale erörtert hatte, ${ }^{260}$ letzteres Problem in mehreren Artikeln, wobei er sich von der Burgfriedenspolitik, die er zunächst selbst verfochten hatte, allmählich distanzierte.

Den imperialistischen Charakter des Kriegs betonend, ging Grimm davon aus, daß dieser die Entwicklung des kapitalistischen Systems gewaltig fördern werde.

Noch ist der Kapitalismus nicht auf seinem Höhepunkt angelangt. Es hieße die elementarsten Tatsachen übersehen, wollte man annehmen, daß dem Kriege bereits die soziale Revolution folgen würde, [ . . .] der Krieg wird vielleicht politische Umwälzungen hervorrufen, er wird vielleicht die Landkarte Europas ändern, aber seine ökonomische Wirkung wird nicht der Sturz des Kapitalismus sein, sondern eine gewaltige Förderung [ . . .] des Konzentrationsprozesses, der großkapitalistischen Herrschaft. [ . . .]

Ausbreitung der großkapitalistischen Herrschaft aber bedeutet vermehrte Ausbeutung, verschärften Druck, Zunahme des Massenelends auf der ganzen Linie.

Unter diesen Umständen könne von einer Zertrümmerung der Internationale keine Rede sein; im Gegenteil: es resultiere daraus die Notwendigkeit eines noch engeren internationalen Zusammenschlusses der Arbeiterklasse; wenngleich es noch zu früh sei, sich bereits den Kopf darüber zu zerbrechen, sei doch klar, daß das Programm der Internationale, zumal hinsichtlich ihrer ,,Thesen von der nationalen Selbständigkeit der Völker”, einer Revision bedürfe. ${ }^{261}$ Gleich Troelstra konstatierte Grimm, daß die Parteien beider kriegführenden Seiten das Recht auf die Verteidigung des Vaterlands in Anspruch nahmen; aber im Gegensatz zu jenem kam er seinerseits nicht zu dem Schluß, daß alle gerechtfertigt waren, sondern, da $\beta$ alle - n.b. nicht nur die deutsche Partei - versagt hatten. Die von beiden Seiten vorgebrachten Argumente seien, weil nur der Rechtfertigung der Teilnahme der Arbeiter am Krieg dienend, bedauerlich.

Wir erblicken darin aber den Ausgangspunkt für die Kritik an den [. . .] Richtlinien der Internationalen. Diese Kritik wird kommen, und sie $m u \beta$ einsetzen, noch bevor der Krieg zu Ende ist. ${ }^{262}$

$260 \mathrm{Vgl}$. W. Gautschi, Lenin als Emigrant in der Schweiz, [Zürich, Köln 1973] S. 112ff.; Aksel'rod an Grimm, Dezember 1915, in Die Zimmerwalder Bewegung. Protokolle und Korrespondenz, hrsg. von H. Lademacher, 2 Bde, Den Haag, Paris 1967, Bd 2, S. 371ff., 372: ,entwickelte ich den Gedanken betreffend die Veranstaltung, in chronologisch aufeinanderfolgender Reihe privater internationaler Konferenzen von Vertretern aus verschiedenen Ländern, auf immer breiterer Basis, zum Zwecke, auf diese Weise einen immer erweiterten Zentralpunkt für eine einheitliche propagandistische und organisatorische Tätigkeit zur Vorbereitung und Einberufung eines internationalen sozialist[ischen] Kongresses zu schaffen."

261 [R. Grimm,] ,Die Internationale”, in: Berner Tagwacht, 1914, Nr 216 (16.9.).

262 [R. Grimm,] ,Reflexionen", ebd., $\mathrm{Nr} 221$ (22.9.). 
So hieß es denn auch in der am 27 . September von der italienisch-schweizerischen Konferenz in Lugano verabschiedeten, auf dem Entwurf von Grimm basierenden Resolution:

Die gegenwärtige Katastrophe ist das Ergebnis der imperialistischen Politik der Großmächte [. . .].

Die deutschen und die österreichischen Bourgeois haben kein Recht, sich zur Verteidigung des Krieges auf den Kampf gegen den Zarismus und für die Freiheit der nationalen Kultur zu berufen [. . .].

Auch die französischen und die englischen Bourgeois haben kein Recht, sich in der Verteidigung ihrer Länder auf den Kampf gegen den deutschen Imperialismus und für die Freiheit der Völker zu berufen. Ihr Ziel ist nicht die Befreiung der Völker von dem kapitalistischen. und militaristischen Druck, denn durch ihre Bündnispolitik mit dem zaristischen Rußland haben sie diesen Druck verschärft und die Entwicklung zu höherer Kultur verhindert.

Die wahren Ursachen und der eigentliche Charakter des gegenwärtigen Krieges werden verdunkelt durch den in allen Ländern von den herrschenden Klassen absichtlich entfachten chauvinistischen Taumel. Auch Teile der Arbeiterklasse wurden von dieser chauvinistischen Strömung mitgerissen [. . . ]. ${ }^{263}$

Rosa Luxemburg ging hierauf ein, wenn sie in ihrem Brief an Moor betonte, daß zunächst einmal eine ,innere Klärung in jeder nationalen Partei" nötig sei, dabei einräumend, daß nicht nur die deutsche Partei ihre Stellung zum Krieg klären müßte, sondern ebenso ,,Franzosen, Engländern, Italiener etc." 264 Ebenso bemerkte Liebknecht nunmehr, daB die anderen Parteien nicht ganz frei von Schuld waren. Allerdings - schrieb er am 10. Oktober an den Parteivorstand - trage die deutsche Partei die weitaus größte Schuld, woraus besondere Pflichten resultierten:

Wie die Sozialdemokratie zur Intensierung [sic] des Krieges international gewirkt hat, so kann sie noch heute, auch während des kriegerischen Prozesses, zu seiner Schwächung, Hemmung international wirken. Das Signal dazu hat die deutsche Sozialdemokratie zu geben, wie sie das Signal zur Intensierung des Krieges gegeben hat [. . . ]. Ich fordere, daß dieses Signal gegeben wird. ${ }^{265}$

Wenn die Parteiinstanzen das Signal nicht gaben, mußte es die Opposition tun; dann mußte die Erneuerung der Internationale von der letzteren ausgehen.

${ }^{263}$ „,Die Konferenz in Lugano”, ebd., Nr 227 (29.9.); Die Zimmerwalder Bewegung, a.a.O., Bd 1, S. $22 \mathrm{f}$.

264 Rosa Luxemburg an Moor, 12.10.1914, S. $15 f$.

${ }^{265}$ Liebknecht, Klassenkampf, S. 40 (Brief an den Parteivorstand, 10. 10.1914). 
Natürlich ist die Internationale unsterblich, weil und solange die objektiven Ursachen dauern. Nur ist die Frage, auf welchem Wege und in welcher Form sie wieder auferstehen wird; jedenfalls nicht ohne gründlichste Läuterung. ${ }^{266}$

Je mehr die Erbitterung der Radikalen über die offiziellen Instanzen der Partei zunahm, je deutlicher sie erkannten, daß der 4 . August nicht nur ein Unfall war, je klarer ihnen wurde, daß er nicht nur ein deutsches Problem war, desto höhere Ansprüche stellten sie in bezug auf die zu erneuernde Internationale, desto skeptischer beurteilten sie die Versuche einer möglichst schnellen Reaktivierung der bisherigen Internationale. Wenn diese Versuche, die nur über die offiziellen Instanzen laufen konnten, Erfolg hätten, würden diese rehabilitiert, bevor die klärende Auseinandersetzung, die erst nach dem Krieg richtig beginnen könnte, stattgefunden hätte, d.h. bevor die Opposition sich voll hätte entfalten können. So schrieb Rosa Luxemburg an Moor:

Der deutsche wie der internationale Sozialismus [ . . .] werden durch diesen Krieg vor die Schicksalsfrage gestellt. Gelingt es nicht, nach dem Kriege eine regelrechte [ . . . ] Absage des internationalen Sozialismus an den Imperialismus und Militarismus unter allen ihren Vorwänden zu erreichen, dann kann sich der Sozialismus begraben lassen [. . . ]. Die Klärung nach dem Kriege wird über das Sein oder Nichtsein des Sozialismus entscheiden. ${ }^{267}$

Angesichts der , unermeßlichen welthistorischen Bedeutung” dieser Klärung warnte Rosa Luxemburg,

$\mathrm{da} B$ man keine voreiligen, unbedachten Schritte von seiten der Internationale unternimmt, die etwa darauf hinausgingen, so schnell wie möglich eine Sitzung des Internationalen Büros oder eine Konferenz einzuberufen. [. . . ] Entweder werden sich die Vertreter der einzelnen Nationen untereinander böse verzanken [. . .], was jedenfalls nur eine traurige Dokumentierung des Zusammenbruchs der Internationale wäre. Oder aber es werden sich alle kriegführenden Parteien - vielleicht unter dem Segen der Neutralen - gegenseitig Pardon erteilen für die begangenen Schweinereien [. . .]; das wäre dann aber noch fataler, denn das hieße, unter dem heuchlerischen Schein der Internationale tatsächlich den internationalen Sozialismus begraben. Also lieber keine Versuche, künstlich die Internationale zusammenzuleimen $[\ldots] .{ }^{268}$

Für eine so nachdrückliche Warnung gab es damals Grund genug. Aus Rosa Luxemburgs Schreiben vom 9. November geht hervor, daß sie das

206 Ebd., S. $40 f$.

267 Rosa Luxemburg an Moor, 12.10.1914, S. 15.

268 Ebd., S. 15. 
Zirkular der SDAP vom 2. Oktober tatsächlich erhalten hatte; es dürfte sie - auf dem Umweg über Stuttgart - um den 10. Oktober erreicht haben. Aber dieser holländische Vorstoß war bekanntlich nicht der einzige. So hatte das National Executive Committee der SPA in seiner Sitzung am 19.20. September einen Aufruf an alle sozialistischen Parteien beschlossen, in dem es die Einberufung eines internationalen Kongresses zur Beratung über Schritte zur Beendigung des Kriegs vorschlug. ${ }^{269}$ Die russischen Menschewiki in der Schweiz und in den skandinavischen Ländern lancierten ähnliche Ideen. ${ }^{270}$ Die schweizerischen und die italienischen Sozialisten hatten sich am 27. September in Lugano auf den Vorschlag einer Konferenz der Parteien der neutralen Länder geeinigt; die Geschäftsleitung der SPS, die davon in einem Zirkular vom 5. Oktober Kenntnis gab, sollte für die Dauer des Kriegs die Funktion einer Vermittlungsstelle der Internationale übernehmen, ,,bis das Internationale Sozialistische Bureau seine Tätigkeit wieder aufnehmen kann". ${ }^{271}$ Das Kooperationskomitee der skandinavischen Parteien, das am 10.-11. Oktober in Stockholm zusammenkam, sprach sich gleichfalls für die Einberufung einer Konferenz der Parteien der neutralen Länder aus. ${ }^{272}$

Allerdings dürfte Rosa Luxemburg am 12. Oktober über das Projekt der skandinavischen Parteien noch nicht informiert gewesen sein; der Vorwärts berichtete darüber erst am 16. Oktober. ${ }^{273}$ Der amerikanische Aufruf, der erst Mitte Oktober bei den europäischen Parteien einging, dürfte ihr wohl ebenfalls noch nicht bekannt gewesen sein; die Berner Tagwacht erwähnte ihn am 13., Het Volk am 19., der Vorwärts sogar erst am 20. Oktober. ${ }^{274}$ Jedoch berichtete der Vorwärts am 10. Oktober von einem Meeting in New York, auf dem verschiedene Redner betont hatten, daß der Geist der internationalen Solidarität durchaus noch nicht tot sei. ${ }^{275}$ Ferner brachte er

\footnotetext{
$269 \mathrm{Vgl}$. The American Socialists and the War. A documentary history of the attitude of the Socialist Party toward war and militarism since the outbreak of the Great War, hrsg. von A. Trachtenberg, New York 1917; ISB-Archiv, Mf. III; NT 572/4.

$270 \mathrm{Vgl}$. Blänsdorf, Die Zweite Internationale, S. 72ff.; Anm. 260.

271 Vgl. das Rundschreiben an die sozialistischen Parteien der neutralen Länder, 5.10.1914, abgedruckt in Die Zimmerwalder Bewegung, Bd 1, S. 24-27; NT 572/2,3-5. $272 \mathrm{Vgl}$. ,,Protokoll fört vid sammanträde med skand. arbetarrörelsens samarbetskommittei Stockholm den 10 och 11 oktober 1914”, ABA; ,,Vorschlag der soc[ialistischen] Parteien von Schweden, Norwegen und Dänemark", NT 402/2-4; Graß, Friedensaktivität, S. 82ff.

${ }^{273} \mathrm{Vgl}$. ,Verlegung des Internationalen Sozialistischen Bureaus”, in: Vorwärts, 1914, $\mathrm{Nr} 283$ (16.10.), Beilage.

274 Vgl. ,,Sozialistische Friedensbestrebungen”, in: Berner Tagwacht, 1914, Nr 239 (13.10.); , ,Uit de Internationale”, in: Het Volk, Nr 4459 (19.10.1914); ,,Ein Aufruf der amerikanischen Genossen", in: Vorwärts, 1914, $\mathrm{Nr} 287$ (20.10.), Beilage.

$275 \mathrm{Vgl}$. ,Die Sozialisten Amerikas und der Krieg”, ebd., Nr 277 (10.10.).
} 
am gleichen Tag eine von Vandervelde in den USA abgegebene Erklärung, $\mathrm{da} B$ die deutsche Partei nicht der geringste Vorwurf treffe. ${ }^{276}$ Was aber die Konferenz von Lugano betraf, wußte Rosa Luxemburg immerhin das, was in der Berner Tagwacht stand. Auf ihren Artikel ,,Gegen den Franktireurkrieg" anspielend, der dort kurz darauf erschien, ${ }^{277}$ hatte Grimm am Vorabend der Konferenz geschrieben, einstweilen hätten , die Kanonen die Beziehungen der sozialistischen Parteien unterbrochen. Diese Beziehungen wieder anzuknüpfen, in diesem Sinne den Frieden vorzubereiten [. . . ] - das ist die Aufgabe der Konferenz in Lugano." 278 Aber die publizierte Resolution gab über die Ergebnisse der vertraulichen Konferenz nur wenig Aufschluß. 279 Am 9. Oktober brachte die Berner Tagwacht indessen den Text eines Aufrufs der Geschäftsleitung der SPS vom 7. Oktober, worin es hieß:

Die Konferenz in Lugano [. . .] hat die schweizerische Geschäftsleitung mit der vorläufigen Weiterführung der Geschäfte des internationalen sozialistischen Bureaus beauftragt. Wir haben [ . . .] uns bereits mit den Bruderparteien in Verbindung gesetzt. Womöglich wird noch vor Neujahr eine Konferenz der sozialdemokratischen Parteiorganisationen der neutralen Länder stattfinden. ${ }^{280}$

Rosa Luxemburg hatte Moor, dem sie zuletzt anläßlich der Brüsseler Sitzung des ISB Ende Juli, in der er die SPS vertreten hatte, begegnet war, seither zwei Karten geschrieben. ${ }^{281}$ Bemerkenswerterweise war ihr ausführlicher Brief vom 12. Oktober, in dem sie sich so nachdrücklich gegen „Versuche, künstlich die Internationale zusammenzuleimen”, aussprach, der Begleitbrief zu der Erklärung vom 10. September, die endlich zu verschicken die Berliner Unterzeichner - wohl ebenfalls im Hinblick auf jene Versuche - jetzt beschlossen hatten. ${ }^{282}$ Anscheinend hatte - immerhin für Rosa Luxemburg - die Erklärung vom 10. September jetzt einen neuen Zweck erhalten: während der Hinweis auf die Opposition in der deutschen Partei zunächst in erster Linie dazu hatte dienen sollen, die deutsche Sozialdemokratie in den Augen der anderen Parteien zu rehabilitieren, sollte er nun letztere davon abhalten, daß sie etwa dadurch, daß sie der

276 Vgl. ,Vandervelde über die deutschen Sozialdemokraten”, ebd.

m Unter dem Titel ,Parteipflichten!”, in: Berner Tagwacht, 1914, Nr 228 (30.9.).

278 [R. Grimm,] ,Lugano", ebd., Nr 225 (26.9.).

279 Vgl. Anm. 263.

280 ,"Sozialdemokratische Partei der Schweiz”, ebd., Nr 236 (9.10.).

281 Rosa Luxemburg an Moor, 12.10.1914, S. 14.

282 Vgl. ebd. S. 17; Liebknecht, Betrachtungen und Erinnerungen, S. 278: „, Vor oder nach der letzterwähnten Szene [in der Besprechung der Opposition am 26./27. September in Berlin] beschlossen Mehring, Rosa und ich, die bekannte, auch von Clara Zetkin bereits unterzeichnete Erklärung vom 10. September zu publizieren." 
Führung der deutschen Partei allzu nachsichtig begegneten, den Prozeß der Klärung innerhalb der deutschen Sozialdemokratie störten; ja die Opposition in der deutschen Partei erhielt nun eine paradigmatische Bedeutung. Da die deutsche Sozialdemokratie - formulierte Rosa Luxemburg den jetzt aufkeimenden Gedanken ein halbes Jahr später - bisher nicht nur der stärkste Vortrupp, sondern ebenso das denkende Hirn der Internationale gewesen sei, müsse in ihr, an ihrem Fall ,der Selbstbesinnungsprozeß ansetzen". ${ }^{283}$ Um keine Mißverständnisse aufkommen zu lassen, wies Rosa Luxemburg in ihrem Brief an Moor - sei es, ,nicht zur öffentlichen Verwendung" - nachdrücklich darauf hin, wogegen die Opposition sich richtete: ,,die offizielle Haltung der Reichstagsfraktion, des Parteivorstandes und der Parteiredakteure". 284

Bei der Verbreitung der Erklärung folgten Rosa Luxemburg und Liebknecht anscheinend dem ursprünglichen Plan, dieselbe ,,in der ausländischen Parteipresse (Schweiz, Italien, Holland, Schweden)" zu veröffentlichen. ${ }^{285}$ Während Rosa Luxemburg sie am 12. Oktober - für Berner Tagwacht und Züricher Volksrecht - an Moor schickte, den sie zugleich bat, sie auch an den Avanti! weiterzuschicken, ${ }^{286}$ sandte Liebknecht sie am gleichen Tag an Branting für den Social-Demokraten ${ }^{287}$ sowie - über Stockholm - nochmals an Grimm für die Berner Tagwacht ${ }^{288}$ und an Wibaut für Het Volk, ${ }^{289}$ ferner wohl noch einmal direkt an Angelica Balabanoff für den Avanti!. ${ }^{290}$ Dabei war die Erklärung nur eine von fünf römisch numerierten Anlagen - Anlage ,,II" - zu dem gleichlautenden maschinenschriftlichen Schreiben, das er an die Genannten richtete ${ }^{291}$ Anlage ,I" war sein Schreiben an die Bremer Bürger-Zeitung vom 3. September, Anlage ,III" sein Schreiben vom 26. September, Anlagen ,IV" und ,V" verschiedene Pressestimmen zu seinem Besuch in Belgien: Übersetzungen eines Berichts in Het Volk und einer Notiz im Kopenhagener Politiken; ${ }^{292}$ ferner ein - aus

283 Junius-Broschüre, S. 55.

224 Rosa Luxemburg an Moor, 12.10.1914, S. 14.

$285 \mathrm{Vgl}$. oben, S. 55.

286 Rosa Luxemburg an Moor, 12.10.1914, S. 17.

$287 \mathrm{Vgl}$. Anhang, Nr 3, 3 a.

$288 \mathrm{Vgl}$. Anhang, $\mathrm{Nr} 3 \mathrm{c}$.

$289 \mathrm{Vgl}$. Anhang, Nr 3, 3 b; Nr 5.

290 Vgl. Rosa Luxemburg an Moor, 12.10.1914, S. 17: ,,Schreibe an die Angelica Balabanoff, daß gleichzeitig auch an sie ein Brief geht auf demselben Wege [. . .]. Die ,Erklärung' schicke auch an den, Avanti', da man ja nicht wissen kann, ob er auf anderem Wege kriegt."

291 Alle fünf Anlagen im Nachlaß Branting.

292 „,Liebknecht in Brussel”, in: Het Volk, Nr 4437 (23.9.1914); Viggo Toepfer, ,Dr. Liebknecht om Belgien. Fordømmer han Tysklands Gerninger", in: Politiken, 1914, Nr 270 (27.9.). Die Übersetzung des erstgenannten Artikels lautet: ,,Liebknecht in Brüssel. 
der Frankfurter Zeitung übernommener-Bericht in der Chemnitzer Volksstimme, laut dem Huysmans sich geweigert hatte, Liebknecht die Hand zu reichen. ${ }^{293}$ An Wibaut sandte Liebknecht anscheinend nur die - im SDAPArchiv im IISG befindlichen - Anlagen ,,II" und ,III”, da ,I" ja, weil bereits in Het Volk veröffentlicht, , für Sie erledigt", während ,IV" und „,V" für die Holländer nichts Neues enthielten. ${ }^{294}$

Die jetzt versandte, d.h. definitive Fassung der Erklärung, die von der oben zitierten in verschiedenen Punkten abweicht, dürfte erst Anfang Oktober in Berlin entstanden sein. Wenn es in der Stuttgarter Fassung unter Hinweis auf die Artikel Südekums und Fischers, in der Parteipresse des Auslands" - hieß: ,, Wir sehen uns deshalb gezwungen, den ausländischen Genossen zu versichern", so wird in der neuen Fassung - unter Hinweis auf die bewußten Artikel ,,in der Parteipresse des neutralen Auslands (Schweden, Italien, Schweiz)" - festgestellt: ,Wir sehen uns dadurch gezwungen, an der gleichen Stelle zu erklären”, d.h. die Wendung

/ Antwerpen, 22. Sept. (R.B.). Der deutsche sozialdemokratische Reichstagsabgeordnete Dr. Karl Liebknecht hat einen Besuch in Brüssel gemacht und mit verschiedenen Führern der belgischen sozialdemokratischen Partei gesprochen. Er erklärte ihnen, wie die Kriegskredite in Deutschland durch die deutschen Sozialisten mit bewilligt wurden; nicht alle hätten dafür gestimmt, doch hätten die Berichte, daß französische Truppen in Belgien eingedrungen wären, viel zu der Bewilligung beigetragen. / Es kostete den [sic] belgischen Parteigenossen wenig Mühe, Liebknecht von dieser Täuschung zu überzeugen. Liebknecht erklärte ferner, daß man in Deutschland sehr gereizt sei über die Greuel, die man Deutschen gegenüber begangen habe. Auch über diesen Punkt konnte man ihm bessere Aufklärungen geben und, nachdem er gesehen hatte, wie sich die Deutschen betragen, und er die Plünderungen und Verwüstungen angesehen hatte, erklärte Liebknecht, daß die Handlungsweise seiner Landsleute nicht zu beschönigen sei; er sprach die Hoffnung aus, daß das deutsche Volk wohl noch die Wahrheit erfahren würde. / Beim Verlassen von Brüssel drückte Liebknecht sein Bedauern darüber aus, $\mathrm{da} \beta$ er Löwen und Tirlemont nicht besuchen konnte, weil in der Nähe dieser Orte Gefechte stattfänden; er gab die Absicht zu erkennen, nach Belgien zurückzukehren, wenn es ihm gestattet würde." Die Wiedergabe der Notiz im Politiken entspricht der Nachschrift zu dem Brief von Scheidemann an Liebknecht vom 7.10.1914, Liebknecht, Klassenkampf, S. 37: ,,Soeben haben wir die Übersetzung [. . .]."

$293 \mathrm{Vgl}$. „Belgische Sozialisten in Holland”, in: Frankfurter Zeitung, 1914, Nr 279 (8.10., 1. Morgenblatt); , Krieg und Sozialdemokratie”, in: Volksstimme (Chemnitz), 1914, Nr 234 (9.10.). Nach der maschinenschriftlichen Abschrift hieß es dort: ,,Krieg und Sozialdemokratie. / Die ,Frankfurter Zeitung' läßt sich aus Amsterdam melden: / ,Der sozialistische belgische Abgeordnete Terwagne ist laut ,Telegraaf' hier angekommen [. . . . Er erzählt ferner, Liebknecht sei in Brüssel gewesen und habe Camille Huysmans [. . .] die Hand hingehalten mit den Worten, er habe zu der Gruppe gehört, die gegen den Krieg gestimmt hätte. Huysmans habe die Hand verweigert, weil Liebknecht nicht öffentlich protestiert hätte. [... J' / Wir wissen nicht, ob die Behauptung über Karl Liebknecht richtig ist. Aber wir wissen bestimmt dreierlei: . . . . . . . . . . . . Und endlich: den Rücken zugedreht bekäme jeder, der sich jetzt bei den belgischen und französischen Sozialisten anbiedern wollte."

$294 \mathrm{Vgl}$. Anhang, Nr 3 b; Anlagen: SDAP-Archiv, Mappe 2119. 
Brst jetst erhalten wir Ronntniss von folgender

I r $<2$; $r$ u

die, obwohl sie bereits vor mehr als einen Nonat abgafasst

ist, an Aktualitdt niohts eingobüsst hat:

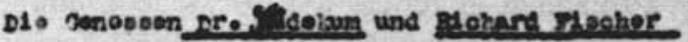

haben in dor Parteijeose cos noutral on molande

(Botwacian, Itelion, Sohwv1z) cen Vorsuok untersomens

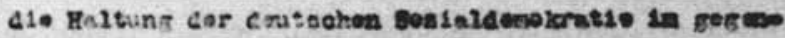

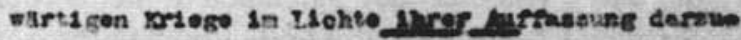

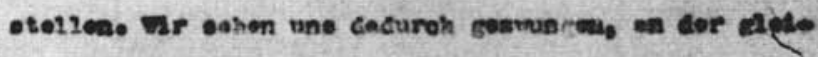
ohon Gtoxze su erisidrong aneo elr une olohomioh pale -

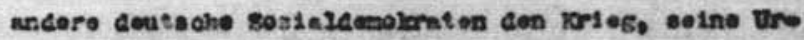

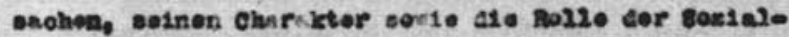

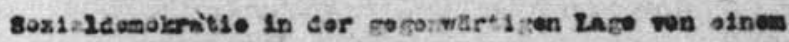

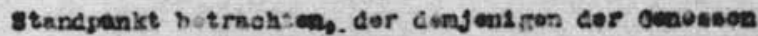

gucolaum und glecher durahme nioht ontoprthehte Dor

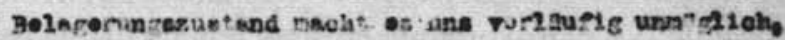

unsare marmatin orront11ah su vortrotene

Mon 20. 5iptarber 29240

Karl diclinedt

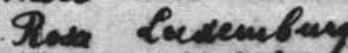
Than chelising

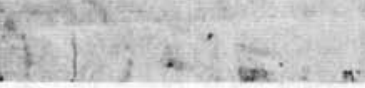

gettin

Erklärung der deutschen Radikalen vom 10. September 1914, definitive Fassung vom Oktober (Anlage ,,Il” zu Nr 3) 
gegen die Artikel Südekums und Fischers wurde jetzt zugleich benutzt, um zu begründen, was von vornherein geplant war: die Publikation der Erklärung , in der ausländischen Parteipresse”. Die Änderung dürfte eine Reaktion auf die Vorwürfe gewesen sein, die der Parteivorstand Liebknecht am 2. Oktober u.a. deshalb gemacht hatte, weil er sich im Ausland zu parteiinternen Vorgängen geäußert hatte. ${ }^{295} \mathrm{Daß}$ Liebknecht daran lag, sich gegen neue Vorwürfe dieser Art abzusichern, zeigt seine Bitte an alle Adressaten, beim Ausdruck ,,hervorzuheben, daß diese Erklärung [. . .], wie die Erklärungen der Genossen Südekum und Fischer, im Ausland wiedergegeben werden muß und das Ausland interessiert", und darauf hinzuweisen, daß es ,charakteristisch" sei, ,,daß sich solche Diskussionen jetzt vielfach im neutralen Ausland abspielen", ${ }^{296}$ ferner die Bitte, die er im Hinblick auf den Passus von der , gleichen Stelle" - speziell an Wibaut richtete, nämlich die Erklärung in der holländischen Presse ,,erst, wenn sie in der Schweizer Presse stand", veröffentlichen zu lassen. ${ }^{297}$

Übrigens trug die Erklärung erst in dieser - wohl erst nach dem 2. Oktober entstandenen - definitiven Fassung, in der die Abgrenzung von den Artikeln Südekums und Fischers noch durch ein ,,durchaus" verstärkt war, das Datum ,,Am 10. September 1914”, das auf den ursprünglichen $A n l a ß$ deutet. Über den maschinenschriftlichen Text wurde - auf einer anderen Maschine - nachträglich die Worte geschrieben: ,,Erst jetzt erhalten wir Kenntnis von folgender [Erklärung], die, obwohl sie bereits vor mehr als einem Monat abgefaßt ist, an Aktualität nichts eingebüßt hat:" Unter den Text sind von Rosa Luxemburgs Hand die Namen der vier Unterzeichner gesetzt. ${ }^{298}$

Wenige Tage später schickte Liebknecht Grimm noch einmal auf direktem Weg den Brief vom 12. Oktober; ${ }^{299}$ zu dieser zweiten Sendung dürfte die im Grimm-Nachlaß vorhandene maschinenschriftliche Abschrift der definitiven Fassung der Erklärung vom 10. September gehören, unter die nunmehr von Liebknechts Hand die Namen der vier Unterzeichner gesetzt

295 Vgl. Liebknecht, Klassenkampf, S. 32ff.; Rosa Luxemburg an Levi, 16.10.[1914], RLGB, Bd 5, S. 456: „Hier erhebt man einen förmlichen Kreuzzug gegen Karl”. $296 \mathrm{Vgl}$. Anhang, Nr 3.

297 Vgl. Anhang, Nr 3 b; Liebknecht, Klassenkampf, S. 26; noch in der Broschüre war die Fiktion, daB das Schreiben , An die Redaktionen einiger schwedischer, italienischer und Schweizer Parteizeitungen" gerichtet gewesen sei, aufrechterhalten.

298 Dem Exemplar im SDAP-Archiv, Mappe 2119, gleicht das im Nachlaß Branting; nach der Wiedergabe durch Ernst Meyer (s. Anm. 6) zu urteilen, hatte das Moor übersandte Exemplar dieselbe Form.

299 Vgl. Anhang, Nr 3, 3 c. Daß Liebknecht diesen Brief erst einige Tage später nochmals an Grimm sandte, ergibt sich aus seiner Bemerkung, er wisse nicht, ob das über Stockholm gesandte Schreiben eingetroffen sei. Vgl. Anhang, Nr 3 c. 
waren. ${ }^{300}$ Die Veröffentlichung in der Berner Tagwacht folgte aber nicht der letzteren, sondern der über Stockholm gesandten Fassung. ${ }^{301}$ Schon am 16. Oktober verarbeitete Branting, der sich bereits vorher über den Inhalt von Liebknechts in Het Volk veröffentlichtem Schreiben vom 3. September durch Ankersmit hatte informieren lassen, ${ }^{302}$ die beiden Schreiben vom 3. und 26. September in einem Leitartikel des Social-Demokraten; ${ }^{303}$ die Erklärung vom 10. September wurde in einem dort am 30. Oktober veröffentlichten Artikel zitiert, in dem ebenfalls die Anlagen ,IV" und „V" verwertet waren. ${ }^{304}$ Die Berner Tagwacht brachte die Erklärung vom 10. September sowie das Schreiben vom 26. September am 30. Oktober ${ }^{305}$ das Schreiben vom 3. September am 3. November. ${ }^{306}$ Das Züricher Volksrecht brachte die Erklärung am 31. Oktober, ${ }^{307}$ Het Volk am 4. November. ${ }^{308}$ Dagegen scheint sie der Avanti! nicht veröffentlicht zu haben.

Bemerkenswert ist die besondere Bedeutung, die Rosa Luxemburg und Liebknecht der Publikation der Erklärung in der Schweizer Presse beimaBen; anscheinend gab hierbei nicht allein den Ausschlag, daß dieselbe so am ehesten bekannt wurde. Daß Rosa Luxemburg gerade Moor so nachdrücklich vor verfrühten Versuchen, , die Internationale zusammenzuleimen", warnte, deutet darauf hin, daß sie dabei in erster Linie nicht den holländischen Vorstoß, sondern den der SPS im Sinn hatte, ja aus ihrem Schreiben vom 9. November geht hervor, daß sie dem holländischen Vor-

300 Nachlaß Grimm/Zimmerwald-Bewegung, G 2.

301 Die über Stockholm gesandte Fassung - und ebenso die Wiedergabe in der Berner Tagwacht (s. Anm. 305) - weicht in einigen Details von der Abschrift ab; es heißt dort: ,,im Lichte ihrer Auffassung” statt ,,im Lichte ihrer Auffassung”; , ,Klara Zetkin” statt „Clara Zetkin”; auch sind die Namen ,,Südekum und Fischer” dort bei der zweiten Nennung nicht hervorgehoben; schließlich hat Liebknecht - im Gegensatz zu Rosa Luxemburg - vor die vier Namen ,,gez." gesetzt.

302 Ankersmit an Branting, 13.10.1914 (Telegr.), NachlaB Branting.

${ }^{303} \mathrm{Vgl}$. Hj. B[rantin]g, ,Kriget och Internationalen. Meningsskiljaktigheterna inom den tyska socialdemokratin", in: Social-Demokraten, 1914, Nr 240 (16.10.).

304 Vgl. ,,Minoritets-meningen inom det tyska partiet”, ebd., $\mathrm{Nr} 252$ (30.10.). Der Artikel scheint auch gegen deutschfreundliche bürgerliche Blätter in Schweden selbst gerichtet gewesen zu sein.

305 Vgl. ,Die deutsche Partei und der Krieg”, in: Berner Tagwacht, 1914, Nr 254 (30.10.).

$306 \mathrm{Vgl}$. ,Ein Brief des Abgeordneten Liebknecht”, ebd., Nr 257 (3.11.): ,,Erst jetzt erhalten wir Kenntnis von einem Briefe, den der deutsche Reichstagsabgeordnete Dr.

Karl Liebknecht am 3. September an die Redaktion des Bremer Parteiblattes sandte. Der Brief ging uns mit erheblicher Verspätung zu, da er, wie aus den Poststempeln ersichtlich ist, eine kleine Weltreise über Stockholm-London machte. [. . .]."

307 Vgl. ,Der europäische Krieg. Die andere Auffassung”, in: Volksrecht, 1914, Nr 254 (31.10.).

${ }^{308} \mathrm{Vgl}$. ,,Uit de Internationale”, in: Het Volk, Nr 4473 (4.11.1914): ,,Eerst thans krijgen wij kennis [. . .]." 
schlag zunächst durchaus nicht ablehnend gegenüberstand. ${ }^{309}$ Zwar ist denkbar, daß sie gegenüber Troelstra angesichts der eigenartigen Weise, in der dieser den deutschen Parteivorstand über Liebknechts Besuch in Amsterdam informiert hatte, bereits gewisse Vorbehalte hegte; aber das Zirkular vom 2. Oktober war ja in erster Linie von dem Vorsitzenden der SDAP, Vliegen, unterzeichnet. ${ }^{310}$ Vor allem jedoch lag in diesem Zirkular der Nachdruck darauf, da $\beta$ die Zeit für eine internationale Konferenz noch nicht gekommen sei, so da $\beta$ Rosa Luxemburg meinen konnte, da $\beta$ der Standpunkt des Vorstands der SDAP ihrer eigenen Auffassung entspreche. $\mathrm{DaB}$ dieser Schein trog, wurde jedoch bald erkennbar; denn dasselbe Ereignis, das Rosa Luxemburg vor übertriebener Eile warnen ließ, d.h. der schweizerische Vorstoß, brachte Troelstra zu der Einsicht, daß es keine Zeit mehr zu verlieren gab.

\section{Troelstras Reise im Herbst 1914}

Nachdem der deutsche Parteivorstand schon vorher zugestimmt hatte, kam die erste Reaktion auf das Zirkular der SDAP vom 2. Oktober von der British Section of the International, namens derer Middleton in einem Brief vom 10. Oktober Troelstra informierte, daß alle Mitglieder die holländischen Vorschläge voll unterstützten, aber ein Mitglied gemeint habe,

that it might be advisable for one of our Dutch Comrades - either yourself or Van Kol - to visit the various European Capitals for purposes of informal consultations, prior to any conference being called. ${ }^{311}$

Troelstra erhielt diesen Brief kaum vor dem 13., vielleicht selbst erst am 14. Oktober; ${ }^{312}$ aber schon am Abend des 15 . Oktober brach er - laut eigener

\footnotetext{
$309 \mathrm{Vgl}$. Anhang, Nr 4.

$310 \mathrm{Vgl}$. Anm. 200; außer der Unterschrift von Vliegen trug das Zirkular - links davon die Unterschriften der beiden Vertreter der SDAP im ISB - Troelstra und Van Kol. 311 Middleton an Troelstra, 10.10.1914, NT 548/1; ders. an Vliegen, 10.10.1914, SDAPArchiv, Mappe 2084. - Wohl ohne daß Troelstra davon vor seiner Abreise noch erfuhr, ging am 15. Oktober ein Brief von Keir Hardie ein, der der Verlegung des ISB nach Holland ebenfalls zustimmte, aber bedauerte, ,that you have abandoned the idea of holding a special International Conference. I agree with your reasons, that is to say, that such a conference is not necessary to make the transfer [. . . ], but, as you are aware, the British Section of the Bureau [. . .] decided that if possible a special conference should be called, apart altogether from the question of the transfer." Keir Hardie an Vliegen, 12.10.1914, SDAP-Archiv, Mappe 2122. Vgl. ferner - für die BSP - Inkpin an Troelstra, 14.10.1914, NT 543/36: ,We heartily endorse the views expressed in the letter and approve of the provisional transfer of the Bureau to a neutral state [. . . , but are strongly of the opinion that [...] it would be better to transfer the Bureau to Switzerland."

312 Vgl. Troelstra an Branting, [Poststempel: 14.10.1914,] Nachlaß Branting: ,Einer
} 
Aussage der ,,Anregung der englischen Genossen" folgend - zu solch einer Reise auf, die ihn nach Berlin (16.-22.10.), Stockholm (23.-25.10.), Kopenhagen (26.10.), nochmals Berlin (26.-27.10.), Wien (28.-29.10.), Zürich, Bern und nochmals Zürich (30.10.-6.11.) führte. ${ }^{313}$ Für die Wahl der Route waren - abermals laut Troelstras eigener Aussage - drei Ereignisse maßgeblich: Kautskys 60. Geburtstag am 16. Oktober, der Parteitag der schwedischen Partei, auf dem die durch den jüngsten Wahlerfolg der letzteren akut gewordene Frage ihres Regierungseintritts anstand, sowie der Parteitag der SPS. ${ }^{314}$ Aber es ist unverkennbar, daß diese Ereignisse nur eine sekundäre Rolle spielten; denn die Absicht, zu Kautskys Geburtstag nach Berlin zu fahren, hatte Troelstra vorher nicht bekundet; was den Parteitag der SPS anging, so brachte erst die Berner Tagwacht vom 10. Oktober die Nachricht, daß er zum 31 . Oktober einberufen war. ${ }^{315}$ Die Idee, am schwedischen Parteitag teilzunehmen, kam Troelstra desgleichen jetzt erst, wobei er sich noch nicht einmal genau darüber informierte, wann derselbe stattfinden sollte: während Het Volk in seiner Frühausgabe vom 15. Oktober - nach dem Vorwärts vom 11. Oktober - berichtete, daß er vom 23. bis 30. November stattfinden sollte, ${ }^{316}$ reiste Troelstra - offenbar in großer Eile - in der Meinung ab, daß er bereits zum 23. Oktober einberufen wäre. ${ }^{317}$

$\mathrm{Daß}$ Troelstra in der Sitzung des Parteivorstands der SDAP am 10.

Anregung der englischen Genossen folgend [. . .], reise ich morgen 14. [!] Oct[ober] nach Berlin und beabsichtige ich, Ihrem Kongreß am 23. beizuwohnen."

${ }_{313}$ Vgl. [P. J.] Troelstra, ,Internationale Reisbrieven”, in: Het Volk, $\mathrm{Nr} 4466$ (27.10.1914); Nr 4467 (28.10.); Nr 4468 (29.10.); Nr 4470 (31.10.); Nr 4472 (3.11.); Nr 4474 (5.11.); Nr 4479 (11.11.); Nr 4480 (12.11.); Nr 4482 (14.11.); Nr 4487 (20.11.); Nr 4489 (23.11.); Nr 4498 (3.12.).

314 Ebd., $\mathrm{Nr} 4466$.

${ }^{315}$ Vgl. ,Schweizerischer Parteitag”, in: Berner Tagwacht, 1914, Nr 237 (10.10.). Im übrigen kündigte Troelstra Studer seine eventuelle Teilnahme an dem Kongreß erst von Berlin aus an. Vgl. Anm. 327.

${ }^{316} \mathrm{Vgl}$. ,Der schwedische Parteivorstand über die Teilnahme an der Regierung”, in: Vorwärts, 1914, Nr 278 (11.10.), 1. Beilage; ,,Het Zweedsche Partijbestuur over het deelnemen aan de regeering", in: Het Volk, $\mathrm{Nr} 4456$ (15.10.).

$317 \mathrm{Vgl}$. Anm. 312; Branting an Troelstra (Telegr. nach Berlin), 19.10.1914, NT 543/27: ,, unser congress wird erst 23 november stattfinden". - Am Tag nach Troelstras Abreise berichtete Het Volk: ,,Troelstra is gisteravond, in opdracht van het Partijbestuur der S.D.A.P., naar Berlijn gegaan, om daar met verschillende leiders der Duitsche soc.dem. Partij besprekingen te voeren over den oorlog. Daarna zal hij zich naar Stockholm begeven [. . .]. Vandaar zal hij naar Bern vertrekken [. . ]. Hij zal zijn verblijf in Berlijn, Stockholm en Bern benutten om pogingen te doen het Int. Soc. Bureau, dat nu niet meer funktionneert, van Brussel naar Holland te verplaatsen." Het Volk, Nr 4457 (16.10.1914). Diese Meldung - erklärte Vliegen in der Sitzung des Parteivorstands der SDAP am nächsten Tag - sei , zeer onhandig en vooral geschikt om van Belgen juist niet gedaan te krijgen, wat wij wenschelijk achten - de verplaatsing van het bureau. [ . . .] Er wordt besloten in Het Volk een bericht op te nemen, waardoor den ongunstigen indruk zooveel mogelijk wordt weggenomen. Na discussie wordt dit bericht vastgesteld". 
Oktober nichts von einer Absicht dieser Art verlauten lieB, dann aber abfuhr, ohne die nächste Sitzung abzuwarten, die am 17. Oktober anstand, deutet darauf hin, daß erst nach dem 10 . Oktober - für ihn selbst überraschend - ein Umstand eintrat, durch den er sich dazu genötigt sah. Die „Anregung der englischen Genossen”, die ihn vielleicht inspirierte, war im Hinblick darauf, da $\beta$ er nicht nur bei den Belgiern in dem Ruf stand, deutschfreundlich zu sein, in jedem Fall ein höchst willkommener Vorwand, gab jedoch zu einem derart überstürzten Aufbruch keinen Anlaß, im Gegenteil - es hätte nahegelegen, zunächst weitere Reaktionen, die in den nächsten Tagen kommen mußten, abzuwarten. ${ }^{318}$

Aber nachdem zunächst Branting in einem Brief vom 3. Oktober Troelstra über die geplante Sitzung des Kooperationskomitees der skandinavischen Parteien, die ,,vielleicht die nötigen Schritte für einen größeren Konferenz nehmen könnte", informiert hatte, ${ }^{319}$ ging - wohl nach dem 10 , aber vor dem 14. Oktober - das erwähnte Zirkular der SPS ein. ${ }^{320}$ Auf den Brief von Branting, nach dem die Zustimmung der skandinavischen Parteien zur Verlegung des ISB nach Holland zu erwarten war, hatte Troelstra noch gelassen reagiert: er hatte Branting informiert, daß sich die ,,belgischen Freunde" quergelegt hätten; sobald indessen Vandervelde aus den USA zurück sei, werde die SDAP, ,gewappnet mit der Antwort der verschiedenen Parteien auf unser Rundschreiben", ihren Versuch erneuern; ferner hatte er nochmals betont, daß ,,wirklich jede Konferenz jetzt verfrüht wäre", die Politiker der Internationale hätten sich z.Z. zur Mitarbeit am Friedensschluß, ,durch Studium der internationalen Verhältnisse vorzubereiten"; endlich hatte er, hier bereits auf den - von ihm erhofften - Regierungseintritt der schwedischen Partei eingehend, bemerkt, daß er sich gerne einmal ,,über die großen Fragen, davor wir gestellt sind”, aussprechen würde. ,,Später hoffentlich." 321 Das Zirkular der SPS, aus dem hervorging, daß dieselbe gleichfalls im Begriff war, die Funktionen der Exekutive des ISB zu übernehmen, zwang dagegen zu sofortiger Aktion. Hals über Kopf brach Troelstra auf, um-dem entspricht die Route

„,Vergadering Partijbestuur 17 October 1914", SDAP-Archiv, Mappe 26. Anscheinend ebensowenig informiert über den Termin des schwedischen Parteitags, erklärte der Parteivorstand der SDAP zu Troelstras Reise: ,,Hij gaat naar Zweden ter bijwoning van het congres over de portefeuillekwestie, en doet en passant Berlijn aan ten einde Kautsky een bezoek te brengen naar aanleiding van diens 60 sten verjaardag." ,Troelstra's reis", in: Het Volk, Nr 4459 (19.10.1914).

318 Vgl. Graß, Friedensaktivität, S. 99, und Blänsdorf, Die Zweite Internationale, S. 94, die Troelstra $m$.E. allzu unkritisch vertrauen.

319 Branting an Troelstra, 3.10.1914, NT 543/23.

$320 \mathrm{Vgl}$. Anm. 271.

321 Troelstra an Branting, 6.10.1914, Nachlaß Branting. 
- möglichst schnell die eindeutige Unterstützung möglichst vieler Parteien für die Verlegung des ISB nach Holland zu gewinnen; ${ }^{322}$ ein weiterer Zweck der Reise war, durch direkte Gespräche die Kontakte zu den anderen Parteien zu verbessern, um - so erklärte Troelstra, seine eigenen Konferenzpläne enthüllend, in dem ersten seiner Reisbrieven - ,,so die ersten vorbereitenden Schritte zu einer internationalen Konferenz zu tun". ${ }^{323}$ Schon in Bentheim, bat er noch Albarda, telegraphisch Vanderveldes Meinung zur Verlegung des ISB nach Holland einzuholen. ${ }^{324}$ Vandervelde antwortete am 18. Oktober:

$\mathrm{Si}$ autres Belges consentent accepte transfert provisoire siège mais sans transmission pouvoirs. ${ }^{325}$

Diese Antwort erhielt Troelstra in Berlin, ${ }^{326}$ von wo er dann dem Vorsitzenden der SPS, Fritz Studer, einen Brief schrieb, aus dem dieser den Eindruck gewann, da $B$ die Belgier ,,mit der interimistischen Besorgung der Geschäfte durch die Direktion bez. das Sekretariat der holländischen Partei einverstanden" wären. ${ }^{327}$

Am 17. Oktober berichtete Troelstra in Berlin dem deutschen Parteivorstand zunächst über die Mission Matthijsens, wobei er - den Aufzeichnungen Otto Brauns zufolge - nicht verhehlte, daß die Belgier nicht einmal einer Konferenz über die Verlegung zugestimmt hatten. Ferner brachte er die in dem Zirkular der SPS enthaltenen Vorschläge zur Sprache, die der SPD in keiner Weise zusagten. ${ }^{328}$ Sodann skizzierte er sein eigenes Aktionsprogramm:

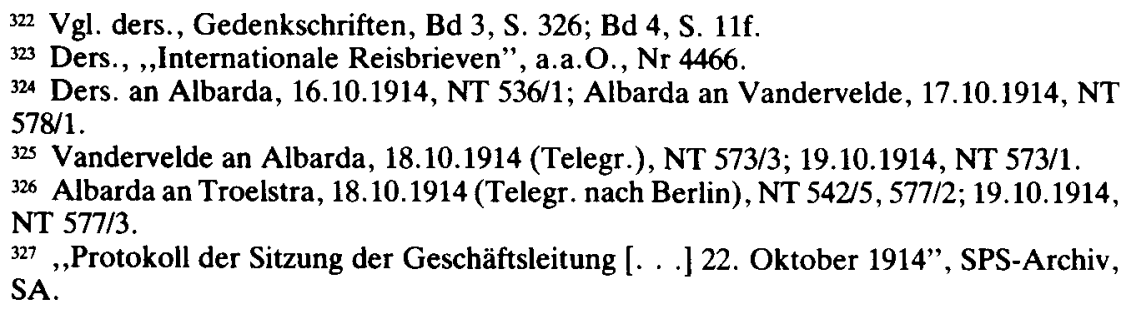
$328 \mathrm{Vgl}$. Tagebücher Otto Brauns, 17.10.1914: ,,Heute war in der P[artei-]V[orstands-] S[itzung] der Gen. Troelstra aus Holland, der mit uns über die Verlegung des Intern[ationalen] Bureaus von Brüssel nach Holland verhandeln will. Der 2. Sekr[etär] der holl[ändischen] Partei ist in Brüssel gewesen [. . . ], wobei er wenig Gegenliebe gefunden hat. [ . . ] Die guten Leute halten sich also noch immer für die geeigneten Vertreter der Internationale [. . . ]. Die Schweizer hatten sich übrigens nach einer Konferenz mit den Italienern, die ihre Neutralität durch Beschimpfung der deutschen Partei betätigen, mit großer Beflissenheit zur Führung der Geschäfte des internationalen Bureaus erboten $\mathrm{u}[\mathrm{nd}]$ in diesem Sinne bereits Rundschreiben an die angeschlossenen Parteien ergehen lassen. Nun, daraus wird hoffentlich nichts. Wie jetzt in Brüssel das Bureau eine Filiale der belgischen Partei ist und ganz in deren Dienst und den der Verbündeten Belgiens 
Für die Tätigkeit des intern[ationalen] Bureaus in Holland hat sich $\operatorname{Tr}[o e l-$ stra] auch bereits ein Programm entworfen. 1. Archiv der Zeitungen aus allen Ländern zur Information der angeschlossenen Parteien. 2. Zentrale für Friedensvermittlungsbestrebungen, event[uel]1 Herausgabe eines Manifestes, das die Zustimmung der Gen[ossen] aller Länder gefunden hat. 3. Vorbereitung einer Konferenz, in der über die von den Parteien einzuschlagenden Schritte zur Herbeiführung des Friedens beraten werden soll. Vorher sollte jedes Land seine Vorschläge schriftlich einreichen. ${ }^{329}$

Ferner legte Troelstra dar, daß ein unentschiedener Kriegsausgang am besten wäre; denn er hätte nicht nur einen Kompromißfrieden zur Folge, sondern darüber hinaus u.U. eine interparlamentarische Aktion, ,, die die allgemeine $A$ brüstung anzubahnen hätte, die dann nach der Schwächung aller Nationen [. . .] Aussicht auf Erfolg hätte". ${ }^{330}$ Von neuem wies er darauf hin, daß die Sozialisten die Arbeit für den Frieden nicht nur den Diplomaten überlassen dürften. ${ }^{331}$

Der deutsche Parteivorstand, dessen Mehrheit, was die Friedensfrage anging, eine Festlegung nicht opportun fand, ${ }^{332}$ reagierte reserviert. Selbst Haase äußerte sich skeptisch: eine Konferenz sei nur sinnvoll, wenn es nicht zu gegenseitigen Anklagen käme; vertrauliche Berichte könnten einer Ausgleichung der Gegensätze dienen; aber das sei ,, noch nicht spruchreif"; wenn Frieden geschlossen werde, werde die Partei ihre Stimme hören lassen; bestimmte Forderungen seien aber noch nicht formuliert; das wichtigste sei jetzt die Vorbereitung der Internationale. Scheidemann hingegen warnte, nicht erneut die eigene Kraft zu überschätzen; dann werde die Zensur nur schärfer; die Erläuterung der eigenen Haltung könnte jede der Parteien publizieren; zu den Annektionsplänen öffentlich Stellung zu nehmen, sei nicht ratsam. Es komme, hörte Troelstra ferner,

gestellt wird, würde es in Bern eine Filiale der französischen Partei mit der gleichen parteiischen Wirksamkeit werden."

329 Ebd.

${ }^{330}$ Ebd. Braun notierte hierzu: ,,Ob in den andren kriegführenden Ländern die Hoffnungen $\operatorname{Tr}$ [oelstra]s Aussicht auf Verwirklichung haben, kann ich nicht beurteilen. In Deutschland, glaube ich aber, würde so ein unentschiedener Ausgang des Krieges, so ein Versumpfen nichts weiter als einen latenten Kriegszustand zur Folge haben. Nicht Abrüsten, sondern noch wahnsinnigeres Wettrüsten als bisher würde einsetzen, um die ausgebliebene Entscheidung nach einigen Jahren in einem noch entsetzlicheren Kriege zu erzwingen."

${ }^{331}$ Vgl. Troelstras Rede-Disposition, NT 401/1.

332 Dies scheint Blänsdorf, Die Zweite Internationale, S. 98, vollkommen zu übersehen. Vgl. Anm. 330 sowie Scheidemanns Neujahrsgruß in der Bergischen Arbeiterstimme vom 31.12.1914: ,wir wollen auch die Absichten unserer Feinde zuschanden machen: wir wollen siegen!" Zitiert nach Scheidemann, Memoiren, Bd 1, S. 328. Die Neigung Blänsdorfs, , ,die formale Verständigungshaltung der SPD zu überschätzen", kritisiert zu Recht Boll, Frieden ohne Revolution?, a.a.O., S. 167, Anm. 19. 
primär darauf an, daß Frieden geschlossen werde; der eigene Einfluß darauf sei gering; die Hauptsache sei jetzt, daß jede Partei im eigenen Land ihre Position verstärkte. ${ }^{333}$ - Der ,,Pessimismus”, den Troelstra laut seinem in Stockholm erstatteten Bericht bei den Führern der deutschen Partei wahrzunehmen meinte, ${ }^{334}$ bestärkte ihn in seiner Überzeugung von der Bedeutung seiner eigenen Aktivität zum Zweck der Friedensvorbereitung.

In Stockholm erfuhr Troelstra, daß sich das Kooperationskomitee der drei skandinavischen Parteien bereits in seiner Sitzung am 10.-11. Oktober zugunsten einer Verlegung des ISB nach Holland ausgesprochen hatte. ${ }^{335}$ Die Stockholmer Vertreter der beiden Fraktionen der russischen Partei Šljapnikov und Larin - taten nun dasselbe. ${ }^{336}$ Das Aktionsprogramm, das Troelstra am 24. Oktober dem erneut einberufenen skandinavischen Kooperationskomitee vortrug, fand desgleichen Zustimmung. ${ }^{337}$ Dafür mußte sich Troelstra seinerseits dem skandinavischen Plan einer Konferenz der Parteien der neutralen Länder in Den Haag bzw. Kopenhagen anschlieBen, der seinen eigenen Plänen teils nicht ganz entsprach, teils vorgriff. ${ }^{338}$ Allerdings stellte er die Bedingung, daß die Konferenz frühestens sechs Wochen später, d.h. Anfang Dezember, stattfände, woraufhin der 6. Dezember ins Auge gefaßt wurde; ferner wollte er den Plan selbst propagieren, sofern die Parteien der kriegführenden Länder, die Bericht erstattend bzw. beratend beteiligt sein sollten, einverstanden wären. ${ }^{339}$

Schon der deutsche Parteivorstand, dem Troelstra den Plan, seinen Vorbehalt erwähnend, am 27. Oktober vortrug, hatte jedoch - laut dem Bericht Otto Brauns - , die stärksten Bedenken", da eine Konferenz, zu der Italiener, Spanier, Schweizer, Bulgaren ,u[nd] ähnl[iche] Nationen” zusammenkämen, voraussichtlich ein Manifest beschließen würde, das einen Protest der deutschen Partei provozieren würde, so daß der Riß in der Internationale nur noch tiefer würde. Sich bereitwillig den deutschen Wünschen fügend, änderte Troelstra den Plan dahingehend, daß, nachdem Schweizer und Italiener dies bereits getan hatten, nun Skandinavier und

${ }^{333}$ Vgl. die Notizen Troelstras, NT 401/2-6.

334 Vgl. ,Protokoll fört vid sammanträde med Kommittén för skand. arbetarrörelsens samarbete den 24 oktober 1914", AA; Graß, Friedensaktivität, S. 92.

335 Vgl. Anm. 272; Branting an Troelstra, 16.10.1914, NT 543/24-26; Stauning an Troelstra, 17.10.1914, NT 556/49; Ström an Vliegen, SDAP-Archiv, Mappe 2084.

336 Vgl. Troelstra, ,Internationale Reisbrieven”, $\mathrm{Nr} 4470$.

337 Vgl. ,Protokoll”, a.a.O.; Graß, Friedensaktivität, S. $100 \mathrm{f}$.

$338 \mathrm{Vgl}$. Troelstra an Albarda, 26.10.1914, NT 32/2-9: ,,Voor 14 dagen hadden de Scand[inaviërs] besloten [. . .] bij de Hollandsche partij er op aan te dringen, zoo spoedig mogelijk een conferentie der neutrale partijen bijeen te roepen. Doen wij ' $t$ niet, dan doen zij het (zij moeten 't doen, om ten hunnent de burgerlijke vredesbeweging voor te zijn)".

${ }^{339} \mathrm{Vgl}$. ,Protokoll”; Troelstra an Albarda, 26.10.1914. 
Holländer, eventuell unter Hinzuziehung der Amerikaner, eine Konferenz abhalten sollten, die den Wunsch nach Frieden bekunden sollte, ohne auf die Ursachen des Kriegs, die Kriegführung, die Haltung der Parteien zum Krieg einzugehen. ${ }^{340}$ Noch von Berlin aus Stauning informierend, regte er die Einberufung dieser skandinavisch-holländischen Konferenz nach Kopenhagen an. ${ }^{341}$

Da eine Beteiligung der Parteien der kriegführenden Länder in dem neuen Plan nicht vorgesehen war, mußten sich die Österreicher zu diesem kaum noch äußern. Was dagegen die Verlegung des ISB nach Holland betraf, erhielt Troelstra in Wien außer deren Zustimmung noch die der beiden tschechischen Parteien. ${ }^{342}$ Selbst die der Schweizer schien jetzt kaum noch fraglich; nachdem sich vorher schon die Italiener dahingehend ausgesprochen hatten, hatte die Geschäftsleitung der SPS am 22. Oktober ebenfalls beschlossen, das holländische Angebot zu akzeptieren, gegenüber dem das ihre wenig Unterstützung fand. Die skandinavischen Parteien, deren Konferenzplan den Beschlüssen von Lugano ohnehin entsprach, hatten - gleich der deutschen - wissen lassen, daß sie schon das holländische Anerbieten angenommen hätten; die französische Partei hatte sich gegen jede Verlegung des ISB ausgesprochen; die belgische Exekutive hatte eine Übertragung ihrer ,,pouvoirs" schlicht abgelehnt. ${ }^{343}$

Allerdings erfuhr Troelstra zur gleichen Zeit, daß die französische Partei

340 Vgl. die Notizen Troelstras, NT 401/7-13; Tagebücher Otto Brauns, 27.10.1914. Braun berichtet ferner: ,,Von dem Vorschlage Troelstra's, die sozialistischen Parlamentarier aller Länder sollten auf ihre Regierungen im Sinne der Herbeiführung eines baldigen Friedens einwirken, versprachen wir uns nach Lage der Dinge zur Zeit wenig Erfolg. Im derzeitigen unentschiedenen Stadium des Krieges bestehe bei den Kriegführenden wohl wenig Neigung zum Frieden, und jede Äußerung eines Verlangens nach Friede wird leider als Schwäche ausgelegt und steigert die Kriegsenergie der Gegenpartei."

311 Troelstra an Stauning, 27.10.1914 (Telegr.), NT 575/28 (Entwurf), ABA: ,Hiesige Freunde halten notwendig, daß nur Neutrale beteiligt werden. Einladung von Skandinavien. Ort Kopenhagen. Nachdem Schweizer und Italiener bereits sich geäußert, jetzt Äußerung nordischer Länder. Amerikaner müssen gleichzeitig in eigenem Lande sich äußern. Zusammenkunft also zu beschränken auf Skandinavien und Holland. Dieses ist auch meine Meinung."

342 Vgl. Troelstras Notizen, NT 575/12-15; Troelstra, ,,Internationale Reisbrieven”, $\mathrm{Nr}$ 4474. Allerdings hatte Victor Adler laut Troelstras Notizen betont: ,,Zonder de Belgen gaat het niet." Auch Friedrich Adler hatte die Bedingung gestellt, daß ,,kein Einspruch" erhoben werde.

${ }_{343}$ Vgl. ,Protokoll der Sitzung der Geschäftsleitung [. . .] 22. Oktober 1914”, a.a.O. Die österreichische Partei hatte sich am 17. Oktober telegraphisch für die Verlegung des ISB, aber nicht für eines der beiden fraglichen Länder ausgesprochen; ebenso hatte sich Aksel'rod für die Russen in der Schweiz geäußert. Ebd.; Friedrich Adler an Otto Lang, 19.10.1914, NachlaB Lang, IISG. Im gleichen Sinn hatten die Österreicher der SDAP geantwortet: Victor Adler an Troelstra, 12.10.1914, NT 542/4. 
nicht nur die Schweizer, sondern ebenso die holländischen Vorschläge zurückgewiesen hatte. Am 25. Oktober hatte l'Humanité den betreffenden Beschluß der Commission Administrative Permanente veröffentlicht, ${ }^{344}$ wonach Vaillant zwei Tage später erklärt hatte, er überlasse den Lesern das Urteil über

ces tentatives expropriatrices qui se résument, aujourd'hui, à confier aux Hollandais, avec le siège du bureau, la formation de son comité exécutif enlevé aux Belges, qui, nous avons foi en eux, ne se laisseront pas, contre tout droit, déposséder de leur mandat.

La section allemande, et pour cause, a donné immédiatement son adhésion à la proposition hollandaise. ${ }^{345}$

Aber in der Besprechung, die Troelstra am 31. Oktober mit den Führern der SPS hatte, versicherte ihm Studer, daß die Parteileitung der SPS die Verlegung des ISB nach Holland desungeachtet unterstütze: ,,Auch wenn die Franzosen vorläufig nicht wollen, so $d o c h . "{ }^{346}$ So konnte Troelstra am 1. November nach Den Haag telegraphieren, da $\beta$, ,bisher alles glatt verlaufen" sei ${ }^{347}$ Von dort erhielt er seinerseits die Nachricht, daß die Belgier unterdessen, was die Verlegung des ISB nach Holland anging, einem Kompromiß zugestimmt hätten, weshalb seine ,Heimreise [...] erwünscht" sei. ${ }^{348}$ Der Besuch bei den Franzosen, den er auf Wunsch der skandinavischen Parteien noch geplant hatte ${ }^{349}$ schien nicht mehr nötig.

Am 18. Oktober hatte Van Kol, von einer mehrtägigen Fahrt durch Belgien zurückgekehrt, dem geschäftsführenden Parteivorstand der SDAP berichtet, daß die Belgier empört darüber gewesen seien, daß die holländische Partei, ohne sich an das zu halten, was im September abgemacht worden sei, das ISB in die Hand zu bekommen suchte. ${ }^{350}$ Aus den besänfti-

344 Vgl. „Parti Socialiste [. . .]”, in: l'Humanité, Nr 3843 (25.10.1914).

${ }^{345}$ E. Vaillant, , ,Le Comité belge du Bureau International”, ebd., Nr 3845 (27.10.1914). 346 Notizen Troelstras, NT 575/15-16: ,,Ook als de Franschen voorloopig niet willen, dan toch."

347 Troelstra an Albarda, 1.11.1914 (Telegr.), NT 528/1.

348 Vgl. Anm. 359; Albarda an Victor Adler, 31.10.1914 (Telegr.), Nachlaß Victor Adler, IISG; ders. an Troelstra, 31.10.1914 (Telegr.), NT 577/6; Victor Adler an Troelstra, 1.11.1914 (Telegr.), NT 542/3; Troelstra an Albarda, 1.11.1914 (Telegr.), NT 528/ 1; Van Kol an Troelstra, 2.11.1914 (Telegr.), NT 577/9; Albarda an Troelstra, 2.11.1914 (Telegr.), NT 542/6.

349 Vgl. Troelstra an Albarda, 25.10.1914, NT 32/1: ,,Zal zien over Genève Frankrijk binnen te komen - naar Bordeaux en Havre. Werk voor conf[erentie] 6 Dec[ember] Haag." Ders. an Albarda, 26.10.1914, NT 32/2-9: ,,Zij [de Scandinaviërs] dringen er op aan, dat ik ook de Franschen bezoek - ik zal zien dit over Genève te doen. Wil s.v.p. ons P[artij-]B[estuur] hiervan even in kennis stellen." Ders., Gedenkschriften, Bd 3, S. 326. ${ }^{350} \mathrm{Vgl}$. „Bijeenkomst van het D.B. 18 October 1914”, SDAP-Archiv, Mappe 26; Notizen von Van Kol von dem Gespräch mit Huysmans am 10.10.1914, Nachlaß Van Kol, IISG. 
genden Erklärungen Van Kols hatte Huysmans - laut einem von jenem überbrachten Brief - sodann geschlossen, daß ein Mißverständnis vorlag, nämlich die holländische Partei das Zirkular der Exekutive nur deshalb nicht versandt habe, weil sie a) den darin erwähnten Konferenz-Vorschlag gar nicht gemacht habe, sondern eine Konferenz selbst gar nicht wünsche, b) der belgischen Partei das ISB nicht abzunehmen suche, sondern dieselbe nur bei der Sammlung relevanter Materialien unterstützen wolle, was natürlich dankbar akzeptiert würde. ${ }^{351}$ Da das erneut ein Mißverständnis war, war beschlossen worden, Huysmans einzuladen, zu einer Aussprache nach Amsterdam zu kommen; ein willkommener Vorwand war der gerade eingegangene Konferenz-Vorschlag der SPA gewesen. ${ }^{352}$

Das Gespräch, an dem seitens der Exekutive außer Huysmans noch Bertrand teilnahm, fand am 29. Oktober statt. ${ }^{353}$ Einleitend berichtete Vliegen, da - bis auf die französische - alle Parteien, die bis dahin auf das holländische Zirkular reagiert hatten, im Prinzip einer Verlegung des ISB zugestimmt hatten, die meisten davon der nach Holland, ${ }^{354}$ worauf sich Huysmans nochmals über das Vorgehen der Holländer beklagte; die Berichte über Troelstras Reise, namentlich Berichte in der deutschen Presse, die den Eindruck erzeugten, daß die Verlegung schon beschlossene Sache sei, ${ }^{355}$ hatten ihn in dem Verdacht bestärkt, daß das ganze von Berlin ausginge; die belgische Exekutive habe ein Mandat, dessen Niederlegung ohne Konferenz nicht möglich sei; das ISB könne vorerst ohnehin nur

${ }^{351}$ Huysmans an Van Kuykhof, 10.10.1914, SDAP-Archiv, Mappe 2084.

${ }^{352} \mathrm{Vgl}$. ,Bijeenkomst van het D.B. 18 October 1914", a.a.O.; Van Kol an Huysmans, 19.10.1914, ISB-Archiv, Mf. III.

${ }^{353}$ Vgl. ,Bijeenkomst van het D.B. 29 October 1914”, SDAP-Archiv, Mappe 26.

354 Außer den erwähnten Briefen (s. Anm. 311, 325, 335) war noch eine Antwort der ungarischen Partei eingegangen, die den Wunsch aussprach, ,,da $\beta$ das Bureau nach der Schweiz verlegt werde". Buchinger an Troelstra, 15.10.1914, NT 556/34. Ferner Dubreuilh an Troelstra, Van Kol und Vliegen, 16.10.1914, NT 544/2. Vgl. ferner die von Albarda vor der Sitzung angefertigte Übersicht über die Antworten in seinen Briefen an das Sekretariat bzw. den Parteivorstand der SDAP, 19.10., 22.10., 28.10.1914, SDAPArchiv, Mappe 26. - Später gingen noch Briefe von den russischen Sozialrevolutionären ein, die eine Verlegung des ISB nur dann für zulässig hielten, ,lorsque le Comité Exécutif du Bureau en exprimera, par circulaire aux partis affiliés, la volonté"; von der SLP, die der Verlegung des ISB nach Holland zustimmte, und vom Auslandskomitee der lettischen Partei, das sich für die Schweiz aussprach. Vgl. Roubanovitch an den Parteivorstand der SDAP, 24.10.1914, NT 555/8-9; Petersen an Vliegen, 31.10.1914, SDAPArchiv, Mappe 2084; Braun und Winter an den Parteivorstand der SDAP, 3.11.1914, NT 572/2, 6. Laut einer Mitteilung Studers stimmte auch die bulgarische Partei der Verlegung des ISB nach Holland zu. Vgl. ,Sitzung der Geschäftsleitung [ . . ] 13. November 1914", SPS-Archiv.

${ }^{355}$ Vgl. u.a. ,Die Verlegung des Internationalen Sozialistischen Bureaus”, in: Vorwärts, 1914, Nr 283 (16.10.), Beilage; Nr 291 (24.10.). 
wenig tun. Huysmans meinte aber, es sei denkbar, daß das Sekretariat seine Funktionen in Den Haag ausübte, wonach schließlich vereinbart wurde, daß - gemäß deren Wunsch - der Sitz der Exekutive, samt den relevanten Teilen des Archivs, für die Dauer des Kriegs Den Haag sein sollte, wohin Huysmans jede Woche einmal kommen sollte; der Exekutive sollten die holländischen Vertreter im ISB beitreten, die nur beratende Stimme haben, aber - für die Parteien der neutralen Länder - alle Dokumente mit unterzeichnen sollten. ${ }^{356}$

Daß diese Vereinbarung den Intentionen Troelstras nicht entsprach, war Vliegen spätestens bewußt, seit ihm Albarda - noch am 29. Oktober, aber wohl erst nach der Abreise von Huysmans - telephonisch den Inhalt von Troelstras Brief vom 26. Oktober übermittelt hatte: gleich der deutschen hätten die drei skandinavischen Parteien nicht nur der Verlegung des ISB nach Holland, sondern ebenso seinem, Troelstras, Aktionsprogramm zugestimmt; über Vanderveldes Idee, daß die belgische Exekutive nicht ihre ,,pouvoirs" abgäbe, habe man gelacht; man habe vielmehr sein Präsidium akzeptiert:

sie fanden [ . . .] erwünscht, daß jemand, den man gut kennt und dem man in der Internationale vertraut, die politische Leitung und den mündlichen Verkehr mit den Parteien übernimmt [ . . .]. ${ }^{357}$

\section{$356 \mathrm{Vgl}$, „Bijeenkomst van het D.B. 29 October 1914”, a.a.O.}

357 Troelstra an Albarda, 26.10.1914, a.a.O.: ,,zij vonden [. . .] gewenscht, dat iemand, dien men goed kent en vertrouwt in de Internationale de politieke leiding en het mondeling verkeer met de partijen in handen neemt". Ferner war Troelstra ausführlich auf die Organisation des Büros eingegangen: ,,Ik zie de werkzaamheden van het secretariaat dubbel: als secretariaat, dat correspondentie voert, berichten inwint en vertaalt, voor publicaties zorgt, in zake vrede straks uit de nationale berichten één bericht opmaakt, dat dienen kan als leiddraad voor de beraadslagingen in het Bureau of de conferentie. Ik deelde mede, dat jij je beschikbaar stelde [. . . ]. Verder, dat Hugenholtz het archief en een deel der vertaling kon overnemen [ . . ]. Hiertegen was geen bezwaar. Ook achtte men het natuurlijk, dat Kamiel [Huysmans] gedurende de schorsing van zijn ambt zijn salaris behoudt. [ . . .]/ Ik zou nu maar direct het P[artij-]B[estuur] verzoeken, het organisatorisch besluit te nemen, dat het Bureau (zoodra definitief de overplaatsing is beklonken, wat ik in Frankrijk hoop klaar te spelen) vestigt in den Haag. Dan moet de zaak in de fractie organisatorisch worden geregeld. Liefst zoo: dat de voorzitter [Troelstra], vice voorzitter [Schaper] en secretaris [Albarda] de zaak in handen krijgen, terwijl Hugenholtz wordt aangewezen voor deelname aan het secretariaat [. . . ]. Ik sta er verder op, dat men mij niet slechts als voorzitter der fractie, maar vooral als gedelegeerde in het I[nternationaal] B[ureau] als voorzitter van het Bureau benoemt, zó, dat die functie niet vervalt, indien ik om de een of andere reden, eens niet meer voorzitter der fractie mocht blijven. [. . . ] Wil van Kol een plaats in het Uitv[oerend] Komitee van het Bureau, laat de fractie hem en Hugenholtz er dan ook in benoemen." Albarda gab den Inhalt dieses Briefs am 29. Oktober telephonisch, am folgenden Tag schriftlich an Vliegen durch. Vgl. Albarda an den Parteivorstand der SDAP, 30.10.1914, SDAP-Archiv, Mappe 2084. 
Obwohl Vliegen Huysmans dementsprechend informierte, wobei er erneut betonte, daß der Parteivorstand der SDAP offiziell von Troelstras diesbezüglichen Bemühungen nichts wisse, ${ }^{358}$ war er seinerseits skeptisch. Namens des geschäftsführenden Parteivorstands beschworen er und Van Kuykhof Troelstra in dem Brief, in dem sie die in Amsterdam getroffene Regelung erläuterten, nicht zu versuchen, mehr herauszuholen.

Wir sind überzeugt, daß derartige Versuche ein Scheitern der ganzen Verlegung des Büros zur Folge hätten. Wir meinen, hieraus schließen zu müssen, $\mathrm{da}$ es für die Verlegung nicht nötig ist, daß Sie Ihre Reise fortsetzen.

Die Frage einer internationalen Konferenz kann in der ersten Sitzung des Exekutivkomitees besprochen werden. ${ }^{359}$

Die Amsterdamer Regelung, nach der es für die Schweizer klar war, daß entgegen ihrer Annahme die Belgier der Verlegung des ISB nach Holland in der ursprünglich geplanten Form nie zugestimmt hatten, jedenfalls aber ,,sich [. . . ] Schwierigkeiten ergeben" hatten, ${ }^{360}$ war für Troelstra nicht der einzige Rückschlag. Schon vorher hatte das Mißtrauen, das ihm insbesondere die Linke in der SPS entgegenbrachte, durch die eigenmächtig vorgenommene Änderung des Konferenzplans neue Nahrung erhalten. Während der Parteivorstand der SPS zunächst bereit gewesen war, die Ausführung der Beschlüsse von Lugano der SDAP bzw. den drei skandinavischen Parteien zu überlassen, wurde er durch den Parteitag ausdrücklich verpflichtet, weiter aktiv aufzutreten. ${ }^{361}$ Ebenso drängte die am 28. Oktober nochmals offiziell befragte italienische Partei jetzt, konsequent nach den Beschlüssen von Lugano zu verfahren. ${ }^{362}$ Ferner protestierte die BSP damals dagegen, da $B$ ihre Antwort auf das Zirkular der SDAP , has been misconstrued to be an expression of our agreement that the powers conferred upon the Belgian comrades [. . .] should be transferred from them to the Dutch comrades"; man habe den holländischen Vorschlag so verstan-

358 Vliegen an Huysmans, 2.11.1914, ISB-Archiv, Mf. III.

359 Vliegen und Van Kuykhof an Troelstra, 30.10.1914, NT 558/12: ,Wij zijn overtuigd, dat die pogingen mislukking der heele overbrenging van het Bureau voor gevolg zouden hebben. Wij meenen hieruit te moeten concludeeren, dat het voor die overbrenging niet nodig is, uwe reis verder voort te zetten. / De vraag van een internationale conferentie kan onderwerp van bespreking uitmaken op de eerste vergadering van het Comité Exécutif."

360 ,,Sitzung der Geschäftsleitung [. . .] 13. November 1914”, a.a.O.

$361 \mathrm{Vgl}$. Protokoll über die Verhandlungen des Parteitages vom 31. Oktober und 1. November 1914, abgehalten im neuen Volkshause in Bern, Anhang zu: Jahrbuch der Sozialdemokrat[ischen] Partei der Schweiz und des Schweizerischen Grütlivereins (Jahresbericht und Protokoll) 1914, Zürich 1915, S. 41f. (Resolution).

${ }^{362}$,Sitzung der Geschäftsleitung [. . .] 13. November 1914”; Studer an Troelstra, 3.11.1914, NT 577/11-12: ,Ich habe nun auch die Antwort aus Italien. Die dortigen Genossen wollen, daß wir das I.S.B. übernehmen." 
den, ,,that, for the time being, facilities should be provided for the Belgian comrades to carry on the work of the Bureau in neutral territory"; den Vorzug habe man dabei der Schweiz gegeben. ${ }^{363}$

Gegen Troelstras Änderung des Konferenzplans protestierten ebenfalls die Skandinavier. Man sei, ließ Stauning, der die beiden anderen Parteien unterrichtet hatte, Troelstra wissen, ,,etwas verduzt" darüber, ,da $B$ der Plan, über welchen wir uns in Stockholm einig geworden waren, verändert werden soll". ${ }^{364}$ Aber in den Gesprächen, zu denen Borgbjerg am 1. November in Bern eintraf, konnte Troelstra sich weitgehend durchsetzen: sein Plan wurde nur dahingehend modifiziert, $\mathrm{da} B$ an der nach Kopenhagen einzuberufenden Konferenz außer den skandinavischen Parteien und der SDAP noch - als ,Gäste" - Delegierte der SPS, die zugleich die italienische Partei vertreten sollten, und der SPA teilnehmen sollten; die Parteien der kriegführenden Länder sollten Berichte schicken dürfen. ${ }^{365}$

Anscheinend hatte Grimm, der für die SPS an der Besprechung teilgenommen hatte, zunächst die Absicht, selbst zu jener Konferenz zu fahren. ${ }^{366}$ Aber nachdem Studer, der an sich die Teilnahme der SPS befürwortete, am 10. November an Stauning geschrieben hatte, daß auch die Italiener einzuladen wären, zumal sie das ,,für Holland günstiger stimmen würde", ${ }^{367}$ sprach sich die Geschäftsleitung am 13 . November gegen eine Teilnahme der SPS aus. Statt dessen beharrte die SPS auf dem ursprünglichen Projekt einer Konferenz der Parteien aller neutralen Länder, die auch , über die Zuteilung des intern[ationalen] Bureaus entscheiden” würde. ${ }^{368}$ Dieses Projekt hatte Studer in seinem Brief an Troelstra vom 3. November noch einmal erläutert.

Sind einmal die Organisationen [der neutralen Länder] entschlossen, die Internationale fortzusetzen oder auch neu zu constituieren, und erlassen sie ein klares, entschiedenes Manifest [ . . .], bleiben sie neutral und nehmen nicht für oder gegen die eine oder andere der kriegführenden Parteien Stellung, dann ist schon sehr viel gewonnen. Es wird den andern Bruderorganisationen der kriegführenden Länder dann viel leichter, sich uns wieder anzuschließen.

${ }^{363}$ Inkpin an Troelstra, 30.10.1914, NT 543/37. Vgl. Anm. 311. Vgl. auch den von Vandervelde am 8. November an Albarda bzw. Troelstra übersandten Brief von Inkpin an Vandervelde, 4.11.1914, NT 561/8-9.

364 Stauning an Troelstra, 29.10.1914, NT 556/51-52 (Troelstra erhielt den Brief über Studer).

$365 \mathrm{Vgl}$. ,Aus der proletarischen Internationalen”, in: Berner Tagwacht, 1914, Nr 257

(3.11.); Graß, Friedensaktivität, S. 112f.

$366 \mathrm{Vgl}$. unten.

367 Studer an Stauning, 10.11.1914, ABA.

368 ,Sitzung der Geschäftsleitung [. . .] 13. November 1914”. 
Nur seiner eigenen Meinung verlieh Studer Ausdruck, wenn er im gleichen Brief, die Amsterdamer Regelung akzeptierend, schrieb: ,Uns Schweizern ist der Vorort gleich, wenn nur etwas geschieht. Meine persönliche Meinung ist, daß Sie, lieber Troelstra, unbedingt die Leitung erhalten sollten". ${ }^{669}$ Dagegen trug die Berner Tagwacht, die am 2. November - nach dem Vorwärts - über jene Regelung berichtet hatte, ${ }^{370}$ am nächsten Tag ,,ergänzend" nach,

daß wahrscheinlich unter diesen Umständen die Verlegung [des ISB] nicht stattfindet, und daß sich daher die Konferenz von Kopenhagen auch mit der Frage zu beschäftigen haben wird, ob außerhalb des internationalen $\mathrm{Bu}$ reaus nicht eine Auskunftsstelle und Vermittlungsstelle für die sozialistischen Parteien der neutralen Länder geschaffen werden soll. ${ }^{371}$

Während es bei der ,,Vermittlungsstelle" für die Parteien der neutralen Länder um eine Idee von Grimm ging, ${ }^{372}$ die derselbe hier erneut lancierte, entsprach die erste Feststellung - so scheint es - der spontanen Reaktion von Troelstra, der gegen die Amsterdamer Regelung - darin vom deutschen Parteivorstand, den er anscheinend telegraphisch befragt hatte, bestärkt $t^{373}$ - erhebliche Bedenken hatte..$^{374}$ Jedenfalls war Troelstra nicht geneigt, auf ihrer Basis zu versuchen, die Franzosen doch noch umzustimmen. Am 5. November telegraphierte er von Zürich aus an Albarda, daß er am 7. November zurückkommen würde. ${ }^{375}$

Heimgekehrt nach Holland, machte Troelstra keinen Hehl daraus, daß er enttäuscht war. Er habe - erklärte er in der Sitzung des Parteivorstands am 14. November - gemeint, ,daß das Büro durch die Verlegung eine Art Vermittlungsbüro geworden wäre, ein Ort, wo man einander finden könnte". ${ }^{376}$ Dieser Gedanke habe - außer bei den Franzosen - überall eine positive Resonanz gefunden. Der nun getroffenen Regelung könne er, soweit sie ein Schritt in der erwünschten Richtung sei, im Prinzip zustim-

${ }^{369}$ Studer an Troelstra, 3.11.1914, a.a.O.

370 Vgl. ,,Verlegung des Internationalen Bureaus”, in: Vorwärts, 1914, Nr 208 (31. 10.); ,,Das internationale sozialistische Bureau”, in: Berner Tagwacht, 1914, Nr 256 (2.11.). 371 ,Aus der proletarischen Internationalen", a.a.O.

372 Grimm hatte diesen Vorschlag bereits in der Besprechung am 31. Oktober gemacht. Vgl. Anm. 346.

${ }_{373} \mathrm{Vgl}$. Ebert an Troelstra, 2.11.1914 (Telegr. nach Bern), NT 577/8: ,,nach unserer meinung kann bureau im haag nur unter holländischer verwaltung und verantwortung geführt werden."

$374 \mathrm{Vgl}$. unten.

375 Vgl. Albarda an den Parteivorstand der SDAP, 5.11.1914, SDAP-Archiv, Mappe 2084.

376 ,,Vergadering van het Partijbestuur 14 November 1914”, SDAP-Archiv, Mappe 26: ,,dat door de overbrenging van het bureau dit zou geworden zijn een soort vermittlungsbureau, een plaats, waar men elkander zou kunnen vinden". 
men; aber die den holländischen Vertretern zugedachte abhängige Stellung sei in keinem Falle akzeptabel: sie wären nur ,,Hilfskräfte des belgischen Komitees". ${ }^{377}$ Obwohl die Zustimmung fast sämtlicher Parteien dazu vorlag, ${ }^{378}$ war er jetzt geneigt, die Verlegung des ISB, die in Kopenhagen ohnehin zur Sprache kommen würde, erst einmal auf sich beruhen zu lassen. $\mathrm{Zu}$ dem Unmut über die Intransigenz der Franzosen ${ }^{379}$ kamen Zweifel, ob die nun getroffene Regelung von den Belgiern ernst gemeint sei; jedenfalls lehnte er für seine Person den Eintritt in die belgischholländische Exekutive ab: ,,er will seine Hände freihalten für die Arbeit für die Internationale". ${ }^{380}$ Er befürchtete, was Rosa Luxemburg zu dieser Zeit hoffte: daß ihn die Verlegung des ISB in der nun ins Auge gefaßten Form bei der Verfolgung seiner Ziele vielmehr hemmen würde.

\section{9. ,Wie fein Huysmans das mit dem Internationalen Büro gewendet hat"}

Das Schreiben vom 9. November läßt erkennen, daß Rosa Luxemburg, die gegen die in dem Zirkular der SDAP vom 2. Oktober angeregte Verlegung des ISB nach Holland anscheinend zunächst nichts einzuwenden gehabt hatte, sich hinters Licht geführt fühlte. Wann hatte sie gemerkt, daß sie von unzutreffenden Prämissen ausgegangen war?

Da eine schriftliche Antwort von ihr auf das Zirkular nicht vorliegt, ${ }^{381}$ ist anzunehmen, daß sie ihre Antwort Troelstra mündlich gab; denn es ist schwer vorstellbar, daß er sie in Berlin nicht aufsuchte bzw. traf. Allerdings ist in den Reisbrieven ein Hinweis nicht enthalten. Daß er sie dort nicht namentlich erwähnte, wäre noch erklärlich: denn er schrieb die Reisbrieven bereits im Hinblick auf die intendierte Wiederherstellung der Internationale, ${ }^{382}$ weshalb er von seinen Berliner Gesprächspartnern fast ausschließlich Exponenten des Zentrums - Kautsky, Haase, Bernstein - namentlich erwähnte, die bestritten, da $B$ die Internationale tot sei. ${ }^{383}$ Auffallend ist

37 Ebd.: ,,een hulpkracht van het Belgische comité”.

$378 \mathrm{Vgl}$. Anm. 354.

379 Entgegen der gehegten Hoffnung lehnten die Franzosen auch die Amsterdamer Regelung ab. Dubreuilh an Van Kol, 3.11.1914 (Telegr.), NT 563/9; ders. an Van Kuykhof, 12.11.1914, SDAP-Archiv, Mappe 2127. Vgl. auch Albarda an den Parteivorstand der SDAP, 5.11.1914, ebd., Mappe 2084.

380 ,,Vergadering van het Partijbestuur 14 November 1914", a.a.O.: , ,hij wil zijn handen vrij houden voor het werken in het belang van de Internationale".

$381 \mathrm{Vgl}$. Anm. 354.

382 [P. J. Troelstra,] ,Het geval-Kuyper”, in: Het Volk, Nr 4500 (5.12.1914).

383 Vgl. Troelstra, , Internationale Reisbrieven”, $\mathrm{Nr} 4468,4470$, 4472; ferner: Aufzeichnungen über eine Unterredung mit Haase (vgl. ebd., Nr 4468), NT 576/2-3. Vgl. auch David, KTB, 30.10.1914, S. 57: ,, Troelstra veröffentlicht in Het Volk seine Reiseergebnisse aus Deutschland. Leider gibt er die Anschauungen Haases als maßgebend für die deutsche Partei." 
aber, daß Troelstra nirgends eine Reaktion der polnischen Partei, d.h. der SDKPiL, erwähnt, was er, wenn sie positiv gewesen wäre, kaum versäumt hätte. Jedoch ist denkbar, daß Rosa Luxemburg, nachdem sie erfahren hatte, daß die Zustimmung der Belgier noch nicht vorlag, ausdrücklich die ihre von der jener abhängig gemacht hatte. ${ }^{384}$

Ebenso ist denkbar, daß die Unterredung einen unerfreulichen Verlauf nahm, d.h. daß es zu einer scharfen Kontroverse kam, in der sich zeigte, daß die Kluft, die ihre Positionen trennte, nicht mehr überbrückbar war. Für Rosa Luxemburg war vor der Wiederherstellung der Internationale eine - erst nach dem Krieg mögliche - Klärung innerhalb der einzelnen Parteien, insbesondere der deutschen, nötig, die auf eine Spaltung hinauslief, nämlich

[eine] Abschnürung von Elementen, die eigentlich zum bürgerlichen Lager gehören [. . .], auf der anderen Seite von Elementen, die den Kern des revolutionären Klassenkampfes und des Internationalismus nicht preisgeben wollen. ${ }^{385}$

Für Troelstra hingegen kam es primär darauf an, die nationalen sozialistischen Parteien, die es, im Hinblick auf die kommenden Ereignisse, soweit es ging, intakt zu halten galt, möglichst bald einander anzunähern, so daß sie gemeinsam auf den Frieden hinarbeiten, die Gestaltung desselben wirksam beeinflussen konnten. Zu der wenig später vom Parteitag der SPS angenommenen, von Otto Lang begründeten Resolution zum Krieg, in der es hieß, ein dauerhafter Friede könne nur ,,durch den unversöhnlichen, international geführten Klassenkampf des Proletariats" vorbereitet werden, ${ }^{386}$ bemerkte er in seinen Reisbrieven schroff, sie biete zu einer Zeit, da jedem denkenden Sozialisten die bisherige Taktik problematisch scheinen müßte, kritische Besinnung nötig sei, erneut nur die bekannten Phrasen,

eine Aufforderung zum ,, unversöhnlichen" Klassenkampf, ein Wort, das im Munde eines gemäßigten Mannes wie Lang nichts besagt und das im Munde derer, bei denen es durchaus etwas besagt, z.B. bei Dr. Anton Pannekoek und seinen Freunden hier und anderswo, eine so gründliche Änderung der bisher befolgten Taktik bedeutet, daß jede sozialdemokratische Partei [ . . ] es sich gründlich überlegen würde, bevor sie zu dieser Taktik - der berühmten ,Massenaktion" - überginge.

Was aber die Zukunft der vielkritisierten deutschen Partei betreffe, so sei diese noch nicht klar.

384 Dies hatten jedoch auch die Österreicher getan. Vgl. Anm. 342.

385 Rosa Luxemburg an Moor, 12.10.1914, S. 14f.

$386 \mathrm{Vgl}$. Anm. 361. 
$\mathrm{Zu}$ all dem, was der Krieg dem Proletariat bereits gebracht hat, wird wahrscheinlich in manchen Ländern auch noch das Elend einer Verschärfung der inneren Gegensätze kommen. Auch ich erwarte, sobald in Deutschland Feder und Zunge wieder frei sind, ein neues Dresden, es sei denn, daß der weitere Verlauf des Kriegs in Deutschland klare neue Perspektiven für eine kraftvolle gemeinschaftliche Aktion für den Frieden eröffnet [. . .]. Sollte das passieren, wird m.E. die Partei eher zu mehr positiver Arbeit als früher gerufen, in der Nation verstärkt, von alten Formen und Vorurteilen befreit werden, als daß die Chance einer Änderung ihrer Taktik in Richtung auf den ,,unversöhnlichen" Klassenkampf bestünde.

Die Erfahrung des Kriegs lehre aber insbesondere eines,

daß nämlich der Kampf gegen den Militarismus nicht national, [ . . ] sondern nur international zu führen ist. Man suche also vor allem nach einer neuen Form der Aktion für internationale Abrüstung und Schiedsgerichte $\left[\right.$. . . ]. ${ }^{387}$

Wenn es in Berlin zum offenen Zusammenstoß gekommen wäre, könnte das erklären, weshalb Troelstra Rosa Luxemburg nicht nur in den Passagen über seine Reise, sondern überhaupt in den die Kriegsjahre betreffenden Kapiteln seiner Memoiren nicht ein einziges Mal erwähnt. ${ }^{388}$ Die erwähnte Schilderung der Züricher Sitzung des ISB im September 1911, gemäß der sie dort so vehement für einen Massenstreik im Kriegsfall eintrat, sowie die der Brüsseler Sitzung Ende Juli 1914, gemäß der sie so beredt darüber schwieg, erhielten danach einen neuen Sinn: während darin zunächst nur eine gewisse Sympathie für einen radikalen Standpunkt zum Ausdruck zu kommen schien, den Troelstra an sich selbst gern eingenommen hätte, hätten sie in Wahrheit vielmehr die Tendenz, denselben in diskreter Form zu denunzieren. Schon zu Beginn des Krieges hatte Troelstra nicht verhehlt, daß er von einer ,Massenaktion" nicht viel hielt; ${ }^{389}$ je mehr die radikale Opposition erstarkte, der er sich in Holland konfrontiert sah, desto dezidierter kritisierte er die Ansichten, die sie verkündete. Gerade damals aber, im Oktober 1914, mußte er erkennen, daß die holländischen Radikalen internationale Unterstützung fanden; am 20.-22. Oktober brachte die Berner Tagwacht einen großen Artikel Pannekoeks unter dem Titel ,Der Zusammenbruch der Internationale”, der - daher der zitierte Passus in den Reisbrieven - den Beifall der gesamten radikalen Linken fand. ${ }^{390}$

387 Troelstra, ,Internationale Reisbrieven”, Nr 4480.

388 Auf dieses Faktum hat besonders Mellink, ,De Gedenkschriften van Troelstra”, a.a.O., S. 21f., hingewiesen.

389 Vgl. u.a. [Troelstra,] ,,Het Proletariaat en de Oorlog”, a.a.O.

390 Ant[on] Pannekoek, ,Der Zusammenbruch der Internationale”, in: Berner Tagwacht, 1914, Nr 245 (20.10.), Nr 246 (21.10.), Nr 247 (22.10.). 
Rosa Luxemburg dagegen erfuhr ihrerseits zu jener Zeit, zu der sich Troelstra in Berlin aufhielt, von Plänen Axel'rods und Grimms, die ihren eigenen Ideen weitaus mehr entsprachen; es ging um ,,die durch R[adek] übermittelte Anregung", auf die sich Liebknecht in dem zweiten Brief an Grimm bezog. ${ }^{391}$ Am 23. Oktober schrieb Radek, der erst einige Tage vorher von Bern nach Berlin gekommen war, an Henke:

Axelrod und Grimm sind der Meinung, man müsse mit allen Kräften eine private Konferenz Radikaler aus Frankreich und Deutschland vorbereiten, die in der Schweiz zusammenkommen müßten, um zuerst gemeinsam den Charakter des Krieges und dann ein gemeinsames Wirken [zu] besprechen. Grimm sucht mit Paris und Bordeaux Fühlung zu nehmen. Hier soll ich mit Leuten verhandeln, die ev[entuell] Verständigungsschritte unternehmen. Schreiben Sie, was Sie darüber denken, ob Sie Rücksprache mit Dittmann (trotz alledem), Dißmann, Westmeyer, Crispien nehmen wollen. [. . .] Wie gesagt: die Konferenz hat rein informatorischen Charakter über Ansichten, kann also für die hohe Hermandad [d.h. den Parteivorstand] keinen AnlaB zur Aktion bilden. ${ }^{392}$

Abgesehen davon dürfte Rosa Luxemburg wohl über Troelstras Pläne, selbst wenn er sie ihr nicht selbst erläutert hätte, mittlerweile - etwa über Hilferding ${ }^{393}$ - im Bild gewesen sein. Zudem dürfte sie die Weise, in der Troelstra den deutschen Parteivorstand poussierte, zunehmend irritiert haben. Jedenfalls war das $\mathrm{Maß}$ voll, als Troelstra sogar noch im Auswärtigen Amt vorsprach, wo ihn in Abwesenheit Jagows Unterstaatssekretär Zimmermann empfing. ${ }^{394}$ Der Vorwärts informierte über diese Unterredung, um die Troelstra über die deutsche Gesandtschaft in Den Haag nachgesucht hatte, um aus berufenem Mund zu hören, ob die deutsche Regierung die holländische Neutralität zu achten gewillt sei, am 31. Oktober - unmittelbar unter der Notiz, in der er über die Amsterdamer Regelung in Sachen ISB berichtete. ${ }^{395}$ Sich darauf beziehend, schrieb Rosa Luxemburg einige Tage später schadenfroh an Kostja Zetkin:

Wie fein Huysmans das mit dem Internationalen Büro gewendet hat, nicht?

$391 \mathrm{Vgl}$. Anhang, Nr 3 c.

$392 \mathrm{R}$ [adek] an Henke, 23.10.[1914], a.a.O.

393 Vgl. Tagebücher Otto Brauns, 17.10.1914: ,,wie Mittags, wo uns, obwohl ungeladen, der jetzt so treue Partner der Rosa in der Fronde gegen den P[artei-]V[orstand] Monsieur Hilferding [. . .] beehrte". Troelstra, Gedenkschriften, Bd 4, S. 13: „Kautsky, Hilferding en Haase, welke wij eveneens vaak ontmoetten".

$394 \mathrm{Vgl}$. Troelstra, ,Internationale Reisbrieven”, $\mathrm{Nr} 4466$.

395 Vgl. ,Troelstra über seinen Besuch im Auswärtigen Amt”, in: Vorwärts, 1914, Nr 298 (31.10.). 
Auch die Absage der Franzosen an die Troelstra \& Co. ist fein. Tr[oelstra]s Besuche in den deutschen Ministervorzimmern rechtfertigen das vollauf. ${ }^{396}$

Allerdings sah Rosa Luxemburg zu einer öffentlichen Stellungnahme zunächst keinen Grund. $\mathrm{Zu}$ dem Schreiben vom 9. November sah sie sich wohl erst durch das veranlaßt, was sie von Clara Zetkin erfuhr, nachdem diese am 7. November aus der Schweiz zurückgekehrt war. ,Elle a fait bonne besogne", schrieb Rosa Luxemburg am 10. November an Huysmans, ,et appris quantité de jolis trucs de nos ,patres conscripti' à l'étranger." 397

Clara Zetkin, seit 1907 internationale Sekretärin der sozialistischen Frauen, wollte ihr Amt nutzen, um eine internationale Aktion gegen den Krieg zu organisieren; dazu hatte sie, Kontakt zu schweizerischen und zu italienischen Sozialisten suchend, zunächst am Parteitag der SPS in Bern teilgenommen. Möglicherweise ging auf ihre Anregung der Beschluß des Parteitags zurück, Rosa Luxemburg ein Sympathietelegramm zu senden, nachdem das Reichsgericht am 22. Oktober das Frankfurter Urteil vom Februar - ein Jahr Gefängnis wegen antimilitaristischer Agitation bzw. „Aufforderung zum Ungehorsam gegen die Gesetze" - bestätigt hatte. ${ }^{398}$ Von Bern war Clara Zetkin nach Lugano gefahren, wo sie Angelica Balabanoff getroffen hatte. Einen besonders engen Kontakt hatte sie - vermutlich die ,,durch R[adek] übermittelte Anregung" aufgreifend - zu Grimm geknüpft, den sie von Lugano aus nochmals beschworen hatte:

Behalten Sie nur die Notwendigkeit im Auge, sobald als möglich einen sicheren Verkehr zu organisieren. ${ }^{399}$

Einen geplanten ,Ausflug” nach Mailand hatte sie nicht realisieren können; am 6. November schrieb sie darüber von Zürich aus an Grimm:

Die gute A[ngelica] rieth mir im Namen der Freunde dringend ab. Die Verschärfung der Lage hat auch eine Verschärfung aller Maßregeln gegen Ausländer gebracht. [ . . ] Filippo [Turati] ist sehr krank [. . .]. Wie die Dinge lagen, war es das Klügste, $\mathrm{A}$ [ngelica] genau zu informieren. Ich kann mich absolut auf sie verlassen. Wenn Sie ihr noch nicht die ,,[Berner] Tagw[acht]" mit den Berichten [über den Parteitag] geschickt haben, so

396 Rosa Luxemburg an Kostja Zetkin, [vor dem 19.11.1914,] RLGB, Bd 5, S. 24. Zur Absage der Franzosen vgl. Anm. 344-45; ,,Die französische Partei und die Internationale", in: Vorwärts, 1914, Nr 301 (3.11.), 1. Beilage.

397 An Huysmans, 10.11.1914, S. 67.

398 Vgl. Quack, Geistig frei, a.a.O., S. 80ff.; Protokoll der Verhandlungen des Parteitages, a.a.O.

${ }^{399}$ Clara Zetkin an Grimm, 4.11.1914, NachlaB Grimm/Zimmerwald-Bewegung, Suppl. 
thun Sie es bitte ja. [. . .] Es wäre gut, wenn Sie ihr auch Pannekoeks Artikel über die Internationale zustellen ließen.

Aus dem gleichen Brief geht hervor, daß in den vertraulichen Gesprächen, die Clara Zetkin und Grimm in Bern geführt hatten, auch die Pläne Troelstras eine Rolle gespielt hatten, denen beide ziemlich kritisch gegenüberstanden. Es ist nicht ausgeschlossen, daß sie in ihrem Mißtrauen noch sei es direkt, sei es indirekt - durch Lenin bestärkt wurden, der damals alarmiert durch die Berichte, die ihn aus Stockholm erreichten - nachdrücklich vor Troelstra warnte.

Am 23. Oktober hatte Troelstra in Stockholm Vertreter der beiden Fraktionen der russischen Partei getroffen, die ihn über deren Haltung zum Krieg informiert hatten. ${ }^{401}$ Der Vertreter der Bolschewiki, Šljapnikov, hatte dies auf seine Bitte dann noch einmal in Form eines Briefs getan. ${ }^{402}$ Wenngleich Troelstra die Berechtigung der Vorwürfe bezweifelt hatte, die Sljapnikov der deutschen Partei gemacht hatte, weil sie sich nicht gegen den Krieg gewandt hatte, hatte ihm das, was er erfahren hatte, ,,in bezug auf einen bedeutsamen Punkt eine neue Sicht auf diesen Krieg [...] gegeben". So wenig die englischen und die französischen Sozialisten darauf verweisen könnten, daß die Truppen der Entente dem deutschen Volk die Freiheit brächten, so wenig treffe es $z u, d a ß$ die deutschen Truppen den Sturz des Zarismus herbeiführen könnten; im Gegenteil - der Krieg habe die revolutionäre Bewegung in Rußland selbst geschwächt.

Die russischen Sozialdemokraten bleiben dem Kampf gegen den Zarismus treu, während sie sich zugleich weigern, seinen Sturz als Frucht der Unterwerfung ihrer Nation durch eine andere zu akzeptieren. Und darin haben sie recht. ${ }^{403}$

Seinerseits hatte Šljapnikov - gleich dem Vertreter der Menschewiki, Larin - die Bemühungen Troelstras um eine schnelle Wiederherstellung der Internationale durchaus begrüßt, was Lenin veranlaßt hatte, ihn - in seinem Brief vom 27. Oktober - über die „Position Kautsky-Troelstra” aufzuklären.

Kautsky hasse und verachte ich jetzt am allermeisten: das ist dreckige, lumpige und selbstzufriedene Heuchelei. Es ist doch gar nichts passiert - so

400 An Grimm, 6.11.1914, ebd.

$401 \mathrm{Vgl}$. die Notizen Troelstras, NT 575/1-10; Troelstra an Ankersmit, 23.10.1914, Nachlaß Ankersmit: ,,Ik had heden een hoogst interessante conferentie met vertegenwoordigers der 2 Russ[ische] soc[iaal-]dem[okratische] partijen, die mij een nieuwen kijk geeft op den oorlog." Ders., , ,Internationale Reisbrieven”, $\mathrm{Nr} 4474$.

402 Schlapnikoff an Troelstra, o.D., NT 556/20-22; 11.12.1914, NT 556/19.

403 Troelstra, ,,Internationale Reisbrieven”, Nr 4474. 
meinte er - , die Prinzipien wurden nicht verletzt, alle hatten das Recht, das Vaterland zu verteidigen. Der Internationalismus - man beliebe zu sehen besteht eben darin, daß die Arbeiter aller Länder ,,im Namen der Vaterlandsverteidigung" aufeinander schießen.

Rosa Luxemburg hatte recht, als sie bereits vor langer Zeit schrieb, Kautsky sei die ,,Servilität des Theoretikers" eigen [. . .]. Es gibt jetzt für die ideologische Selbständigkeit des Proletariats nichts Schädlicheres und Gefährlicheres auf der Welt als [ . . ] diese abscheuliche Heuchelei Kautskys, der alles vertuschen und verkleistern will [. . .]. Wenn Kautsky das gelingt, wird er zum Hauptvertreter der bürgerlichen Fäulnis in der Arbeiterbewegung. Und Troelstra wird für ihn sein - oh, dieser Troelstra ist ein gerissenerer Opportunist als der ,,biedere" alte Kautsky! [ . . .] Niemals werde ich vergessen, wie Henriette Roland Holst, als sie einmal bei mir in Paris war, von Troelstra sagte: ,,ein hundsgemeiner Kerl” (auf französisch gredin) ... [. . ] Troelstra + das Opportunistenpack im Vorstand der deutschen Sozialdemokraten zetteln jetzt eine gemeine Intrige an, um alles zu vertuschen. Seien Sie auf der Hut, daß Sie nicht zum unfreiwilligen Opfer dieser Intrige werden!! [ . . .] Der einzige, der den Arbeitern die Wahrheit gesagt hat [. . .], das ist Pannekoek, dessen Artikel wir Ihnen zugeleitet haben [. . .]. Seine Worte, daß es ,,ohne jede Bedeutung sein wird", wenn jetzt die ,Führer” der von den Opportunisten und von Kautsky zu Tode beförderten Internationale sich versammeln und sich anschicken, die Risse „,zusammenzukleistern” - diese Worte sind die einzigen sozialistischen Worte. Das ist die Wahrheit. ${ }^{404}$

Am 31. Oktober schrieb Lenin nochmals an Šljapnikov:

Troelstra hat Sie betrogen oder genasführt. Er ist ein Erzopportunist und Intrigant im Dienste des niederträchtigsten Zentrums der niederträchtigsten Opportunisten - der deutschen Sozialdemokraten [. . .]. Auf keinerlei Konferenzen, auf keinerlei Schritte werden wir uns einlassen, die auf Initiative solcher Schufte unternommen werden, sondern wir werden uns abseits halten: sollen sie sich allein blamieren! [ . . .] Pannekoek hat recht: die II. Internationale ist endgültig gestorben. ${ }^{405}$

Anscheinend sah Clara Zetkin Troelstras Rolle - nach allem, was sie in der Schweiz erfahren hatte - ähnlich. Sich auf einen in Zürich vorgefundenen Brief beziehend, in dem Grimm sie u.a. über den Besuch von Borgbjerg informiert hatte, schrieb sie - in der Annahme, daß der Parteivorstand der SPD eine Beteiligung der Parteien der kriegführenden Länder gewünscht habe - in ihrem Brief vom 6. November:

Unter den vorliegenden Umständen würde die Sache darauf hinauslaufen, daß von den kriegführenden Staaten Deutschl[and] allein vertreten wäre.

404 Lenin an Šljapnikov, 27.10.1914, Werke, Bd 35, S. $142 f$.

${ }_{405}$ An Śljapnikov, 31.10.1914, ebd., S. 145f. 
Das ist wohl auch der Zweck. Ich glaube, es ist nothwendig, daß Sie Ihren Widerspruch aufrecht erhalten und nur für eine Konferenz der Neutralen sind. Jedenfalls müssen wir danach trachten, daß unsererseits sobald als möglich Jemand nach Skandinavien geht, das planmäßig von dem P[artei-] V[orstand] bearbeitet wird. Ihr Schwyzer seid ihm offenbar zu neutral. Wenn etwas in der Sache zu melden sein sollte, so thun Sie es auf offener Karte - falls keine bessere Gelegenheit da ist, und schreiben Sie von einer beabsichtigten Familienmusikaufführung zu Ehren der goldenen Hochzeit Ihrer Großeltern, der P[artei-]V[orstand] ist die 1., Holland die 2. Violine etc. ${ }^{406}$

Aus Rosa Luxemburgs Brief an Huysmans vom 10. November geht hervor, $\mathrm{da} B$ sie bereits einen ersten Bericht Clara Zetkins erhalten hatte. Auf Grund desselben hielt sie es dann wohl für besser, ihre Haltung zu den Plänen Troelstras öffentlich klarzustellen. Möglicherweise wurde sie in dieser Absicht noch bestärkt durch einen am 8. November im Vorwärts erschienenen Artikel, in dem u.a. die Passagen aus den Reisbrieven zitiert waren, in denen Troelstra die Ansichten Kautskys zur Frage der Internationale referiert hatte:

Kautskys Antwort auf meine Frage: Ist die Internationale tot? lautete: Nein! Gewiß ist ihr Zusammenhang loser geworden. Es sind Gegensätze vorhanden, aber keine prinzipieller Art. Keine der sozialistischen Parteien der Welt [ . . ] nimmt eine Haltung ein, die ihr Verbleiben in der Internationale unmöglich macht. [. . . ] Die Friedenswünsche und die Friedenspropaganda werden die internationalen Beziehungen wieder verstärken, und die sozialistischen Parteien [. . . ] werden sich bemühen, gemeinschaftlich einen für alle Nationen heilsamen Frieden herbeizuführen, so daß nach dem Friedensschluß die Internationale wieder kräftig und geschlossen dasteht. ${ }^{407}$

Von dieser Art ,,beruhigenden Versicherungen mancher Genossen, die Internationale sei ja nicht tot, ja es sei nur ein leicht zu verklebender Riß, der in ihr entstanden sei", setzte sich Rosa Luxemburg in ihrem Schreiben vom 9. November deutlich ab. Sie wiederholte ihrerseits, was sie bereits in ihrem Brief an Moor vom 12. Oktober erklärt hatte: was dem internationalen Sozialismus nottue, sei ,,vor allem eine ehrliche und offene Abrechnung mit seinem eigenen schmachvollen Bankerott in diesem Kriege"; der Wiederaufbau der Internationale komme erst in Frage, wenn ,,in jedem

406 Clara Zetkin an Grimm, 6.11.1914, a.a.O.

407 , "Troelstra und die Haltung der deutschen Sozialdemokratie”, in: Vorwärts, 1914, Nr 306 (8.11.). Nach dem Bericht der Berner Tagwacht hatte sich Troelstra ähnlich auf dem Parteitag der SPS ausgesprochen: ,,Man sagt, die Internationale sei tot. Sie kann aber nicht tot sein; sie kann nur tot sein, wenn der Kapitalismus tot ist und sie sich in die Internationale der Menschlichkeit auflösen kann.”, Der Parteitag in Bern”, in: Berner Tagwacht, 1914, Nr 256 (2.11.). 
Lande eine innere Klärung und Entscheidung der sozialistischen Partei über ihre Stellung zum Militarismus stattgefunden hat". Durchblicken lassend, daß sie in dem holländischen Vorstoß einen perfiden Überrumpelungsversuch sah, sprach sie sich, was die Verlegung des ISB betraf, für die Amsterdamer Regelung aus, wobei sie als Bedingung der Möglichkeit dieser Regelung präsentierte, was für sie wohl eher die erhoffte Wirkung war: daß die Exekutive des ISB, die, ,,solange unsere belgischen Freunde sich bereit erklären, weiter ihres Amtes [. . .] zu walten, [. . .] als einziges legales Organ der Internationale gelten muß", in absehbarer Zeit kaum etwas tun könne. ,Alle Versuche”, stellte Rosa Luxemburg noch einmal fest, ,,so schnell wie möglich eine internationale Konferenz zustande zu bringen, scheinen mir gänzlich verfehlt." Worauf es jetzt ankomme, sei vielmehr, , alles zu vermeiden, was den Zusammenbruch der bisherigen Internationale noch weiter fördert". 408

Am 10. November schickte Rosa Luxemburg das Schreiben, das sie am Vortag ,,à Het Volk, à Stockholm et à Berne", d.h. - die Reihenfolge scheint nicht zufällig - die Redaktionen von Het Volk, Social-Demokraten und Berner Tagwacht, gesandt hatte, ebenfalls an Huysmans, den sie beschwor, auf seinem Posten auszuharren.

Je me félicite de la solution que vous avez trouvée pour le Comité Ex[écutif]. Je vous prie de vous maintenir et de persister à votre poste malgré tous les essais qui pourraient être entrepris pour vous arracher votre mandat ou pour vous persuader d'y renoncer. ${ }^{409}$

Ähnlich drückte sich in seiner kurzen Nachschrift Liebknecht aus, ${ }^{410}$ der zudem in einem Brief, den er am gleichen Tag an Wibaut richtete, Kritik an Troelstra übte, dem er - sei es nicht expressis verbis - vorwarf, er habe ihn beim deutschen Parteivorstand denunziert. Um Wibaut, was seine Haltung zu dem letzteren betraf, nicht im unklaren zu lassen, schickte er ihm - ,nur rein privat" - maschinenschriftliche Abschriften des im Oktober geführten Briefwechsels. ${ }^{411}$

Het Volk brachte Rosa Luxemburgs Schreiben am 18. November; aber in einer Vorbemerkung stellte die Redaktion fest, ihr scheine ,,der Ausfall über den ,Bankrott' der Internationale unnötig übertrieben und die Anspielung am Schluß zutreffender". ${ }^{412}$ Am 21. November erschien das

408 Vgl. Anhang, Nr 4.

*09 Rosa Luxemburg an Huysmans, 10.11.1914, S. 67.

410 Ebd., S. 69.

${ }^{411} \mathrm{Vgl}$. Anhang, Nr 5; Anm. 1; SDAP-Archiv, Mappe 2119 (Liebknecht an den Parteivorstand, 2.10., 10.10., 16.10.1914; Scheidemann an Liebknecht, 23.10.1914; Liebknecht an den Parteivorstand, 26.10., 31.10.1914).

412 ,Het Internationaal Bureau”, in: Het Volk, Nr 4485 (18.11.1914). 
Schreiben auch im Social-Demokraten, wo die Forderung, daß vor einer eventuellen Konferenz zunächst ,,eine ehrliche und offene Abrechnung” vonnöten wäre, ebenfalls zurückgewiesen wurde. ${ }^{413}$ Die Berner Tagwacht brachte es dagegen überhaupt nicht. Statt dessen publizierte sie zunächst am 13. November - einen ebenfalls vom 9. November datierenden Artikel der Sozialdemokratischen Korrespondenz über ,Die Wiederherstellung der Internationalen", ${ }^{414}$ dann - am 18. November - einen Brief des Auslandskomitees der lettischen Partei, das sich, die verschiedenen Versuche einer Reaktivierung der Internationale begrüßend, für die Verlegung des ISB in die Schweiz aussprach; die Redaktion fügte hinzu:

Dazu gleich einigè Bemerkungen. Nach dem von der französischen Partei erfolgten Einspruch gegen die holländischen Vorschläge kann wohl von einer auch nur provisorischen Verlegung des internationalen Bureaus keine Rede sein. [ . . .] Dagegen bleibt es den sozialistischen Parteien der neutralen Länder unbenommen, für sich und vorübergehend eine Auskunfts- und Vermittlungsstelle zu schaffen, die die Rechte des internationalen Bureaus in Brüssel unangetastet läßt. Das war auch der Vorschlag der Konferenz in Lugano [. . .].

Uber diese Frage hätte sich auch die Konferenz, die [ . . . ] nach Kopenhagen einberufen wird, aussprechen sollen. [ . . .] Nachdem aber der italienische Parteivorstand erklärte, es sei an den Beschlüssen von Lugano festzuhalten, d.h. die schweizerische Partei sollte vorläufig den Vermittler- und Auskunftsdienst übernehmen, hat die Geschäftsleitung in Zürich beschlossen, die Einladung nach Kopenhagen abzulehnen und gemäß den Beschlüssen von Lugano die Einberufung einer Konferenz der sozialistischen Parteien aller neutralen Staaten vorzubereiten. ${ }^{415}$

Anscheinend fürchtete Grimm, daß aus Rosa Luxemburgs Schreiben auch eine Kritik an den Beschlüssen von Lugano herausgelesen werden könnte, eine Kritik, die den deutschen Radikalen, soweit erkennbar, fernlag. So machte Liebknecht, der dergleichen selbst empfohlen hatte, in seinem Brief an Wibaut vom 10. November keinen Hehl aus seiner Genugtuung über den Schritt der sozialdemokratischen Fraktion im Schweizer Parlament, die den Bundesrat am 31. Oktober ersucht hatte, sich für eine Vermittlungsaktion der Neutralen einzusetzen. ${ }^{416}$,,Der Versuch [. . .]",

413 ,,Till Aktstyckena. Ett brev från Rosa Luxemburg”, in: Social-Demokraten, 1914, Nr 271 (21.11.).

414 ,Die Wiederherstellung der Internationalen", in: Sozialdemokratische Korrespondenz, Nr 116 (9.11.1914); Berner Tagwacht, 1914, Nr 266 (13.11.). Laut Schleifstein, Franz Mehring, a.a.O., S. 302, war der Verfasser Mehring.

415 , Aus der Internationalen”, Berner Tagwacht, 1914, Nr 270 (18.11.). Der Brief des lettischen Auslandskomitees war der gleiche wie der, den dieses an die SDAP gerichtet hatte. Vgl. Anm. 354.

$416 \mathrm{Vgl}$. Protokoll über die Verhandlungen des Parteitages, S. 13f. 
schrieb er, ,scheint einige Resonanz zu finden. Man muß halt alles thun." ${ }^{417}$ Allerdings fügte er im Hinblick auf die kritische Lage, zu der die Anfang November eingeleitete russische Offensive im Osten geführt hatte, hinzu, es sei jetzt freilich ,,das östliche Problem kolossal kompliziert worden", was zeigt, daß ihn die russische Bedrohung, wo sie ernsthaft schien, durchaus nicht kalt ließ. Das Projekt einer Konferenz der Parteien aller neutralen Länder hatte Clara Zetkin in ihrem Brief an Grimm vom 6. November ausdrücklich unterstützt. ${ }^{418}$

So hatte denn auch Rosa Luxemburg bei ihrer Ablehnung der übereilten Einberufung einer Konferenz wohl nicht in erster Linie letzteres Projekt im Auge. Ebensowenig bezog sich ihre Warnung vor Versuchen, an die Stelle der bisherigen Internationale ,Neues, aus dem Kriege geborenes" zu setzen, primär auf die schweizerischen Pläne. Es erhellt vielmehr aus ihrem Brief an Huysmans, in dem sie schrieb: ,d'y substituer une farce et un leurre", ${ }^{419}$ was gemeint war: eine Aussöhnung der sozialistischen Parteien, die darauf basierte, daß sich diese, ohne vorher die prinzipiellen Fragen zu klären, gegenseitig Pardon erteilten, was - so hatte sie bereits an Moor geschrieben - , hieße, unter dem heuchlerischen Schein der Internationale den internationalen Sozialismus begraben". ${ }^{420}$ Dabei zielte sie wohl nunmehr, besser informiert, auf Troelstras Pläne.

Wenn Rosa Luxemburg, obwohl von dem ,,Bankrott" der alten Internationale überzeugt, dafür plädierte, die Rechte der belgischen Exekutive des ISB, die das ,einzige legale Organ der alten Internationale” war, zu respektieren, so vorzugsweise, um deren verfrühte Ersetzung durch „Neues" zu verhüten. Im Hinblick auf das gleiche Ziel begrüßte sie die Amsterdamer Regelung, die die internationalen Aktivitäten Troelstras an die Zustimmung der Belgier band, d.h. - so meinte sie - wirksam blokkierte. Aber analog der innerhalb der deutschen Partei befolgten Taktik wirkte sie zugleich im überkommenen Rahmen für die Sammlung all der Elemente, die den alten revolutionären Zielen treu geblieben waren daher das in ihrer Postkarte an Grimm vom 16. November bekundete Interesse an einer Begegnung. ${ }^{421}$ Auf Grund des Berichts von Clara Zetkin ging sie davon aus, daß Grimm nach Kopenhagen fahren würde. Clara Zetkin schrieb zwei Wochen später selbst nochmals an Grimm:

Was wird's mit der Konferenz in Kopenhagen? Sie sollten dorthin. Wer auch geschickt wird, suchen Sie es einzurichten, daß er mich besucht und über

${ }^{417}$ Vgl. Anhang, Nr 5; Anm. 439.

$418 \mathrm{Vgl}$. oben, S. 96.

${ }^{419}$ Rosa Luxemburg an Huysmans, 10.11.1914, S. 67.

${ }^{420}$ An Moor, 12.10.1914, S. 15.

${ }^{421} \mathrm{Vgl}$. Anhang, $\mathrm{Nr} 6$. 
Berlin reist, um dort mit Rosa, Karl und den anderen Freunden Rücksprache zu nehmen. ${ }^{422}$

Den überkommenen Rahmen, die ,legalen Organe" respektierte Rosa Luxemburg indessen nur, soweit die revolutionären Kräfte dadurch nicht behindert wurden. Obwohl sie voraussah, daß sich am 2. Dezember im Reichstag ,die Geschichte vom 4. August wiederholen" würde, ${ }^{423}$ tat sie, was sie konnte, um die Gegner der Kreditbewilligung zur Abgabe eines Separatvotums - notfalls gegen den Beschluß der Mehrheit - zu bewegen, so daß diese ,,letzte Gelegenheit [ . . . ], durch eine Erklärung der Minderheit die Ehre [der deutschen Sozialdemokratie] zu retten", nicht versäumt würde. ${ }^{424}$ Als jedoch im Reichstag dann nur Liebknecht gegen die Kredite stimmte, gab sie den diesem gemachten Vorwurf des Disziplinbruchs der Fraktion zurück: Eine Fraktion könne Beschlüsse fassen, die den ,flagrantesten Disziplinbruch gegenüber der Gesamtpartei" darstellten; angesichts dessen, da $B$ in ,,einer demokratischen Partei wie der unseren” die Ansicht und der Wille nicht einer Handvoll von Personen, sondern ,,der großen Mehrheit der Proletarier, der Millionen, die nach reiflicher Prüfung, nach offener, eingehender Diskussion ihre Entschlüsse fassen", maßgeblich seien, blieben für die Dauer des Kriegs, in dem eine freie Diskussion nicht möglich sei, die vor dem Krieg gefaßten Beschlüsse, vor allem das Parteiprogramm, entscheidend.

So bleibt die Tatsache, daß seit dem Ausbruch des Krieges unter dem Schutze des Belagerungszustandes fortlaufend schwerste Disziplinbrüche begangen werden, die die Sozialdemokratie ihrer bisherigen Richtung, ihrer Physiognomie, ihrer Ziele zu berauben geeignet sind. Disziplinbrüche, die darin bestehen, daß einzelne Organe der Partei, anstatt dem Gesamtwillen, d.h. dem Parteiprogramm zu dienen, auf eigene Faust diesen Gesamtwillen beugen.

Aber Rosa Luxemburg erwartete, daß nach dem Krieg ,,die große Mehrheit der Parteigenossen" gegen die Fraktion sein würde. ${ }^{425}$ Die Aufgabe der Opposition - schrieb Clara Zetkin am 3. Dezember an Heleen Ankersmit - bestehe primär darin,

eine Sammlung der zielklaren, entschiedenen Elemente für die unvermeidliche grundsätzliche Auseinandersetzung vorzubereiten. Ich sage die unver-

422 Clara Zetkin an Grimm, 3.12.1914, in Die Zimmerwalder Bewegung, Bd 2, Nr 10, S. 11.

${ }^{423}$ Rosa Luxemburg an Kostja Zetkin, 17.11.[1914], RLGB, Bd 5, S. 25; an Levi, 17.11.[1914], ebd., S. 458.

${ }^{424}$ An Kostja Zetkin, 17.11.[1914], S. 25.

125 [Rosa Luxemburg,] ,Parteidisziplin”, in: [Sozialdemokratische Korrespondenz, Nr 125 (4.12.1914)] RLGW, Bd 4, S. 17. 
meidliche Auseinandersetzung, weil eine solche der entschiedenen Linken bei allen Wünschen der Einheit der Partei durch die Entwicklung der Rechten aufgezwungen wird [. . .]. Es wäre unklug, sich darüber zu täuschen, daß es jetzt eine Minderheit ist. Aber ebenso unklug würde es sein, die Tatsache zu übersehen und zu unterschätzen, daß diese Minderheit unaufhaltsam mit der Dauer des Krieges wächst. ${ }^{426}$

Tatsächlich war das Wachstum der Opposition im Spätherbst unverkennbar. So berichtete z.B. der Polizeipräsident von Berlin am 23. November über die sozialdemokratische Partei seines Bereichs, es hätten in der Woche vorher mehrere Versammlungen stattgefunden, , in denen von einigen Rednern über den Groß-Kapitalismus als Wurzel des Krieges hergezogen, Stellung gegen Annexionen genommen und, freilich gegen lebhaften Widerspruch anderer Redner, der Revisionismus [. . .] gebrandmarkt wurde". ${ }^{427}$ Außer in Berlin hatte die radikale Opposition in Sachsen, Thüringen, am Niederrhein, in Stuttgart, Hamburg, Bremen einen stärkeren Anhang. Aber insgesamt war sie noch schwach; nach einer Schätzung Davids hatte sie Ende Oktober etwa ein Fünftel der Partei auf ihrer Seite. ${ }^{428}$ Nach außen war sie bisher kaum hervorgetreten.

Das änderte sich schlagartig am 2. Dezember. Obwohl von Liebknecht unternommene Versuche, noch weitere der mittlerweile 17 Gegner der Kreditbewilligung in der Fraktion für ein Separatvotum im Plenum zu gewinnen, tatsächlich mißglückt waren, ${ }^{429}$ vielleicht aber auch gerade deshalb, weil seine Abstimmung im Plenum die Tat eines einzelnen war, war ihre moralische Wirkung enorm. Zwar lehnte es der Reichstagspräsident ab, die schriftliche Erklärung, in der Liebknecht seine Abstimmung begründete, in den stenographischen Bericht der Sitzung aufzunehmen; ${ }^{430}$ aber dieselbe wurde - als Nr 1 der sog. ,Spartakusbriefe” - illegal verbreitet. ${ }^{431}$ Überdies erschien sie eine Woche später in der Berner Tagwacht ${ }^{432}$ danach in einer Vielzahl anderer ausländischer Blätter. ${ }^{433}$ Der entscheidende Absatz lautete:

${ }_{426}$ Clara Zetkin an Heleen Ankersmit, 3.12.1914, in: Dies., Ausgewählte Reden und Schriften, Bd 1, S. 643f.

${ }^{427}$ Zitiert nach Wohlgemuth, Die Entstehung, S. 60.

${ }^{428}$ Vgl. David, KTB, 31.10.1914, S. 57.

${ }^{429} \mathrm{Vgl}$. Liebknecht, Klassenkampf, S. 53ff.; Wohlgemuth, Burgkrieg, S. 79ff.

${ }^{430} \mathrm{Vgl}$. Liebknecht, Klassenkampf, S. $63 f$.

${ }^{431} \mathrm{Vgl}$. Spartakusbriefe, hrsg. vom Institut für Marxismus-Leninismus beim ZK der SED, Berlin 1958, S. 3f.

${ }^{432}$,,Die Erklärung Dr. Liebknechts”, in: Berner Tagwacht, 1914, Nr 288 (9.12.).

${ }^{433}$ Vgl. u.a. ,Uit de Duitsche Rijksdagzitting. De verklaring van Karl Liebknecht”, in: Het Volk, Nr 4504 (10.12.1914): ,,Wij ontvangen den volledigen tekst van de schriftelijke verklaring [. . .]." 
Ein schleuniger, für keinen Teil demütigender Friede, ein Friede ohne Eroberungen, ist zu fordern; alle Bemühungen dafür sind zu begrüßen. Nur die gleichzeitige dauernde Stärkung der auf einen solchen Frieden gerichteten Strömungen in allen kriegführenden Staaten kann dem blutigen Gemetzel vor der völligen Erschöpfung aller beteiligten Völker Einhalt gebieten. Nur ein auf dem Boden der internationalen Solidarität der Arbeiterklasse und der Freiheit aller Völker erwachsener Friede kann ein gesicherter sein. So gilt es für das Proletariat aller Länder, auch heute im Kriege gemeinsame sozialistische Arbeit für den Frieden zu leisten. ${ }^{434}$

Besonders im Ausland wurde Liebknechts Name danach zum Begriff, wobei sich aber die Führer der französischen Partei etwa durch seine Abstimmung vor allem in der eigenen Politik bestätigt sahen, ${ }^{435}$ während bei den Parteien des neutralen Auslands der Beifall mehr dem mutigen Protest gegen den Krieg im allgemeinen galt. Nachdem schon Het Volk seiner Freude Ausdruck verliehen, ja selbst die Erwartung ausgesprochen hatte, daß ,,Liebknechts mutig formulierte und wohldurchdachte Erklärung [. . . ] vielleicht in kurzer Zeit [. . .] von der Mehrheit der deutschen Partei als Wahrheit über den Krieg anerkannt würde", ${ }^{436}$ schrieb Wibaut in Het Weekblad:

Zum zweitenmal wird der Name Liebknecht von einem Mann getragen, der den erhabenen Mut hat, Widerstand gegen den Krieg zu leisten zu einer Zeit, da das Kriegführen für das Vaterland von allen im Land, jetzt auch den Sozialdemokraten, als Pflicht akzeptiert ist. [ . . .]

Wir erkennen eine Disziplin an, die von einem Abgeordneten fordert, seine persönliche Einsicht gegenüber dem Parteiprogramm zurückzustellen. Aber eine Disziplin, deren Geltung auf nichts anderem als der Tatsache

434 Liebknecht, Klassenkampf, S. 64. In der von Liebknecht in der Sitzung der Reichstagsfraktion am 29. November 1914 vorgeschlagenen Erklärung hatte der betreffende Passus gelautet: ,Wir erheben die Forderung eines schleunigen, für keinen Teil demütigenden Friedens. Wir danken unseren Freunden in den neutralen Staaten für ihre wertvolle Initiative in dieser Richtung und begrüßen die Friedensbemühungen der neutralen Mächte, deren Zurückweisung nur den Zielen der Annexionspolitik und dem an langer Kriegsdauer interessierten Rüstungskapital entgegenkommt. / Wir warnen die Regierungen und die herrschenden Klassen aller kriegführenden Länder vor der Fortsetzung des blutigen Gemetzels und rufen die arbeitenden Massen dieser Länder auf, seine Beendigung zu erkämpfen. Nur ein auf dem Boden der internationalen Solidarität erwachsener Friede kann ein gesicherter sein. Proletarier aller Länder, vereinigt euch wieder, trotz alledem!" Ebd., S. 60; maschinenschriftliche Abschrift unter dem Titel „,Die von Liebknecht [von dessen Hand eingefügt: am 29.11.14] der sozialdemokratischen Reichstagsfraktion zur Abgabe in der Reichstagssitzung vom 2. Dezember 1914 vorgeschlagene Erklärung", NachlaB Grimm/Zimmerwald-Bewegung, G 1.

435 Vgl. Compère-Morel, ,Heureux symptomes", in: l'Humanité, Nr 3884 (5.12.1914); Pierre Renaudel, ,Bravo, Liebknecht!”, ebd., Nr 3891 (12.12.1914).

${ }^{436}$,De Oorlog. [. . .]”, in: Het Volk, Nr 4504 (10.12.1914). 
beruht, daß ihr Gebot der Wille der Mehrheit ist [ . . ], scheint uns im Falle wichtiger Entscheidungen nicht akzeptabel. [ . . .]

Für uns ist es Karl Liebknecht, der am 2. Dezember richtig gestimmt hat [...]: er hat durch seine Tat das Herz vieler Sozialdemokraten froh gemacht. ${ }^{437}$

Nur wenige sahen, wovor Wibauts Kollege im Parteivorstand der SDAP Jos. Loopuit, bei allem Respekt vor dem persönlichen Mut Liebknechts, warnte: Falls Liebknecht einen starken Anhang habe, sei seine Tat nicht nur ein Ausdruck seines persönlichen Muts, sondern der Auftakt zur Spaltung der Sozialdemokratie, die zu begrüßen niemand Anlaß habe jedenfalls niemand, der auf dem Boden des Programms der SDAP stehe. ${ }^{438}$

Die Führer der radikalen Linken in Deutschland, die indessen in der Arbeit ,für die künftige Organisation”, von der Rosa Luxemburg damals an Kostja Zetkin schrieb, ${ }^{439}$ den ersten Schritt zum Wiederaufbau der Internationale erblickten, versäumten ihrerseits keine Gelegenheit, den anderen sozialistischen Parteien zu erklären, worauf es ihnen dabei ankam. Als der Herausgeber des ILP-Organs The Labour Leader, Archibald Fenner Brockway, bekannte Sozialisten eine Friedensbotschaft für die Weihnachtsnummer einzusenden bat, gingen Liebknecht, Rosa Luxemburg, Mehring und Clara Zetkin, denen die Bitte anscheinend durch Bertha Braunthal und Toni Gernsheim von Rotterdam aus übermittelt wurde, ${ }^{40}$

${ }^{437}$ F. M. W[ibaut], , ,Discipline en Karakter”, in: Het Weekblad, Nr 292 (11.12.1914). $\mathrm{Zu}$ den brieflichen Reaktionen vgl. J. Jemnitz, ,Der Widerhall der Rede Karl Liebknechts im Reichstag am 2. Dezember 1914”, in: Acta Historica Academiae Scientiarum Hungaricae, Jg. 20 (1974), S. 412-19. Laut Jemnitz, der den Fond 210 des Zentralen Parteiarchivs im Institut für Marxismus-Leninismus beim ZK der KPdSU, Moskau, ausgewertet hat, kamen die meisten ausländischen Sympathiekundgebungen aus Holland, darunter eine von Van Kol, der schrieb: „Cher citoyen, dans ces temps où le courage physique fête des orgies, mais où souvent le courage moral ne manque que trop, votre vigoureuse protestation au Reichstag m'a touché jusqu'au fond du coeur. [. . . ] Merci! Karl, pour cette acte, dont l'Internationale Socialiste peut être fière et récoltera les fruits. Même le jour viendra, où les socialistes allemands arracheront le bandeau de leurs yeux, et vous sauront gré de ce que vous avez fait pour leur et notre cause." Ebd., S. 416.

438 Jos. Loopuit, ,,De daad van Karl Liebknecht”, in: Het Volk, Nr 4509 (16.12.1914).

${ }_{439}$ Rosa Luxemburg an Kostja Zetkin, [vor dem 24.12.1914,] RLGB, Bd 5, S. 29.

$440 \mathrm{Vgl}$. Bertha Braunthal an Mathilde Wibaut, 2.12.1914, Nachlaß Wibaut, Mappe 16: , Ich habe Ihnen ja bei meinem Besuche erzählt, daß die Independent Labour Party in England und ihr wöchentliches Organ, der ,Labour Leader', strenge auf dem internationalen Standpunkt stehen und die schärfste Opposition gegenüber dem Krieg und der Regierung an den Tag legen. [. . . ] Der Herausgeber des Labour Leader ersuchte mich nun, mich an deutsche und holländische führende Parteigenossen mit der Bitte zu wenden, für die Weihnachtsnummer des Labour Leader eine Friedensbotschaft einzusenden und sich über den Vorschlag der englischen Genossen, einen Vereinigten 
gerne darauf ein. ${ }^{411}$ Liebknecht schrieb u.a.:

Jede sozialistische Partei hat ihren Feind, den Feind des internationalen Proletariats, im eigenen Lande; dort hat sie ihn zu bekämpfen. [. . .] Der Weltkrieg aber, der die bisherige Internationale zertrümmerte, ist die gewaltigste Predigt für die neue Internationale, eine Internationale freilich anderen Geistes, anderer Entschlossenheit als jene, deren die kapitalistischen Mächte am 4. August 1914 so spielend Herr wurden.

Nur im Zusammenwirken der arbeitenden Massen aller Länder für den Frieden liegt schon jetzt im Kriege das einzige Heil der Menschheit. ${ }^{442}$

Mehring erinnerte an die Parole aus der Zeit des Sozialistengesetzes:

Mit den Führern, wenn diese wollen, ohne die Führer, wenn sie untätig bleiben, trotz den Führern, wenn sie widerstreben. ${ }^{443}$

Rosa Luxemburg endlich legte erneut den Nachdruck auf die ,,rücksichtslose Erkenntnis der begangenen Fehler", um sodann abermals vor der Schaffung einer Internationale zu warnen, die ,,nur ein empörendes Zerrbild des Sozialismus, ein Produkt der Heuchelei" wäre.

Aus diesem Kriege werden die Volksmassen nur noch mit stürmischerem Drang unter unsere alte Fahne der sozialistischen Internationale zurückkehren, nicht um sie bei der nächsten imperialistischen Orgie wieder zu verraten, sondern um sie [. . .] auf den Trümmern des blutigen Imperialismus siegreich aufzupflanzen. ${ }^{444}$

Am 5. Januar 1915 schickte Liebknecht Abschriften der Briefe auch an Grimm zum Abdruck in der Berner Tagwacht, ${ }^{445}$ die - unabhängig davon

Staatenbund von Europa zu gründen, auszusprechen." Laut Jemnitz, ,,Der Widerhall”, a.a.O., S. 415, wurde die Bitte Liebknecht am 3. Dezember 1914 durch Toni Gernsheimer übermittelt.

441 „,German Socialists Want Peace. [. . .]”, in: Labour Leader, 1914, Nr 53 (31.12.). Außer den vier Genannten hatte auch der deutsche Parteivorstand ein Telegramm gesandt, das - umrahmt von deren Briefen - auf der ersten Seite publiziert war. Zum deutschen Text der Briefe Mehrings, Rosa Luxemburgs und Liebknechts vgl. Liebknecht, Klassenkampf, S. 68-73. Clara Zetkin hatte ihren in englischer Sprache geschriebenen Brief von Stuttgart aus direkt gesandt. Vgl. Anm. 445.

442 Liebknecht, Klassenkampf, S. 72.

${ }^{44}$ Ebd., S. 68.

${ }^{444}$ Ebd., S. 69ff.

445 Vgl. Anhang, Nr 7; Anlagen: NachlaB Grimm/Zimmerwald-Bewegung, C 21 (Abschrift des Briefs von Liebknecht), C 23 (Abschrift des Briefs von Rosa Luxemburg), C 25 (Abschrift des Briefs von Mehring). Vgl. ferner Clara Zetkin an Grimm, 7.1.1915, ebd., Suppl. (Kopie): ,,Noch Eins: die Abschrift meiner Zuschrift an den Labour Leader kann ich heute nicht beilegen. Sie ist englisch und lang, und ich möchte sie selbst übersetzen, dazu fehlt mir aber heute die Zeit. Sie erhalten den Text nächste Woche." 
- zwei der Briefe brachte, ${ }^{446}$ wogegen Het Volk, nach Abschriften der Originale, die die Redaktion erhalten hatte, alle vier Briefe veröffentlichte. ${ }^{447}$

\section{Die ersten Schritte der belgisch-holländischen Exekutive}

Unterdessen sollten sich die Hoffnungen, die Rosa Luxemburg, was das ISB betraf, an die Amsterdamer Regelung geknüpft hatte, nicht ganz erfüllen. Am Tag nach der Sitzung des Parteivorstands der SDAP, in der Troelstra seine Enttäuschung zum Ausdruck gebracht hatte, d.h. am 15. November, war Huysmans in Den Haag gewesen, wo sich beide ausgesprochen hatten. Nachdem ihm Huysmans erklärt hatte, er ginge davon aus, $\mathrm{da}$ die Holländer in der Exekutive gleichberechtigt wären, was ebenfalls Anseeles Meinung sei, hatte Troelstra seine Bedenken fallen lassen. ${ }^{448}$ Außer Troelstra und Van Kol bestimmte der geschäftsführende Parteivorstand am 25. November auf dessen Andringen den Sekretär der Fraktion, Albarda, zum dritten holländischen Mitglied. ${ }^{449}$ Allerdings verging noch ein Monat, bis Huysmans in seinem ,,Circulaire I" die dem ISB angeschlossenen Parteien von der Verlegung des ISB nach Den Haag in Kenntnis setzen konnte, wobei er erklärte, daß die Exekutive von Anfang an bestrebt gewesen sei, , de maintenir les relations entre [les] partis affiliés", aber sich darüber klar sei, ,,que le jour de l'action n'a pas encore sonné"; eine Sitzung des ISB daher für verfrüht haltend, bat er - ganz im Sinn des

446 „Franz Mehring über die deutsche Partei”, in: Berner Tagwacht, 1915, Nr 3 (6.1.); „,Rosa Luxemburg über die Internationale”, ebd., Nr 5 (8.1.). Während die Wiedergabe von Mehrings Brief dem deutschen Originaltext entspricht, der demnach bereits im Besitz der Redaktion gewesen sein muB, stützte diese sich laut eigener Angabe bei der vom deutschen Originaltext abweichenden - Wiedergabe des Briefs von Rosa Luxemburg, ,,den wir für die Leser der Tagwacht übersetzen”, auf den Labour Leader.

447 ,Uit de Internationale. Socialistische stemmen uit Duitschland", in: Het Volk, $\mathrm{Nr}$ 4524 (6.1.1915). In der Vorbemerkung der Redaktion hieß es: ,,Wij zijn in de gelegenheid gesteld, de oorspronkelijke Duitsche brieven voor onze vertaling te benutten [. . . ]. Klara Zetkin's brief vertalen wij uit den ,Labour Leader' uit het Engelsch, waarin ook het origineel geschreven werd."

448 Vgl. ,Vergadering van het Partijbestuur 21 November 1914”, SDAP-Archiv, Mappe 26.

499 Vgl. ,Bijeenkomst D.B. 25 November 1914”, ebd., Mappe 26; Albarda an den Parteivorstand der SDAP, 24.11.1914, ebd., Mappe 2084; ders. an Wibaut, 24.11.1914, Nachlaß Wibaut, Mappe 14. - Nach Troelstras Erkrankung wurden im Sommer 1915 Vliegen und Wibaut zu Stellvertretern ernannt - gemäß Troelstras Anregung Vliegen für Van Kol und Wibaut für ihn selbst, um zu verhindern, daß Van Kol und Vliegen, die ihre Sympathien für die Entente nie verhehlten, gleichzeitig der Exekutive angehörten, ,wat het comité zou kunnen blootstellen aan de verdenking - van Duitschen kant - van te zeer bevriend te zijn met de geallieerden". Albarda an Van Kuykhof, 21.8.1915, SDAP-Archiv, Mappe 2084; ders. an Wibaut, 26.8.1915, Nachlaß Wibaut, Mappe 14. 
Troelstra'schen Aktionsprogramms - zunächst um Übersendung des einschlägigen Dokumentationsmaterials. ${ }^{450}$

Die Arbeit der neuen belgisch-holländischen Exekutive wurde von vornherein dadurch erschwert, daß Huysmans, der die Verbindung herzustellen, d.h. regelmäßig nach Den Haag zu kommen hatte, dazu jedesmal die Grenze überqueren mußte, was ohne einen von den deutschen Behörden ausgestellten $\mathrm{PaB}$, der nicht leicht zu bekommen war, nicht ungefährlich war. Der deutsche Parteivorstand, der, den Belgiern gegenüber mißtrauisch, der ganzen Lösung skeptisch gegenüberstand, ${ }^{451}$ lehnte die Bitte der Holländer, in Berlin zu Huysmans' Gunsten zu intervenieren, ab. Die Beziehungen zur Regierung - schrieb Scheidemann an Troelstra - seien ,,bisher nicht so intim [. . . Keiner von uns hat auch die Absicht, die Regierung um derartige Gefälligkeiten zu bitten." ${ }^{452}$ Schon deshalb, weil er keinen $\mathrm{Pa} B$ bekam, konnte Huysmans denn auch seine Absicht, zu der Kopenhagener Konferenz zu fahren, nicht realisieren. ${ }^{453}$ Außerdem wurde

450 ,Circulaire I”, Dezember 1914, ISB-Archiv, Mf. III. Huysmans kam zu Weihnachten nach Den Haag; er dürfte das Zirkular - gleich mehreren anderen Schreiben - am 24.12. bzw. einem der folgenden Tage verfaßt haben. Das an die SDAP gesandte Exemplar (in holländischer Sprache) trägt den Eingangsstempel vom 28.12.1914. SDAP-Archiv, Mappe 2084.

451 Vgl. Anm. 373; Ebert vor dem Parteiausschuß, Prot. PA SPD, Bd 1, 12.-13.1.1915, S. [129]: ,,Unsere Stellung zum I.S.B. kann erst nach weiterer Klärung und nach sorgfältiger Prüfung festgelegt werden. [. . . ] Solange der Vorsitz des Bureaus in Händen eines Ministers eines kriegführenden Landes liegt, wird es bei der Vorbereitung einer gemeinsamen Friedensaktion und bei der Vermittlung zwischen den Parteien der Internationale versagen. Ehe uns nicht Gewähr für objektive Leitung des Bureaus gegeben ist, können wir dafür nicht die Verantwortung übernehmen." Am 5. Januar 1915 hatte Hermann Müller unter Bezugnahme auf das Zirkular vom Dezember (s. Anm. 450) zunächst rückgefragt, ob a) die Holländer beschließende Stimme hätten, b) die französische Partei ihren Widerspruch gegen die Verlegung des ISB nach Den Haag aufgegeben hätte. Vgl. Korrespondenzbuch des ISB (H 52), ISB-Archiv, Mf. I.

${ }^{452}$ Scheidemann an Troelstra, 8.1.1915, Korrespondenzbuch des ISB (H 53). Zunächst hatte Van Kol deshalb am 29.12.1914 an Haase geschrieben; danach hatte Troelstra noch einmal an Scheidemann telegraphiert. Vgl. ebd. (H 28, 41, 51). Huysmans war über die Reaktion des deutschen Parteivorstands so empört, daß er davon am 15., 16. und 17.1.1915 durch in französischer, englischer und deutscher Sprache abgefaßte Zirkulare sämtliche dem ISB angeschlossenen Parteien - u.a. Rosa Luxemburg - in Kenntnis setzte. Vgl. ebd. (H 50, 65, 78); Nachlaß Victor Adler (französischer Text); Nachlaß Aksel'rod, A 21 IX (deutscher Text), IISG. In einem Brief an Stauning, von dem dieser am 28.1. eine Kopie an Huysmans schickte, bedauerte Haase ,,de ne pas pouvoir procurer le passe-port désiré. Si même il avait pu le faire, il aurait, à son avis, rendu un mauvais service à Huysmans." Korrespondenzbuch des ISB (H 92).

${ }^{453}$ Huysmans an Stauning, 14.1.1915, ABA: ,Es ist mir unmöglich, nach Kopenhagen zu kommen, weil die deutsche Regierung mir einen Passierschein verweigert. [ . . .] Es tut mir also leid, daß ich nicht nach Kopenhagen kommen kann, obgleich es vielleicht gut gewesen wäre, daß der internationale Sekretär als Gast die Verhandlungen hätte beigewohnt." 
ihm dies von der belgischen Parteileitung, die gegen die Konferenz protestierte, ausdrücklich untersagt. ${ }^{454}$

Die Kopenhagener Konferenz war unterdessen zunächst auf den 15.-17., dann auf den 17.-18. Januar 1915 verschoben worden, wobei in erster Linie die Rücksicht auf die Amerikaner maßgeblich war, die nicht eher kommen konnten, vermutlich aber auch die Hoffnung, die Schweizer doch noch umzustimmen. ${ }^{455}$ Auf Anregung von Wibaut, der meinte, das Fernbleiben der Schweizer und der Italiener nähre den Verdacht, daß die Konferenz unter deutschem Einfluß stehe, sprach sich auch der Vorstand der SDAP dafür aus, daß Stauning versuchen sollte, jene doch noch zur Teilnahme zu bewegen. ${ }^{456}$ Stauning unternahm derartige Versuche in der Tat, zumal die italienische Partei, anscheinend von der SPS nur unzureichend informiert, ${ }^{457}$ wissen ließ, daß Morgari, der für den Avanti! verschiedene Parteien zu besuchen plane, u.a. nach Kopenhagen kommen wolle. ${ }^{458}$ Aber trotz weitgehender Konzessionen seitens der skandinavischen Parteien die schweizerischen, italienischen und amerikanischen ,Gäste” sollten faktisch ,,gleichberechtigt" sein - beharrte die Geschäftsleitung der SPS auf ihrer Ablehnung. ${ }^{459}$ Es seien dabei - schrieb Studer am 13. Januar an

454 Vgl. den Protest des Bureau du Conseil Général der belgischen Partei, NT 408/1; Nachlaß Wibaut, Mappe 224; Nachlaß Van Kol.

${ }_{455}$ Stauning an den Parteivorstand der SDAP, 21.11.1914 (Telegr.), SDAP-Archiv, Mappe 2084; Stauning an die Vorstände von SDAP und SPS, 23.11.1914, NT 406/29. Ob bzw. inwieweit Stauning bewußt war, daß die Geschäftsleitung der SPS bereits beschlossen hatte, die Teilnahme an der Konferenz abzulehnen, geht aus seinem Brief nicht klar hervor; es heißt in diesem nur: ,Möglicherweise hätte ein einzelner Vertreter aus Amerika bis zu dem 8. Dezember in Kopenhagen eintreffen können, aber diesen Termin konnten wir nicht ansetzen, weil wir wußten, daß dann den Schweizer Genossen Schwierigkeiten entstanden wären." Vgl. auch Anm. 463. Zur Vorgeschichte der Konferenz ausführlich Graß, Friedensaktivität, S. 107ff.

456 Vgl. ,, Vergadering Partijbestuur 19 December 1914", SDAP-Archiv, Mappe 26; Van Kuykhof an Stauning, 23.12.1914, AA.

${ }_{457}$ Vgl. Angelica Balabanoff an Grimm, [23.11.1914,] Nachlaß Grimm/ZimmerwaldBewegung, Suppl.: ,,Schreiben Sie mir bitte sofort, aus welchen Gründen - offiziell oder offiziös, die ital[ienische] Partei aus der Einladung nach Kopenhagen ausgeschlossen worden ist. [. . . ] Ich brauche Ihre Antwort wegen der event[uellen] Stellungnahme der ital[ienischen] Partei."

${ }_{458} \mathrm{Vgl}$. das u.a. an die dänische Partei gesandte Rundschreiben Lazzaris vom 26.12.1914, ABA. Während in diesem Schreiben von einer Teilnahme Morgaris an der Kopenhagener Konferenz nicht die Rede ist, konnte Studer, der ein gleiches Schreiben erhalten hatte, am 30. Dezember berichten, Morgari werde ,, auch am Kongreß in Kopenhagen teilnehmen”. ,Protokoll der Sitzung der Geschäftsleitung [ . . ] vom 30. Dezember 1914”, SPS-Archiv. Vgl. auch „Bijeenkomst van het D.B. 2 Januari 1915”, SDAP-Archiv, Mappe 26.

${ }^{459}$ Am 22. Dezember hatte Studer nochmals deutlich die Bedingungen für eine Teilnahme der SPS formuliert. Studer an Stauning, 22.12.1914, ABA: ,, Wir sind immer noch der bestimmten Meinung, daß zur Konferenz die Parteien aller neutralen Staaten einge- 
Stauning - ,,in erster Linie finanzielle Gründe, dann aber auch taktischpolitische" entscheidend gewesen: solch eine Teilkonferenz ,,sei nicht von großem Werte"; sie ,,rufe [. . .] nur [. . .] Mißverständnisse hervor". ${ }^{460}$ Aus ähnlichen Gründen zog sich Hillquit, der - von Hyndman gewarnt Greulich über die Haltung der SPS befragt hatte, zurück. ${ }^{461}$ Auch Morgari, den Grimm warnte, sah von der geplanten Fahrt nach Kopenhagen ab. ${ }^{462}$ So kamen dort denn schließlich - ermuntert durch die Grußbotschaften einer Reihe von Parteien - nur Vertreter der drei skandinavischen Parteien und der SDAP zusammen - von der letzteren Troelstra, Van Kol, Vliegen, Wibaut. ${ }^{463}$

laden werden sollten. Das Ausschalten von Italien und andern macht sicher böses Blut [ . . . . Es behagt uns auch nicht recht, nur als Gäste zugelassen zu werden. Wir ersuchen Sie daher dringend, da es ja noch Zeit ist, die Genossen aller neutralen europäischen Staaten zur Conferenz einzuladen.” Am 30. Dezember konnte Studer von ,einer weitern Zuschrift von Kopenhagen” berichten, in der den Schweizern ,ebenfalls volle Berechtigung zuerkannt" wurde, was indessen an der Haltung der Geschäftsleitung nichts änderte. ,Protokoll der Sitzung der Geschäftsleitung [. . . ] vom 30. Dezember 1914"; Studer an Stauning, 4.1.1915, ABA. Unterdessen lud Stauning Morgari ein, an der Konferenz teilzunehmen. Stauning an Morgari, 31.12.1914 (Telegr.), ABA (Konzept); ders. an den PSI-Parteivorstand, 31.12.1914, ebd. (Konzept). Gleichzeitig suchte er noch einmal in einem ausführlichen Brief an Studer, in dem er dies erwähnte, die Bedenken der Schweizer zu zerstreuen. Ders. an Studer, 31.12.1914, ebd. (Konzept). Obwohl - laut Studer - auch Morgari hatte wissen lassen, , daB er [ . . .] teilnehmen werde”, blieb die Geschäftsleitung bei ihrer Ablehnung. ,Protokoll der außerordentlichen Sitzung der Geschäftsleitung [. . . 11. Januar 1915", SPS-Archiv.

${ }^{460}$ Studer an Stauning, 13.1.1915, ABA.

461 Vgl. Hyndman an Stauning, 21.12.1914; Hillquit an Stauning, 28.12.1914, ABA; „Protokoll der außerordentlichen Sitzung der Geschäftsleitung [. . . ] 11. Januar 1915”. ${ }^{462}$ Vgl. ,Sitzung der Schweiz[erischen] Geschäftsleitung [ . . ] 18. Februar 1915”, SPSArchiv.

${ }^{463}$ Was die Haltung der SDAP betrifft, so hatte Stauning am 28. Dezember auf die Anfrage Van Kuykhofs geantwortet, es seien ,,folgende Länder eingeladen: Amerika, Holland, Schweiz, Norwegen, Schweden und Dänemark. Dieses ist geschehen auf Verabredung zwischen einem Vertreter aus Dänemark (Gen. Borgbjerg) und Gen. Troelstra sowie mit den Genossen in der Schweiz (Grimm u.a.). Die Schweizer erklärten, daß sie in dieser Sache Mandat von Italien (auf der Lugano-Konferenz) erhalten hätten." Ferner hätten sie erklärt, daß eine Teilnahme der SPS so gut wie sicher sei; aber eine offizielle Antwort sei bisher nicht eingegangen. Stauning an Van Kuykhof, 28.12.1914, SDAP-Archiv, Mappe 2118. Wenige Tage später hatte Stauning noch ergänzend von der annoncierten Studienreise Morgaris berichtet. ,Ich habe sofort an ihn telegraphiert, $\mathrm{da} ß$ es uns selbstredend lieb sein würde, wenn er seine Reise so einrichten könnte, daß er am 17. Januar, an welchem Tage die erwähnte Konferenz stattfindet, in Dänemark sein könne." Stauning an Van Kuykhof, 2.1.1915, ebd., Mappe 2084. Nach diesen Auskünften hatte der Parteivorstand der SDAP seine Bedenken fallen lassen. „Vergadering Partijbestuur 9 Januari 1915”, ebd., Mappe 26. - Die von den nicht teilnehmenden Parteien eingegangenen Botschaften und andere Materialien wurden soweit nicht in deutscher Sprache abgefaßt, in deutscher Übersetzung - für die Teilnehmer hektographiert. Vgl. NT 406, 408; Nachlaß Wibaut, Mappe 224. - Über die 
Durch die Änderung des Konferenzplans gemäß dem Wunsch der deutschen Parteiführung hatte Troelstra sich zwar deren Gunst erworben, aber zugleich den Gegensatz in die Gruppe der Parteien der neutralen Länder selbst hineingetragen; denn der durch die Änderung hervorgerufene Verdacht, daß die Konferenz ein pro-deutsches Manöver sei, veranlaßte all die Parteien, die bereits den Schein pro-deutscher Haltung scheuten, sich von ihr zu distanzieren. Zwar maß Troelstra dem nicht allzu viel Bedeutung bei; aber er bemühte sich in Kopenhagen, jenen Verdacht abzubauen. Daß die dort vertretenen Parteien in der Sache selbst neutral waren, unterlag für ihn nicht dem geringsten Zweifel. ${ }^{464}$

Troelstra hatte der Konferenz, in der er immer noch ein Pendant zu Lugano sah, ${ }^{465}$ ohnehin nur eine sehr bescheidene Rolle zugedacht. Sie könne - hatte er in der Sitzung des Vorstands der SDAP am 9. Januar erklärt - nicht selbständig etwas Neues beschließen, sondern nur an die vor dem Krieg gefaßten Beschlüsse, besonders die Kopenhagener Resolution von 1910 , erinnern. ${ }^{466}$ Ähnlich hatte er sich am 12. Januar in der Sitzung der Exekutive des ISB, zu der Huysmans und Bertrand nach Den Haag gekommen waren, ausgesprochen. ${ }^{467}$ Dagegen war Albarda, der in gleichem Sinn auf Wibaut einzuwirken suchte, für eine entschiedenere Stellungnahme der Konferenz, die den Aufwand sonst nicht lohnen würde, eingetreten. Wenn in Holland von den ,,Tribunisten”, in Deutschland von Liebknecht, Clara Zetkin u.a. fortgesetzt verkündet werde, daß die Internationale , tot" sei, hatte das - so fürchtete er - eine suggestive Wirkung: es konnte sie tatsächlich töten. Die Konferenz müsse daher - im Sinn der von den deutschen Radikalen befürworteten Friedensaktion - ein kraftvolles Wort an die sozialistischen Parteien richten, besonders die der kriegführenden Länder.

Verhandlungen wurde von holländischer Seite durch den Redakteur von Het Volk De Roode, der als Gast teilnehmen durfte, ein Bericht angefertigt: ,,Overzicht van het verhandelde op de Konferentie van Kopenhagen op 17 en 18 Jan[uari]" (mschr., hektogr., 9 S.), NT 407/1-9. Von dänischer Seite fertigte einen ähnlichen Bericht Borgbjerg an. - Für eine umfassende Darstellung der Konferenz vgl. Graß, Friedensaktivität, S. 121ff.; Blänsdorf, Die Zweite Internationale, S. 126ff.

${ }_{464}$,Overzicht", S. 3; vgl. auch Stauning an Hyndman, 1.1.1915, NT 406/30-32.

465 Nach dem Troelstra'schen Entwurf der Konferenz-Resolution, NT 405/1-7, sollte der erste Absatz derselben lauten: ,Im Anschluß an die Konferenz der soz[ial-]dem[okratischen] Parteien Italiens und der Schweiz in Lugano sind die sozialistischen Parteien der drei skand[inavischen] Länder und Hollands zu einer Konferenz zusammengetreten." Vgl. Anm. 341.

466 ,Vergadering Partijbestuur 9 Januari 1915", a.a.O.

${ }^{467}$ Albarda an Wibaut, 12.1.1915, Nachlaß Wibaut, Mappe 224. 
Es muß deutlich ausgesprochen werden, daß der Friede nur dann herbeigeführt werden kann, wenn die Sozialisten der verschiedenen kriegführenden Länder ihn zu fördern wünschen. [. . .] An beiden Seiten der Linie, die die kriegführenden Parteien trennt, muß sich der Friedenswille geltend machen. [...]

Die von Liebknecht und den Seinen in Deutschland hervorgerufene bzw. geleitete Strömung wird durch eine Äußerung der Konferenz in diesem Geist gestärkt werden. Hunderttausende, die entmutigt dasitzen, werden sich wieder aufrichten, wenn sich die alte Stimme des internationalen Sozialismus kraftvoll hören läßt. [. . .]

Auch in den Armeen nimmt die Abneigung gegen die Fortsetzung des Krieges zu. [. . .] Darf eine sozialistische Konferenz es unterlassen, diese erfreulichen Stimmungen zu verstärken? ${ }^{468}$

Während Troelstra eingewandt hatte, für das, was Albarda wolle, sei die Zeit noch nicht gekommen, zeigte Wibaut sich für dessen Überlegungen empfänglich; er sprach sich auf der Konferenz in ihrem Sinne aus, so daß sie teilweise ins Manifest eingingen. Die - einstimmig beschlossene - Endfassung des letzteren war das Resultat verschiedener Kompromisse, wobei sich die holländische Delegation in zwei entscheidenden Fragen durchsetzen konnte. Während es den Skandinaviern vorzugsweise darauf ankam, in ihren eigenen Ländern - bei schwächerer Betonung sozialistischer Ideen - die Führung einer breiten Volksbewegung für den Frieden zu übernehmen, nämlich - so Branting - ,,die Strömung für den Frieden, die in den neutralen Ländern vorhanden ist, zu kondensieren, um ihr mehr Einfluß auf ihre Regierungen zu geben", ${ }^{469}$ mußte sich die Konferenz nach Ansicht der holländischen Teilnehmer vor allem - so Troelstra - , über die Internationale, für die internationale Idee" aussprechen. ${ }^{470}$,,Wir haben", erklärte Wibaut, , ,als Sozialdemokraten $z u$ Sozialdemokraten zu sprechen, insbesondere zu den Sozialdemokraten der kriegführenden Länder."471

468 Ebd.; ,,Duidelijk moet worden uitgesproken, dat de vrede alleen dan kan worden te voorschijn geroepen, als de socialisten der verschillende belligerante landen hem wenschen te bevorderen. [. . . ] Aan weerszijden van de lijn, die de krijgvoerende partijen scheidt, moet de vredeswil zich doen gelden. [ . . .] / De strooming door Liebknecht c.s. in Duitschland gewekt of geleid, zal kracht ontleenen aan een uiting van de konferentie in dezen geest. Honderdduizenden, die ontmoedigd ter neer zitten, zullen weer oprijzen als de oude stem van het internationalistische socialisme zich krachtig doet horen. [ . . .]/ Er groeit ook in de legers een weerzin tegen het voortzetten van de oorlog. [ . . .] Mag een socialistische konferentie nalaten deze verblijdende stemmingen aan te wakkeren?"

469 , Overzicht", S. 2: , de stroming voor den vrede, die in de neutrale landen aanwezig is, te condenseeren, om ze meer invloed te geven op hun regeringen".

${ }^{470}$ Ebd., S. 4: ,,over de Internationale, voor de internationale idee”.

${ }^{471}$ Ebd., S. 5: ,,Wij hebben te spreken als sociaal-democraten tot sociaal-democraten, in het bijzonder tot de sociaal-democraten der oorlogvoerende landen." Unzutreffend 
Gemäß holländischem Wunsch erhielt das Manifest, das nur in den einleitenden Absätzen auf dem von Stauning stammenden skandinavischen Entwurf, im übrigen dagegen vorzugsweise auf dem Troelstra'schen Entwurf basierte, einen entschieden sozialistischen Charakter. Es wies auf den ,Kapitalismus in seiner imperialistischen Gestaltung” hin, der zu diesem Krieg geführt habe; es betonte die Notwendigkeit, ,,die internationale Solidarität während der gegenwärtigen Krise aufrecht zu erhalten"; es erinnerte ,,die sozialdemokratischen Arbeiter, namentlich in den kriegführenden Ländern" an die Forderungen der Kopenhagener Resolution von 1910, in der ,,die Prinzipien internationaler Solidarität” festgelegt seien; es betonte ,die Pflicht aller sozialistischen Parteien, im Sinne eines baldigen Friedens zu wirken”, für ,,Friedensbedingungen, welche nicht den Keim zu neuen Kriegen enthalten”; es rief die Arbeiterklasse auf, verstärkt ,,den Kampf für die Eroberung der politischen Macht zu führen". ${ }^{472}$ Aus dem skandinavischen Entwurf wurde dann noch der Aufruf an die Parteien der neutralen Länder, sich für Vermittlungsaktionen einzusetzen, übernommen. ${ }^{473}$

Die zweite Frage, in der sich die holländische Delegation durchsetzen konnte, betraf die ,,Vergewaltigung Belgiens”. ${ }^{474}$ Während es die Skandinavier im Namen der Neutralität der Konferenz bei einem allgemeinen Hinweis auf das Selbstbestimmungsrecht belassen wollten, forderten die holländischen Delegierten, die sich von dem Los der Belgier direkter betroffen fühlten, einen ausdrücklichen Protest, wobei für Troelstra zu den moralischen noch taktische Erwägungen hinzukamen, nämlich - außer der Rücksicht auf die belgischen Mitglieder der Exekutive des ISB - die Überlegung, daß vielmehr ein Verzicht auf einen ausdrücklichen Protest den Verdacht nähren müßte, daß die Konferenz nicht neutral sei: ,,Würden

wohl die Auffassung von Blänsdorf, Die Zweite Internationale, S. 128, daB Wibaut den Standpunkt der Skandinavier , unterstützt" habe; gegenüber jenen - laut Stauning kam es darauf an ,,de burgerlijke vredesbeweging voor te zijn" - legte er vielmehr den Nachdruck darauf, daß die Sozialdemokratie die Konkurrenz des bürgerlichen Pazifismus nicht zu fürchten brauche: ,Van de burgerlijke vredesbeweging kunnen wij ons niet overal ver houden. Wij behoeven niet te vreezen, dat zij de leiding zal nemen. Vanzelf staan wij aan de spits, en het karakter der beweging zal met den dag meer proletarisch worden."

${ }^{472}$ Zum holländischen Entwurf vgl. Anm. 471, ferner die maschinenschriftliche Abschrift, Nachlaß Wibaut, Mappe 224; zum skandinavischen Entwurf vgl. ,,Entwurf zu einem Manifest”, NT 408/4-6. Zur definitiven Fassung vgl. den von Troelstra handschriftlich korrigierten maschinenschriftlichen Text, NT 408/13-14, ferner , Mitteilungen über die Konferenz in Kopenhagen am 17.-18. Januar 1915 (Offizieller Bericht)" (hektogr., 13 S.), S. 9-11, Collection IIe Internationale, IISG.

${ }^{473}$ Ebd., S. 11; NT 580/91-92.

474, ,Overzicht", S. 5. 
wir also diesen Protest unterlassen, würde das dem Prestige der Konferenz sehr abträglich sein." 475

Das Manifest entzog tatsächlich den entsprechenden Verdächtigungen weitgehend den Boden. Darauf eingehend, schrieb Wibaut:

Die Konferenz zu Kopenhagen hat all diese Vermutungen Lügen gestraft. [. . .] Sie hat das sozialdemokratische Proletariat der kriegführenden Länder daran erinnert, daß es seine Pflicht ist, bereits jetzt, jedes in seinem Land und nach seinen Kräften, für die Beendigung des Krieges einzutreten. ${ }^{476}$

Dementsprechend fiel sogar das Urteil Rosa Luxemburgs verhältnismäßig mild aus. Sie mockierte sich zwar über den ,, unverwüstliche[n] Optimismus, der, aus der furchtbaren Katastrophe des gegenwärtigen Krieges unversehrt hervorgegangen, noch am Grabe alter Hoffnungen neue Resolutionen pflanzt", meinte aber, im Fall der Sozialisten der neutralen Länder sei das ja ,eine verhältnismäßig harmlose Verirrung". Ohnehin müsse die ,,rettende Tat" von den Parteien der kriegführenden Länder kommen. ${ }^{477}$

Dem hätte Troelstra, wenngleich etwas anderes meinend, durchaus zugestimmt. Schon im Herbst hatte er, seinerseits die Resolution des Parteitags der SPS zum Krieg kritisierend, erklärt, was nötig sei, seien keine Resolutionen dieser Art, sondern sei die nüchterne Besinnung, was konkret zu tun sei, ${ }^{478}$ weshalb er, was Konferenzen nach der Art der Kopenhagener anging, selbst zunächst zurückhaltend gewesen war. Die Möglichkeiten der Konferenz - so hatte er in Kopenhagen selbst erklärt seien nur beschränkt: ,,der Krieg, nicht Konferenzen werden den Frieden bringen." ${ }^{479}$ Aber den Gedanken, der seit Kriegsbeginn sein Leitmotiv war, wiederholend, hatte er betont, das Proletariat, das vom Krieg überrascht worden sei, dürfe sich nicht ebenso vom Frieden überrumpeln lassen.

Der Friede darf nicht durch die Generäle und die Diplomaten geschlossen werden. [...]

Das Proletariat ist berufen, dem Frieden seinen Stempel aufzudrücken,

475 Ebd., S. 6: ,,Verzuimden wij dus dit protest, het zou aan het prestige der konferentie zeer veel afbreuk doen." Ebd., S. 6. Angesichts der skandinavischen Bedenken wurde dann die im holländischen Entwurf enthaltene Wendung von der ,,Vergewaltigung Belgiens” auf Wibauts eigenen Vorschlag durch „Bruch des Völkerrechts Belgien gegenüber" ersetzt. Vgl. hierzu auch Troelstra, Gedenkschriften, Bd 4, S. 25.

${ }_{476}$ F. M. W[ibaut], ,De Kopenhaagsche Conferentie”, in: Het Weekblad, Nr 297 (29.1.1915).

47 Luxemburg, ,Der Wiederaufbau der Internationale”, S. $28 \mathrm{ff}$.

$478 \mathrm{Vgl}$. [Troelstra,] ,Internationale Reisbrieven”, Nr 4480.

479 ,Overzicht”, S. 3: , , de oorlog, geen konferenties zal den vrede brengen." 
aber es kann das nicht allein tun. Es muß das vielmehr unter den bestehenden Machtverhältnissen tun. Wir müssen also alle Friedenselemente zusammenholen, eine Sammlungspolitik führen, alle anderen Elemente zwingen, uns zu folgen. ${ }^{480}$

Dabei setzte Troelstra, der noch immer davon ausging, daß der Krieg in absehbarer Zeit sein Ende finden würde, seine Hoffnung ebenfalls auf ein Erstarken der Opposition in den kriegführenden Ländern selbst. Auf der Durchreise durch Deutschland meinte er schon einen Umschwung in der Stimmung feststellen zu können. Daraus, daß - im Gegensatz zur Bremer Bürger-Zeitung, deren Redaktion er auf der Rückreise besuchte - der Vorwärts nicht das ganze Kopenhagener Manifest, sondern nur die Einleitung gebracht hatte ${ }^{481}$ schloß er nicht nur, daß - gleich den französischen die deutschen Sozialisten nichts von Frieden wissen wollten, sondern ebenso, daß jene schon ein Nachlassen der Kriegsbegeisterung befürchteten; bestärkt in dieser Annahme wurde er durch Scheidemanns Artikel im Hamburger Echo, der die Arbeiter zum ,,Durchhalten” aufrief ${ }^{482}$ - ,,ganz bestimmt eine sonderbare Nutzanwendung [ . . . ] der Friedensgrundsätze der Internationale!" ${ }^{483}$ Aber trotz der zunehmenden Zweifel, was den Friedenswillen der deutschen Parteiführung anging, hatte Troelstra, wenn er auf eine zunehmende Opposition gegen den Krieg hoffte, eine Opposition im Sinn, die sich im Rahmen der parteiinternen Legalität hielt, d.h. die Einheit der Partei nicht in Frage stellte. Was die SPD betraf, so baute er vorzugsweise auf die gemäßigte Opposition um Haase, die sich von der radikalen Linken deutlich abgrenzte.

$\mathrm{DaB}$ die internationale Sozialdemokratie - so meinte Troelstra in einem Bericht, den er in Leeuwarden gab - den Krieg nicht habe verhindern können, müsse endlich hingenommen werden; es sei sinnlos, darüber zu klagen; es komme vielmehr darauf an, sich auf den Frieden vorzubereiten. Die geeignetste Friedensaktion war für ihn ein - parallel zum Friedenskongreß der Diplomaten abzuhaltender - interparlamentarischer Kon-

40 Ebd., S. 3: ,De vrede mag niet worden gesloten door de generaals en de diplomaten. $[. .$.$] / Het proletariaat is aangewezen om op den vrede zijn stempel te drukken, maar$ het kan het niet alleen doen. Het moet het doen onder de bestaande machtsverhoudingen. Wij moeten dus alle vredeselementen bijeen halen, een verzamel-politiek voeren, alle andere elementen dwingen, ons te volgen."

481 Vgl. ,Die Friedens-Konferenz in Kopenhagen”, in: Vorwärts, 1915, Nr 21 (21.1.).

482 Vgl. Philipp Scheidemann, , Warum wir durchhalten müssen”, in: Hamburger Echo, 1915, Nr 18 (22.1.): ,,Alle unsere Bekundungen des guten Willens, dem Frieden die Wege zu ebenen, haben ein gleichtönendes Echo nicht hervorgerufen. [ . . ] Deshalb bleibt uns gar nichts anderes übrig: wir müssen durchhalten!"

${ }^{483}$,,Verslag van de reis naar Kopenhagen”, Februar 1915 (fragmentarisches Konzept von Troelstras Hand), NT 404/22-28. 
greß. Dieser Kongre $B$, der, von offiziellen Delegationen der verschiedenen Parlamente beschickt, diese bindende Beschlüsse fassen könnte, müßte dafür sorgen, da $B$ in den Friedensvertrag Bestimmungen über Abrüstung, Schiedsgerichte etc. aufgenommen würden. ${ }^{484}$ Allerdings - schrieb Troelstra damals - genüge es nicht, die Demokratisierung der auswärtigen Politik bloß zu fordern. Die Geschichte lehre, daß die Parlamente neue Rechte erobern müßten, wobei es zunächst nicht auf Verfassungsartikel, sondern ,,eine Tat" ankomme. Woran Troelstra hierbei dachte, war eine machtvolle Bewegung der Massen, ihrer Parteien, die den welthistorischen Moment ergriffe; in diesem Sinne meinte er, , daß jede wirkliche Friedensbewegung eine politische Bewegung sein muß". ${ }^{485}$ Die sozialistischen Parteien müßten dabei, jede in ihrem Land, die treibende Kraft sein. Je mehr der festgelaufene Krieg sich ad absurdum führe, desto stärker werde in den Parteien der kriegführenden Länder der Wunsch nach Verständigung hervortreten, wobei die Parteien der neutralen Länder Hilfestellung leisten könnten. Man habe sich daher gedrängt gefühlt, in Kopenhagen den ersten Schritt zu internationaler Zusammenarbeit zu tun. ${ }^{486}$

Was die unmittelbaren Pläne des Exekutivkomitees des ISB anging, hatte die Kopenhagener Konferenz sie durch das Ersuchen unterstützt,

sobald die Verhältnisse solches erlauben, spätestens beim Anfang der Friedensunterhandlungen, die sozialdemokratischen Parteien zur Beratung über gemeinsame Forderungen in Bezug auf den Friedensschluß zusammenzubringen. ${ }^{487}$

Das Exekutivkomitee war bereits vor der Konferenz - wovon Troelstra dort berichtete - in diesem Sinn aktiv geworden. ${ }^{488}$ Anscheinend hatte sich Huysmans Troelstras Aktionsprogramm - immerhin, was die ersten Schritte zur Reaktivierung der Internationale anging - weitgehend zueigen gemacht. Jedenfalls hatte er am 16. Dezember auf eine betreffende Anregung Middletons erwidert, es sei ,,quite impossible, useless and dangerous to summon a meeting of the Bureau now"; aber die Exekutive bleibe durchaus nicht untätig. ${ }^{489} \mathrm{Ja}$ es scheint, daß er, nachdem er sich einmal zur Kooperation entschlossen hatte, die Devise seiner holländi-

${ }^{444}$ Vgl. „De Kopenhaagsche Conferentie. Troelstra's rede”, in: Friesch Volksblad, 1915, Nr 7 (13.2.).

485 „,Een interparlementair Vredeskongres”, Ende Januar 1915 (unvollendetes Ms. von Troelstras Hand), NT 404/1-8: ,dat elke werkelijke vredesbeweging een politieke beweging moet zijn".

486 „De Kopenhaagsche Conferentie. Troelstra's rede”, a.a.O.

487 ,Mitteilungen über die Konferenz in Kopenhagen”, S. 11.

488 Vgl. „Overzicht”, S. 4.

489 Huysmans an Middleton, 16.12.1914, ISB-Archiv, Mf. II. 
schen Partner übernommen hatte: ,Nach meiner bescheidenen Auffassung”, schrieb er an Stauning, ,,kann die Internationale nur leben bleiben, wenn sie actionsfähig ist." ${ }^{490}$ Nicht bereit, sich in Sachen ISB das Heft aus der Hand nehmen zu lassen, entfaltete er nunmehr selbst eine energische Aktivität. Schon am 26. Dezember hatte er - laut dem Korrespondenzbuch des ISB - an Vandervelde geschrieben: ,Une initiative du Bureau serait partout bien accueillie. Il serait prudent de nous voir avant Copenhague. Je te propose le 12 janvier à La Haye." 491

Auf Huysmans' Vorschlag wurde in der Sitzung am 12. Januar, an der Vandervelde nicht teilnehmen konnte, beschlossen, Vertreter der Parteien der kriegführenden Länder vom 20. bis 25 . Februar zu vertraulichen Gesprächen nach Den Haag zu bitten. ${ }^{492}$ Während Troelstra vereinbarungsgemäß am 13. Januar Hermann Müller informierte, ${ }^{493}$ unterrichtete Huysmans am gleichen Tag zunächst Vandervelde, ${ }^{494}$ dann - am 15. Januar - in gleichlautenden Schreiben in englischer bzw. französischer Sprache die englischen, französischen und russischen Sozialisten, wobei er unerwähnt lie $B$, da $\beta$ die deutschen Sozialisten gleichfalls eingeladen waren. ${ }^{495}$ Auf Grund von Überlegungen, die bereits in den Plänen hervorgetreten waren, die Matthijsen im Herbst den Belgiern unterbreitet hatte, war ein schrittweises Vorgehen beabsichtigt, wobei die erste Gesprächsrunde nur einer , information préalable" dienen sollte. Das Exekutivkomitee sollte zunächst nacheinander mit den einzelnen Delegationen für sich konferieren. „,Daraus”, erklärte Troelstra in Kopenhagen, ,,kann vielleicht eine internationale Konferenz hervorgehen. Gelingt das, dann kann ein Friedensprogramm gemacht werden." 496

Die Mehrheit der Parteien reagierte positiv. Der deutsche Parteivorstand - antwortete Hermann Müller am 20. Januar - wolle die Sache prüfen. ${ }^{497}$ Die British Section, die ihrerseits am 11. Januar beschlossen hatte, zum 14.-15. Februar eine Konferenz der Parteien der EntenteLänder nach London einzuberufen, ${ }^{498}$ sprach sich desungeachtet am 2. Februar grundsätzlich für eine Teilnahme an den Gesprächen in Den Haag

490 An Stauning, 14.1.1915, a.a.O.

491 An Vandervelde, 26.12.1914, Korrespondenzbuch des ISB (H 21).

$492 \mathrm{Vgl}$. hierzu Blänsdorf, Die Zweite Internationale, S. 138ff.

493 In seiner Antwort auf Hermann Müllers Brief vom 5.1.1915 (s. Anm. 451): Troelstra an Hermann Müller, 13.1.1915, Korrespondenzbuch des ISB (H 52).

494 Huysmans an Vandervelde, 13.1.1915, ebd. (H 77).

$495 \mathrm{Vgl}$. Korrespondenzbuch des ISB (H 49, 60); Nachlaß Aksel'rod, A 21 IX (französische Version).

496 „,Overzicht”, S. 4: ,,Daaruit kan misschien een internationale konferentie voortkomen. Slaagt dat, dan kan een vredesprogram worden gemaakt."

497 Hermann Müller an Troelstra, 20.1.1915, Korrespondenzbuch des ISB (H 103).

$498 \mathrm{Vgl}$. Blänsdorf, Die Zweite Internationale, S. $150 \mathrm{ff}$. 
aus, drängte aber darauf, daß - so Middleton in seinem Brief vom 3. Februar - Gespräche mit ,,representatives of all sections of the I.S.B." geführt würden, ferner ,,that a full meeting of the I.S.B. should be held in addition to the separate interviews" ${ }^{499}$ Aksel'rod, der ebenfalls betonte, $\mathrm{da} \beta$ auch die deutschen und die österreichischen Sozialisten einzuladen wären, hielt derartige Gespräche für besonders nützlich, ${ }^{500}$ nicht zuletzt so führte er in einem Brief an Troelstra aus - im Hinblick auf die ,,unversöhnlichen Gegensätze"' in der russischen Sozialdemokratie.

Vorläufig begnüge ich mich, darauf hinzuweisen, daß z.B. die Lenin'sche Richtung die Internationale als tot und ihre leitenden Kreise als simple Verräter erklärt. Eine ganz neue auf den Ruinen der alten, vom Opportunismus durchseuchten Internationale müsse gegründet werden. Und nicht der Kampf für den Frieden, nicht ,Krieg dem Kriege”, sondern die Entfachung des ,,bürgerlichen", d.h. des revolutionären Krieges, [ . . ] [müsse] jetzt die Parole der internationalen Sozialdemokratie sein.

Eine Verständigung mit den Vertretern dieser Richtung sei kaum möglich, zumal dieselben ,,die völlige Zersetzung und Zertrümmerung der bisherigen Internationale" nicht nur wünschten, sondern selbst aktiv betrieben. ,,Und, soviel ich weiß, machen sich solche oder ähnliche Tendenzen auch in proletarischen Kreisen anderer Länder bemerkbar." Wasser auf die Mühlen dieser Elemente gössen aber jene Sozialisten, die, vom nationalistischen, ja chauvinistischen Taumel mitgerissen, ,wirklich die internationalen Interessen, Pflichten und Prinzipien der proletarischen Parteien auf dem Altare des Imperialismus opfern". Diese seien für , unsern internationalen Bund" vielleicht noch gefährlicher.

Um diesen polar entgegengesetzten Strömungen mit Erfolg entgegenzuwirken, [ . . .] wäre es daher nach meiner Ansicht notwendig, zuerst eine Verständigung und Einigung zwischen solchen Vertretern der Arbeiterparteien herbeizuführen, die weder im Banne nationalistischer und imperialistischer Tendenzen stehen, noch von anarcho-syndikalistischen oder vulgär revolutionären Bestrebungen beherrscht sind [ . . . ]. Gerade der unoffizielle Charakter der in Aussicht genommenen Verhandlungen erlaubt dem Exekutivkomitee, nicht einzig und allein an die offiziellen Instanzen sich zu wenden, sondern auch einzelne, tatsächlich eine führende oder einflußreiche Stellung einnehmende Genossen bei der Einladung zu berücksichtigen. Leute wie Kautsky, Haase oder Liebknecht dürften bei den Unterhandlungen nicht fehlen. ${ }^{501}$

499 Middleton an Huysmans, 3.2.1915, ISB-Archiv, Mf. II. Zurückhaltender hatten sich vorher Inkpin - für die BSP - und MacDonald - persönlich - geäußert. Vgl. Inkpin an Huysmans, 23.1.1915, ebd.; MacDonald an Huysmans, 27.1.1915, ebd.

500 Aksel'rod an Huysmans, 25.1.1915, Korrespondenzbuch des ISB (H 95).

so1 Ders. an Troelstra, 27.1.1915, NT 406/0, 1-3. 
Vermutlich war es der am 2. Februar eingegangene Brief von Aksel'rod, der Huysmans veranlaßte, am gleichen Tag noch Victor Adler anzuschreiben, wobei er sich - was zu Verwirrung führte - auf ein Zirkular bezog, von dem er nicht wisse, ob Adler es erhalten hätte. ${ }^{502}$ Am 12. Februar telegraphierte letzterer, daß die österreichische Partei ,,prinzipiell einverstanden" sei..$^{503}$ Am 16. Februar fuhren Adler und Seitz nach Berlin, um gegebenenfalls, nach Abstimmung mit der deutschen Partei, von dort aus weiter nach Den Haag zu fahren. Mit dem Parteivorstand gelangten sie zu dem Schluß, daß jedenfalls nur eine gemeinsame Friedensaktion der Parteien beider kriegführender Seiten in Betracht käme. ${ }^{504}$ Aber im Gegensatz zu den Belgiern, die am 13. Februar ebenfalls zusagten, ${ }^{505}$ lehnten die Franzosen ab. Schon am 20. Januar hatte Vaillant wissen lassen, ,ces projets menaçants" bestätigten nur die französischen Bedenken gegen die Verlegung des ISB. ${ }^{506}$ Am 29. Januar entschied die Commission Administrative Permanente, die übrigens den Protest gegen die Verlegung des ISB aufrechterhielt, es sei - so Dubreuilh in seinem Brief vom gleichen Tag ,,inopportun d'entrer en rapports indirects avec les sections des autres pays belligérants". ${ }^{50}$ Der Brief traf am 16. Februar in Den Haag ein, worauf Troelstra - Huysmans, der zur Londoner Konferenz gefahren war, war noch nicht zurück - die Gespräche in Den Haag erst einmal telegraphisch absagte. ${ }^{508}$

Allerdings fand dennoch am 19. Februar eine Aussprache der durch Troelstra, Albarda und Huysmans vertretenen Exekutive mit zwei Vertretern der belgischen Partei, Vandersmissen und Wauters, die die Nachricht nicht mehr rechtzeitig erhalten hatten, statt. ${ }^{509}$ Vandersmissen beharrte auf dem ebenso von den Franzosen eingenommenen Standpunkt, daß an Friede erst zu denken sei, wenn der deutsche Militarismus vernichtet sei,

502 Huysmans an Victor Adler, 2.2.1915, Nachlaß Victor Adler, IISG. Ebenfalls am 2.2.1915 schrieb Huysmans noch einmal an Aksel'rod, MacDonald, Garle, Hyndman und Keir Hardie, um den Plan der Exekutive nochmals zu erläutern. Nachlaß Aksel'rod, A 21 IX; ISB-Archiv, Mf. II.

503 Victor Adler an Huysmans, 12.2.1915 (Telegr.), 12.2.1915, ISB-Archiv, Mf. II.

so4 Ders. an Huysmans, 16.2.1915 (Telegr.), ISB-Archiv, Mf. II; Tagebücher Otto Brauns, 17.2.1915.

sos Vandersmissen an Huysmans, 13.2.1915, Korrespondenzbuch des ISB (H 124).

s06 Vaillant an Huysmans, 20.1.1915, ebd. (H 85).

507 Dubreuilh an Huysmans, 29.1.1915, ebd. (H 128).

508 Troelstra an Aksel'rod, Victor Adler, Van Kol in Paris, 16.2.1915 (Telegr.), ebd. (H 130-32); Nachlaß Aksel'rod, A 60 XVIII; Huysmans an Victor Adler, 18.2.1915, abgedruckt in Victor Adler, Briefwechsel mit August Bebel und Karl Kautsky [. . .], hrsg. von F. Adler, Wien 1954, V 34, S. 612.

$509 \mathrm{Vgl}$. ,Internationaal Socialistisch Bureau. Konferentie van het ,Comité Exécutif' met de Belgische Delegatie. 19 Februari 1915" (hektogr., 6 S.), NT 412/1-6. 
und an Gespräche mit den deutschen Sozialisten erst, wenn diese ihre Haltung revidiert hätten, wozu Wauters noch bemerkte, ,,daß wir Liebknechts Aktion gerne sich entwickeln sehen". ${ }^{510} \mathrm{Zu}$ Troelstras Einwand, $\mathrm{da}$ (as um der Zukunft der Internationale willen besser wäre, die Schuldfrage auf sich beruhen zu lassen, erklärte Huysmans, er glaube, dieses Problem werde sich durch den zu erwartenden Umschwung bei den deutschen Arbeitern wohl binnen kurzem lösen. Sobald sich die deutschen Truppen ostwärts der Linie Luxemburg-Verviers befänden, würde sich eine Friedensaktion aufdrängen. ${ }^{511}$

\section{Der letzte Aktionsversuch der radikalen Linken innerhalb des vorhan- denen Rahmens}

Was die deutsche Sozialdemokratie betraf, entsprach - so schien es Huysmans' Haltung völlig Rosa Luxemburgs Erwartung. Jedenfalls stimmten beide in der - durch die Ereignisse genährten - Hoffnung auf ein schnelles Erstarken der oppositionellen Kräfte in der deutschen Partei durchaus überein. Das Erstarren der Fronten in einem aussichtslosen Stellungskrieg, die bürgerliche Annektionshetze, die auf eine äußerste Anspannung der Kräfte, einen klaren Sieg setzte, die Härte des ersten Kriegswinters, besonders die gespannte Ernährungslage - all das führte in der Tat dazu, daß die Unruhe in der Partei merklich zunahm. Die erbitterten Auseinandersetzungen über die Kriegspolitik der Partei erreichten in der Sitzung der Reichstagsfraktion vom 2. bis 4 . Februar einen neuen Höhepunkt. Die gemäßigte Opposition, für die die Kreditbewilligung keine prinzipielle, sondern vielmehr eine taktische Frage war, lehnte zwar den Alleingang Liebknechts ab, forderte nun aber unter Hinweis darauf, $\mathrm{da} \beta$ der Verteidigungs- jetzt zum Eroberungskrieg werde, desgleichen eine Friedensaktion der Partei. Jedoch wurde von der Rechten, die dadurch die ,Politik des 4. August” gefährdet sah, ein entsprechender Antrag Hochs auf das erbittertste bekämpft. Die Rechte konnte durchsetzen, daß derselbe nur dem Parteiausschuß überwiesen wurde, ferner, daß nicht nur das Verhalten Liebknechts, sondern ebenso das Ledebours, der unter Protest gegen die Geschäftsführung des Fraktionsvorstands aus diesem ausgetreten war, mißbilligt wurde..$^{512}$ Nach der Sitzung klagte Kautsky in einem

${ }^{510}$ Ebd., S. 3f.: ,,dat wij Liebknecht's aktie gaarne tot ontwikkeling zien komen”.

511 Ebd., S. 5f.

$512 \mathrm{Vgl}$. Die Reichstagsfraktion der deutschen Sozialdemokratie 1898 bis 1918, bearb. von E. Matthias und E. Pikart, 2 Tle, Düsseldorf [1966], Nr 357-59, S. 26ff.; David, KTB, 2.-4.2.1915, S. 101f.; Liebknecht, Klassenkampf, S. 78ff.; Wilhelm Dittmann, Erinnarungen, Ms., IISG. 
Brief an Victor Adler, der ,,rücksichtslose Terrorismus" der Rechten sei kaum noch erträglich; wenn die größte Gefahr für die Einheit der Partei zunächst von links zu kommen schien, so komme sie jetzt von der Rechten, die glaube, ,,der Moment sei günstig, die Partei von allem ,Marxismus' zu reinigen". ${ }^{513}$

Gleichzeitig fand Rosa Luxemburg, die damals, empört über die ,,Vorgänge in der Fraktion", auf ,,schärfste Aktion dagegen" drängte, selbst bei ihren engsten Freunden keine Unterstützung. Anscheinend wurde befürchtet, die radikale Linke würde sich jetzt, da die Massen in Bewegung kamen, durch ein überstürztes Vorgehen nutzlos isolieren. Auch Rosa Luxemburgs Vorschlag einer strafferen Zusammenfassung der oppositionellen Kräfte durch ein ,Komitee” fand keine Resonanz, wonach sie selbst bemerkte: ,,es war nur wieder ein Versuch." ${ }^{514}$ Clara Zetkin warnte noch im März in einem Brief an Grimm: ,Wir müssen auch den Schein einer Sonderorganisation meiden, weil die Massen eine solche Absplitterung nicht verstehen werden." Worauf es ankomme, sei die Zusammenfassung der oppositionellen Kräfte ,,in der Arbeit für ein bestimmtes Programm". ${ }^{515}$ Während ihres Aufenthalts in Berlin Anfang Februar wurde demgemäß beschlossen, sich vorerst auf die seit dem Herbst geplante Herausgabe der Internationale zu konzentrieren, die laut Clara Zetkin die Funktion eines, ,sammelnden und führenden wissenschaftlich-volkstümlichen Zentralorgan[s]” erfüllen sollte. ${ }^{516}$ „,Nun wollen wir”, schrieb Rosa Luxemburg Mitte Februar an Kostja Zetkin, ,,mit Zeitschrift, Broschüren etc. wirken als lose Personen, gewiß, auch das wird eine Wirkung ausüben. Die Stimmung ist mit jedem Tage günstiger". ${ }^{517} \mathrm{Ja}$ es herrsche, meinte sie in ihrem Brief an Alexander Winkler, ,,ein wahrer Heißhunger nach einem sozialdemokratischen Wort im alten Sinne".

Die Massen der Parteigenossen, das sieht man immer deutlicher, haben nicht ,umgelernt", sie haben blo $\beta$ verlernt, ihren Führern unbedingt zu trauen, da diese so kläglich versagt haben. ${ }^{518}$

Je mehr das, was zunächst nur eine abstrakte Hoffnung gewesen war, zur festen Überzeugung wurde, nämlich, daß die Masse der Parteigenossen der

${ }^{513}$ Kautsky an Victor Adler, 11.2.1915, abgedruckt in Victor Adler, Briefwechsel, a.a.O., K 150, S. 611.

514 Vgl. Rosa Luxemburg an Kostja Zetkin, [4.2.1915,] [vor dem 6.2.1915,] [nach dem 9.2.1915,] RLGB, Bd 5, S. 39f., 42.

515 Clara Zetkin an Grimm, 13.3.1915, Nachlaß Grimm/Zimmerwald-Bewegung, Suppl.

516 An Grimm, 1.1.1915, ebd.

517 Rosa Luxemburg an Kostja Zetkin, [nach dem 9.2.1915,] a.a.O., S. 42.

518 An Alexander Winkler, 11.2.1915, RLGB, Bd 5, S. 45. 
, alten Tradition" der Partei durchaus treu geblieben sei, desto weniger waren die Radikalen geneigt, es vorerst dabei, daß die Internationale tot war, zu belassen. Die anfängliche Sorge vor ihrer verfrühten Reaktivierung, die die oppositionelle Bewegung u.U. im Keim erstickt hätte, wich allmählich einer optimistischeren Sicht, wozu wohl auch die positive Resonanz beitrug, die Liebknechts Abstimmung am 2. Dezember bei den ausländischen Parteien fand. Allerdings war die Freude über diese Resonanz besonders im Fall der französischen Partei, deren Führer die deutsche Opposition priesen, aber ihrerseits verkündeten, sie seien ,,plus que quiconque résolus à la victoire", ${ }^{519}$ nicht ungetrübt. So betonte Clara Zetkin Anfang Januar gegenüber Grimm:

Natürlich ist das Verhalten der Internationalen von großem Einfluß auf die weitere Entwicklung des Parteilebens in Deutschland. [. . . ] Daß die Franzosen die Situation erheblich erschweren, ist ja menschlich begreiflich, aber politisch peinlich und ungeschickt. Unsere Revisionisten finden eine starke Stütze darin..$^{520}$

U.a. im Hinblick darauf drängte wohl nach ihr auch Liebknecht letzterer in seinem Brief vom 5. Januar - nochmals nachdrücklich darauf, daß Grimm, dessen Wirken ihm nicht nur im Hinblick auf die , Zukunft der Internationale", sondern - n.b. - ebenso unter dem Aspekt, ,ihrer aktuellen politischen Leistungsfähigkeit" besonders wichtig schien, möglichst vor dem 15. Januar - an diesem Tag sollte Rosa Luxemburg zunächst ihre Gefängnisstrafe antreten - zu einer Besprechung des weiteren Vorgehens nach Berlin käme. ${ }^{521}$ Das Interesse der deutschen Radikalen dürfte dabei vorzugsweise jener im Oktober ,,durch R[adek] übermittelten Anregung" Grimms, d.h. der Herstellung des Kontakts zur Opposition in der französischen Partei, gegolten haben. Clara Zetkin, die den ihr nach Stuttgart gesandten Brief Liebknechts samt Anlagen an Grimm weiterleitete, drängte ebenfalls noch einmal auf das Treffen. ${ }^{522}$ Aber aus ihren weiteren Briefen geht hervor, daß dasselbe nicht nur vor, sondern auch nach dem 15. Januar - aus gesundheitlichen Gründen wurde Rosa Luxemburg ein Strafaufschub bis zum 31. März bewilligt - nicht zustande kam. ${ }^{523}$ Anscheinend hielt Grimm, über die Opposition in der deutschen Partei gut unterrichtet, die Reise nach Berlin für nicht so nötig, zumal in jenen Tagen ja Morgari

\footnotetext{
519 Vgl. ,Déclaration du Parti Socialiste”, in: l'Humanité, Nr 3904 (25.12.1914).

520 Clara Zetkin an Grimm, 1.1.1915, a.a.O.

$521 \mathrm{Vgl}$. Anhang, Nr 7.

522 Clara Zetkin an Grimm, 7.1.1915, Nachlaß Grimm/Zimmerwald-Bewegung, Suppl

$523 \mathrm{Vgl}$. dies. an Grimm, 14.1., 20.1., 28.1., 20.2.1915, ebd.
} 
dorthin fuhr, der auf der Rückfahrt nochmals über Bern kam. ${ }^{524}$ Statt dessen fuhr Grimm Ende Januar nach Paris, um sich erst einmal über die Situation in der französischen Partei zu informieren. ,Ich hoffe", schrieb ihm Clara Zetkin, die er davon kurz in Kenntnis gesetzt hatte, ,,daß Sie den Franzosen etwas Vernunft beibringen, so da $B$ aus der internationalen Friedensaktion etwas wird." ${ }^{25}$ Über Grimms Besuch in Paris berichtete später Alfred Rosmer:

Son voyage avait un double but: d'abord s'informer de la situation véritable du socialisme en France; du dehors, on n'entendait qu'une voix, mais on ne pouvait pas croire qu'il n'y eût pas d'opposants; il fallait voir sur place. Ensuite, sur la base de la situation observée, examiner la possibilité de rassembler les socialistes fidèles à l'Internationale dans tous les pays, tout au moins établir déjà une liaison entre eux. ${ }^{526}$

Nachdem Grimm zunächst Renaudel aufgesucht hatte, der die einmütige Haltung der französischen Partei betonte, wandte er sich - wohl auf Aksel'rods Empfehlung - an die Redakteure des russischen Blatts Naše Slovo, d.h. Martov, Trockij etc., die den Kontakt zu Vertretern der französischen Opposition, Rosmer, Dunois etc., vermittelten.

C'était déjà une petite réunion internationale, avec nos camarades russes, polonais, et Grimm, qui, depuis Lugano, pouvait également représenter le Parti socialiste italien [. . . ].

Grimm nous parla d'abord de la Conférence de Lugano [. . . ]; les socialistes suisses et italiens avaient songé en premier lieu à établir un lien entre eux, puis à convoquer une réunion des socialistes des pays neutres. L'action de Liebknecht en Allemagne montra bientôt qu'on pouvait s'orienter déjà vers une véritable conférence socialiste internationale, avec participation des délégués des pays belligérants aussi bien que des pays neutres; mais la position prise par les directions des Partis socialistes des pays belligérants rendait la tâche difficile, et contraignait de commencer d'abord par un travail de reconnaissance et d'information. Grimm nous donna ensuite des renseignements précis sur la situation en Allemagne, avant tout sur les développements de la propagande et de l'action faites par Liebknecht et ses amis que nous suivions anxieusement. En conclusion, on régla, pratiquement, les moyens d'assurer désormais une liaison régulière entre nous, de façon à contrebattre le bourrage de crânes de la presse officielle. ${ }^{527}$

524 Zur Hinfahrt vgl. Anm. 462; zur Rückfahrt vgl. ,,Protokoll der Sitzung der Geschäftsleitung [.. ] vom 22. Januar 1915”, SPS-Archiv, Studer: ,,Von Morgari liegt eine Postkarte aus Bern vor. Aus dieser geht hervor, daß Morgari am Kongreß in Kopenhagen nicht teilnahm, seine Informationstournee auf Berlin, Genf und Bern beschränkte und bereits wieder auf der Rückreise nach Italien begriffen ist."

525 Clara Zetkin an Grimm, 28.1.1915, a.a.O.

526 A. Rosmer, Le mouvement ouvrier pendant la guerre. De l'union sacrée à Zimmerwald, Paris [1936], S. 368.

s27 Ebd., S. 369. 
Allerdings war unverkennbar, daß die Opposition innerhalb der SFIO bislang unbedeutend war. Davon konnten auch die deutschen Radikalen nicht ganz abstrahieren, weshalb ihre Haltung zur französischen Partei zwiespältig blieb. Aber dies galt nicht nur in bezug auf die französische, sondern desgleichen in bezug auf alle anderen Parteien, ihre offiziellen Führer, Instanzen, Aktivitäten. Charakteristisch dafür war der Standpunkt zu der Kopenhagener Konferenz, den Clara Zetkin unmittelbar vor dieser Heleen Ankersmit erläuterte.

Die internationale Solidarität der Proletarier aller Länder wäre eine trügerische Phrase, wenn sie darin bestehen sollte, daß die Sozialisten den Arbeitern sagen: in Zeiten des Friedens liebt Euch; in Zeiten des Kriegs schneidet Euch die Hälse ab.

Vorbedingung für ein internationales Zusammenwirken sei daher eine grundsätzliche Klärung der Haltung zu Militarismus und Krieg; diese erfordere aber eine rücksichtslose Kritik an dem Verhalten der sozialdemokratischen Parteien in den kriegführenden Ländern.

Jede Nation hat die Pflicht, innerhalb ihrer Grenze für diese Klärung zu sorgen. Deshalb tue ich, was ich kann, um in Deutschland diese Klärung herbeizuführen [. . . ].

Soweit die Kopenhagener Konferenz ein ,Zusammenleimen der Internationale" bezwecke, sei sie aussichtslos, ja ,,schädlich". Ohnehin sei fraglich, ob sie für den Friedensschluß Bedeutung hätte. Wichtiger blieben ,,die Massenaktionen breiter Volksschichten, namentlich aber in den kriegführenden Staaten". Aber diese Massenaktionen galt es erst noch auszulösen.

Meiner Ansicht nach müssen wir aber gegenwärtig alles unterstützen und fördern, was eine Friedensaktion herbeiführen und verstärken könnte, ohne Illusion über den evtl. Erfolg. [ . . . ] Wir müssen abwarten, ob die Konferenz wenigstens in dieser Richtung etwas leistet. ${ }^{528}$

In der Fraktionssitzung am 4. Februar wies dann Liebknecht, sich auf die in Frankreich sich formierende Opposition beziehend, namentlich auf Pierre Monatte hin, der im Dezember dagegen protestiert hatte, daß die CGTFührung es abgelehnt hatte, die Einberufung der Kopenhagener Konferenz ausdrücklich zu begrüßen; aber ebenso hob er die spätere Billigung des Kopenhagener Manifests durch Renaudel hervor. ${ }^{529}$

528 Clara Zetkin an Heleen Ankersmit, 16.1.1915, abgedruckt in W. Eildermann, ,Unveröffentlichte Briefe Clara Zetkins an Heleen Ankersmit", in: Beiträge zur Geschichte der deutschen Arbeiterbewegung, Jg. 8 (1967), S. 670f.

$529 \mathrm{Vgl}$. Dittmann, Erinnerungen, a.a.O. Zur Opposition Monattes vgl. ,Das Erwachen 
Die Kriegspolitik der französischen Sozialisten mochte sich von der der deutschen im Prinzip nicht unterscheiden; aber - meinte Rosa Luxemburg noch Anfang Februar - angesichts der enormen Dienste, die letztere dem vaterländischen Imperialismus leisteten, seien jene, samt ihren ,,naiven Ministern”, ja doch ,,wahre Stümper". ${ }^{530}$ Anscheinend hatten die deutschen Radikalen noch nicht jede Hoffnung aufgegeben, immerhin die , offiziellen Führer" der ausländischen Parteien, denen sie sich in der Erbitterung über die Führer der SPD verbunden fühlten, auf den Weg der ,,alten Tradition" zurückführen, d.h. im Sinne einer gemeinsamen Friedensaktion beeinflussen zu können, weshalb sie Chancen, die sich für die Ausübung solch eines Einflusses im offiziellen Rahmen der ja immerhin nicht völlig toten Internationale boten, nicht verschmähten. So hatte Clara Zetkin bis zuletzt gezweifelt, ob die Schweizer klug daran getan hätten, die Kopenhagener Konferenz zu boykottieren. ,Wenn Sie selbst gehen könnten", hatte sie Anfang Januar an Grimm geschrieben, ,,so würde ich das für sehr nützlich halten, denn die Troelstra'sche Staatsmännelei fände an Ihnen ihren Meister. "531 Ebenso waren Rosa Luxemburg und Clara Zetkin Mitte Februar selbst bereit, zu den von der Exekutive des ISB geplanten Gesprächen nach Den Haag zu fahren; denn Huysmans hatte - anscheinend hinter Troelstras Rücken - auch Vertreter der deutschen Opposition nach Den Haag eingeladen, nämlich - wohl Aksel'rods Anregung folgend - auf einer Postkarte an Liebknecht, den er wohl primär im Auge hatte. ${ }^{532} \mathrm{Im}$ Korrespondenzbuch des ISB ist diese Karte nicht vermerkt; aber im März schrieb Clara Zetkin hierüber an Grimm:

Von Karl und Rosa erhielt ich Bescheid, mich sofort zu einer Reise nach Holland zu rüsten, Huysmans hatte Nachricht gegeben, daß er eine ,,Reunion" von Vertretern aller kriegführenden Länder in die Wege geleitet hatte. Sie sollte bald nach der Londoner Konferenz im Haag stattfinden. Es sei sehr wichtig, daß dabei auch aus Deutschland die Opposition anwesend sei. Da K[arl] selbst als Soldat an die Scholle gefesselt ist, sollte ich mit $\mathrm{R}$ [osa] zusammen gehen. Als internationale Sekretärin der sozialistischen

der französischen Arbeiter”, in: Berner Tagwacht, 1915, Nr 3 (6.1.); ,Beginnende Einsicht", in: Vorwärts, 1915, Nr 16 (16.1.); ferner Monattes eigene Darstellung in seinem - nach dem Krieg noch einmal publizierten - Flugblatt. ,,Au Comité confédéral, en décembre 1914", in: La Vie Ouvrière, 1919, Nr 20 (10.9.). Zur Reaktion Renaudels auf die Kopenhagener Beschlüsse vgl. Pierre Renaudel, ,Les textes de Copenhague", in: l'Humanité, Nr 3941 (31.1.1915).

530 Luxemburg, ,,Der Wiederaufbau der Internationale”, S. 24.

531 Clara Zetkin an Grimm, 1.1.1915.

532 Vgl. Jemnitz, ,,Der Widerhall”, S. 417. Laut Jemnitz hatte Huysmans betont, daß es ihm lieb wäre, wenn an den Gesprächen in Den Haag Liebknecht und Rosa Luxemburg und überhaupt die verschiedenen Minderheiten teilnehmen könnten. 
Frauen könne ich auf Grund der bisherigen Erfolge, trotz des Kriegs international zu arbeiten, mit Fug und Recht Anspruch auf Zulassung erheben. ${ }^{533}$

Für Rosa Luxemburg war dieser Plan verhängnisvoll. Nachdem die Militärbehörden bereits - am 6 . Februar - Liebknecht durch die Einberufung zum Militärdienst mundtot gemacht hatten, ${ }^{534}$ warteten sie nur auf einen Vorwand, Rosa Luxemburg, über deren Auftreten in einer Reihe von Versammlungen sie bestens informiert waren, gleichfalls auszuschalten. Als sie - berichtete laut Otto Brauns Darstellung Haase dem Parteivorstand - einen $\mathrm{Pa}$ nach Holland - ,,sie wolle dort eine Freundin besuchen" - beantragte, wurde ihr erklärt, der Grund für den gewährten Haftaufschub sei wohl entfallen. Am 18. Februar wurde sie verhaftet. ${ }^{535}$

Obwohl sie in Berlin, wohin sie sich zunächst begab, erfuhr, daß die ,Reunion" nicht stattfände, fuhr Clara Zetkin Ende Februar - Anfang März allein nach Holland, wo sie zwar nicht Huysmans, aber Wibaut, Mendels, Pannekoek und Henriette Roland Holst traf.

Das Resultat unserer Unterhaltung ist dies: die Holländer wollen an Huysmans herantreten und ihn veranlassen, recht bald einen abermaligen Versuch zu einer Reunion zu machen, die die Genossen aus den kriegführenden Ländern zusammenbringt. Sie soll in der Schweiz stattfinden und auf Vertreter der neutralen Staaten ausgedehnt werden. So zumal von der Schweiz, Holland und Italien. Ferner soll der Charakter der Zwanglosigkeit festgehalten werden, damit auch die Opposition an der Reunion teilnehmen kann. ${ }^{536}$

Unterdessen war auch Haase in Aktion getreten. Nachdem er schon im Januar einen Besuch in der Schweiz, besonders bei Grimm, geplant hatte, aber diesen Plan nicht hatte ausführen können, ${ }^{537}$ hatte er am 8 . Februar in

${ }_{533}$ Clara Zetkin an Grimm, 13.3.1915, a.a.O.

534 Vgl. das Faksimile des Gestellungsbefehls vom 31.1.1915 in KLGRS, Bd 8, bei S. 16; Rosa Luxemburg an Helene Winkler, 11.2.1915, a.a.O., S. 46.

535 Vgl. Tagebücher Otto Brauns, 20.2.1915: ,,Heute erzählte Haase, wie es zur Verhaftung Rosa's gekommen sei. Danach liegt noch eine viel größere polnisch-galizische Frechheit vor, als ich annahm. Die superkluge Genossin ist nämlich zur Polizei gegangen und hat ersucht, ihr einen $\mathrm{Pa} B$ nach Holland auszustellen, sie wolle dort eine Freundin besuchen. Da hat man ihr denn gesagt, sie habe doch noch ein Jahr Gefängnis zu verbüßen [...]. Wenn sie nunmehr nach Holland reisen wolle, sei sie wohl auch haftfähig. Dann hat man sich an den Frankfurter Staatsanwalt gewandt, der sofort einen Haftbefehl erlassen hat."Vgl. auch die Darstellung, die Liebknecht am 9. März im Preußischen Abgeordnetenhaus gab, KLGRS, Bd 8, S. 211f.

536 Clara Zetkin an Grimm, 13.3.1915. Vgl. auch Henriette Roland Holst an Wibaut, 1.3.1915, NachlaB Wibaut, Mappe 23; Huysmans an Wibaut, [6.3.1915,] ebd.

$537 \mathrm{Vgl}$. Haase an Grimm, 11.1.1915, Nachlaß Grimm/Zimmerwald-Bewegung, Suppl.: , ,ich beabsichtige für einige Tage nach der Schweiz zu fahren und Sie zu besuchen. Seien Sie so freundlich, mir mitzuteilen, ob ich Sie in der letzten Woche dieses Monats zu Hause antreffe und vielleicht auch noch einige Freunde sprechen könnte." Ferner Haase 
einem privaten Brief an Troelstra seinen Wunsch bekundet, in jedem Fall ,Sie und die anderen Freunde zu besuchen, namentlich auch Camille [Huysmans] zu sehen". ${ }^{538}$ Mitte März telegraphierte Troelstra, er erwarte Haases Besuch am 23. März; da er sich aber anscheinend nicht der von Haase angegebenen Privatadresse bedient hatte, erfuhr der Parteivorstand davon. ,Wir machten ihm", so Scheidemann, ,einen Strich durch die Rechnung, indem wir beschlossen, daß alle Mitglieder des Parteivorstandes, die dem Internationalen Sozialistischen Büro angehörten, nach Holland gehen sollten." ${ }^{539}$ Außer Haase fuhren so noch Ebert, Molkenbuhr und Hermann Müller nach Den Haag zu einer Aussprache, deren privater Charakter dadurch unterstrichen wurde, daß sie nicht in den Räumen des ISB, sondern in Troelstras Wohnung stattfand; von der Exekutive des ISB waren Troelstra, Albarda, Huysmans und Anseele anwesend; auf deutschen Wunsch wurde Van Kol, der sich Anfang Februar in Paris für einen französischen Sieg ausgesprochen hatte, nicht hinzugezogen. ${ }^{540} \mathrm{Die} \mathrm{Be}-$ sprechung führte zu dem Schluß, daß - nachdem die Parteien der EntenteStaaten in London konferiert hatten - nun auch die Parteien der Mittelmächte eine eigene Konferenz abhalten sollten, die dann am 12.-13. April in Wien stattfand. ${ }^{541}$

Ein weiteres Ergebnis der Besprechung bestand darin, daß Huysmans seine Beziehung zum deutschen Parteivorstand normalisierte, wonach er gleich Troelstra - für die Radikalen nicht mehr interessant war. Zumal nachdem - auf ein entsprechendes Zirkular vom 22. Februar hin ${ }^{542}-$ außer den Franzosen, die sich der Stimme enthalten hatten, sämtliche Parteien der für die Exekutive gefundenen Lösung zugestimmt hatten, ${ }^{543}$ war Huysmans aufrichtig bestrebt, sich nicht nur in dem von Rosa Luxem-

an seinen Sohn Ernst, 11.1.1915, abgedruckt in Hugo Haase. Sein Leben und Wirken, mit einer Auswahl von Briefen, Reden und Aufsätzen hrsg. von E. Haase, Berlin o.J., S. 104. Anscheinend konnte Haase seinen Plan im Hinblick auf die bevorstehende Fraktionssitzung nicht realisieren. Vgl. David, KTB, 23.1.1915, S. 99f.; 30.1.1915, S. 100f.

${ }_{538}$ Haase an Troelstra, 8.2.1915, NT 547/1.

539 Scheidemann, Memoiren, Bd 1, S. 340f.

540 Vgl. Troelstra an Albarda, 23.3.1915, NT 536/2-3; David, KTB, 30.3.1915, S. 117; 3.4.1915, S. 118; Prot. PA SPD, Bd 1, 7.-8.4.1915, S. [149]f. Zur Affäre Van Kol vgl. ,Groupe socialiste au Parlement”, in: l'Humanité, Nr 3946 (5.2.1915); Troelstra und Albarda an den Parteivorstand der SDAP, 18.2.1915, SDAP-Archiv, Mappe 2084; Van Kuykhof an Van Kol, 4.3.1915, Nachlaß Van Kol. Nach den Gesprächen in den Haag schrieb Van Kol anscheinend einen erklärenden Brief an Haase, worauf Haase seine ,Hoffnung auf ein nicht zu fernes Wiedersehen bei gemeinsamen Wirken für das, was unser Innerstes bewegt”, ausdrückte. Haase an Van Kol, 3.4.1915, ebd.

$541 \mathrm{Vgl}$. hierzu Blänsdorf, Die Zweite Internationale, S. $169 f f$.

$\$ 42$ Vgl. ,Circulaire Il”, 22.2.1915, ISB-Archiv, Mf. III.

${ }_{543} \mathrm{Vgl}$. Korrespondenzbuch des ISB (H 148ff.). 
burg gewünschten Sinn in seiner ,,legalen" Funktion zu behaupten, sondern dieselbe auf ,legale" Weise - was eine Umgehung der offiziellen Instanzen der Parteien ausschloß - aktiv auszuüben. Anfang Mai schrieb er in diesem Sinn an Branting:

Présente mes amitiés aux camarades. Dis leur que les relations du secrétariat avec tous les partis sont rétablies. J'ai fait taire mon coeur pour ne voir que l'oeuvre de demain et je suis resté, malgré la guerre, le secrétaire international des partis socialistes, y compris ceux d'Allemagne et d'Autriche..$^{544}$

Allerdings war für die Internationale auf dem offiziellen Weg vorerst nicht viel zu tun. Da die Franzosen auf ihrer Ablehnung beharrten, war es noch nicht einmal möglich, Delegierte der Parteien der kriegführenden Länder zu sondierenden Gesprächen zu versammeln. Nach dem Eintritt Hendersons ins Kabinett zog sich die British Section ebenfalls zurück. ${ }^{545}$

Ebenso aussichtslos waren nach der Kopenhagener Konferenz die von der SPS im Februar eingeleiteten Versuche, doch noch das Projekt einer Konferenz der Parteien sämtlicher neutralen Länder zu realisieren ${ }^{546}$ so daß sich Grimm entschloß, selbständig vorzugehen. Unter Bezugnahme auf einen ihm durch Aksel'rod übermittelten Vorschlag Martovs schrieb er jenem Anfang Mai, da über die ,,offiziellen Parteien” kaum etwas zu machen sei, halte er dafür, , ,daß sich die Vertreter der Opposition aus allen Ländern versammeln sollten”, wobei er ,,natürlich nicht die Spaltung”, sondern ,,die Festlegung einer Aktionslinie für den Kampf gegen den Krieg" im Sinn hatte, eine ,,gemeinsame Grundlage [. . .], so daß gleichzeitig von Vertretern aller Länder an die Arbeiter herangetreten werden kann". ${ }^{547}$ Den Gedanken aufnehmend, den er laut eigener Aussage ,,schon im September wiederholt äußerte, freilich ohne da $B$ er praktische Gestalt angenommen hätte", 548 beschritt er den Weg, der nach Zimmerwald führte. . .

544 Huysmans an Branting, 4.5.1915, ISB-Archiv, Mf. II. Vgl. auch Huysmans' Erklärung auf dem außerordentlichen Parteitag der SDAP im Januar 1916: ,Ik wilde niet, dat later zou kunnen worden gezegd, dat wij eenige verantwoordelijkheid zouden hebben in het feit, dat een ons toevertrouwd wapen werd stukgeslagen door onze schuld. Ik was onder den indruk dat vooral in een eensgezinde, handelende Internationale ook de vertrapte en bedreigde nationaliteiten hun steun en hun herstelling konden vinden." Verslag van het Buitengewoon Congres der S.D.A.P., gehouden op 8 en 9 Januari 1916 te Amhem, Amsterdam [1916], S. 30.

545 Middleton an Huysmans, 20.5.1915, NT 552/11-12 (Abschrift).

546 Vgl. hierzu GraB, Friedensaktivität, S. $139 \mathrm{ff}$.

547 Grimm an Aksel'rod, 6.5.1915, in Die Zimmerwalder Bewegung, Bd 2, Nr 35, S. 65. Vgl. Martov an Grimm, 29.4.1915, ebd., Nr 31, S. 50ff.; Aksel'rod an Grimm, 5.5.1915, ebd., S. 61f.

548 Grimm an Aksel'rod, 6.5.1915, a.a.O., S. 65. 
Bekanntlich konnte von den Führern der radikalen Linken in Deutschland keiner an der Zimmerwalder Konferenz teilnehmen. Aber Liebknecht sandte ihr jene berühmte Grußbotschaft, deren entscheidende Sätze lauteten:

Die Prinzipien unsrer Stellung zum Weltkrieg, als Spezialfall der Prinzipien unsrer Stellung zur kapitalistischen Gesellschaftsordnung gilts kurz zu klären: kurz - so hoffe ich! Denn hier sind wir alle, seid ihr alle einig, müssen wir einig sein.

Die taktischen Folgerungen aus diesen Prinzipien gilts vor allem [zu] ziehen - rücksichtslos, für alle Länder!

Burgkrieg, nicht Burgfrieden!

Internationale Solidarität des Proletariats über, gegen pseudo-nationale, pseudo-patriotische Klassenharmonie; internationaler Klassenkampf über Staatenkrieg, gegen Staatenkrieg. Internationaler Klassenkampf für den Frieden, für die sozialistische Revolution. ${ }^{549}$

Von holländischer Seite nahm an der Zimmerwalder Konferenz, deren - ihrer Ansicht nach zu wenig radikalen - Resultate Rosa Luxemburg enttäuschten, ${ }^{550}$ Henriette Roland Holst teil, die später meinte, daß der einzige, der - außer ihr - in Holland die Idee der Konferenz vielleicht begriffen hätte, Troelstra gewesen sei; aber dieser habe sich bei Kriegsausbruch ,,in die Gefangenschaft des bürgerlich-niederländischen Nationalismus begeben". ${ }^{551}$ Troelstra selbst, der - nach einem schweren Kollaps im Juni 1915 - seine politische Arbeit erst einmal einige Monate unterbrechen mußte, erklärte im Sommer 1916:

Als Kundgebung des Friedenswillens und als Aufruf zur sozialistischen Selbstbesinnung habe ich die Konferenz von Zimmerwald begrüßt. Ich meine aber, die sozialistischen Arbeiter warnen zu müssen gegen den Gebrauch, den gewisse intransigente Kreise davon machen, um [ . . ] die Spaltung in die Parteien, in die Internationale hineinzutragen. ${ }^{552}$

Huysmans hatte sich schon vorher von dem Zimmerwalder ,Abenteuer” deutlich distanziert. 553

Die Fronten klärten sich.

549 Liebknecht an die Teilnehmer der Zimmerwalder Konferenz, 2.9.1915, in Die Zimmerwalder Bewegung, Bd 2, Nr 6311, S. 101.

550 Vgl. Rosa Luxemburg an Clara Zetkin, 18.10.1915, RLGB, Bd 5, S. 81f.

551 H. Roland Holst, ,Herinneringen aan Zimmerwald”, in: Fundament, Jg. 2 (1935), Nr 7, S. 28.

552 Rede zur Eröffnung der Konferenz der Parteien der neutralen Länder in den Haag am 31. Juli 1916, NT 414/5.

553 Vgl. Verslag van het Buitengewoon Congres der S.D.A.P., gehouden op 8 en 9 Januari 1916, a.a.O., S. 30: ,,Ongeduldige partijgenooten hebben dan ook elders internationale conferenties bijeengeroepen (gelach), maar u hebt kunnen vaststellen, dat de 


\section{Zwei Konzeptionen einer künftigen Internationale}

$\mathrm{Da}$ der 4. August 1914 in der Geschichte der Arbeiterbewegung eine deutliche Zäsur darstellte, war den Zeitgenossen unmittelbar bewußt: als der Krieg, den die internationale Organisation des klassenbewußten Proletariats nicht zu verhüten vermocht hatte, einmal da war, entschieden sich die sozialistischen Parteien der betroffenen Länder beinah ausnahmslos nicht für die internationale Solidarität der Arbeiter, sondern das Bekenntnis zur Nation, nicht für den verschärften Klassenkampf, sondern den Burgfrieden, so daß praktisch von der Internationale kaum noch etwas übrigblieb. Aber diese negative Erfahrung des totalen Versagens der Internationale, die all dem gegenüberstand, was sie bis dahin positiv gewesen war, war zunächst noch vollkommen abstrakt. Was daraus für ihre Zukunft folgte, wurde erst allmählich klar - nicht nur für die Sozialisten der neutralen Länder, die zu retten suchten, was zu retten war, sondern ebenso die radikale Linke, die zwar bald erklärte, daß die alte Internationale tot sei, dies indessen - keinesfalls bereit, es dabei zu belassen - selbst zunächst kaum glauben wollte.

Namentlich für Rosa Luxemburg war die Internationale nicht nur eine Organisation gewesen, die bestimmten politischen Zielen diente, sondern ebenso - samt all den persönlichen Kontakten, Kongressen, Kontroversen etc. - ein eigentümliches Milieu, das nicht von einem Tag zum andern zu bestehen aufhörte. Erst in dem $\mathrm{Ma} \beta$, in dem sie sich realisierte, daß sich die Personen, denen sie sich eng verbunden gefühlt hatte, unter den veränderten Umständen anders verhielten, verhielt sie sich zu ihnen anders, ohne daß jeder, der zum politischen Gegner, eo ipso zur Unperson wurde. Noch Ende 1915 schrieb sie etwa anläßlich des Todes von Vaillant, sie bewahre ihm die aufrichtige Verehrung, die sie stets für ihn empfunden habe, ,,trotz allem [. . .] ungeschmälert"; 554 noch 1917, als sich ihre Wege längst getrennt hatten, bekundete sie ihre Sympathie für Huysmans. ${ }^{55}$

Am 4. August 1914 reduzierte sich für Rosa Luxemburg das Versagen der Internationale noch auf das von einigen Dutzend Führern der deutschen Sozialdemokratie. Aus dieser Auffassung entstand die These, daß gewisse Führer die Partei ,,verraten" hätten, eine These, die zum festen Bestandteil der Ideologie der radikalen Linken wurde. Wenn Rosa Luxem-

voornaamste belanghebbenden aldaar schitterden door hun afwezigheid [ . . ]. / Bij dit avontuur zal ik dan ook niet langer blijven stil staan. Ik zal maar zeggen, dat de bedoeling goed kon zijn, maar ik houd er nochtans aan te verklaaren, in naam van mijn collega's, dat, ondanks alle mogelijke onteigeningsplannen, het Bureau gevestigd is en gevestigd blijft in Den Haag."

554 Rosa Luxemburg an Luise Kautsky, 27.12.1915, RLGB, Bd 5, S. 95.

555 An Diefenbach, 23.6.1917, ebd., S. 263f. 
burg jedoch zunächst gemeint hatte, diesen ,,Verrat" durch einen öffentlichen Protest aus den Reihen der Partei neutralisieren zu können, mußte sie schon bald erfahren, daß er in Wirklichkeit die Zustimmung des Gros der Funktionäre fand, während sich ,,die Massen" irreführen ließen. Aber das Versagen der Internationale blieb für sie noch immer vorzugsweise das der deutschen Partei. Was die anderen Parteien, besonders die französische und belgische, betraf, so war sie bereit, anzuerkennen, daß diese durch die deutsche Aggression in eine ,Zwangslage” versetzt waren, die selbst den Regierungseintritt ihrer Führer rechtfertigte. Während die Mehrheit der deutschen Partei zur Begründung ihrer nationalen Haltung auf die traditionelle Parole ,,Gegen den Zarismus!” zurückgriff, tat sich Rosa Luxemburgs entschieden internationalistische Haltung zunächst, ebenso traditionell, in der Parteinahme für die französische Republik kund, die akut bedroht schien. Erst nach der Marne-Schlacht wurde sie allmählich auch den anderen Parteien gegenüber kritischer, wenngleich ihr Urteil über diese im Vergleich zu dem über die deutsche Partei immer mild blieb. ${ }^{556}$

So groß die Hoffnung gewesen war, die sie einst auf die deutsche Sozialdemokratie gesetzt hatte, so groß war nun ihre Erbitterung, so daß sie bereits im Oktober 1914 zu dem Schluß gelangte, daß die Spaltung der Partei kaum noch vermeidbar sei. Was nötig war, war eine prinzipielle Auseinandersetzung, die jedoch erst nach dem Krieg stattfinden konnte. Rosa Luxemburg verhehlte sich durchaus nicht, daß die Opposition vorerst noch schwach war, sah darin jedoch in erster Linie eine Konsequenz des Kriegszustands, besonders der Zensur. Sie erwartete, daß sie die Massen, die das Kriegselend erfahren hatten, nach dem Krieg - bei freier Diskussion - auf ihrer Seite finden würde. Der öffentliche Protest, der ursprünglich dazu hatte dienen sollen, die Ehre der Partei zu retten, erhielt jetzt einen neuen Sinn: es ging darum, den anderen Parteien kundzutun, $\mathrm{da} \beta$ es innerhalb der deutschen Partei überhaupt eine Opposition gab, um sie davon abzuhalten, daß sie deren Führern leichtfertig entgegenkamen.

Je klarer Rosa Luxemburg erkannte, daß der ,Verrat" nicht nur die Sache einiger Dutzend Führer war, vielmehr die große Mehrheit, sämtliche Instanzen der Partei den ,,neuen Kurs" voll unterstützten, desto stärker wurde ihre Überzeugung, da $ß$ in Wahrheit nur die radikale Linke, die stets nur die Spitze eines Flügels der Partei gebildet hatte, der ,,alten Tradition” derselben treu geblieben war, eine Überzeugung, die dann ebenfalls zum festen Bestandteil der Ideologie der radikalen Linken wurde. Gleichzeitig ging in der Auffassung von Rosa Luxemburg die führende Rolle, die sie der

556 Vgl. B. Kautsky, ,,Rosa Luxemburg. Eine biographische Skizze”, in: Luxemburg, Briefe an Freunde, S. 221f. 
deutschen Partei beigemessen hatte, auf die radikale Opposition in dieser über, derart, daß nun diese Opposition zum Vorbild für die ganze Internationale wurde.

Allerdings waren die Führer der radikalen Linken zunächst - im Hinblick auf deren Schwäche - sorgsam darauf bedacht, den Verfechtern des ,,neuen Kurses" nicht den gesuchten Vorwand für ihren Ausschluß aus der Partei zu bieten, der sie isoliert, ihre Wirkungsmöglichkeiten eingeengt, die Aussicht darauf, daß die Minorität innerhalb der Partei selbst zur Majorität würde, zunichte gemacht hätte. Sich noch im unklaren über die Form, in der sich die erwartete Spaltung der Partei einmal vollziehen würde, beschränkten sie sich einstweilen darauf, innerhalb des parteilegalen Rahmens Kräfte für die künftige Auseinandersetzung - bzw. ,,Abrechnung" - zu sammeln. Zugleich war insbesondere Rosa Luxemburg bemüht, zu verhindern, daß dieser Auseinandersetzung durch eine verfrühte Reaktivierung der Internationale vorgegriffen würde; denn solch eine Reaktivierung hätte erfordert, daß die Führer der anderen Parteien denen der deutschen - bzw. die Führer der verschiedenen Parteien einander gegenseitig - ihren ,,Sündenfall' verziehen hätten, was bedeutet hätte, daß die Internationale selbst den ,,neuen Kurs", d.h. die Preisgabe des revolutionären Klassenkampfs zugunsten des nationalen Interesses bzw. seine Unterordnung unter dieses, sanktioniert hätte, wodurch sie in den Augen Rosa Luxemburgs zur Farce geworden wäre.

Jene Auseinandersetzung, von der für Rosa Luxemburg die Zukunft des gesamten Sozialismus abhing, hatte für sie absoluten Vorrang, weshalb sie, was die ausländischen Sozialisten anging, zunächst in erster Linie nicht die Führer der Parteien der feindlichen Länder kritisierte, die für sie, weil Feinde ihrer Feinde, d.h. der Führer der deutschen Partei, vielmehr Verbündete waren, sondern die Führer der Parteien der neutralen Länder, die - vermittlungswillig - die vorhandenen Gegensätze zu ,,verkleistern" suchten, also ihren Feinden Freundesdienste leisteten. Das galt insbesondere für Troelstra, dem sie nicht die Haltung vorwarf, die er in Holland einnahm, sondern daß er sich - jedenfalls in ihren Augen - zum Agenten des deutschen Parteivorstands machte.

Je klarer aber wurde, daß die neutralen Vermittlungsversuche bei der abweisenden Haltung der französischen Partei einstweilen keine Chance hatten, je ähnlicher diese Haltung der der deutschen Partei wurde, je mehr sich in der französischen Partei selbst Opposition dagegen regte, desto deutlicher erkannten die Führer der deutschen Linken, daß eine prinzipielle Klärung nicht nur in der deutschen Partei, sondern in der ganzen Internationale nötig war, wobei es primär auf die rücksichtslose Kritik der , offiziellen" Politik der Parteien der kriegführenden Ländern - all dieser 
Parteien in gleicher Weise - ankàm. Allerdings blieben die deutschen Radikalen, die davon ausgingen, da $B$ jede der betreffenden Parteien diese Klärung für sich selbst durchführen mußte, in der Kritik der ausländischen Parteien weiterhin zurückhaltend; im Gegenteil: sie hörten nicht auf, sich über die Manier zu empören, in der die deutsche Parteipresse über jene herzog, weshalb sie etwa - Rosa Luxemburg setzte hiervon Anfang Januar 1915 Marta Rosenbaum in Kenntnis - die von einem Angestellten der Generalkommission, Albert Baumeister, herausgegebene Internationale Korrespondenz, , die systematisch das Gift gegen die ausländischen Genossen verbreitet", zu abonnieren beschlossen, , um der Mache entgegenwirken zu können". 557

Die verzweifelte Empörung, die Rosa Luxemburg am 4. August 1914 erfaßt hatte, wich allmählich einer distanzierteren Betrachtung. Nicht, $\mathrm{da} B$ sie , die Lage rosiger beurteilte", schrieb sie drei Monate danach an Diefenbach. ,Aber die Heftigkeit des ersten Schlages, den man empfangen, ist abgestumpft, nachdem die Schläge zum täglichen Brot geworden sind." 558 Je klarer ihr wurde, daß die Partei, die ganze Internationale ,,kaputt sind, gründlich kaputt”, je deutlicher sie die ,,wachsenden Dimensionen dieses Unglücks" sah, desto mehr wurde dasselbe für sie , zu einem weltgeschichtlichen Drama, dem gegenüber wieder die objektive historische Beurteilung Platz greift". ${ }^{559}$ Die Entwicklung, die zum Krieg geführt hatte, schrieb sie im April 1915, ,,begann nicht erst im Juli 1914, sondern sie reicht Jahrzehnte zurück, wo sich Faden an Faden [ . . .] knüpfte, bis das dichtmaschige Netz der imperialistischen Weltpolitik fünf Weltteile umstrickt hatte"; vor diesem Hintergrund, ,von Erscheinungen, deren Wurzeln in die plutonischen Tiefen des ökonomischen Werdens hinabreichen", war die Idee der nationalen Verteidigung nur eine ,Illusion”. 560 Was aber das Versagen der sozialistischen Parteien anging, wurde Rosa Luxemburg zunehmend klar, ,,daß der Kladderadatsch des 4. August 1914 wohl schon im Wesen der Arbeiterbewegung vor dem 4. August 1914 wurzelte". ${ }^{561}$ Die Konsequenz, die es daraus zu ziehen galt, konnte nur in einer radikalen Läuterung bestehen, die - bei Berufung auf die ,,alte Tradition” - im Grunde einen Neuanfang bedeutete. Während Rosa Luxemburg im Herbst in ihren Briefen mehrfach durchblicken ließ, daß ihr der Neuanfang nicht

557 Rosa Luxemburg an Marta Rosenbaum, 5.1.1915, RLGB, Bd 5, S. 32.

558 An Diefenbach, 1.11.1914, ebd., S. 19.

559 Ebd., S. 19.

\$60 Junius-Broschüre, S. 137.

561 Gracchus [Rosa Luxemburg], ,Rückblick auf die Gothaer Konferenz”, in: [Der Kampf (Duisburg), 1917, Nr 51 (25.5.)] RLGW, Bd 4, S. 271. 
leicht fiel, ${ }^{562}$ gab ihr die ,,ausgezeichnete" Stimmung der Massen, die sie Anfang 1915 konstatierte, neue Zuversicht. ${ }^{563}$,Ohne sehr stürmische Kämpfe"', bemerkte sie in einem Brief an Alexander Winkler, ,,wird es natürlich nicht abgehen, aber ich hoffe, die alte Tradition wird sich doch stärker erweisen als der ,neue Kurs'. ${ }^{564} \mathrm{Daß}$ es aber nicht nur um die ,,alte Tradition" ging, sondern ebenso um einen Neubeginn, war ihr bewußt. So schrieb sie an Mehring im August 1915:

Freilich ist jetzt die ganze Lage derart verworren, daß eine richtige Freude am Kampf gar nicht aufkommen kann. Alles ist noch in der Verschiebung begriffen, der große Bergrutsch scheint gar kein Ende zu nehmen [. . .]. Im ersten Moment, damals am 4. August, war ich entsetzt, fast gebrochen; seitdem bin ich ganz ruhig geworden [. . ]; elementare Verheerungen haben ja etwas Beruhigendes gerade in ihrer Größe und Blindheit. Und schließlich, wenn es schon so um die Dinge stand und die ganze Friedensherrlichkeit bloß Irrlicht auf dem Sumpfe war, dann ist es ja besser, da $B$ die Sache mal zum Klappen kam. Aber vorläufig haben wir die Qual und die Unbehaglichkeit des Übergangszustands, und auf uns paßt wirklich: Le mort saisit le vif. Die Jämmerlichkeit unserer schwankenden Freunde [ . . ] ist $\mathrm{ja}$ auch nichts anderes als die Frucht von der allgemeinen Korruption, an der die Baracke, die im Frieden so stolz glänzte, zusammengekracht ist. Wohin man greift ist morscher Zunder. Das muß sich, denk' ich mir, alles noch weiter zurechtrutschen und noch mehr auseinanderfallen, damit das gesunde Holz endlich herauskommt. ${ }^{565}$

Die Quintessenz der Auseinandersetzung war ein kompromißloses ,Entweder - Oder”. Der Weltkrieg - stellte sie im April fest - widerlege selbst die von ihm erst geschaffene Täuschung: trotz allem ,steigt aus dem ,Burgfrieden' [...] der Klassenkampf und aus den Blutdämpfen der Schlachtfelder die internationale Solidarität der Arbeiter empor", aber nicht etwa in jenen ,,schwächlichen Versuchen, die alte Internationale künstlich zu galvanisieren", den verschiedenen internationalen Konferenzen. Die dort formulierten Forderungen für den Frieden waren utopisch bzw. mußten allesamt auf eine hinauslaufen: ,,Abschaffung des kapitalistischen Klassenstaates". Das entscheidende Problem, vor das der Krieg die sozialistischen Parteien gestellt hatte, war demnach ,,die Aktionsfähigkeit der proletarischen Massen im Kampf gegen den Imperialismus", einem Kampfe, der nur international zu führen war. Nationale Interessen waren im Zeitalter imperialistischer Politik eine Fiktion; denn diese war ,,eine

$562 \mathrm{Vgl}$. besonders Rosa Luxemburg an Levi, 6.10.[1914], a.a.O., S. 455f.; an Kostja Zetkin, [vor dem 24.12.1914,] a.a.O., S. 28f.

563 An Helene Winkler, 11.2.1915, S. 46.

564 An Alexander Winkler, 11.2.1915, a.a.O., S. 45.

565 An Mehring, 31.8.1915, RLGB, Bd 5, S. 70f. 
von Hause aus internationale Erscheinung, ein unteilbares Ganzes, [ . . ] dem sich kein einzelner Staat zu entziehen vermag". Nicht einmal das ,kleine Holland". ${ }^{566}$

Was daraus für die Internationale folgte, resümierte Rosa Luxemburg in ihren bald darauf entworfenen Thesen, die zugleich erkennen lassen, was die Losung des Internationalismus für sie bedeutete. Die Hauptaufgabe des Sozialismus bestand darin, ,,das Proletariat aller Länder zu einer lebendigen revolutionären Macht zusammenzufassen”, wozu es eine ,starke internationale Organisation" zu schaffen galt, eine ,,neue Arbeiterinternationale", die die Leitung des revolutionären Klassenkampfs in allen Ländern übernehmen mußte, wobei es primär darauf ankam, einerseits ,,das Proletariat in jedem Lande aufs schärfste der nationalen Bourgeoisie entgegenzustellen", seinen ,,politischen und geistigen Gegensatz" zu dieser fortgesetzt hervorzukehren, andererseits die ,,internationale Zusammenhörigkeit der Proletarier aller Länder" dauernd zu betonen, zu betätigen. Die Disziplin gegenüber der Internationale mußte allen anderen Organisationspflichten vorangehen. Die nationalen Sektionen mußten sich darauf konzentrieren, daß sie mittels ihrer Organisationen jederzeit imstande waren, den Willen der Internationale ,zur Tat der breitesten Arbeitermassen aller Länder zu machen", die sie zugleich ,,von der Vormundschaft der Bourgeoisie, die sich in dem Einfluß der nationalistischen Ideologie äußert", befreien mußten.

Die einzige Verteidigung aller wahren nationalen Freiheit ist heute der revolutionäre Klassenkampf gegen den Imperialismus; das Vaterland der Proletarier, dessen Verteidigung alles andere untergeordnet werden muß, ist die sozialistische Internationale. ${ }^{567}$

Demgegenüber war Troelstra in den ersten Monaten des Kriegs zu Schlüssen gekommen, die in die entgegengesetzte Richtung führten. Die Ohnmacht der Internationale, die sich bei Kriegsausbruch erwiesen habe, habe eigentlich - erklärte er - kaum jemand überraschen können.

Denn daß eine Bewegung, die in dem Land, wo sie am stärksten ist, nur ein Drittel der Bevölkerung hinter sich hat - und in den meisten Ländern Europas weit darunter bleibt - [ . . ], daß diese, kaum im Entstehen begriffene, Organisation von Minderheiten der verschiedenen Nationen [. . .] einen Weltkrieg verhindern könnte, [ . . ] das kann nur einer glauben, der seine Gedanken von phantastischen Ideen beherrschen läßt [. . . ${ }^{568}$

Ebenso normal sei es gewesen, daß sich die betroffenen sozialistischen

566 Junius-Broschüre, S. 152f., 159, 137, 141f.

567 Entwurf zu den Junius-Thesen, RLGW, Bd 4, S. 43-47.

568 Troelstra, De wereldoorlog en de sociaaldemocratie, S. 48. 
Parteien, als der Krieg erst einmal ausgebrochen war, zugunsten der Verteidigung des eigenen Landes ausgesprochen hätten. Abgesehen davon, daß die Internationale die nationale Idee stets klar bejaht habe, hätten sich die sozialistischen Parteien, zumal soweit sie nicht nur Sekten, sondern echte Massenparteien waren, der nationalen Begeisterung, die die Massen im August 1914 erfaßt hatte, kaum entziehen können. ${ }^{569} \mathrm{Daß}$ sich aber die Annahme über die Stimmung der Massen bei Kriegsausbruch, auf der das in die Stuttgarter Resolution von 1907 aufgenommene Amendement Lenin-Luxemburg-Martov beruht habe, falsch erwiesen habe, bedeute noch nicht, daß der Krieg nicht eine revolutionäre Bewegung hervorbringen könnte; im Gegenteil - es deute bereits mancherlei auf einen Stimmungsumschwung hin, die Friedenssehnsucht werde immer stärker. Je evidenter aber werde, daß die Fortsetzung des Kriegs nur im Interesse kleiner Cliquen liege, ,, desto mehr wird die Situation reif für Widerstand, notfalls auf revolutionärem Weg." 570 Solch eine Revolution, die aus dem Wunsch nach Frieden resultiere, würde sich jedoch nicht auf den Sturz des Kapitalismus, nicht gegen die gesamte bürgerliche Gesellschaft richten, sondern wäre eine breite Volksbewegung unter Einschluß bürgerlicher Gruppen. Es sei nicht anzunehmen, daß sich die Klassenverhältnisse im Verlauf des Kriegs so weit geändert hätten, daß das Proletariat jetzt realisieren könnte, wozu es vor dem Krieg nicht stark genug gewesen sei. Die sozialistischen Parteien hätten - nicht zuletzt infolge innerer Konflikte - eher an Kraft eingebüßt.

Deshalb können wir uns schwer vorstellen, daß wir aus diesem Krieg in ein sozialistisches Regime übergehen. Wohl, daß er den Anstoß gibt und Baustoffe liefert zu einer politischen Reorganisation, worin die Gewerkschaftsbewegung eine große Rolle spielt, und zur allmählichen Übernahme dafür geeigneter Betriebszweige durch Organe der Gemeinschaft. ${ }^{571}$

Allerdings schien Troelstra eine sozialistische Revolution denkbar, wenn der Weltkrieg sich noch Jahre hinzöge bzw. nur der erste einer Reihe Kriege wäre, so daß das Elend, das die Folge wäre, zu totaler Anarchie führen würde. ,,Das kapitalistische System würde, wenn schon nicht durch die Sozialdemokratie, so durch seine eigene Unhaltbarkeit überwunden werden." Aber Troelstra wies auf diese Möglichkeit nur hin, um abermals Marchlewskis Worte - jetzt nicht mehr in deutscher, sondern holländischer Sprache - zu zitieren, nämlich das Proletariat zu ermahnen, wenn die Zeit gekommen sei, bereit zu sein..$^{572}$

\footnotetext{
569 Ebd., S. $52 f$.

570 Ebd., S. 129.

571 Ebd., S. 131.

572 Ebd., S. 131.
} 
Der Idee der prinzipiellen Auseinandersetzung konnte Troelstra nicht viel abgewinnen, da die inneren Konflikte, die die Folge wären, die sozialistische Bewegung lähmen müßten. Wenn die Internationale die in sie gesetzten Hoffnungen enttäuscht habe, sei das darauf zurückzuführen, daß ihre Führer übertriebene Hoffnungen geweckt hatten.

Es hatte sich wirklich um die Internationale eine Aureole von Romantik gebildet, die jetzt verschwunden ist. ${ }^{573}$

Was jetzt nötig sei, seien keine neuen radikalen Resolutionen über , unversöhnlichen Klassenkampf', ,,Massenaktion" etc., sondern sei ein nüchterneres Urteil über die vorhandenen Möglichkeiten; denn daß sich die sozialistischen Parteien, allen voran die deutsche, im August 1914 so wenig revolutionär verhalten, sich vielmehr so vorbehaltlos zur Nation bekannt hatten, sei kein vermeidbarer, bedauernswerter Un- bzw. Umfall, gegen den zu protestieren sei, sondern eine hinzunehmende Realität, an der sich sozialdemokratische Politik zu orientieren habe. Besonders die deutsche Sozialdemokratie müsse daraus Konsequenzen ziehen; denn wenn sie bisher davon ausgegangen sei, daß das Proletariat von der bürgerlichen $\mathrm{Ge}$ sellschaft durch eine unüberbrückbare Kluft getrennt sei, so daß proletarische Politik ausschließlich Klassenpolitik sein müsse, so sei dieser - der Erweiterung des tatsächlichen politischen Einflusses der Partei wenig dienliche - ,negative Standpunkt”, der sich in prinzipienfesten Resolutionen, scharfen Reden im Parlament, symbolischen, den Gegensatz akzentuierenden Gesten manifestiert habe, durch den elementaren Ausbruch des nationalen Gefühls im August 1914 ad absurdum geführt worden. Jedenfalls sei fraglich, ob diese - aus den halbfeudalen preußisch-deutschen Zuständen erklärbare - Haltung künftig noch maßgeblich sein könne für die Parteien in England und Frankreich, den skandinavischen Ländern, Holland, Belgien, der Schweiz und Italien, wo ein höher entwickeltes parlamentarisches System für eine Ausübung realen Einflusses weit bessere Möglichkeiten biete. Es sei zu erwarten, daß sich die Parteien dieser Länder von der Führung der deutschen Partei befreien würden. ${ }^{574} \mathrm{Ja}$ die letztere müsse sich selbst endlich auf den politischen Kampf um die konsequente Realisierung des parlamentarischen Systems konzentrieren; denn nur auf diesem Weg gewinne das Proletariat reale Macht:

sowohl zur Vollendung der bürgerlichen Revolution, als auch, um das Parlament zum Hebel des proletarischen Willens zu machen, hat es den Kampf für die konsequente Realisierung des parlamentarischen Systems als Hauptziel seiner Aktion zu betrachten. Es sei denn, man meinte, daß die

${ }^{573}$ Ebd., S. 54.

574 Ebd., S. $109 f$. 
Zeit gekommen sei für ein eigenes politisches System der Sozialdemokratie, neben und teilweise statt des bürgerlichen parlamentarischen Systems $[\ldots] .{ }^{575}$

Auf eine Broschüre Herman Gorters eingehend, ${ }^{576}$ wies Troelstra die Auffassung zurück, daß der Imperialismus die Bourgeoisie der ganzen Welt im Klassenkampf gegen das Proletariat der ganzen Welt vereine, eine Auffassung, die gerade jetzt, wo der Imperialismus dazu geführt habe, daß sich die nationalen Bourgeoisien, unterstützt von ihren Arbeitern, aufs bitterste bekriegten, etwas sonderbar anmute. Gorter erkläre zur Haupttendenz, was in Wahrheit - gegenüber dem nationalen Antagonismus nur eine Nebentendenz sei. ${ }^{577}$ Jedenfalls könne die Internationale nicht von den Nationen abstrahieren.

Der Weg zur sozialistischen Internationale führt nicht oberhalb oder jenseits oder gegen, sondern durch die sozialistischen Nationen. Um die Internationale aus einem Wunsch zur Wirklichkeit, aus einem Begriff zur Tatsache zu machen, muß das Proletariat erst die Nationen erobern - um sein internationales Wesen vollkommen entfalten zu können, sich erst ,,zur nationalen Klasse erheben." 578

$\mathrm{Daß}$ das - vorerst lockere - Band der Internationale im August 1914 zerrissen sei, bedeute keineswegs, daß diese ,tot" sei,

es lehrt uns nur, daß wir sowohl uns in jeder Nation stärker, als auch die Internationale - soweit die Macht des Proletariats in jedem Land dies zuläßt - fester machen müssen. ${ }^{579}$

Der Gegensatz dieser Konzeption der Internationale zu der Rosa Luxemburgs ist evident. Gleich dieser konnte Troelstra meinen, die Tradition der alten Internationale fortzuführen. Aber auch Troelstra, der den Ausdruck ,Internationalismus" bezeichnenderweise nicht mehr benutzte, war sich bewußt, daß es bei seiner Konzeption, gemäß der eine starke Internationale nicht der Anfang, sondern das Ergebnis des Prozesses war, in dem das Proletariat die Macht eroberte, zugleich um etwas Neues ging. Es galt ebenso für die von ihm vertretene Richtung, was Rosa Luxemburg im Frühjahr 1915 schrieb - daß nämlich die Politik des Proletariats ein ,,Zurück" nicht kenne.

575 Ebd., S. 62.

576 H. Gorter, Het imperialisme, de wereldoorlog en de sociaal-democratie, Amsterdam o.J.

57 Troelstra, De wereldoorlog en de sociaaldemocratie, S. 111.

578 Ebd., S. 44.

579 Ebd., S. 49. 
Der Krieg hat [. . .] eine gewaltige Vermischung der Machtverhältnisse [. . .] gebracht, er hat die Beziehungen der Staaten zueinander und der Klassen innerhalb der Gesellschaft einer so scharfen Revision unterzogen, so viel alte Illusionen und Potenzen vernichtet, so viel neuen Drang und neue Aufgaben geschaffen, daß die Rückkehr zum alten Europa, wie es vor dem 4. August 1914 war, ganz so ausgeschlossen ist wie die Rückkehr zu vorrevolutionären Verhältnissen auch nach einer niedergeschlagenen Revolution. ${ }^{580}$

ANHANG: Unveröffentlichte Briefe Rosa Luxemburgs und Karl Liebknechts an Sozialisten im neutralen Ausland, August 1914 - Januar 1915

Die Wiedergabe der Briefe erfolgt in vier Fällen (Nr 1, 3 b, 3 c, 5) nach dem Original, sonst nach Kopien. Die Schreibweise der Vorlage wurde beibehalten, evidente Flüchtigkeitsfehler wurden korrigiert; die Zeichensetzung wurde, wo die Klarheit dies erforderte, gemäß den gegenwärtig geltenden Regeln verändert. Von den Autoren vorgenommene Korrekturen sind im allgemeinen nicht besonders ausgewiesen.

\section{ROSA LUXEMBURG AN PIETER JELLES TROELSTRA ${ }^{581}$}

Berlin Südende, Lindenstr. 2

\section{Lieber Freund!}

Ich habe mich sehr gefreut, Ihre Zeilen zu erhalten. Man hat jetzt ein dringendes BedürfniB, eine Freundeshand über die Grenze zu drücken. Ja, wir haben Furchtbares erlebt und werden noch Ärgeres vielleicht erleben. Der Verlust Jaurès' hat uns ${ }^{582}$ einen Schlag beigebracht, den man nie verwindet. Aber es giebt Stunden, wo ich ihn beneide, weil er einen solchen Zusammenbruch dessen, was uns das Theuerste war an Friedensidealen und Kultur, nicht mit ansehen mußte. Ich zweifle übrigens nicht, daß er heute an der Seite Jules' ${ }^{\prime 58}$ stände, jene dort waren wirklich und sind in einer furchtbaren Zwangslage. Ich bin aber mit Ihnen nicht einverstanden, daß diese Zwangslage für Alle in gleichem Maße vorlag. Unsere Lage hier

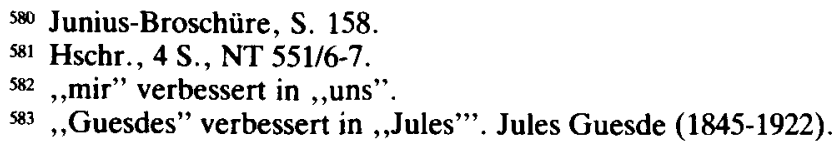


beurteile ich ganz anders. Wenn Sie sagen: es war für uns zu früh, die Gegner haben den Moment gewählt, wo wir nicht reif waren, so weiß ich, daß man sich die Reife zum Kampf um das Theuerste nicht anders als im Kampf erwirbt. Und es giebt Lagen, es giebt Momente, wo Privatmensch wie Politiker wie Völker sich sagen müssen wie die Franzosen: tout est perdu, sauf l'honneur! Die Ehre ist und bleibt das Höchste und das einzige sichere Unterpfand der Zukunft für Menschen und für Völker, das ist meine tiefste Überzeugung. Jetzt habe ich noch eine Bitte an Sie: lassen Sie mir doch Het Volk ${ }^{584}$ schicken, ich möchte so gern lesen, was man im Auslande über uns schreibt. Aber adressieren Sie die Zeitung nicht hierher, weil ich nächstens für einige Wochen zur Klara ${ }^{585}$ reise, sondern zu Kunstmaler Zundel ${ }^{586}$, Wilhelmshöhe bei Stuttgart. Schreiben Sie bald wieder, Klara wird sich auch freuen, von Ihnen zu hören. Und bei der ersten Möglichkeit, Camille ${ }^{587} \mathrm{zu}$ grüßen, thun Sie das von mir, und geben Sie mir Nachricht. Herzliche Grüße von anderen u[nd] mir

[Nachschrift auf dem Rand:]

Ihre R. Lübeck

Es wird Sie vielleicht interessieren als Parlamentarier, daß die hiesige soz[ial]d[emokratische] Fraktion heftige Debatten hatte, vierzehn Abgeordnete, darunter Haase, Ledebour, Liebkn[echt $]^{588}$, waren ${ }^{589}$ in der Opposition, sie sollen große Sympathien haben, was man so hören kann.

\section{KARL LIEBKNECHT AN HJALMAR BRANTING ${ }^{590}$}

Berlin, 23.9.[19]14.

Verehrter Genosse Branting!

Ich komme soeben von einer Fahrt durch das unglückliche Belgien und durch Holland zurück. Ich traf die Genossen Huysmans und Vandersmis$\operatorname{sen}^{591}$ und andre belgische Freunde; und in Amsterdam Wibaut, Vliegen,

\footnotetext{
584 Het Volk. Dagblad voor de arbeiderspartij, Amsterdam 1900ff, Organ der SDAP. 585 Clara Zetkin (1857-1933).

${ }_{586}$ Friedrich Zundel (1875-1948), zweiter Ehemann von Clara Zetkin.

587 Camille Huysmans (1871-1968), seit 1904 Sekretär des ISB, seit 1910 Abgeordneter im belgischen Parlament.

588 ,,u.a." verbessert in ,,Liebkn[echt]".

589 , sind" verbessert in ,waren".

590 Hschr., 6 S., Nachlaß Branting. - Hjalmar Branting (1860-1925), 1889 Mitgründer der schwedischen sozialdemokratischen Partei, seit 1897 Abgeordneter in der Zweiten Kammer des schwedischen Reichstags.

591 Laurent Vandersmissen (1874-1916), seit 1909 allgemeiner Sekretär des POB.
} 
- Buli Ju'decede, Siedcurto?.

Sieber

$551 / 6$

Sieber Srecued!

Jcle leabe curde sets gapents the Giten yn erealten. lean bol peft en dringrects bebrêfmi pivie Rreuseshew when tre rveesqe gir dricklen. Jay war habeu Hurablbaves evede mil rocosen voch Auguas ard. bocht exletem ber vecher Jacies' hat ins siven Jchlog beigetradeh dew wan's wir nevuriat. Oher es ciebt sturdong wo nat teu Reucerdes wet ec evina Dobleer Geranenbred was cus Das theiceste corar. an Friedencidealen mip tultur.

Brief Rosa Luxemburgs an Troelstra (Nr 1), erste Seite.

https://doi.org/10.1017/S0020859000111514 Published online by Cambridge University Press 
van der Goes und Mendels. ${ }^{52}$ Ihre verzweifelte Stimmung, die ich nur allzusehr begreife, hat mich tief erschüttert. Der vorläufig geringe, aber doch reale Trost einer Hoffnung auf Rehabilitation der deutschen Sozialdemokratie, den ich ihnen - trotz der officiösen Beschönigungsreisen der Südekum und Genossen ${ }^{593}$ - spenden konnte, wurde von ihnen aufgenommen, wie vom gekreuzigten Jesus der Essigtrank. Sie werden meinen und unsrer Minorität Standpunkt kennen. Wir hoffen, daß die Minorität zur Majorität wird. Verwüstend sind die Wirkungen des Sündenfalls nicht nur auf die Internationale, sondern auch, und in viel böserem Sinn, auf die deutsche Bewegung, ihre Presse und ihre Aktionen; die Wirkungen des Sündenfalls, der sogar vom , patriotischen" Gesichtspunkt aus den schwersten Fehler bedeutete: die Beseitigung aller Hemmungen, die im Auslande (dem feindlichen) gegen den Krieg bestanden.

Näheres heute zu schreiben, verbieten die Umstände.

Jede schwache Möglichkeit einer Beendigung des wahnwitzigen Massenmords wird in diesen Tagen erwogen. Nichts möchte man unversucht lassen. Haben Sie den Gedanken einer gemeinsamen Demarche aller neutralen Mächte (oder doch der Wesentlichsten) geprüft? Einer gleichzeitigen Demarche bei allen kriegführenden Mächten? Ich übersehe das ,,Phantastische" dieses Vorschlags nicht; und doch. Ich hoffe, die Ver[einigten] St[aaten], Holland u[nd] die Schweiz geneigt; wohl auch Italien? dessen Neutralität auf lahmsten Füßen steht. Vielleicht entschließen auch Sie sich, in dieser Richtung in Skandinavien zu wirken.

Meine Frau hat Ihnen inzwischen weitere Telegrammbitten übermittelt. Ich danke Ihnen herzlichst für Ihre bisherigen Mühen und - für die künftigen; denn ich $m u \beta$ leider sogleich noch einmal lästig fallen. Es handelt sich um eine Anzahl in Lüttich festgenommener russischer Studenten, die, beziehungsweise deren Frauen, mich - übrigens ganz legal! gebeten haben, ihre Angehörigen zu benachrichtigen. Sie befinden sich im Munsterlager bei Hannover, die Frauen sind frei; die Männer werden wohl bald frei kommen.

Ich nehme an, Sie haben einen oder den andren Freund zur Disposition,

${ }^{592}$ Florentinus M. Wibaut (1859-1936), seit 1905 Mitglied des Parteivorstands der SDAP. Willem H. Vliegen (1883-1947), Mitgründer der SDAP, 1902-14 Redakteur von Het Volk, seit 1906 Parteivorsitzender der SDAP, seit 1909 Abgeordneter in der Zweiten Kammer des niederländischen Parlaments. Frank van der Goes (1859-1939), Mitgründer der SDAP, seit 1896 Redakteur der (zweiten) Nieuwe Tijd, seit 1910 Mitglied des Parteivorstands der SDAP, seit 1912 Auslandsredakteur von Het Volk. Maurits Mendels (1868-1944), seit 1899 Mitglied der SDAP, 1909 kurzfristig der SDP, 1909-14 Mitglied des Parteivorstands der SDAP, seit 1913 Abgeordneter in der Zweiten Kammer des niederländischen Parlaments.

593 Vgl. Anm. 84, 115, 221, 222. 
der die Arbeit, um die ich Sie im Namen dieser armen Leute bitte, auf sich nehmen kann. Sollte die Ausführung nicht möglich sein, so schicken Sie mir die Anlage ruhig zurück. ${ }^{594}$ Ich würde nicht wagen, Sie so ausgiebig in Anspruch zu nehmen, wüßte ich mir einen anderen Rat, den Leuten zu helfen.

Darf ich Sie um die Aufstellung der Kosten bitten? Ich werde Ihnen für die jetzt neu erbetenen Telegramme ca 30 Mark vorläufig zugehen lassen. Vielen herzlichen Dank - zugleich im Namen derer, die mich beauftragt haben; und beste Grüße Ihnen und allen Freunden

Ihr Dr. K. Liebknecht

Das Rotunterstrichene sind jeweils die Adressen; es sind also 29 Telegramme!!!

3. KARL LIEBKNECHT AN HJALMAR BRANTING, FLORENTINUS MARINUS WIBAUT UND ROBERT GRIMM ${ }^{595}$

[Maschinenschriftlicher Text:]

Berlin, den 12. Oktober 1914.

Berlin-Lichterfelde, Hortensienstr. 14. ${ }^{59}$

Verehrter Genosse!

Ich habe einen ganzen Korb voll Anliegen.

1. Anbei die Abschrift eines von mir an die Bremer Bürgerzeitung gerichteten Briefes vom 3. September 1914, der bereits in Het Volk vom 14. September abgedruckt ist, ${ }^{597}$ und den ich bitten möchte, gleichfalls zu veröffentlichen, und zwar unter Hervorhebung des Datums.

(,,Erst heute wird uns bekannt, daß Genosse Liebknecht bereits am 3. September ds. Js. folgenden Brief an die Bremer Bürgerzeitung gerichtet hat" oder ähnlich.)

2. Die anliegende gemeinsame Erklärung vom 10 . September ${ }^{598}$ bitten wir abzudrucken. Ich bitte auch hier hervorzuheben, daß diese Erklärung Ihnen erst jetzt bekannt wird und daß sie, wie die Erklärungen der Genos-

594 Die Anlage scheint nicht überliefert zu sein; aber Nr 3 a läßt den Schluß zu, daß Branting Liebknechts Bitte erfüllte.

595 Gleichlautender mschr. Text, $4 \mathrm{~S}$., mit hschr. Bemerkungen für die einzelnen Adressaten; a) Nachlaß Branting; b) Nachlaß Wibaut, Mappe 27; c) Nachlaß Grimm/Zimmerwald-Bewegung, Suppl. - Zu Robert Grimm (1881-1958) vgl. oben, S. 65.

5\% Adresse in allen drei Briefen hschr. hinzugefügt.

597 Vgl. Anm. 89, 165.

598 Siehe oben, S. 71ff.; vgl. Anm. 298. 
sen Südekum und Fischer, ${ }^{599} \mathrm{im}$ Ausland wiedergegeben werden muß, und das Ausland interessiert. Lieb wäre mir, wenn Sie etwa zusetzen würden: ,Es ist charakteristisch für die heutige Lage der Internationale und für die allgemeine politische Situation, daß sich solche Diskussionen jetzt vielfach im neutralen Ausland abspielen."

3. Von meinem Brief vom 26. September $1914^{600}$ bitte ich insbesondere den blauangestrichenen Passus ${ }^{611}$ veröffentlichen zu wollen; aber ohne noch meinen Namen anzugeben.

4. a) Einige ausländische Zeitungen haben angebliche Äußerungen von mir über die deutschen Leistungen in Belgien veröffentlicht. Ich lege 2 Beispiele bei. ${ }^{602}$

b) Der Amsterdamer Telegraaf bringt eine Meldung über mein Zusammentreffen mit Huysmans, die ich in der Wiedergabe der Frankfurter Zeitung gleichfalls beifüge. ${ }^{603}$

Zu b: Ist unwahr, oder ein Qui pro quo. Zwischen Wendel ${ }^{604}$ und Huysmans hat sich eine unliebsame Scene abgespielt, zumal er die Verletzung der belgischen Neutralität als deutscher Soldat (Landsturmmann) gegenüber Huysmans verteidigte. ${ }^{605}$ Mein Zusammensein mit Huysmans war so herzlich wie möglich. ${ }^{606}$ Ein Teil der deutschen Parteipresse excediert bei

599 Vgl. Anm. 84, 221, 222.

600 Vgl. Anm. 235.

601 Blau angestrichen ist der zweite Teil des Schreibens, von ,, Ich brauche nicht hervorzuheben, daß nach meiner Überzeugung jede Annexion" bis ,,Ich zweifle nicht daran, daß Sie mir zustimmen." Liebknecht, Klassenkampf, S. 27f.

602 Vgl. Anm. 292.

${ }^{603}$ Vgl. Anm. 293.

${ }^{604}$ Hermann Wendel (1884-1936), seit 1912 Mitglied des Reichstags.

${ }_{605}$ Nachdem sich Wendel zunächst der Heeresverwaltung zur Verfügung gestellt hatte, war er Mitte August in Frankfurt a.M. als Freiwilliger in ein Landsturmbataillon eingetreten; in einem Schreiben vom 11.9.1914 erklärte er hierzu: ,,Gründe: 1 . wollte ich nicht hinter dem Ofen hocken, wenn ein ganzes Volk im Kampfe um seine Existenz aufsteht; 2. war es meine Absicht, überall durch Wort und Tat im Sinne der - im Krieg arg mitgenommenen - Menschlichkeit zu wirken. Was ich in dieser Richtung in den acht Tagen, die ich letzthin in Belgien war, geleistet habe, würde allein schon eine Rechtfertigung, wenn es einer solchen bedürfte, meiner Haltung sein.” ,Aus der Partei. Gen. Wendel schreibt [. . . ]", in: Vorwärts, 1914, Nr 255 (18.9.), Beilage. Zu dem Vorfall in Brüssel vgl. ,Socialistes belges et Socialistes allemands”, a.a.O. (Anm. 156): „Etant de passage à Bruxelles avec un convoi de vivres, Hermann Wendel profita de l'occasion pour ,aller serrer la main aux camarades de la Maison du Peuple'. L'accueil qu'il y reçut fut plutôt froid". In der anschließenden Diskussion hatte Wendel bezweifelt, daß Belgien wirklich neutral gewesen sei; die deutsche Regierung habe hierzu Dokumente vorgelegt, die der Reichstagsfraktion eine Ablehnung der Kredite unmöglich gemacht hätten. ,,Quelqu'un lui ayant demandé ce qu'il pensait de la violation du territoire et de la neutralité de la Belgique, Wendel répondit ceci: ,Mon avis, mais mon avis personnel, [. . . est qu'en temps de guerre il ne peut être question de sentimentalité."' 606 Vgl. Anm. 162. 
der Besprechung dieser Meldung ganz toll (vergleiche den Kommentar der Chemnitzer Volksstimme, Anlage zu $5^{607}$ ). Ich bitte davon Notiz zu nehmen.

$Z u$ a: Unter Drohung mit dem Militärknüppel will man mich zu einer Berichtigung nach dem Willen des Auswärtigen Amts zwingen. Das ist unanständig und macht es fast unmöglich, irgend etwas zu berichtigen. Die ganze Presse ist ja heute voll von Lügen; warum gerade das berichtigen? Meine Ansicht über Belgien ist für Deutschlands Regierung und Militär ganz und gar nicht schmeichelhaft. Ein einfaches Dementi wird mißbraucht werden. Meine wirkliche Auffassung kann ich wegen des Kriegszustandes jetzt nicht veröffentlichen.

Ich bitte etwa zu schreiben:

,,Diese Meldungen entbehren der Authentizität. Genosse Liebknecht wird seine sicherlich kritische Ansicht schon selbst öffentlich sagen, wenn es ihm die politischen Verhältnisse in Deutschland gestatten werden."

5. Über die Haltung eines großen Teils der hiesigen Parteipresse ist man hier in Genossenkreisen vielfach sehr erregt.

Der Belagerungszustand kann rechtfertigen, daß - außer in ganz wichtigen Dingen, die einen ernsten Konflikt mit der Militärdiktatur lohnen geschwiegen wird; niemals aber, daß die Parteipresse selbst positive Dinge schreibt, die dem Wesen der Socialdemokratie und ihrem Programm widersprechen - ein böser Chauvinismus, ein Geist militaristischer Verwirrung macht sich vielfach breit; Hatz gegen die Brüderparteien des Auslands; Verschleierung der Klassengegensätze bis zur Teilnahme an der nationalen Jugendwehr u.s.w.

Ganz unmöglich ist auch das Verhalten gegenüber dem Vorwärtsverbot. Nie hätte man sich selbst so ins Gesicht speien dürfen, wie an der Spitze der No. vom 1. Oktober des Vorwärts - Erlaß des Generals von Kessel geschehen ${ }^{608}$ Ich kann mir nicht denken, daß nicht auch Sie diese Ansicht hegen.

Diese Bemerkungen zu 5 natürlich nur zu Ihrer Information über meine Auffassung, nicht zur Veröffentlichung. ${ }^{609}$

Mit herzlichen Grüßen Ihr Dr. K. Liebknecht ${ }^{610}$

[Handschriftliche Zusätze:]

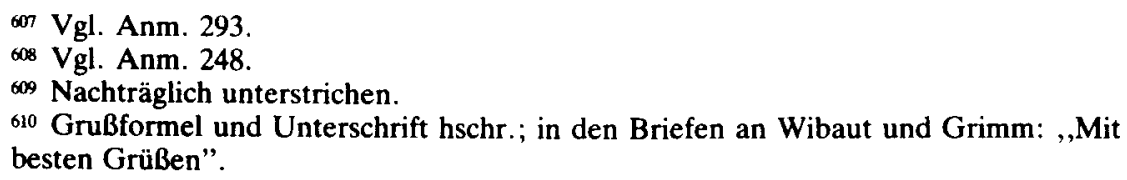




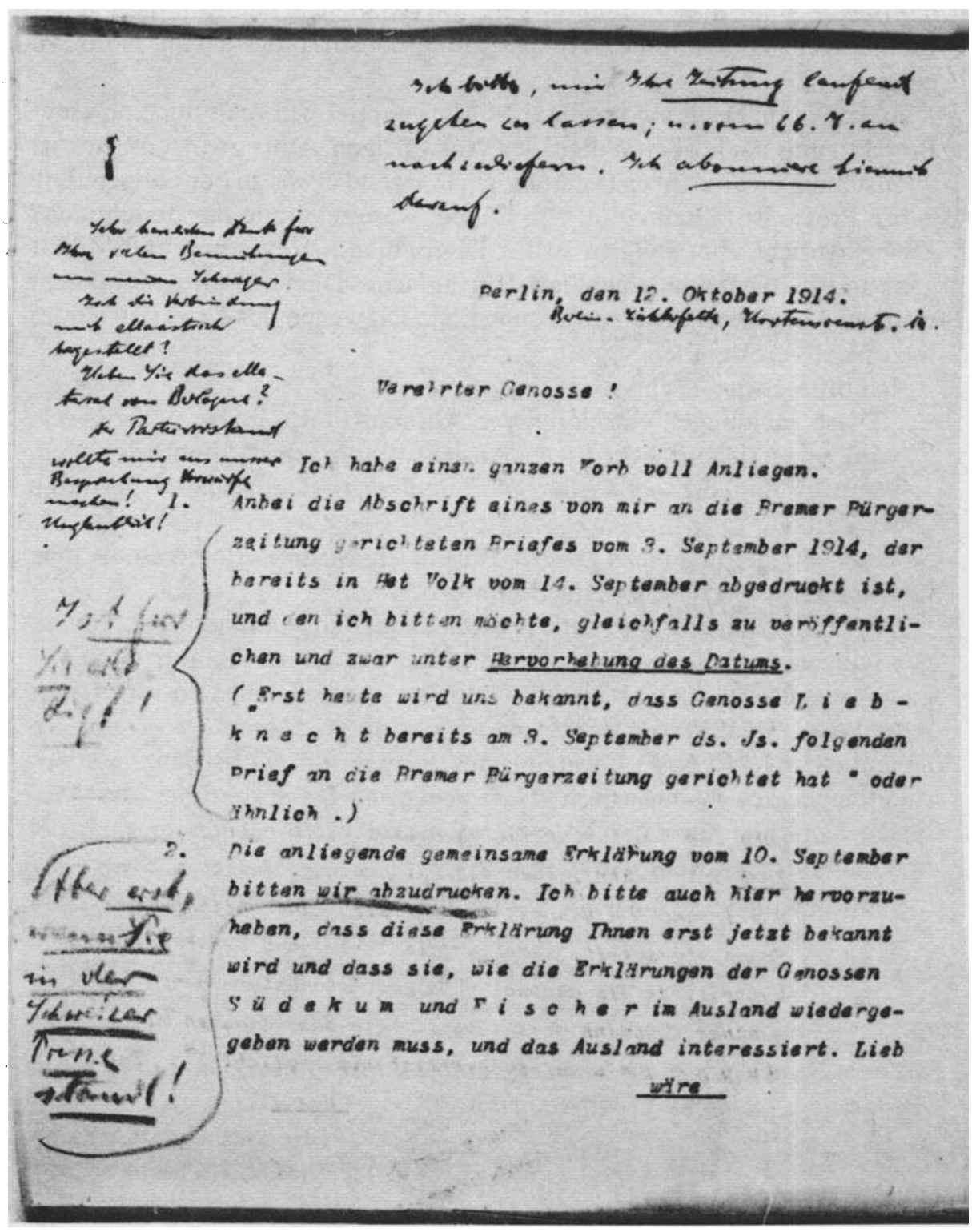

Brief Liebknechts an Wibaut $(\mathrm{Nr} 3$ b), erste Seite 
[Auf der ersten Seite:]

Bitte, lassen Sie mir Ihre Zeitung ${ }^{611}$ laufend zugehen; u[nd] vom 26.7. an nachliefern. Ich abonniere hiermit darauf.

Ich sandte Ihnen eine Abschrift meines Briefs vom 2. d. Mts. an den Parteivorstand $;{ }^{612}$ natürlich nur zur Kenntnisnahme. Es ist völlig unfaßbar, wie man mir aus rein parteigenössischen Besprechungen einen Vorwurf machen will. Auch das gehört zu den Rätseln der Kriegspsychologie.

Den Rest meiner Schuld lasse ich Ihnen gleichzeitig zugehen. Die 30 $\mathrm{M}[\mathrm{ar}] \mathrm{k}$ haben Sie wohl erhalten? ${ }^{613}$

\section{3 b. AN FLORENTINUS MARINUS WIBAUT}

[Auf der ersten Seite:]

Ich bitte, mir Ihre Zeitung ${ }^{614}$ laufend zugehen zu lassen; u[nd] vom 26.7. an nachzuliefern. Ich abonniere hiermit darauf.

Sehr herzlichen Dank für Ihre vielen Bemühungen um meinen Schwager.

Ist die Verbindung mit Maastricht hergestellt?

Haben Sie das Material von Bologne?

Der Parteivorstand wollte mir aus unsrer Besprechung Vorwürfe machen! Unglaublich!

[Am Rand zu Absatz 1:] Ist für Sie erledigt!

[Am Rand zu Absatz 2, Satz 1:] Aber erst, wenn sie in der Schweizer Presse stand!

\section{C. AN ROBERT GRIMM}

[Auf der ersten Seite:]

Ich bitte, mir Ihre Zeitung ${ }^{615}$ laufend zugehen zu lassen, $u[n d]$ möglichst die No. vom 26. Juli d. Js. ab nachzuliefern. Ich abonniere darauf.

[Auf der vierten Seite:]

Ein gleiches Schreiben an Sie ging über Schweden. Ich weiß nicht, ob es eintraf. Auf die durch R[adek] übermittelte Anregung ${ }^{616}$ antworte ich noch. Viele Grüße allen Freunden. K.L.

611 Gemeint ist der Stockholmer Social-Demokraten.

$612 \mathrm{Vgl}$. Anm. 1.

$613 \mathrm{Vgl}$. oben, Nr 2.

614 Het Volk.

615 Berner Tagwacht.

616 Vgl. oben, S. 92. 
4. ROSA LUXEMBURG AN DIE REDAKTIONEN VON HET VOLK, SOCIAL-DEMOKRATEN UND BERNER TAGWACHT ${ }^{617}$

Berlin, 9.11.[19]14.

W.G. Ich bitte Sie um die Veröffentlichung der folgenden Zeilen:

Als ich gleich anderen Mitgliedern des Intern[ationalen] Soz[ialistischen] Bureaus $^{618}$ vor einigen Wochen die Anregung des Parteivorstands der holländischen Sozialdemokratie erhielt, den Sitz des Int[ernationalen] Bureaus zeitweilig nach Holland zu verlegen, ${ }^{619}$ nahm ich als selbstverständlich an, daß dieser Vorschlag nach einer Rücksprache mit den belgischen Genossen vom Exekutivkomité und mit ihrem Einverständnis gemacht war. Es war naheliegend anzunehmen, daß die belgischen Genossen bei den derzeitigen Zuständen ihres Landes verhindert waren, als Exekutivkomité des Int[ernationalen] Soz[ialistischen] B[ureaus] zu fungieren, und den Wunsch hatten, sich dieser Würde zu entledigen. Die neuerdings im „,Vorwärts” erschienene Nachricht, daß die Genossen Huysmans und Bertrand in Amsterdam ihre Bereitwilligkeit erklärt haben, einen Teil des Exekutivkomités nach dem Haag zu verlegen, ${ }^{620}$ bietet nunmehr die glücklichste Lösung der Schwierigkeit. Es ist klar, daß, solange unsere belgischen Freunde sich bereit erklären, weiter ihres Amtes als Int[ernationales] Exekutivkomité zu walten, dieses als einziges legales Organ der alten Internationale gelten muß und $\mathrm{da} B$ den belgischen Genossen anheimgestellt werden kann, ob sie sich noch durch Bureau-Mitglieder aus anderen Ländern ergänzen wollen. Das von den Gen. Huysmans und Bertrand getroffene Arrangement erscheint praktisch umsomehr ausführbar, als dem Int[ernationalen] Bureau einstweilen leider ein schmaler Spielraum der Betätigung übrig bleibt. Alle Versuche, so schnell wie möglich künstlich eine internationale Konferenz zustande zu bringen, scheinen mir gänzlich verfehlt. Die beruhigenden Versicherungen mancher Genossen, die Internationale sei nicht tot, ja es sei nur ein leicht zu verklebender Riß, der in ihr entstanden sei, sind sehr angenehm. Was dem intern[ationalen] Sozialismus aber Not tut, ist $\mathrm{m}$.E. vor allem eine ehrliche und offene Abrechnung mit seinem eigenen schmachvollen Bankrott in diesem Kriege. Bevor in jedem Lande eine innere Klärung und Entscheidung der

${ }^{617}$ Mschr., 2 S., Nachlaß Branting. In diesem Exemplar über dem mschr. Text von Rosa Luxemburgs Hand: , An die Redaktion des ,Sozialdemokraten'.,

618 Die Worte, ,gleich anderen Mitgliedern des Intern[ationalen] Soz[ialistischen] Bureaus" nachträglich von Liebknechts Hand hinzugefügt.

$619 \mathrm{Vgl}$. Anm. 200.

$620 \mathrm{Vgl}$. Anm. 370. 
sozialistischen Partei über ihre Stellung zum Militarismus stattgefunden hat, fehlen noch die soliden Fundamente für den Wiederaufbau der Internationale. Bis dahin müssen wir uns damit begnügen, alles zu vermeiden, was den Zusammenbruch der bisherigen Internationale noch weiter fördert und was an ihre Stelle Neues, aus dem Kriege geborenes zu unterschieben versucht.

Mit soz[ialistischem] Gruß R. Luxemburg ${ }^{621}$

\section{KARL LIEBKNECHT AN FLORENTINUS MARINUS WIBAUT ${ }^{622}$}

Berlin N.4, den 10.11.[19]14. Chausseestr. 121, II.

\section{Lieber Genosse Wibaut!}

Ich danke Ihnen nachträglich vielmals für die große Mühe, die Sie sich wegen meines Schwagers gegeben haben. Wir hatten einigemale indirekte Nachricht, wonach er in Brügge und dann in Ostende gewesen zu sein scheint. Seitdem ist die Spur wieder verloren.

Wegen meines Besuchs bei Ihnen suchte man mir hier einen Strick zu drehen; ein unglaubliches Geklatsch hat sich daran geknüpft. Troelstra hatte, nicht an mich, sondern an den Parteivorstand, irgend etwas darüber geschrieben, wonach er davon auszugehen schien, als sei ich im Auftrag des $\mathrm{P}$ [artei-]V[orstands] bei Ihnen gewesen. ${ }^{623}$ Hätte er an unsrer Besprechung teilgenommen, er wüßte, daß nach dem ganzen Charakter meiner Darlegungen, und meinem ganzen Standpunkt, davon keine Rede sein konnte.

$\mathrm{Zu}$ Ihrer Information lege ich Abschrift einer Correspondenz bei; ${ }^{624} \mathrm{Sie}$ können davon auch den übrigen Teilnehmern an unserer Besprechung Kenntniß geben; ${ }^{625}$ nur rein privat.

Wäre es möglich, Het Volk regelmäßig zu erhalten? Ich abonniere hiermit darauf?

Haben Sie den über Stockholm gegangenen Brief erhalten?'26

Die Zustände hier sind höchst unerfreulich; die Partei ist in einem traurigen Zustande. Es regt sich aber immer mehr in den Massen, und die Jugend ist überwiegend gut geblieben.

621 Grußformel und Unterschrift hschr.

${ }^{622}$ Briefkopf der Rechtsanwaltspraxis von Th. Liebknecht, Dr. K. Liebknecht und Dr. James Friedlaender. Hschr., 2 S., Nachlaß Wibaut, Mappe 27.

$623 \mathrm{Vgl}$. Anm. 176.

${ }_{624} \mathrm{Vgl}$. Anm. 1, 411.

${ }^{625}$ Am Rand: ,,Ich bitte Sie darum!"

${ }^{626} \mathrm{Nr} 3$. 
Der Versuch mit der gemeinsamen Intervention der Neutralen, der nach den Schweizer Nachrichten in Gang ist, scheint einige Resonanz zu finden. Man muß halt alles thun. Freilich ist jetzt das östliche Problem ganz kolossal kompliciert worden.

Grüßen Sie bitte alle Freunde, u[nd] bestellen Sie auch dem Gen. Mendels unseren herzlichen Dank für seine Mühwaltung wegen meines Schwagers.

Ihnen $u[n d]$ den Ihren viele Grüße u[nd] alles Beste

Ihr Dr. Karl Liebknecht.

Beste Grüße auch Huysmans, wenn Sie ihn sehen.

\section{ROSA LUXEMBURG AN ROBERT GRIMM ${ }^{627}$}

16.11.[1914]

Sehr geehrter Genosse!

Sie beabsichtigen bald, wie ich annehme, nach Skandinavien zu fahren. Hoffentlich gehen Sie über Berlin und werden uns einen Besuch abstatten, was wir freudig begrüßen würden. Schreiben Sie mir eine Postkarte, ob wir Sie erwarten dürfen; event[uell] ein Telegramm. Das neulich erwähnte Tel[egramm] habe ich nicht erhalten. ${ }^{628}$ Besten Gruß auch von Klara. ${ }^{629}$

Ihre R.L.

Berlin Südende Lindenstr. 2

Lieber Genosse Grimm!

Ob ich noch etwas gegen Heine's Wald- u[nd] Wiesen-Geschreibe schicke, das Sie ja schon wirksam abgefertigt haben, ${ }^{631}$ wird sich morgen entscheiden.

627 Postkarte, hschr., Nachlaß Grimm/Zimmerwald-Bewegung, Suppl. (Kopie).

628 Vermutlich bezieht sich Rosa Luxemburg hier auf das Sympathietelegramm des Parteitags der SPS. Vgl. ,,Der Parteitag in Bern”, in: Berner Tagwacht, 1914, Nr 256 (2.11.); , Der Parteitag der schweizerischen Sozialdemokratie”, in: Vorwärts, 1914, Nr 303 (5.11.): ,Der Genossin Rosa Luxemburg wurde ein Sympathietelegramm geschickt."

${ }_{629}$ Clara Zetkin.

630 Hschr., 2 S., Nachlaß Grimm/Zimmerwald-Bewegung, Suppl. (Kopie) 
Heute zweierlei:

1) Anbei das Original der Briefe, die wir dem Labour Leader auf Wunsch zur Weihnachtsnummer schickten. Uns wäre Abdruck sehr lieb! Und bitte - aus taktischen Gründen - recht bald. ${ }^{632}$

2) Wir müssen absolutissime mit Ihnen sprechen. Und zwar ganz ohne Verzug. $\mathrm{Pa} B$ giebts nicht. Wir sind auch par ordre an Berlin gebunden. Die kategorischen Gründe, die nichts mit Bequemlichkeit oder Arbeitsbelastung zu thun haben, kann ich nicht schreiben. Vom 15. ab geht schon gar nichts mehr. ${ }^{633} 24$ Stunden Anwesenheit hier genügt; selbst 12 Stunden. Spätestens am 13. d. Mts. Gern kämen die Muhammed's zu den Bergen; so müssen wir den Bergbewohner bitten, beschwören, an die Spree zu kommen.

Wir wissen, Sie stecken über die Ohren in der Arbeit; die neue Zeitschrift ${ }^{634}$ u.s.w.; u[nd] wir schätzen die Wichtigkeit dieser Leistungen so hoch ein wie möglich. Um so mehr aber müssen wir Sie sehen u[nd] sprechen. An Ihrer Wirksamkeit hängt ein großes Stück der Zukunft der Internationale; $u[n d]$ auch ihrer aktuellen politischen Leistungsfähigkeit. Könnten Sie am 12. hier sein, wär's glänzend; wenn noch früher, um so besser. Clara wird auch da sein. Schleunigste Disposition u[nd] Nachricht über Clara oder direkt, dann aber auch an Clara, die ja auch disponieren

631 Wolfgang Heine, ,Eine andere Stimme”, in: Berner Tagwacht, 1914, Nr 304 (29.12.), Beilage; Nr 305 (30.12.), 2. Beilage. Veranlaßt durch die Veröffentlichung von Liebknechts Erklärung vom 2. Dezember in der Berner Tagwacht (vgl. Anm. 437), hatte Heine erklärt, von einer Vergewaltigung Liebknechts sei keine Rede gewesen. Liebknechts Verhalten, daß auch er nicht unter dem Gesichtspunkt der Parteidisziplin, sondern nach dem Inhalt der Erklärung beurteilt sehen wolle, sei eine unverantwortliche Demonstration; zudem richte sich Liebknecht in seiner Kritik nur einseitig gegen die deutsche, nicht aber die ausländischen Parteien. ,Die deutsche Sozialdemokratie hat, indem sie sich auf die Seite des Vaterlandes stellte, nicht ihre alte Politik aufgegeben, sondern lediglich nach dem gehandelt, was ihre größten Führer stets angegeben haben. [ . . . / Auch wir tun das unsrige, um sinnlosen VölkerhaB [ . . ] nicht festwurzeln zu lassen [. . . ]. / Aber der Völkerfriede und der Sieg der sozialistischen Idee können nicht damit eingeleitet werden, daß Deutschland einer Koalition von Franzosen, Russen, Mongolen, Briten, Indern und Negern geopfert wird”. Dem Artikel war eine ,,Anmerkung der Redaktion" hinzugefügt, in der Heines Schweigen über Belgien, sein Rassismus und seine ungerechtfertigte Berufung auf Bebel kritisiert wurden; wenn schon, hätte Heine sich den ,Bebel von 1870" (der sich bei der Abstimmung über die Kriegskredite der Stimme enthalten hatte) zum Vorbild nehmen sollen; im übrigen predige Heine eine ,,veränderte Ausgabe der Lehre von der Harmonie zwischen Kapital und Arbeit in der auswärtigen Politik', die auf, ,den Verzicht auf die Beseitigung des Ausbeutungsverhältnisses" hinauslaufe.

$632 \mathrm{Vgl}$. Anm. 441, 445, 446.

633 Am 15. Januar 1915 sollte Rosa Luxemburg ihre Gefängnisstrafe antreten.

${ }^{634}$ Die Zeitschrift Neues Leben. Monatsschrift für sozialistische Bildung, hrsg. von Robert Grimm und Jacob Lorenz, deren erste Nummer Ende Januar 1915 erschien. 
muß. Es sollte doch mit dem Teufel gehen, wenn uns diese unumgänglich nötige Zusammenkunft nicht gelänge.

Wir danken Ihnen im Voraus herzlichst u[nd] grüßen Sie u[nd] alle Freunde vielmals

[Auf der ersten Seite:]

Ihr K.L.

Am Zug holen wir Sie ab; vielleicht fahren Sie ab St[uttgart] mit Clara.

Ich lege zur Information noch 3 weitere Schriftstücke bei. ${ }^{635}$

635 Möglicherweise handelte es sich hierbei um die Abschriften der beiden Schreiben Liebknechts an den Vorstand der sozialdemokratischen Reichstagsfraktion vom 12.11. und 3.12.1914 (NachlaB Grimm/Zimmerwald-Bewegung, C 21; Liebknecht, Klassenkampf, S. 53f., 65f.) sowie der von Liebknecht der Fraktion am 29. November 1914 vorgeschlagenen Erklärung (s. Anm. 434). 